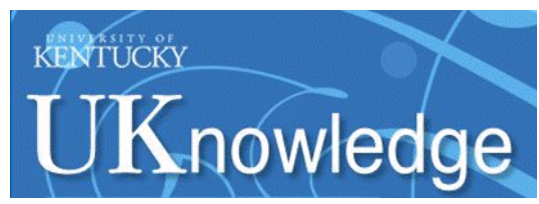

University of Kentucky

UKnowledge

\title{
MOTIVATION AND THE PRIMACY OF PERCEPTION
}

Peter A. Antich

University of Kentucky, paantich@gmail.com

Author ORCID Identifier:

(iD) https://orcid.org/0000-0002-2768-8998

Digital Object Identifier: https://doi.org/10.13023/ETD.2017.437

Right click to open a feedback form in a new tab to let us know how this document benefits you.

\section{Recommended Citation}

Antich, Peter A., "MOTIVATION AND THE PRIMACY OF PERCEPTION" (2017). Theses and Dissertations-Philosophy. 19.

https://uknowledge.uky.edu/philosophy_etds/19

This Doctoral Dissertation is brought to you for free and open access by the Philosophy at UKnowledge. It has been accepted for inclusion in Theses and Dissertations--Philosophy by an authorized administrator of UKnowledge. For more information, please contact UKnowledge@lsv.uky.edu. 


\section{STUDENT AGREEMENT:}

I represent that my thesis or dissertation and abstract are my original work. Proper attribution has been given to all outside sources. I understand that I am solely responsible for obtaining any needed copyright permissions. I have obtained needed written permission statement(s) from the owner(s) of each third-party copyrighted matter to be included in my work, allowing electronic distribution (if such use is not permitted by the fair use doctrine) which will be submitted to UKnowledge as Additional File.

I hereby grant to The University of Kentucky and its agents the irrevocable, non-exclusive, and royalty-free license to archive and make accessible my work in whole or in part in all forms of media, now or hereafter known. I agree that the document mentioned above may be made available immediately for worldwide access unless an embargo applies.

I retain all other ownership rights to the copyright of my work. I also retain the right to use in future works (such as articles or books) all or part of my work. I understand that I am free to register the copyright to my work.

\section{REVIEW, APPROVAL AND ACCEPTANCE}

The document mentioned above has been reviewed and accepted by the student's advisor, on behalf of the advisory committee, and by the Director of Graduate Studies (DGS), on behalf of the program; we verify that this is the final, approved version of the student's thesis including all changes required by the advisory committee. The undersigned agree to abide by the statements above.

Peter A. Antich, Student

Dr. Eric Sanday, Major Professor

Dr. Clare Batty, Director of Graduate Studies 


\section{MOTIVATION AND THE PRIMACY OF PERCEPTION}

\section{DISSERTATION}

A dissertation submitted in partial fulfillment of the requirements for the degree of Doctor of Philosophy in the College of Arts and Sciences at the University of Kentucky

By

Peter A. Antich

Lexington, Kentucky

Direction: Dr. Eric Sanday, Professor of Philosophy

Lexington, Kentucky

2017

Copyright (C) Peter A. Antich 2017 
ABSTRACT OF DISSERTATION

\section{MOTIVATION AND THE PRIMACY OF PERCEPTION}

In this dissertation, I provide an interpretation and defense of Merleau-Ponty's thesis of the primacy of perception, namely, the thesis that all knowledge is founded on perceptual experience. I take as an interpretative and argumentative key Merleau-Ponty's phenomenological conception of motivation. Whereas epistemology has traditionally accepted a dichotomy between reason and natural causality, I show that this dichotomy is not exhaustive of the forms of epistemic grounding. There is a third type of grounding, the one characteristic of the grounding relations found in perception: motivation. I argue that introducing motivation as a form of epistemic grounding allows us to see how Merleau-Ponty's thesis of the primacy of perception avoids both rationalism and empiricism. Whereas empiricism has argued that all the content of our knowledge is grounded in causal interactions between the world and our senses, and rationalism has held that experience does not suffice as a reason for knowledge, thinking of the relation between experience and knowledge in terms of motivation allows us to see how knowledge can be grounded in experience while at the same time transcending it.

KEYWORDS: Phenomenology, Epistemology, Motivation, Perception, Merleau-Ponty

Peter A. Antich 


\section{MOTIVATION AND THE PRIMACY OF PERCEPTION}

\section{By}

Peter A. Antich

Dr. Eric Sanday

Director of Dissertation

Dr. Clare Batty

Director of Graduate Studies 


\section{ACKNOWLEDGEMENTS}

With thanks to my many teachers, who labored on the difficult task of turning a soul toward what is. Thanks especially to Eric Sanday for his insights and advice, which guided this dissertation, as well as to Ron Bruzina and Dan Breazeale for the role they have played throughout my graduate career. Sebastian Luft and John Russon also contributed many helpful comments and suggestions to this project. 


\section{TABLE OF CONTENTS}

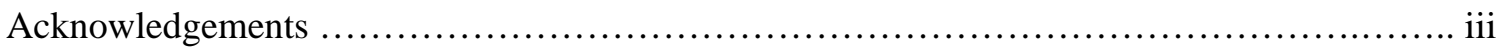

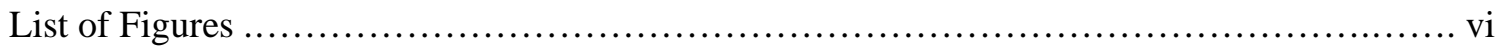

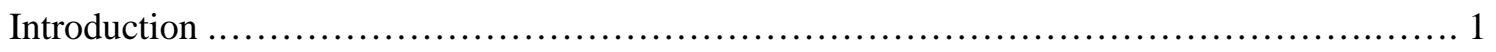

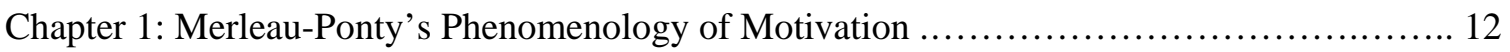

1. Motives Operate through Their Meanings …............................ 15

2. Motives Don't Require Explicit Awareness to Operate ...................... 19

3. Motivation is Spontaneous ........................................... 20

4. Motivation is an Internal Relation ...................................... 21

5. Motivation is a Reciprocal Relation ..................................... 26

6. Motivation Tends to Equilibrium ...................................... 29

7. Motivation does not Ground with Necessity .............................. 37

8. Motivation is Normative ............................................... 37

9. The Output of Motivation Transcends its Input ............................ 38

10. Motives are Neither Reasons Nor Causes ................................ 39

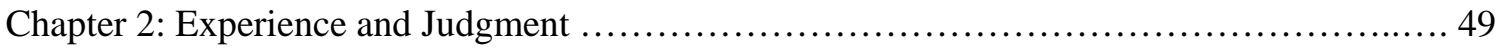

1. Davidson and McDowell ................................................ 50

2. Experience and Judgment ........................................... 53

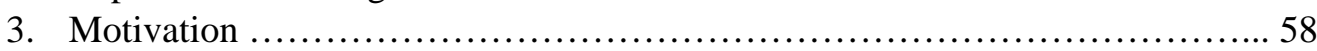

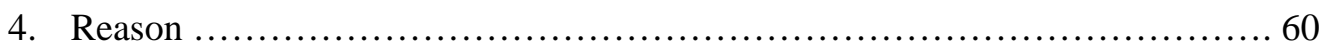

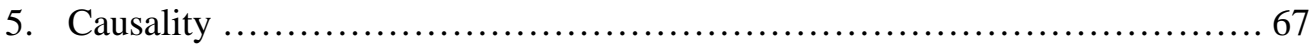

6. Expression and Motivation ........................................... 68

Chapter 3: The Primacy of Perception .................................................. 77

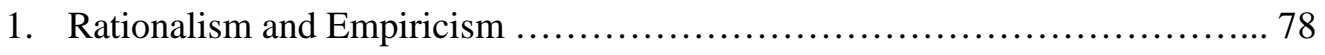

2. Arguments against Rationalism and Empiricism .......................... 81

3. Motivation as a Ground of Knowledge .................................... 95

4. A Priori Justification ................................................. 115

5. Empiricism and Nativism ........................................ 122

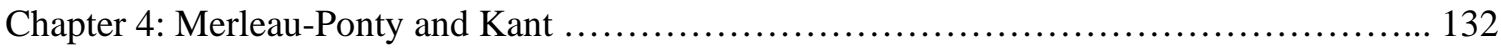

1. Kant on Experience .................................................. 134

2. Kant on Justification ................................................ 137

3. Kant and Merleau-Ponty on Perceptual Experience ......................... 144

4. Reflective Method ............................................... 157

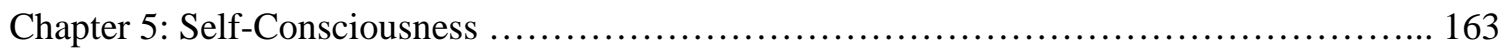

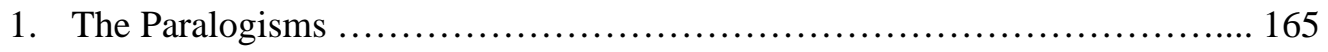

2. The Tacit Cogito ................................................ 170

3. The Unity of Transcendental and Empirical Apperception ................... 182 
Conclusion

Appendix: Historical Background: Motivation in Husserl and Stein

214

1. Husserl ............................................................ 215

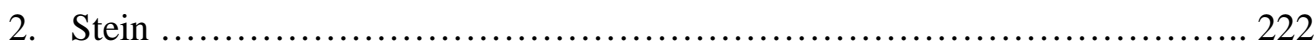

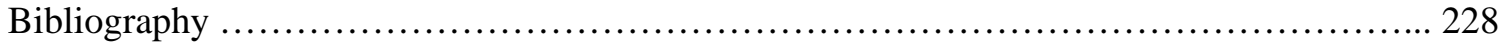

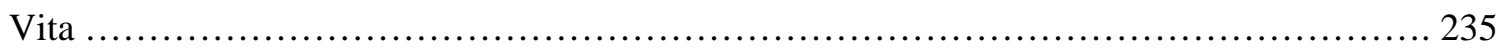




\section{LIST OF FIGURES}

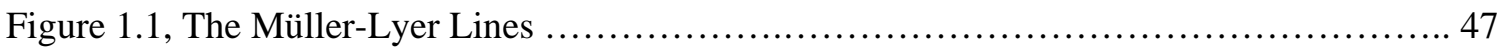

Figure 1.2, "My Wife and My Mother-in-Law” .............................................. 48

Figure 2.1, Zöllner Illusion ...................................................... 76

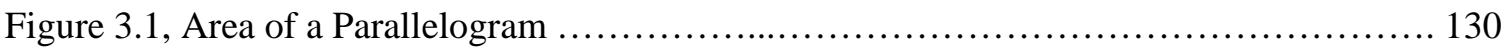

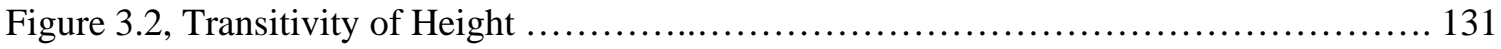

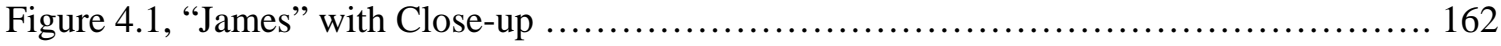

Figure 5.1, An example of Rubin's Vase ............................................... 201 


\section{INTRODUCTION}

Epistemology has long accepted a dichotomy between two sorts of grounds: reasons and causes. According to this dichotomy, we can understand why we believe what we do in terms either of reasons that justify our beliefs or in terms of causal interactions between our minds and the world. This, for example, is this dichotomy that Sellars and McDowell give expression to in distinguishing between a "logical space of reasons" and a "logical space of nature." In the logical space of reasons, according to Sellars, we are concerned with the justification of beliefs, i.e., with the giving and taking of reasons in favor of a belief. In contrast, in the logical space of nature we are concerned not with justification, but with explanation. In understanding how the interactions between our senses and the world cause certain sensations in us, for instance, we at most explain our sensations. We are not responsible for these sensations - we cannot revise them in response to reasons - and so in answering why we have these sensations and not others we are concerned not with justification, but with explanation; not with the logical space of reasons, but with the logical space of nature.

The first thesis of this dissertation is that the dichotomy of reason and causality is a false one. These two forms of grounding, while genuine forms of grounding with respective and exclusive domains, are not exhaustive of the forms of epistemic grounding. A central contention of Maurice Merleau-Ponty's Phenomenology of Perception is that neither reason nor causality correctly describe the sort of grounding relations characteristic of perception. To understand perception, he argues, we need to introduce a new way of thinking about epistemic grounds, namely, what he - following the phenomenological tradition - calls "motivation" (MerleauPonty, 2012, p. 51). In the following chapters, I take up this thought, arguing that there is a form of epistemic grounding which does not amount to justification, but also does not merely explain our beliefs. Instead, it is the primary character of perception to solicit our belief. We find ourselves existing in the world long before there is any question about the world's existence. Indeed, perception convinces us so thoroughly of the world it presents to us that when the child 
first ponders the merely ambiguous and incomplete distinction between wakefulness and dreaming it is for the child an uncanny event. Primordially, perception does not justify our belief in the world, but gives us over to this belief, which is why a project of radical doubt, like Descartes', is always possible. When the question of the world's existence emerges, it will seem as if perception, not justifying our faith in the world, merely explains it. Or, on the other hand, perception may be taken as one reason, among many, that factors into our deliberation about the world's existence. The ease with which perception gives itself to be taken as a reason might tempt one to think that the primary bond between perception and knowledge is one of reason. And yet this would be to mistake the initial situation, in which our perception of the world solicits our belief, rather that counts as a reason in favor of the world or mere explanation of the circumstance that we believe. Our first epistemic bond with the world is motivation.

And yet, motivation is ambiguous, in the sense that it contains the germ of the distinction between reason and cause, or we might say reversible, in the sense that any case of motivation can be taken up as a case of reason or of causality, but not both simultaneously. As we saw above, one's perception of the world permits itself to be taken as a mere explanation of one's belief in the world or as a reason in favor of the world's existence. The same ground, which initially instilled in us belief, is ready to be taken as either explanation or justification. When reflection comes back over the relation between perception and knowledge with these two terms, it traps itself in an antinomy: On the one hand, experience must be the ultimate cause of our knowledge. But on the other, experience does not suffice as a reason for our knowledge, and the empirical circumstances in which we acquire knowledge concerns merely the explanation of our possession of knowledge and not the justification of this knowledge. This antinomy describes the opposition of empiricism and rationalism in brief.

This antinomy, which we will see governing a variety of epistemological questions, can only be resolved by returning to the element from which both derive: motivation. Only by 
describing the ambiguous mode of grounding provided by motivation do we achieve a solid understanding of our epistemic situation.

Understanding the grounding relation between perception and knowledge in terms of motivation leads me to my second thesis: that all our knowledge is founded in perceptual experience. Perception and knowledge stand in what Husserl would call a Fundierung relation, i.e., a two way relation in which the latter is inseparable from, or demands supplementation by, the former, and the former requires clarification and determination by the latter. This thesis does not, then, dissolve any distinction between the two, nor does it attempt to reduce knowledge to perception; it only shows how knowledge has its origin within perception. This is the thesis of, as Merleau-Ponty puts it, the primacy of perception: "The perceived world is the always presupposed foundation of all rationality, all value and all existence. This thesis does not destroy either rationality or the absolute. It only tries to bring them down to earth" (1964, p. 13). It is motivation that will allow us to get this thesis into view, for as we will see, once we cease to approach the relation between experience and knowledge in terms of causality and reason, we are free to move past the dichotomy of empiricism and rationalism which cuts to the core of modern philosophy.

\section{A. Method}

A couple methodological points need to be made from the beginning. This dissertation is, first of all, a work of phenomenology. It is oriented toward an accurate and precise description of the experience of knowledge, of what it is like to come to know. But the phenomenological framework that I develop will allow me to intervene in epistemological debates. In each chapter, I resolve an epistemological debate precisely by moving past the phenomenologically inadequate terms that the debate trades on and attending instead to the primary phenomenon of knowing: solicitation.

First, there are some principled worries about connecting phenomenology and epistemology in this way. On the one hand, one might wonder whether phenomenology can be 
used to answer epistemological questions. For example, as Pietersma has pointed out, the sort of externalist who thinks that justification has nothing to do with what is phenomenally available to subjects might think that phenomenology cannot help us with epistemological questions (2006, p. 10). ${ }^{1}$ On the other, one might wonder whether phenomenology is properly interested in epistemological questions. But, as we will see, the debates into which I intervene are stymied by an inadequate phenomenology of knowledge. Consequently, once the phenomenological backdrop of these debates is altered, there is room for the debate itself to be reconfigured. Further, while there may be a sense in which phenomenology is not interested in epistemological questions - for example, phenomenology is not properly interested in skeptical questions about the existence of the objects of knowledge, for it is proper to phenomenology to receive the phenomenon of knowledge as it is given - phenomenology nevertheless interrogates the phenomenon of knowledge, i.e., it is interested in how knowledge is possible, how it is grounded, and what it is.

Second, at the heart of the phenomenological method I employ is eidetic analysis. In each case, I derive the primary support for my conclusions by attending to particular phenomena examples - in order to draw out their necessary conditions and essential features. These examples are drawn from common experience, but also from developmental psychology, the history of science, and literature. These fields allow us to notice essential features of experience that common experience is blind to, precisely because common experience aims not at itself, but at the world. For example, Karl Ove Knausgaard claims that "Writing is drawing the essence of what we know out of the shadows. That is what writing is about. Not what happens there, not what actions are played out there, but the there itself" (2013, p. 192). Literature, then, is a means

\footnotetext{
${ }^{1}$ There are, of course, other worries about thinking phenomenologically about epistemology. For example, Dennett argues that phenomenology is not an admissible method for investigating consciousness (Dennett, 1991). See (Zahavi, 2007) and (Carman, 2007) for replies. I don't intend to address all such worries in this introduction, only to forward that epistemological questions at least tacitly rely on descriptions of the phenomenon of knowledge, and so there is room for phenomenology to intervene in such debates. My hope is that the merit of this approach will be made apparent in the course of this dissertation.
} 
of opening up the world by breaking through common experience's understanding of itself. Similarly, psychology allows us to loosen the bond between the subject and the world so as to attend to the ligaments of this bond. Of course, literature (as well as the history of science) describes the particular and not the universal, and psychology treats the subject as mundane, as a piece of the world. Thus, the former seems to lack the eidetic reduction and the latter the phenomenological one. But these distinctions cannot be so firmly drawn. Precisely at the heart of the particular, literature discloses the universal, which explains the paradoxical phenomenon that the more an author immerses herself in the particularities of a world, the more the reader finds himself expressed in the author's world. ${ }^{2}$

Similarly, psychology illuminates our experience of the world. It is true that psychology delivers results on the basis of particular, contingent cases. And yet contingency has the power to illuminate the necessary, which is why Merleau-Ponty can draw conclusions about essential features of normal experience by analyzing contingent abnormal cases. We see the value of “attention” in experience, for example, if we turn to cases of “neglect,” e.g., by considering patients who have a functional visual system but cannot become aware of objects on the left side of the visual field. There is a sort of empirical eidetic variation at play in these cases: psychology makes manifest what results for perception if certain factors are altered. On the other hand, psychology is “mundane.” And yet it does not fail to link up with our experience of the world. If neuroscience teaches us about the existence of mirror neurons, this gives a new weight to our lived sense of relating primarily not to private subjectivities, but to other modes of conduct, i.e., to the familiar experience of feeling oneself in the other's action. In other words, phenomenology

\footnotetext{
${ }^{2}$ Of his project of drawing out the essence of "the there," Knausgaard has said in an interview, "There was one woman in San Francisco [who asked] 'How do you manage to write about the Indian American woman because that is what you have been doing, you know?' I said 'No I haven't. I've been writing about the Scandinavian middle aged man.' And she said 'No, it's the Indian American.' ... [My project was to ask] How did I become the man I am, you know? How did it happen? What is the identity, what is it to be someone? And I thought I would just be as private and intimate as I could and be as true as I could to myself. ... So I thought it was too private and too personal and I thought there would be no recognition, and no identification possible in this book. But it doesn't work like that” (Knausgaard, 2015).
} 
learns from each of these fields, because they each make contact with our experience, or in other words, because each draws out of the shadows the essence of what we know.

Third, the scope of this dissertation is both systematic and historical. My aim is to provide a phenomenological account of epistemic grounding that can resolve epistemological debates via an interpretation of Merleau-Ponty’s phenomenology. While I will focus primarily on systematic concerns and secondarily on historical ones, this dissertation is also meant to make and justify a nontrivial interpretative claim: that Merleau-Ponty’s thesis of the primacy of perception ought to be understood in terms of motivation.

Given the historical nature of this dissertation, two notes on my interpretative method must be made. First, I will treat Merleau-Ponty’s work throughout his career as relatively continuous, borrowing freely from different eras of his thinking. In the few cases where I find a potential problem in transposing concepts and terminology between works, I argue on the basis of those specific cases and not in terms of any general framework about architectonic shifts in Merleau-Ponty's thinking. There might be some concern about such liberality, for there is a question about how continuous Merleau-Ponty's thinking is. Barbaras, for example, pursues a developmental hypothesis, according to which Merleau-Ponty’s thinking must make an ontological turn from a "phenomenology of perception" to a "philosophy of perception, discovering in perception a mode of being that holds good for every possible being” (2004, p. xxi). ${ }^{3}$ Or, Gardner argues that The Phenomenology of Perception is read along two lines, one psychological, in conformity with Merleau-Ponty’s early work, and another transcendental, in conformity with Merleau-Ponty’s later work (Gardner, 2015). ${ }^{4}$ All admit that there are changes in

\footnotetext{
${ }^{3}$ At the same time, Barbaras takes it that it is the very questions pursued in Merleau-Ponty’s early work that motivates this ontological turn, and so proposes to treat these early works as an "introduction to ontology” (Barbaras, 2004, p. xxxiii). Indeed, Barbaras concludes that the ontological turn is not a break from phenomenology, but its culmination: "We must not see Merleau-Ponty's ontology as opposed to the phenomenological enterprise; on the contrary, it is its fulfillment” (Barbaras, 2004, p. 77).

${ }^{4}$ Another possible shift has been articulated by Besmer. He holds that there is a transition in MerleauPonty's middle period from an understanding of the relation between perception and linguistic meaning in
} 
Merleau-Ponty’s thinking, but I agree with Dillon that there are no reversals from Merleau-

Ponty's articulation of the primacy of perception in the 40's to his articulation of perceptual faith in the 50’s (Dillon, 1988, p. 51). Second, in illustrating or arguing in favor of Merleau-Ponty's ideas, I will often draw freely from the phenomenological tradition. Generally speaking, this move does not seem problematic to me, given that Merleau-Ponty himself draws much of his thinking relatively freely from the phenomenological tradition. In drawing on this tradition, I do not mean to assume that Merleau-Ponty's thinking is in every respect compatible with Husserl's, only that Merleau-Ponty relies to a considerable extent on major aspects of Husserl's thinking and so it is reasonable to invoke these aspects to understand Merleau-Ponty's arguments.

Finally, my interest in the thesis of the primacy of perception is narrower than MerleauPonty's. In this dissertation, I will be concerned with the primacy of perception as an epistemological thesis. But, for Merleau-Ponty, this thesis is not only epistemological, but also ontological. ${ }^{5}$ I will, in general, avoid the ontological dimension of Merleau-Ponty’s project. I do not mean to imply that these two dimensions are ultimately separable, but I do suppose that the epistemological dimension can be treated in isolation from the ontological one. ${ }^{6}$

terms of Fundierung to understanding meaning in terms of Stiftung (or institution) (Besmer, 2007, pp. 100102).

${ }^{5}$ It seems to me that Dillon is ultimately right to draw a correlation between an epistemological thesis (the primacy of perception) and an ontological thesis (the primacy of phenomena), and to write that "The thesis of the primacy of perception is properly phenomenological because ... it asserts the ontological primacy of phenomena as its correlate” (Dillon, 1988, p. 53).

${ }^{6}$ Many scholars have pointed out how Merleau-Ponty's epistemology ultimately depends on an ontology. Dillon, for example, has argued that it is Merleau-Ponty's ontological thinking that, by undermining dualism, makes Merleau-Ponty's account of knowledge possible, and so claims that "for Merleau-Ponty, epistemological problems are never treated as only that; rather he tends programmatically to search for resolution by looking for the ontological presuppositions underlying the standpoints within which such problems crop up” (Dillon, 1988, p. 4). Pietersma makes a similar claim (though one concerning the dualism of subject and object, rather than that of mind and matter) (Pietersma, 2006, p. 160). However, as my project will demonstrate, one does not need to begin from Merleau-Ponty's ontology to argue for his epistemology, at least the sorts of epistemological questions I will be asking. Demonstration of MerleauPonty's ontology, it seems to me, requires an additional kind of consideration, namely a consideration of the transcendental nature of Merleau-Ponty's phenomenology. This kind of consideration would supply an important complement to the present project - for it is implicated in my project - but is not an immediate necessity. 


\section{B. Overview}

I defend these two theses, that motivation is an epistemic ground and the primacy of perception, over the course of five chapters. In chapter 1, I explain what it means to consider motivation as an epistemic ground and show that motivation is not reducible to a species of either causality or reason. I argue that motivation is a form of grounding that is spontaneous, operates in virtue of implicit meanings, and is normative. This allows me to argue that motivation is not a species of reason, because whereas reason is active and explicit, motivation is spontaneous and implicit. Further, motivation is not a species of causality, because causality is passive, does not operate in virtue of meanings at all, and is not normative. Finally, I argue that motivation is unique in the way in which the outputs of motivation transcend its inputs, i.e., its outputs are not definable in terms of, and are not contents of, its inputs.

In chapter 2, I consider the relation between experience and empirical judgments. It is clear that experience in some sense grounds empirical judgments, but it is far from clear in what sense exactly it does so. Davidson, for example, holds that experiences, being non-propositional, are not the kinds of things that can justify judgments, and so experience can at most cause our judgments. McDowell, in contrast, holds that in virtue of its type of content experience can count as a reason for judgment. I argue that this debate is rooted in an inadequate phenomenology of the relation between experience and judgment. In fact, neither reason nor causality properly describe this relation, for this relation - I argue - is spontaneous (and not active, as it would have to be if it were relation of reasoning) and normative (and so cannot be merely causal). Motivation, I conclude, does a better job of describing the type of grounding with which experience provides empirical judgment than do either reason or causality.

In chapter 3, I turn to the relation between experience and a priori judgments. While it is obvious that experience in some sense grounds our empirical judgments, it is not at all obvious that it grounds our a priori judgments. Indeed, rationalists have long held that experience is just not the sort of thing that can ground a priori judgments, because experience delivers particular 
and contingent facts, but a priori judgments must hold universally and with necessity.

Empiricists, in contrast, have argued that our a priori knowledge is derived from experience. In chapter 3 , I argue that thinking the relation between experience and the a priori in terms of motivation provides the best solution to the long-standing debate between rationalism and empiricism.

I first consider the classical arguments in favor of both rationalism and empiricism. I argue that empiricism must be wrong that all the content of our a priori knowledge is contained in experience. On the other hand, I argue that rationalism is wrong to think that experience is not the sort of thing that can ground a priori knowledge. Further, thinking of the grounding relation between experience and knowledge in terms of motivation is what allows me to avoid both alternatives. Because the outputs of motivation transcend the inputs, if knowledge is motivated by experience then there is no reason to think that the content of knowledge is contained in experience. Conversely, this same feature of motivation explains how experience, being contingent and particular, can motivate universal and necessary judgments.

I then consider contemporary debates between rationalism and empiricism. I divide these debates into two parts. One debate, between empiricism and nativism, concerns the acquisitions of the meanings employed in non-experiential knowledge. Empiricists hold that all meanings are definable in terms of sensory primitives. In contrast, nativists hold that some meanings are not definable in terms of sensory primitives, and so must be innate to the mind. I argue that thinking the relation between experience and non-experiential knowledge in terms of motivation avoids both options: some meanings are not definable in terms of sensory primitives, but are not therefore innate, because they are motivated by experience. A second debate, concerns the justification of our knowledge. With regard to this question, empiricists hold that knowledge can only be justified in terms of experience. In contrast, rationalists hold that experience simply cannot justify some of what we hold to be knowledge, and so there must be some other form of justification, i.e., rational insight. Once again, motivation avoids both alternatives. Rationalists 
are right that there are certain kinds of knowledge which experience cannot justify, but this does not mean that experience cannot ground this knowledge in the mode of motivation. I argue that on all these fronts motivation provides a better way of thinking about the relation between experience and knowledge than do either rationalism or empiricism.

However, there is a kind of a priori justification which avoids both rationalism and empiricism, and which has fundamentally shaped the past two centuries of philosophy: the method of transcendental justification exercised by Kant. Kant's whole critique of metaphysics centers around his claim that the ground of a priori synthetic knowledge is experience, considered with regard to its possibility: transcendental method justifies certain judgments $a$ priori by showing them to be conditions for the possibility of experience. In chapter 4 , I move to consider this type of a priori justification.

My contention is that, contrary to appearances, the projects of Merleau-Ponty and Kant are not contradictory but compatible; that, indeed, they require each other. The two projects operate on different levels: they are concerned with different senses of experience and so approach experience with different standards. Whereas Merleau-Ponty is concerned with experience understood as perception, and so approaches experience with the standard of motivation, Kant is concerned with experience in the sense of empirical judgment, and so approaches experience with the standard of justification. The many seemingly opposed conclusions they reach are a consequence of their pursuing investigations on different levels with different standards. Nevertheless, I argue that transcendental justification ultimately relies upon an a priori which is not transcendentally justified, but is instead motivated in the course of experience, in the manner I describe in chapter 3. Transcendental method justifies certain judgments on the ground that they are conditions for determinate features of experience. But for this method to work, we must have some knowledge of the determinate features of experience. I argue that this knowledge is not justified but motivated. 
In chapter 5, I argue that this line of thinking leaves the door open for a certain kind of metaphysics. Admittedly, Kant must be right that no synthetic a priori judgments can be justified through reason alone. However, this does not mean that experience cannot motivate synthetic $a$ priori judgments. I make this point with regard to a specific metaphysical question discussed by Kant - that of the Third Paralogism - namely, self-identity. I argue that the structure of experience suffices to motivate the thought of self-identity. But if we approach this thought with the standard of justification, everything changes. Kant is right that empirical apperception does not suffice to justify self-identity, and so something like transcendental apperception will be required instead. However, these two levels - motivation and justification - are not indifferent to each other. Indeed, they require each other. For, I will argue, it is only possible to refer transcendental and empirical apperception to the same subject, to the same I, if we understand how both arise from the reflective apprehension of the pre-reflective experience of self described by Merleau-Ponty.

In my conclusion, I turn to consider perhaps the most difficult consequence of this line of thinking: that the contingent is the ground of the necessary. This leads me to a reflection on the ambiguity - to use Merleau-Ponty's term - of knowledge and how this ambiguity can be taken up authentically. 


\section{CHAPTER 1. MERLEAU-PONTY'S PHENOMENOLOGY OF MOTIVATION}

Motivation is the conceptual structure underlying every major argument in this

dissertation. In each of the following chapters, I will reconfigure an existing philosophical

question by introducing motivation as a novel form of epistemic grounding. For this reason, it is essential, first of all, to establish a clear understanding of what I mean by this term. This is the purpose of the present chapter. I explain what distinguishes motivation as a form of grounding from other forms of grounding, namely, reason and causality. And I show that motivation can be understood as an epistemic ground, not only - as it is generally understood - as a practical ground.

Two points should be made at the outset. First, while this dissertation will be concerned with motivation only as an epistemic ground, in the present chapter I will occasionally resort to cases of practical motivation in order to clarify essential structures of motivation. ${ }^{7}$ Further, as I mentioned in my introduction, my interests in this dissertation are both systematic and historical. The claims I make about motivation I intend both to defend myself and to attribute to MerleauPonty. ${ }^{8}$

I structure this study around 10 theses about motivation:

1) Motives operate through their meaning

2) Motives don’t require explicit awareness in order to operate

3) Motivation is spontaneous

\footnotetext{
${ }^{7}$ In general, I do not think there is any problem in transitioning between cases of epistemic, practical, or even aesthetic motivation. In each case, it is a question of the constitution of a spontaneous sense: a meaning we do not create but find. Our existence gears into spontaneous meaning in every domain, including the practical and epistemic. Epistemically, perception spontaneously reveals a meaning in things. Practically, situations are spontaneously revealed as having meaning for my conduct. I can then actively accept or reject these meanings in my judgments or my decisions. Motivation is the form of grounding characteristic of this spontaneous sense. The essential structures of motivation apply in each domain of spontaneous sense, though differently in each.

${ }^{8}$ Merleau-Ponty himself borrows the term "motivation” from the phenomenological tradition. See Appendix I for a discussion of Husserl's and Stein's treatment of motivation. However, Merleau-Ponty gives a unique sense to motivation in contrasting it as an epistemic ground not only to causality but also to reason. See Merleau-Ponty 2012 (pp. 48-51).
} 
4) Motivation is an internal relation

5) Motivation is a reciprocal relation

6) Motivation tends to equilibrium

7) Motivation does not ground with necessity

8) Motivation is normative

9) The outputs of motivation transcend the inputs

10) Motives are neither reasons nor causes

In what follows, I defend each of these theses in turn. But first I offer a few examples of perceptual motivation.

\section{A. The shipwreck example}

If I am walking on a beach toward a boat that has run aground, and if the funnel or the mast merges with the forest that borders the dune, then there will be a moment in which these details suddenly reunite with the boat and become welded to it. (Merleau-Ponty, 2012, p. 17).

Merleau-Ponty describes a perceptual gestalt shift: a scene which had appeared as a bank of trees is reinterpreted as a shipwreck. What is this experience like? Has one begun by noting various incongruities in the interpretation of the vertical poles as tree trunks - perhaps that they are too long or too short, not quite the right color, or that they lack branches? While it is certainly possible that one arrives at the new interpretation in this manner, by noting incongruous details, one need not. Just as likely, as one approaches the ship, a feeling of tension gradually builds, without one knowing what causes the tension. One senses a problem in the interpretation, without being able to adduce evidence as to the problem, perhaps without ever yet paying attention to the building awareness of a problem. Then, with the arrival of the new interpretation, the tension is released: a more stable, more complete interpretation achieves dominance. ${ }^{9}$

\footnotetext{
9 This experience of building tension without explicit recognition of incongruities in, or problems with, a perceptual interpretation, can be illustrated with another example. Suppose I walk into a familiar room and suddenly sense that something is "wrong," i.e., something is different: there is a tension between the perceived room and my familiar sense of the room. Something is wrong, and yet I have no explicit recognition of what is creating the tension. While in fact several of the pictures on the wall have been
} 


\section{B. The bell tower example}

... Objects interposed between me and the one I am focusing upon are not perceived for themselves. But they are, nevertheless, perceived, and we have no reason to deny this marginal perception a role in the vision of distance since the apparent distance shrinks the moment a screen hides the interposed objects. The objects that fill the field do not act on the apparent distance like a cause on its effect. When the screen is moved aside, we see the distance being born from the interposed objects. This is the silent language perception speaks to us: the interposed objects, in this natural text, 'mean' a larger distance. It is, nevertheless, not a question of the logic of constituted truth (one of the connections that objective logic knows), for there is no reason for the bell tower to appear to me as smaller and farther away the moment that I can see more clearly the details of the hills and the fields that separate me from it. There is no reason, but there is a motive (Merleau-Ponty, 2012, pp. 49-50).

The presence of objects interposed between myself and an object to which I am attending

motivates a sense of the size and distance of the object. This is true even if I pay no attention to the interposed objects, even if they don't figure in my awareness at all. For example, I see the full moon on the horizon as large. ${ }^{10}$ But if I screen from my vision the horizon above which it hovers, the moon will suddenly shrink. I do not think (i.e., judge) that it must be smaller than I thought it

was. Rather, I see it as smaller.

\section{The portrait example}

It took centuries of painting before the reflections upon the eye were seen, without which the painting remains lifeless and blind, as in the paintings by primitive peoples. The reflection is not seen for itself, since it was able to go unnoticed for so long, and yet it has a function in perception, since its mere absence is enough to remove the life and the expression from objects and from faces. The reflection is only seen out of the corner of the eye. It is not presented as the aim of our perception, it is the auxiliary or the mediator of our perception. It is not itself seen, but makes the rest be seen (Merleau-Ponty, 2012, pp. 322-3).

The presence of a reflection in the eye of the subject of a portrait imbues the subject with life.

This simple perceptual cue motivates one to see the subject with a particular quality: that of liveliness. ${ }^{11}$ Further, this perceptual cue serves as a motive whether or not it is explicitly

rearranged, I have only a vague sense that something is different, but can't quite "put my finger on" what it is.

${ }^{10}$ Cf. Merleau-Ponty 2012 (pp. 270-1).

${ }^{11}$ Consider the impression Knausgaard receives from a self-portrait of Rembrandt, how much of it has to do with the eyes and (if not explicitly) with the reflection they hold: "Old age. All the facial detail is 
recognized by the viewer, for it took centuries to be noticed for itself. There are thus motives at work in perception to the function of which explicit attention is accidental, attendant at most.

With these examples in mind, I turn to an explication and defense of the 10 theses listed above.

\section{Motives Operate through Their Meaning}

One phenomenon triggers another, according to Merleau-Ponty, not through objective causation, but through “the sense [sens] it offers” (Merleau-Ponty, 2012, p. 51). Motives, in other words, operate through their meanings. For an initial indication of this idea, consider the reflection in the eye of the portrait subject. What should we say is the motive here? Is it the white paint on this particular sector of the canvas that motivates us? Is it the light waves striking our eyes? Or would it be more accurate to say that it is the reflection in the eye that motivates us? The physical factors, the matter and the light waves it emits, are causes of sensations. But these sensations alone do not suffice for seeing life, because these sensations can be had without one's seeing life: a patch of white light does not make one see life. One could respond that it is my eyes being struck by light of this wavelength in conjunction with light of a particular other wavelength, the dark of a pupil, that causes me to see life. But these colors will often go together without one seeing life. What is right in this response is that the stroke of white only motivates by entering into the whole of its surroundings. But the whole that makes the reflection motivate is not this complex of white and black light, but the eye to which it belongs. It is by entering into a whole of

visible; all the traces life has left there are to be seen. The face is furrowed, wrinkled, sagging, ravaged by time. But the eyes are bright and, if not young, then somehow transcend the time that otherwise marks the face. It is as though someone else is looking at us, from somewhere inside the face, where everything is different. One can hardly be closer to another person. ... What is depicted here, what Rembrandt painted, is this person's very being, that which he woke to every morning, that which immersed itself in thought, but which itself was not thought, that which immediately immersed itself in feelings, but which itself was not feeling, and that which he went to sleep to, in the end for good. That which, in a human, time does not touch and whence the light in the eyes springs. The difference between this painting and the other the late Rembrandt painted is the difference between seeing and being seen” (2013, pp. 26-7). See Rembrandt's "Self Portrait at the Age of 63" at the National Gallery. To reword this impression: it is the eyes which deliver Rembrandt not as a mass of historical details, but as a subject, a power of seeing which transcends its predicates (e.g., thoughts, feelings). 
meaning, "the eye" and not the bare color, that the white becomes not just bare color but a meaning, "the reflection in the eye," and so invokes the perception of life.

But is this an essential feature of perceptual relations? We need a more precise understanding of what Merleau-Ponty means by “sens,” what I am calling “meaning,” and why perceptual phenomena are grounded in virtue of meanings. To this end, I first offer a criterion for distinguishing meaning-ful from non-meaningful relations, and then offer a brief account of Merleau-Ponty’s notion of “sens.”

\section{A. A Criterion}

By “meaning” I intend something like that as which an object or event is intended. Meaning, in other words, is characterized by something like Heidegger's hermeneutical "as structure.” The phrases “The $15^{\text {th }}$ state incorporated into the Union” and "The Bluegrass State” have the same referent but different meanings (nothing in the meaning of a "Bluegrass State" necessarily implies that it be $15^{\text {th }}$ state incorporated into the union). I can think of Kentucky as either of these things, but this does not imply that the two meanings are the same. A similar idea would be expressed in saying that meaning is intensional rather than extensional, though these terms refer to linguistic meanings, whereas sens is pre-linguistic.

With this basic understanding of meaning, we can supply a criterion for distinguishing grounds that operate in virtue of their meaning from those that don't. A ground that operates in virtue of its meaning will operate in virtue of that as which it is a ground. Put otherwise, a ground can be said to operate in virtue of its meaning if the terms used to describe that ground determine the truth value of statements about the grounding relationship. Imagine that upon the death of a close friend I undertake a journey in order to pay my respects or comfort the grieving family. There are all sorts of features of my friend that could be used accurately to describe her: suppose besides being my friend she used to reside at 71 east $5^{\text {th }}$ Street and on Saturdays volunteered at the local animal shelter. She could be intended in any of these meanings. If someone approached me and asked why I was travelling, I could truly respond "Because my friend has died.” 
However, I would respond falsely were I to say, "Because of the death of the Saturday animal shelter volunteer," or "Because of the death of the resident of 71 east $5^{\text {th }}$ street.” These descriptors of my friend are not incorrect, but it is incorrect to frame them as motives of my journey. If I were traveling because of the death of the Saturday volunteer, I would be motivated to undertake my journey every time the holder of this office passed away, which I am not. It is only as my friend that the loss touches me, only as my friend's, that the death summons. No bare event or state of affairs is a motive: only as something, i.e., in virtue of its meaning, can an event, thing, or state of affairs become a motive.

In contrast, because causal relations hold not between meanings but between objects, events, or states of affairs, it is a matter of indifference what terms are used to describe the relata: if asked why a pool ball is in motion, one can answer as truly "Because it was struck by the 9 ball” as "Because it was struck by the yellow-striped ball” as "Because it was struck by a collection of matter with the requisite momentum.”

\section{B. Merleau-Ponty's Account of Sens}

First, a word about translation. I have chosen to translate Merleau-Ponty’s term “sens” as “meaning,” because I think this term can be used to make Merleau-Ponty’s point about motivation most clearly. However, the alternate translation, "sense," may capture more of the nuance of the term. Whereas "meaning” might seem to imply some sort of explicit semantic content, "sense” does not. One can get the sense (or "make sense”) of a scene, or a mood, or a melody without being able to formulate this sense in words. When I use the term "meaning” as a translation of Merleau-Ponty’s “sens,” I don’t mean to exclude non-semantic contents.

Merleau-Ponty tends to talk about meaning in terms of part-whole relations. ${ }^{12}$ Thus, in the introduction to the Phenomenology of Perception, Merleau-Ponty writes,

\footnotetext{
${ }^{12}$ Donald Landes writes, for example, that "in [Merleau-Ponty's] earliest works, the notion of sense emerges through Gestalt psychology as a way of describing the sense of the whole that is irreducible to its parts, and hence the emergence of meaning in experience without any thetic intervention by consciousness" (Landes, 2013, p. 205).
} 
Consider a white patch against a homogenous background. All points on the patch have a certain common 'function' that makes them into a 'figure.' The figure's color is denser and somehow more resistant than the background's color. The borders of the white patch 'belong' to the patch and, despite being contiguous with it, do not join with the background. The patch seems to be placed upon the background and does not interrupt it. Each part announces more than it contains, and thus this elementary perception is already charged with a sense [sens] (2012, p. 4).

Perception is meaningful, according to Merleau-Ponty, because it is primordially composed of a figure on a background, i.e., there is no perception more original than a figure on a background, on the basis of which a figure on a background could be composed. Perception does not yield, in other words, as its basis mutually indifferent atomic sensations which must be combined into the perception of a whole, a figure. Rather, the perception of the figure or the whole is primordial, and consequently each part is not isolated from the others, but "announces more than it contains." This "announcing" beyond itself, i.e., the intrinsic relation to the whole, implies that the part has a sense. Sense, then, for Merleau-Ponty, fundamentally names the way in which experience is prepredicatively composed of organized wholes or structures. ${ }^{13}$ To make sense of a situation is to resolve the givens of a situation into a coherent (though not necessarily explicit) structure. Further, it's because meaning has to do with the way in which we organize a situation that it can be described in terms of an "as structure": the way in which we organize a situation is that as which we intend a situation (e.g., that I perceive a figure with the structure of a table implies that "table" is that as which I perceive the object). Let this suffice for a cursory account of MerleauPonty's understanding of meaning.

\footnotetext{
${ }^{13}$ What do I mean by "structure" here? This can be indicated by a brief recourse to the Structure of Behavior. Merleau-Ponty introduces the category of "form" in Structure of Behavior in order to account for certain phenomena of the nervous system, such as reflexes. He writes there, "We will say there is form whenever the properties of a system are modified by every change brought about in a single one of its parts and, on the contrary, are conserved when they all change while maintaining the same relationship among themselves" (Merleau-Ponty, 1963, p. 47). Form or structure is thus something like the concept of similar figures in geometry: a change in one of the parts makes the whole dissimilar, but if all parts are changed to maintain the same relationship, the whole is similar.
} 
Even if it is implicit and indeterminate, a motive has its effect through the way in which it as a situation is organized into a structure. Thus, in the shipwreck example, the perceptual situation motivates an interpretation, not qua a set of mutually indifferent atomic sensation, but qua a perceptual field in which the various aspects of the situation shape each other and are in tension until such a time as a coherent structure or interpretation can be negotiated. Similarly, the interposed hill is a motive for seeing the bell tower as far away only as an interposed hill (if I were surveying the scene from above, the hill would have no value in the perception of the bell tower), i.e., as part of the perceived structuring of distances I have in view.

\section{Motives Don't Require Explicit Awareness to Operate}

Merleau-Ponty writes that no "explicit positing” need occur for a motive to have its effect. In other words, one doesn't need to notice or be aware of the motive for it to motivate. While motives operate through their meaning, then, they do not need to operate through any meaning of which I am consciously aware. This is easy enough to see in the above examples:

1. I do not first note various perceptual incongruities and then decide that what I thought were tree trunks are in fact the ship's masts. These incongruities, which afterwards can in some cases be enumerated and will appear as obvious clues, needn't themselves gain my attention in order to shape my perception.

2. Attending to the hill that stands between me and the bell tower is not a necessary condition for my perception of the hill to shape my perception of the distance to the bell tower. Similarly, I may be so captivated by the moon that I don't notice any of the objects on the horizon - yet they will encourage me to see the moon as a certain size.

3. The reflection in the eye of the portrayed subject affects how I see the subject. According to Merleau-Ponty, the reflection could only go so long unnoticed by artists because it is not normally seen for itself: it belonged only to the background of perception, not to the foreground.

However, nothing here forbids explicit positing. My stopping to note the hill and its position between the tower and myself will not affect my perception of the distance between here 
and the tower. While at least some motives can be raised to explicit awareness, doing so need not affect the process of motivation. Thus, even if I stop and note the hill between myself and the tower, and take it as an index of distance, once a screen is placed between myself and the tower the perceived distance of the tower decreases. This occurs even though I now know about the hill, and take it as an index of distance. Motivation thus continues to operate independently of explicit awareness. This consideration allows us to see the following:

\section{Motivation is Spontaneous}

Motives present a subject with a curious quasi-responsibility. If asked why one is motivated to do or think in a particular manner, one may be unable to respond. Motivation is thus not entirely within the realm of responsibility, as reasons must be. On the other hand, one can through reflection set about describing one's motives, making them explicit and thus possible features of responses. Such description can be more or less astute. Moreover, it need not alter the process of motivation. ${ }^{14}$ Thus, motivation is neither entirely within nor entirely without the space of responsibility.

This point can be put more finely by distinguishing between passivity, spontaneity, and activity. I mean spontaneity in the sense that Merleau-Ponty intends when he claims that the meaning we find in the world is the product of a "spontaneous valuation” (2012, p. 465). For example, the following series:

is always perceived as a collection six groups of dots two millimeters apart (the dots are grouped with the near dots, rather than the far dots). This gestalt is spontaneously attributed to the series; it is not the product of decision of deliberation, and if asked I can give no reason as to why they should be grouped that way rather than another. More accurately, I can attempt to explain why I grouped them that way, e.g., "It makes sense to group dots that are closer together.” But such

\footnotetext{
${ }^{14}$ Though it seems very likely to me that it often does alter this process - a proposition to which psychoanalysis and the phenomenon of cognitive penetration attest.
} 
explanations are speculative and at best rationalizations, as can be seen by the fact that if I did have good contravening reasons, I would not be able to revise this perception. For example, in the case of the Müller-Lyer illusion, my "spontaneous valuation” of the lines as of different lengths conflicts with the reasons I have for thinking they are the same length (e.g., that I have measured the two lines). ${ }^{15}$ While I am free actively to affirm or deny the spontaneous sense that I perceive, I am not free to change the perception itself: despite my knowledge to the contrary, the lines still appear different in length. Thus, I am not active with respect to this spontaneous sense. But neither am I simply passive. The world does not cause this perception in us, and conversely, we do not simply receive it. Instead, the body spontaneously produces it. ${ }^{16}$

In the bell tower example, there is a sense in which the removal of the screen should not cause my perception of distance to change. Once I know the distance, the presence of the screen should be indifferent to me. And yet whenever the screen is placed back in front of me, the perceived distance shrinks to what it was before. The motivation of this perception thus occurs spontaneously.

\section{Motivation is an Internal Relation}

What does Merleau-Ponty mean when he writes that motivation is an internal relation (2012, p. 51)? One option is that Merleau-Ponty means the term in the sense defined by G. E.

\footnotetext{
${ }^{15}$ In the Müller-Lyer illusion, two lines of equal length appear unequal due to the addition of arrows attached to the ends of the lines, in the one line the arrows pointing away from the line, and in the other toward it. See Figure 1.1.

${ }^{16}$ It would be more exact to say that I am at most partially active with respect to this spontaneous sense. For often our redescriptions of the world do in fact change our perceptions of it. If a friend sees a different gestalt before us than I do, I will ask myself “Could it be like he says?” Then somehow the perceptual field changes, and the gestalt perceived by my friend pops into view; if I seek, I find. Similarly, as soon as I measure the lines in the Müller-Lyer illusion it is not exactly true that the lines remain different in length. Instead, they are thrown into confusion, neither quite equal nor quite different. Nevertheless, the decisive fact remains that I cannot make myself see what I in fact know. The same is true in regard to practical motivation. The spontaneous sense of a situation often conflicts with my reasoned stance toward it. But it is also true that in reasoning through a situation, in drawing distinctions and applying general maxims, I reconfigure the motivational field that produces the spontaneous valuation, and this valuation may itself be transformed thereby. Nevertheless, in both cases it remains true that I am at most partially active with respect to the spontaneous sense: as with sleep I can gather all the circumstances of sleep around myself in petition for its arrival, but it is useless unless sleep comes to me, so here my reasoning is like a petition for spontaneous insight that may or may not come.
} 
Moore, i.e., that an internal relation is a necessary one, such that if the relata exist, then they necessarily stand in the specified relation to one another. This is more or less the sense that O’Conaill, following Morriston, has attributed to Merleau-Ponty. O’Conaill writes that MerleauPonty understands an internal relation to be one in which "the relata are logically interdependent; that is, they cannot be defined independently of each other” (2012, p. 582) That this interdependence is logical is important, for on O’Conaill's interpretation, Merleau-Ponty thinks a relation is internal only if the relata are inconceivable without one another, and therefore cannot exist without one another. But, as Morriston points out, if Merleau-Ponty understands internal relationship in this strong sense of logical existential interdependence (that the relata cannot exist without one another), then it seems like paradigmatic instances of motivation will not qualify as internal relations. I invoked Merleau-Ponty’s example of being motivated to undertake a journey by the death of a friend, but the death can certainly occur without one's undertaking the journey, and the journey can occur without the death (Morriston, 1979). O’Conaill accepts Morriston’s criticism only in part: while Morriston is right that the motivated is only prefigured in the motive (but can be conceived without it), he does not recognize that the state of being motivated is logically dependent on what one is motivated to do (we cannot think of being motivated to do $X$, without thinking of $X$ ). O’Conaill's qualification, however, does not succeed in restoring Merleau-Ponty's claim that motivation is an internal relation, on O’Conaill's account of what Merleau-Ponty means by an internal relation (O'Conaill, 2012, p. 583). If we accept this account, it seems we will also have to accept that Merleau-Ponty was wrong to think that motivation is an internal relation.

A second option presents itself in Husserl's distinction between independent and nonindependent parts. According to Husserl, non-independent parts or moments can exist (by essence) only as parts of more inclusive wholes (2001, p. 12). Such non-independent parts can be said to be founded upon, i.e., necessarily supplemented by, some other moment (Husserl, 2001, p. 25). For example, the white color of a piece of paper is a non-independent part of the paper, 
insofar as it cannot exist without the extension of the paper. The color can thus be said to be founded upon the extension. Further, some foundational relationships are reciprocal (Husserl, 2001, p. 27).

A reciprocal foundational relationship between parts of a whole seems like a plausible candidate for what Merleau-Ponty means by “internal relation.” Consider how Merleau-Ponty articulates the relationship between apparent size and apparent distance:

The phenomenon 'apparent size' and the phenomenon of distance are two moments of the overall organization of the field, ... the former is related to the latter neither in the relation of sign to signification, nor in the relation of cause to effect, and ... like the motivating and the motivated, they communicate through their sense. ... Apparent size, then, cannot be defined independently of distance: apparent size is implied by distance just as much as it implies distance (2012, pp. 271-3).

But while Husserl's conception of foundational relationships is certainly in the background of Merleau-Ponty's conception of internal relationships, and is helpful insofar as it restructures dialogue about internal relations in terms of parts and wholes, as an interpretations of what Merleau-Ponty means by “internal relationship” it runs afoul of same problem Morriston pointed out for the more analytic definition of internal relation: the motivated is not a nonindependent part of the motivation relation, insofar as it can exist without the motivating.

How then should we approach Merleau-Ponty's concept of internal relations? I propose that, for Merleau-Ponty, the relata in an internal relation are logically interdependent, not in terms of their existence (this is the error made on both the analytic and my suggested Husserlian approach), but in terms of their meaning. Morriston is, of course, right that the journey can occur without the death, and the death without the journey. The existence of the one is not logically dependent on the existence of the other. However, the meaning of the one is logically dependent on the meaning of the other. The journey means something very different without my friend's death (it is perhaps a vacation, and not a final visitation). Conversely, Morriston is correct that the death occurs whether or not I undertake the journey - and yet, is it not clear, all things being equal and assuming the journey is well within my means, that the death meant something 
different to me if I chose not to undertake the journey than if I had chosen to undertake it? In my choice, the death reveals the meaning it has for me, it reveals whether it stands more toward the core or the periphery of my existence.

Let's briefly look at a few examples of what Merleau-Ponty considers to be internal relations. First, consider the notes of a melody. With the first note of a melody, we already have a vague horizon of meaning that will shape the meaning of every subsequent note. The sixth note will only mean what it does relative to the previous five: it conveys something it could not possibly convey were it played in isolation. Conversely, the first note is by itself indeterminate. It could be the beginning of any number of melodies, joyful, ironic, or somber. If we look back on this indeterminate first note from the vantage of the sixth, the first will no longer mean what it did: it will have been given meaning as the inception of this particular playful tune. Of course, these notes could exist without the others. But they could not mean what they do without the others. Second, according to Merleau-Ponty, the parts of a perceived form or structure bear an internal relation to each other. Merleau-Ponty writes,

The parts of a thing are not linked together by a simple external association .... . There are no indifferent givens that together set about forming a thing because some factual contiguities or resemblances associate them. Rather, because we first perceive a whole as a thing, the analytic attitude can later discern resemblances or contiguities there (2012, p. 16).

Perceptions are not composed of elemental givens with independent meanings, which can be indifferently synthesized into a whole. Rather, the meanings of the parts of perceptions depend on each other and on the whole. ${ }^{17}$ Third, Merleau-Ponty describes the perception of color and of lighting as standing in a reciprocal relationship (2012, pp. 320-1). On the one hand, the perception of color is determined by the perception of lighting: a blue piece of paper under a

\footnotetext{
${ }^{17}$ This is most obvious in cases of Gestalt reversibility, such as "My Wife and My Mother-in-Law" (see Figure 1.2). When one suddenly sees what was at first the young girl now as an old woman, all the parts will be concordantly re-determined: what was a chin is now a nose, an ear now an eye. The parts are not atoms of meaning, which subsequent to their interpretation can be associated into a whole. Rather, they draw their meaning from the whole.
} 
yellow light emits wavelengths that would appear brown under daylight, and yet the paper is perceived as blue. The perception of the paper is adjusted to, and dependent upon, the perception of the lighting as yellow. Thus, what I perceive is not an immediate, isolated sense given, but a part dependent in its meaning on the other parts of perception. In this sense, the perception of color reveals its dependence on the perception of lighting, precisely where it seems to be independent. Conversely, if one strongly illuminates the interior of a black box, and weakly illuminates the interior of a white box, the two will appear an identical gray. If one then places a piece of white paper in the first and black paper in the second, the first will be perceived as a strongly illumined black box, and the second as a weakly illumined white box. The perception of lighting is thus dependent on the perception of color.

Notice how different this sort of internal relation is from a causal relation. While in both cases, the relation is the ground of a relatum being as it is, the causal relation can be merely the occasion for the relatum being as it is, whereas the internal relation sustains the relatum being as it is. Of course, in the example of the melody, the successive notes fall out of existence, yet their meanings sustain each other note in its meaning. Were the meaning of the others to be truly and totally forgotten, the final note would lose its meaning. In contrast, one billiard ball driven to motion by another is subsequently entirely indifferent to the existence of the other. Thus, Merleau-Ponty considers causal relations to be external relations (and conversely, relations between reasons as internal, insofar for example as a conclusion is dependent for its evident truth on the truth of its premises).

I have argued that for Merleau-Ponty motivation is an internal relation, and an internal relation is one in which the meanings of the relata are interdependent. This means that the meanings of a motive and a motivatum are interdependent. How does this play out in our examples? In the shipwreck example, the meaning of what I am seeing - tree trunks or ship’s masts - is dependent upon the perceptual givens preceding the interpretation, and they conversely are dependent upon the interpretation: the various parts and qualities I am perceiving will be 
differently determined on the basis of what I am seeing. Or again, the sense or meaning of the portrait's face - its life or absence of life - is dependent in part on the reflection in the eye.

\section{Motivation is a Reciprocal Relation}

One of the more novel aspects of Merleau-Ponty's thinking about motivation is his claim that it is a reciprocal relation. Whereas Merleau-Ponty's phenomenological predecessors, Husserl and Stein, clearly describe the motivated as internally related to the motivating, they do little to suggest that the motivating is logically dependent on the motivated. Merleau-Ponty argues that the internal relation, the relation of logical dependency, between the motivating and the motivated is reciprocal. In other words, precisely through the meaning it motivates, the meaning of the motivating factor is itself transformed. I will call "proactive” the influence that the motivating factor has on the motivated, and "retroactive" the influence of the motivated on the motivating.

It is easy enough to see a retroactive effect in some cases of motivation. The example of the melody, given above, demonstrated this effect: the meaning of the first note is indeterminate until it is given a particular shape, mood, and force by the notes that follow. From out of the range of possible meanings established by the first note, the ensuing notes will select one and thereby determine the meaning of the first note in a particular manner. Retroactive effects are also frequently operative in our processing of sentences. Imagine someone asks you, "Is the mouse working?” The meaning of the parts of the sentence stand in a reciprocal relationship: they determine each other. The word “mouse” establishes an indeterminate horizon, a vaguely defined range, of possible meaning such that when the word "working” arrives, one is already disposed to understand it in a certain manner: working here means something like "functioning properly," not something like "has steady employment." Thus, the meaning of "working” is motivated by what is here doing the working: the mouse. Conversely, what is meant by "mouse" is here determined by what is meant by “working.” Prior to the “working,” I do not know whether I am being asked about the computer interface device or the rodent. But as soon as I have "working," a meaning coalesces and the sentence falls into a particular place: the question is whether this device is 
functioning properly. The tension between competing interpretations of "mouse," a tension which perhaps had never even come to my attention, is now resolved. Thus, what was the motivated factor serves conversely to determine the motivating factor. Whereas "mouse” puts forward a vague sense that makes "working” mean "functioning properly," and thus operates proactively, in the same breath "working” fixes "mouse” as this electronic device, determining after its initial occurrence the "mouse" that put forward a vague sense, and thus operates retroactively. In this case, each relies on the other for its meaning: alone, their meanings would be indeterminate. Motivation can thus name this reciprocal process, by which the components of a whole fix each other and the whole to which they belong.

Thus at least some relations of motivation are reciprocal, i.e., contain a retroactive effect. But should we think that all are? To answer this question, we need to do clarify what sort of things Merleau-Ponty thinks the retroactive effect can do.

\section{A. The Retroactive Effect}

Merleau-Ponty describes the retroactive effect as explication or validation. He writes, for example,

To the extent that the motivated phenomenon is brought about, its internal relation with the motivating phenomenon appears, and rather than merely succeeding it, the motivated phenomenon makes the motivating one explicit and clarifies it, such that the motivated seems to have preexisted its own motive (2012, p. 51).

That the retroactive effect is one of explication is easy to see in the above examples. While the sixth note doesn't explicate the first in the sense of making it explicit (of bringing it to the forefront of consciousness), it does give a particular shape to what was its indeterminate meaning: out of an amorphous block of possibility, the sixth note does the work of carving a refined shape. The motivated clarifies the motive. Validation is one mode of such clarification or explication. Discussing a practical motivation, in which the death of a friend motivates one to decide to undertake a journey, Merleau-Ponty writes, 
The motive is an antecedent that only acts though its sense, and it must even be added that it is the decision that confirms this sense as valid and that gives it its force and its efficacy. Motive and decision are two elements of a situation: the first is the situation as a fact; the second is the situation taken up. ... By deciding to undertake this journey, I validate this motive that is proposed and I take up this situation. The relation between motivating and motivated is thus reciprocal (2012, p. 270).

Such validation is a kind of explication or clarification, because by itself the actual force of the motive is ambiguous. What does the death of my friend mean to me? Is it the sort of event that will motivate my journey, or does it sadden me but not compel the journey? As I argued above, it is not until we know the motivated that we will know the actual force of the motive. The decision validates the motive. Thus, validation is a means by which the motivated determines the indeterminate meaning of the motive.

Note that, according to Merleau-Ponty, through this retroactive component, motivation tends to obscure itself. Because the meaning of the motive is reinterpreted in light of the motivated, the original situation of the motive is forgotten or concealed. One of the remarkable features of motivation is how silently this forgetting occurs. By the time one gets to the end of the sentence "Is the mouse working?" one will no longer remember that "mouse” ever could have meant anything other than this electronic device; the ambiguity with which the word was fraught will have been all but erased. Once one has seen these elongated shapes as the masts of a ship, it will be impossible to see them otherwise: one cannot see tree trunks there any longer; especially, one cannot see the indeterminacy and the tension they once bore. The perceptual situation may disclose ships masts so obviously at this point that one must ask "How could I not have seen it before?” Or, take the case in which one is faced with a difficult question, and is given the answer. The answer fits the givens of the question together so seamlessly that one will be unable to work oneself back into the difficulty and the aporia one faced, such that one will be frustrated at having been unable to glimpse the means of obtaining the answer before. Why does this happen? Because the answer has, unbeknownst to us, transformed the givens of the question into a new constellation of meaning that cannot any longer admit the difficulty of the question because it has 
resolved it. The question is reorganized by the answer. Thus, one can no longer see in the ship anything but the parts of a ship: one cannot see those indeterminate situations that posed to us questions and negotiated with us an answer. The process of motivation conceals itself, in other words, because it is so successful. When motivation works, as Merleau-Ponty puts it, "the motivated seems to have preexisted its own motive” (2012, p. 51).

We should now be able to see why every motivational relationship is reciprocal. At a minimum, every motivatum will validate or invalidate its motive, i.e., will retroactively determine the motive's force. But, as we have seen, such validation is only an instance of a more general phenomenon: every motivatum determines its motive, which motive by itself would be indeterminate.

\section{Motivation Tends to Equilibrium}

Any motivational situation is likely composed of a variety of implicit motives, weighing on the sense of that situation in different directions. Motivational situations in which motives conflict but none achieve dominance are, perceptually and theoretically, situations of uncertainty, and practically, situations of indecision. The experience of such situations is marked by the tension of conflicting motives, a tension the grounds of which we may not even be able to make explicit to ourselves. Such tension is resolved when a determination of the situation incorporates or reconciles a sufficient range of motives into a coherent whole, such that the tension is released, and a stable equilibrium of motives is reached. It is a property of our experience of motivation that, generally speaking, determinations which more successfully resolve this tension, i.e., which incorporate as many motives as possible as coherently as possible, have more weight for us.

For example, walking down a street, I notice a person staring out from behind a store window. The person's form and pensive stance suggest humanity. Yet as I approach, I begin to grow uncertain. Something in the person's appearance is not quite right: though I needn't note it explicitly, I sense the person's bearing is outlandish, their body inert and closed off, their figure not fully shaped. My sense of tension grows: the person grows more uncanny. It suddenly occurs 
to me that what I see is not a person but a mannequin. With this determination, the tension is resolved. The interpretation "mannequin” reconciles the humanity of the form with the lifelessness of its bearing. My perceptual situation has achieved harmony through a determination which transforms the conflict of motives into an equilibrium. Due to this equilibrium, the interpretation at which I have arrived is stable. Of course, all this can occur without my ever having to stop and fix the sense of a single motive explicitly.

Motives rarely exist alone. Rather, they belong to complex motivational situations, within which various motives weigh on us in various ways and negotiate a determination of the situation. ${ }^{18}$ In general, the process of motivation tends away from disharmony and tension toward equilibrium and stability, toward a "poise” between weights and counterweights. Note that a situation of indeterminacy tends to have less equilibrium and stability than a well determined situation. Situations of indeterminacy, for example perceptual indeterminacy, are shot through with the possibility of collapsing into instability. In the mannequin example above, the lack of initial determinacy allows the interpretation to dissolve into uncertainty. From a distance, I was able to see the figure as a person due to the lack of distinct perceptual information. But as I approach the situation becomes more determinate, and I am forced to abandon my previous interpretation, which in its collapse is revealed as having possessed only illusory stability. Motivation thus tends to equilibrium, stability, and determinacy. In the shipwreck example, the process of motivation concludes with a more stable interpretation of the scene: the interpretation which can most coherently accommodate the various perceptual motives as they continue to gain clarity upon approach. Or, the perception of the bell tower's distance alters in response to the

\footnotetext{
${ }^{18}$ This description is somewhat misleading, as if perception furnished us with a set of independent motives, which then are integrated into some cohesive interpretation. In fact, each motive of our interpretation takes on its shape - its meaning and what it motivates - in virtue of the environment of motives to which it belongs. The reflection in the eye only has the meaning of "reflection in the eye," and can so operate as a motive, in virtue of the totality of the perceptual scene (if it were a disconnected white patch, it wouldn't take on this meaning).
} 
perception of the hill, so as to accommodate this new motive into a harmonious perception of the whole scene.

\section{Intermission: On Solicitation}

The following three theses about motivation (that motivation does not ground with necessity, that motives are normative, and that the outputs of motivation transcend its inputs) must be grasped together, and so must be gotten into view by another strategy. For this reason, I now take a brief intermission in order to consider a particular way of speaking about motivation: solicitation. By solicitation, I mean the way in which a situation calls for a particular action or judgment. This consideration will allow us to see a number of structures essential to motivation, which afterwards I will formalize in theses 7-9.

Solicitation is a mode of grounding because it allows us to answer questions about our actions and decisions. Take as straightforward a case of solicitation as an invitation to dinner. If I am pulled over on the way to dinner and asked why I am driving, I can truthfully respond that I am driving because I was invited to dinner. As a mode of grounding, solicitation has a characteristic structure that differentiates it from other modes of grounding (namely, causality and reason). We need to do a little phenomenology to get this structure in view.

We can begin to clarify the idea of solicitation by contrasting it with compulsion. First, compulsion is a sufficient ground of acting in a particular manner, whereas solicitation is not. If some friends invite me over for dinner, I may decline. But if they compel my presence by, for example, tying me to the back seat of their car, I will (barring unforeseen circumstances) be in attendance for dinner. But why isn’t solicitation, by itself, sufficient grounds of action? Because, solicitation requires as a supplementary ground the response of the solicited. Solicitation grounds by soliciting a response. A call for help, for example, doesn't by itself produce help: it produces help by suggesting and obtaining an appropriate response. Thus, Fichte defines a summons as “being-determined to be self-determining” (Fichte, 2000, p. 31). 
Further, solicitation involves intention. A response is solicited by awakening an intention: the cry for help obtains my response by awakening in me the intention of helping. If I am in a dark room and a point of light moves across the wall, my eyes will be solicited to follow it. It would be phenomenologically clumsy to claim that the light compels my eyes. My eyes are not drawn by the light as one draws a heavy weight by rope. At a particular moment $\left(\mathrm{T}_{1}\right)$, one gives the rope a tug, and the weight slides toward one, in the direction of the pull as $\mathrm{T}_{1}$. Similarly, at a particular moment $\left(\mathrm{T}_{1}\right)$, the light solicits my attention, drawing my eyes. But unlike the weight, my eyes are not drawn in whatever direction they are pulled at $T_{1}$; my eyes are not pulled in the direction of the light's location at $\mathrm{T}_{1}$, but to wherever the light may be when they can catch it $\left(T_{2}\right)$. Certainly, my eyes are solicited at $T_{1}$. But they are unlike the weight, which is compelled by the event at $T_{1}$, because they are solicited to an event at $T_{2}$. In other words, the light does not drag me along behind it, but awakens within me an intention. My eyes seek the light itself (they intend the light). They do not aim at any particular time or any particular location, they will pursue the light wherever it goes, because what animates them exceeds any particular time or location, namely, the light itself. Thus solicitation, unlike compulsion, operates by awakening an intention. As such, it is not just the relation of a cause to an effect. ${ }^{19}$

In establishing a direction of response, solicitation is a three-place relation: in our example, the light at $\mathrm{T}_{1}$ solicits my eyes to the light at $\mathrm{T}_{2}$. But in a certain manner, one might say that it is the light at $\mathrm{T}_{2}$ (the light which does not yet exist) which solicits one. It is this which beckons us from out of the present light, which makes one realize one's distance from one's goal. Thus, what Heidegger said of the call of conscience - that it comes from me, but beyond me - is a species of a more general truth about solicitation: it comes from the present, but from beyond it.

\footnotetext{
19 To be clear, responses to solicitation don't require an explicit intention on the part of consciousness. Merleau-Ponty writes, "When I am overcome with grief and wholly absorbed in my sorrow, my gaze already wanders out before me, it quietly takes interest in some bright object, it resumes its autonomous existence" (PoP 86). Here some aspect the world ("some bright object") has solicited me beneath my personal existence or my intentionality, and I have responded without any explicit intention of doing so.
} 
This analysis allows us to point to a difference in the temporality of compulsion and solicitation. Solicitation, in awakening an intention, opens a future. In terms of practical motivation, an intention is an intention to do or to achieve something: the object of practical intentionality lies in the future. This is why the light moving across the wall orients me not to itself at $\mathrm{T}_{1}$, but to the possible future in which my attention catches up to it, to the light at $\mathrm{T}_{2}$.

If this point about the temporality of solicitation is correct, it requires us to rethink the structure of grounding characteristic of solicitation. When asked on the train to attend my friend's funeral why I undertake my journey, it will not be enough to respond, "Because my friend has died." Such a response would be correct but only partial and insufficient. A complete response might go something like: "Because my friend has died and I intend to attend her funeral.” The first response lacked any formulation of what I intend the trip to accomplish, that for the sake of which I am travelling, i.e., the "final cause” of my action. We have already seen that solicitation has a two-fold structure of grounding: soliciting situation and responding subject. But the preceding analysis of intentionality has shown that this two-fold grounding structure is itself incomplete. Solicitation operates by awakening an intention. Thus, we need to introduce that which is intended as a partial ground of solicited action. Solicitation has a three-fold grounding structure, involving solicitor, responder, and the intended. We can now see that what makes the grounding structure of solicitation unique is the temporality of its grounding. In the kind of grounding characteristic of compulsion or causality, a past event or circumstance is an adequate ground of a present event or circumstance. Not so in solicitation. In solicitation, one partial ground of action, that which is intended, does not yet exist.

Of course, this last point doesn’t mean that solicited action isn’t adequately grounded, just that its ground isn't reducible to the present. Yet, in another sense, solicitation is never an adequate ground. We need to do a little more phenomenology to get this point in view. Take the example of the cry for help. How does it actually operate? The cry reaches us beneath the level of activity, forcing itself upon us, not as mere sensation, but as carrying a meaning: a summons to 
some course of action. What forces itself upon us is the suggestion of a particular course of action. In suggesting, the cry awakens a vague intention. This intention remains at the level of spontaneity. The cry has put the intention within me, and while I can choose to accept or reject it, I cannot remove it from myself, which is why if I reject the cry it acquires an unforeseen weight that colors my day, now in the mode of guilt, shame, etc. But the possibility that the cry suggests is indeterminate. One acquires the intention to provide aid. Yet, how will one help? What does it mean in this situation to help? The cry suggests a possible action only in the mode of delineating a horizon of possible actions. In other words, any number of actions might constitute an adequate response to the summons. Yet there are general contours of what will and what will not constitute an adequate response: the cry for help allows that I rush to the source of the cry or that I call in authorities, but it does not allow that I proceed indifferently or flee the scene. Thus, the cry delineates, sets the bounds or limits of, a horizon of possible responses. Moreover, the cry norms this horizon, establishing some responses as more fitting than others: if the sufferer is in imminent danger and I have the power to help, both rushing to the source and calling the authorities might constitute adequate responses, but the former will be more fitting. The cry for help is indeterminate because its primary function is to solicit action by pointing out a problem, a lack, or need. This situation is analogous to what Merleau-Ponty says of that of the Russian peasants in 1917: their predicament likely did not yield an explicit representation of the revolution as a solution, and the revolution is at most "at the end of the paths they have taken and is in their projects in the form of a 'things-must-change'” (2012, p. 470).

That to which solicitation solicits is thus indeterminate. Nothing in the situation that solicits one necessarily requires one course of action over or another. Thus, solicitation does not explain one's action in the manner that gravity explains the motion of the planets or that premises combined according to the laws of logic explain a conclusion. Both reason and causality involve necessity. One can explain with necessity why the mass of one's body is attracted to that of the earth, or why from certain premises one must reach a certain conclusion. But when one is asked 
why one called in authorities rather than rushed to the aid of the sufferer, one cannot simply point to the situation. One can give reasons why one chose as one did, yet these will not constitute a necessary ground of one's action. Thus, solicitation is not an adequate ground, in the sense that it doesn't ground one’s action with necessity. Consequently, one’s response to solicitation involves an element of risk and is open to doubt: it may turn out that one's response was not the most fitting, and if this happens one will be responsible and not simply excused by features of the situation. $^{20}$

The other result of this analysis is that, while the to-which of solicitation is indeterminate, solicitation is nevertheless normative. Though the cry for help doesn't mandate any particular response, it establishes the parameters for better and worse responses: it norms a field of possible responses. That solicitation is normative is probably already a result of its difference from compulsion: the intention awakened in solicitation has normative force. Skill mastery is a good example of the normativity of solicitation. To master a skill is to be awake to the normative dimension of a situation. For example, a skilled soccer player is awake to normative differences in the possibilities available: some befit the shape the field is taking and some do not.

I have argued that solicitation opens and norms a field of possible responses, and because it opens a field rather than picking out a single response, that to which one is solicited is indeterminate. Consequently, even if one responds to a solicitation, the solicitation won’t determine one's response, and from the solicitation alone one won't be able to deduce the

\footnotetext{
${ }^{20}$ We might think here of Kierkegaard's Abraham, who in elevating himself above the universal takes leave of rational grounding or in other words undertakes a leap, such that Kierkegaard asks, "How then does the individual assure himself that he is justified?" We never feel certain that Abraham has not merely succumbed to temptation. Similarly, Merleau-Ponty's essay “Cezanne’s Doubt,” which analyzes Cezanne’s doubt about the success of his work, is centrally concerned with this very experience of risk. What Cezanne doubts is whether his works achieve a meaning that is universal and necessary - a meaning open to all because it expresses the world as it had to be expressed - or whether they remain contingent upon particular and accidental features of his life ("trouble with his eyes" or his "nervous temperament"). Cezanne could only experience this doubt as he did because his works and his style were original. If he had painted in a classical or impressionist style, he could have doubted his skill as a painter, but not the universality of his style. His style did not simply take its ground in its predecessors, and thus its legitimacy could become a question for Cezanne and his contemporaries: if its ground is not tradition, is it the particular accidents of Cezanne's body or temperament, in which case it will never really speak to others?
} 
response. But moreover, one's response to a solicitation is in no sense contained in or immanent to the solicitation. One could not, in other words, discover one's response simply by analyzing the solicitation more adequately. The process of solicitation is ampliative: the response exceeds, or contains more than is present in, the solicitation. Say, for example, that I am observing a sculpture in a museum. My fascination draws me into the work, solicits my approach. I walk around the piece in order to get a fuller appreciation. But the draw itself does not contain this series of steps: I will not find a prescribed course of motion by attending more carefully to the draw. The draw is like a true question, one which does not contain its response, and my steps are like an answer.

Finally, solicitation grounds in a uniquely original or creative manner. That which emerges through the process of solicitation contains more than is present in the solicitation. That is, it involves something new and is not merely a reconfiguration or manipulation of the old. Isn't this also true of causes and certain kinds of reasons? A valid conclusion amplifies its premises, and a kinetic interaction produces a novel momentum. But unlike causes and reasons, solicitation grounds indeterminately, and as we saw, that means without necessity. Thus, solicitation is original in a specific sense: it is not sufficiently grounded by anything that came before it, or in other words, the one solicited can't point to anything in the situation that fully or adequately justifies her response in the manner that one executing a geometrical proof can point to reasons that fully justify her conclusion. Solicitation is original in the sense, then, that it must ground or take responsibility for itself: it requires, in other words, a creative or original act - a “leap.” Is solicitation a paradox, since it at once grounds one's response and leaves it ungrounded? One would have to respond that solicitation is no more paradoxical than a question - which grounds its answer in the sense that it establishes the parameters of an appropriate response, but leaves it ungrounded insofar as it does not contain or determine the answer - or than existence itself, which takes up its past precisely in exceeding it.

There are three main takeaways from this analysis of solicitiation. First, solicitation does not ground with necessity. Second, solicitation is normative. Third, the to-which of solicitation 
transcends (is not contained in) the solicitor itself. I would now like to suggest that each of these is an essential feature of motivation.

\section{Motivation does not Ground with Necessity}

Motives do not compel; they solicit. This is part of what it means to say that motivation

grounds spontaneously, rather than merely passively. If a perception is grounded spontaneously, then the perceiving subject must be in the appropriate disposition to have that perception; the perception is not simply produced in the subject by the external world. In the shipwreck example, the subject must have some perceptual schema for "ship" in order to regroup the perceptual givens as a ship. Or in the portrait example, the subject must be familiar with the seeing that can be seen in the eye that contains a reflection. In short, the subject must be able to hear the call of the givens, so to speak, in order to respond appropriately. The subject is the supplemental ground of motivation, and thus motivation does not ground with necessity. Further, motivation does not necessarily ground any particular response. The perception of a bank of trees and the perception of the shipwreck are two ways of responding to the perceptual givens, and the fact that the same givens can motivate both perceptions demonstrates that the givens don't necessarily ground any particular interpretation. The givens give rise only to the tension of the scene and an intention, and correlatively the final interpretation is merely the most satisfying response to the problems posed by the scene. It always remains possible that the gradual enriching of the givens will require yet another interpretation.

\section{Motivation is Normative}

On the other hand, motivation is normative. The subject is not indifferent to which perception she has. While, in the shipwreck example, the givens don't ground with necessity, it is still true that both before and after the gestalt shift the subject thinks she is right to perceive as she does and would be wrong to perceive otherwise (indeed, after the shift she thinks her previous interpretation was wrong). Thus, while motives do not ground any particular response with necessity, they still determine and norm a field of possible responses. 


\section{The Output of Motivation Transcends its Input}

In writing that output of motivation transcends its motives or inputs, I mean that the output is not in any sense contained in its motives; the meanings produced by motivation are not definable in terms of the motivating meanings. The interpretation "shipwreck" is not somehow hidden within the perceptual field which motivates it. Instead, it is a spontaneous and creative resolution to the tensions within the perceptual field that broke apart the previous interpretation. "Shipwreck" cannot be defined simply in terms of this perceptual field, because the schema "shipwreck" must be brought to the field; if the subject lacks this schema, the givens may fail to reorganize themselves and may remain in tension. In part, this is a consequence of the claim that motivation does not ground with necessity. If motives did contain all the resources for their outputs, then they might plausibly ground their outputs with necessity. As it is, motives lack the resources to determine their outputs. In this sense, the outputs of motivation transcend the inputs. ${ }^{21}$ Or, we could also say that motivation is a creative process and its outputs are original with respect to its inputs. ${ }^{22}$

\footnotetext{
${ }^{21}$ While I won't go into further detail, every one of the features disclosed in the analysis of solicitation can be applied to motivation generally. Aside from the characteristics I already delineated, we can note that motivation operates by establishing a finality or direction in the one motivated. There is here only a vague intention, a sense that one's interpretation of the scene is about to change (Merleau-Ponty, 2012, p. 18). Certainly, we couldn't say that one intends to interpret the givens as a ship's mast, because this interpretation can't even figure as a determinate possibility until it has arisen. The intention here is only that of a resolution of the tension within the givens and need not be explicitly represented by the subject of motivation. In awakening this vague intention or expectation of transformation, motivation is oriented toward the future: toward an interpretation to come. Further, this finality figures as a partial ground of motivation: the tension of the scene is oriented toward a new interpretation. If there were not an anticipation of a truer interpretation, one which would give sense to the entire scene and resolve its tensions, the tensions themselves would not arise, for the insufficiencies of the previous interpretation only have the value of tensions when they are animated by a commitment to perceiving the scene rightly.

${ }^{22}$ We can think here again of "Cezanne's Doubt.” Certainly, Cezanne's style has its motives. The style of his predecessors, Cezanne's personal characteristics, and the subjects of his paintings are all partial grounds of his works. Cezanne's works do not emerge from nowhere and without history. And yet Cezanne can only doubt the legitimacy of his work because none of these motives are necessary grounds of his work. The experience of doubt is the experience of lacking adequate ground, of not having anything to point to which would explain one's actions with necessity. The motives of Cezanne's works are thus not necessary grounds. Merleau-Ponty writes that "the artist launches his work just as a man once launched the first word, not knowing whether it will be anything more than a shout, whether it can detach itself from the flow of individual life in which it originates and give the independent existence of an identifiable meaning ... " (1992, p. 19). The artwork doesn't prove itself, except with time. It cannot resort to preexistent standards of measure in order to demonstrate its value, as a new theory in physics demonstrates itself with results
} 


\section{Motives are neither Reasons nor Causes}

We are now in a position to see why Merleau-Ponty claims that the phenomenological concept of motivation subverts the dichotomy of reasons and causes. In distinguishing between reason and causality (as mentioned in my introduction), I intend something like McDowell’s distinction, in Mind and World, between what he calls "the logical space of reasons" and "the logical space of nature.” Sellars articulated the former as follows:

In characterizing an episode or a state as that of knowing, we are not giving an empirical description of that episode or state; we are placing it in the logical space of reasons, of justifying and being able to justify what one says (1997, p. 76).

Relationships within the logical space of reasons are normative: it is right to conclude by reason of Socrates' death that he is mortal, and it would be wrong to conclude otherwise. Justification is thus a kind of normative relation. McDowell defines the latter, the logical space of nature, as the logical space within which the natural sciences operate. Natural sciences explain rather than justify; knowing a cause helps to explain an effect, but it would be a category mistake to take a cause as a warrant or justification for an effect. Socrates is not justified in sitting in the Athenian prison on his final day by his bones and sinews, but by a conception of the good and how to realize it. The logical space of nature is, in other words, lawful but not normative.

interpreted through preexistent measures, or as a mathematical theorem is demonstrated with necessity on the basis of certain preexistent premises. A novel style creates its own standards and awakens them in its audience. In other words, the artist's motives cannot contain the full content of what the artist creates. Merleau-Ponty writes, "The meaning of what the artist is going to say does not exist anywhere - not in things, which as yet have no meaning, nor in the artist himself, in his unformulated life. It summons one away from the already constituted reason in which 'cultured men' are content to shut themselves, toward a reason which contains its own origins" (1992, p. 19). What makes an artwork original is that it "contains its own origins." What can this mean? First, that nothing before it grounds it adequately, with necessity, i.e., can prove its value. Second, it grounds itself, demonstrating its value by teaching its own standards. A novel artist may be rejected by her contemporaries, because they evaluate it on the basis of preexisting standards. Yet if her work is truly original, it will cultivate new standards, and in time demonstrate its worth. 
In this section, I argue that motives are not causes because they operate through their meanings and are normative, and they are not reasons because they are spontaneous and need not be explicit. ${ }^{23}$

\section{A) Motives Are Not Causes}

As I have argued in this chapter, motivational relationships operate through their meaning and are normative. But neither of these features pertain to causality. Motives have their effect in virtue of that as which they are, i.e., in virtue of their meaning and not just as things or events. Consequently, it makes a difference what terms one uses to describe a motive. Because causal relationships hold between objects and events, and not between meanings, they are indifferent to that as which they are described. As I said above, if asked why a pool ball is in motion, one can answer as truly "Because it was struck by the 9 ball” as "Because it was struck by the yellowstriped ball” as "Because it was struck by a collection of matter with the requisite momentum."

Further, causal relations cannot establish normativity; they can make it such that something is the case, but not that something ought to be the case. This is why causality explains rather than justifies. In terms of causality, I can explain why I have the sensations that I do, but this does nothing to establish those sensations as right or wrong. In contrast, motivational relations do establish normativity: I think, for example, that I am perceiving rightly and that if someone were to perceive otherwise they would be mistaken. Therefore, motivational relations are not causal. ${ }^{24}$ This doesn't mean that there is no causal story to be told about goings on in the brain that underpin processes of motivation. But this is as true of reasoning as it is of motivation, and so if one admits a distinction between reason and causality one then one can do so in the case of motivation as well.

\footnotetext{
${ }^{23}$ See also Wrathall (2005) for a strong defense of Merleau-Ponty’s distinction of motives from reasons and causes.

${ }^{24}$ Donnchadh O'Conaill has also made this point: "the intentional content of a state of being motivated is normative in that it presents an object as making a demand, and a certain course of action as an appropriate response” (O'Conaill, 2012, p. 584). See also (O'Conaill, 2014, p. 445). While O’Conaill raises this point specifically with regard to practical motivation, it applies equally well to perceptual motivation.
} 


\section{B) Motives Are Not Reasons}

I have claimed that motives can’t be identified with reasons because motives can be implicit and are spontaneous. I start with the first of these. For example, we can't think of the reflection in the portrait subject's eye as a reason, because it doesn't figure explicitly in the thought process that leads to the perception of the portrait as lively. But this argument depends on the further claims that a) motives can be implicit, and b) reasons cannot. I have argued the first of these claims above. But why should we think that reasons cannot be implicit? Could we think of the process that leads from the reflection to the perception of liveliness as a sort of latent reason? Certainly, we likely will not find in consciousness an explicit synthesis of the form:

i) There is reflection in the eye of the portrait.

ii) Anything with a reflection in its eye should be perceived as lively.

iii) The portrait should be perceived as lively.

And yet, does this consideration - that there need not be an explicit synthesis - suffice to conclude that the perception of liveliness isn't a judgment, an operation of reason?

One of my assumptions has been that reasoning, or the exercise of rational grounding, of using reasons as grounds, is done at the level of explicit thinking. Properly speaking, the assumption goes, there is no such thing as implicit reasoning: if I am reasoning, then I have explicit mental objects standing in explicit relations of grounding with each other. Logical syllogism is thus a paradigm case of reasoning, for here we have three distinct propositions standing explicitly before consciousness, explicitly in a relation of logical grounding. Obviously, at least some instances of reasoning are explicit - but why should we think that all instances of reasoning are explicit?

My initial response to this question depends on pointing out that reasoning is reflective. When we reason, we go back over our assumptions and the relationships in which we have assumed that they stand, in order to test them by a higher standard. Reasoning allows us to say: "While at first it might have seemed that ..., upon closer examination it must be the case that ... 
.” This doesn't mean that reason doesn't depend on an indeterminate background of assumptions upon which one hasn't yet reflected when one begins reasoning, but it does mean that to the extent that we are reasoning, we are making our thoughts explicit. When we reflect on our thinking, we are no longer simply moved along by it toward a conclusion, but stop and make the thinking itself explicit, an object of attention. Thus, reasoning is done at the level of explicit thinking. In other words, one cannot properly be said to have a reason for thinking as one does, unless one has this reason at one's disposal, i.e., has it explicitly. In contrast, one can well have a motive for thinking as one does without yet recognizing this motive. ${ }^{25}$

But McDowell and others have consistently maintained that reasons for belief or action can be implicit. Proponents of this position tend to support it by pointing out that, while in the normal course of experience we do not make our reasons explicit to ourselves, yet when we turn to reflection, we find our reasons readily available. Thus, McDowell has claimed, for example, that while a chess master playing blitz chess isn’t giving reasons for her moves while playing, she yet would be able to give rational explanation of her moves as soon as she is questioned about them. McDowell writes: "What matters is that the agent can answer the 'Why?' question straight off, without any need for reflection or investigation” (2013, p. 47). This phenomenon of the seamless ("straight off”) transition to reflection might lead one to believe that unreflective action is already chock-full of justifications: how else could the chess master respond so readily?

\footnotetext{
${ }^{25}$ One might object: But isn't it the case that implicit thought processes can be more or less rational? For example, it seems perfectly rational to see a painted figure as less alive when its eye holds no reflection of light, but it certainly is irrational to see someone as less competent on the basis of their race or gender. I think it is certainly correct that implicit thought processes can be more or less rational, but wrong to think that this means that implicit thought processes are ever instances of reasoning. To call an implicit thought process rational or irrational makes reference to a standard that transcends implicit thought processes, namely reason. For how does one decide whether an implicit thought process is rational or irrational? One makes this decision by making the implicit thought process explicit, so as to as see whether it holds up "in the light of day," under the standard of reason. The decision thus entails translation to another order.

Further, rational, explicit thought processes can seep down into one's tendencies of implicit thinking, as in habituation: the racist by repeatedly recognizing the irrationality of their implicit tendencies, may gradually replace these irrational implicit tendencies with more rational ones. But here too, the implicit tendency is only termed rational or irrational by reference to an order outside itself: the explicit.
} 
O’Conaill is similarly not impressed with the claim that reasons emerge only in making the grounds of action explicit. He writes,

A process of explicit justification will involve giving reasons, but usually this process does not create reasons; rather the agent makes apparent reasons of which they were already aware. So from the fact that explicit reasons ... do not feature in unreflective action, it does not follow that such action is not rational (2014, p. 448).

And there is truth in this claim: if the subject is asked why she perceived the portrait as lively and is able to recognize the influence of the reflection in the eye on her perception - and so answers the question in these terms, she will not have created this reason, as if out of thin air; she will have given her reason.

But this way of putting things is misleading. The choice is not really between giving reasons already present in perception and creating reasons out of thin air. This choice presupposes that the act of attention, of explicit justification, is neutral, and introduces no transformation in that to which attention attends. Yet this presupposition is belied by the fact that often the transition to reflection is not seamless, and instead the content of unreflective action apparently resists being taken reflectively, as justification. ${ }^{26}$ For example, why did I respond coldly to my friend's warm gesture the other day? Had she committed a legitimate grievance? Was there instead a matter of jealousy on my part? Was I merely tired, hungry, and feeling short? There is no answer readily available here, because these answers are so many ways of crystallizing, or giving determinate form to, the indeterminate field of grounds of my action. Sometimes the process of justification unfolds smoothly: a chess master may know readily enough why she unreflectively made the move she did. But all I need is to demonstrate that it doesn't always. Often there is a legitimate resistance in transforming an unreflective ground of action into a reason. Then my explication will be searching and tentative: it can still be better or worse (more or less true to my actual grounds), but it won't be obvious or final. In such cases, the reasons I

\footnotetext{
${ }^{26}$ Merleau-Ponty argues that attention is transformative in his chapter "Attention and Judgment," from Phenomenology of Perception.
} 
give to explain my judgment might be perfectly good reasons, but as descriptions of the reasons I had, they are at best expressions of my motives and at worst rationalizations of my judgment or action. $^{27}$

It would help, at this point, to be more precise about this phenomenon of resistance. Merleau-Ponty writes that when I express my reasons, I “crystallize a collection of indefinite motives in an act of consciousness" (2012, p. 309). Wrathall understands this claim to mean that when one treats a motive as a reason, one "ends up focusing on some narrow subset of a rich and complex set of motives," thereby treating the motive as more "determinate and prominent" than it was (2005, p. 119). My reason-giving is thus not only poor relative to my motives (focusing on a relatively narrow subset), but also more determinate than my motives. When I give a reason, I introduce a precise ground of belief or action. But the grounds of our beliefs or actions are often diffuse and indeterminate. For example, one may have a vague sense of unease about a conversation, leading one to judge that the conversation is not going well, without formulating or being in a position immediately to formulate judgments about why one thinks it is not going well. ${ }^{28}$ Or, to reformulate my previous example in terms of judgment, I tell my friend that our mutual acquaintance has acted coldly toward us the other night. She disagrees, and asks why I say this. Suddenly, I am put in the position of justifying my belief, and now I begin examining my feelings about the matter. I can reply “Did he not seem distracted all night?” or “Well, he didn’t laugh at that joke,” or “Was there not an expression on his face as I explained my work?” What am I doing in this process of justification? Here, as is often the case, giving reasons is not simply

\footnotetext{
${ }^{27}$ In response to arguments like this, McDowell has at time responded that such motives fall outside scope of my action as a rational agent. See, e.g., (McDowell, 2013, p. 51 \& 55). But if we take this line, I think we will be left with precious few instances of rational agency. We can hardly give expression to the ultimate grounds of our lives. If I reason back far enough into the grounds for my actions, will I arrive finally at the ground: happiness? Duty? Care? Articulating such ultimate grounds is difficult, and yet surely pertains to our rational agency.

${ }^{28}$ I borrow this example from Taylor Carman, who concludes from it that "The content of skillful social intelligence resists abstraction and incorporation into purely rational configurations of inference, deliberation, and decision” (2013, p. 175).
} 
a matter of verbalizing, or calling to attention, “straight off,” unambiguous grounds, but a matter expression. In such cases, I attempt to give determinate form to a vague sense of the situation. It is against this vague sense that the reasons I give are measured: the reasons are formulations which are more or less true to the sense I had. Here, the justifications I give are expressions. Such expressions may leave much of the content of the grounds for my belief or action out of the picture. They may not get these grounds in the picture at all, as when I am unable to express the influence that the reflection in the portrait's eye has on my perception. This being so, the grounds of my judgment are at most partially within the space of reasons.

If the preceding is true, then while motives can be implicit, reasons cannot, and thus motives cannot be considered as reasons. This conclusion can also be reached by noting that motivation is spontaneous. When we reason, we are concerned actively to give and take reasons. In response to these reasons, we can actively revise previously held positions. For example, if I hold $X$, and I hold that if $X$, then $Y$, then I will conclude that $Y$. But if I later find very compelling reasons to reject $Y$, and have very strong reasons to think that if $X$, then $Y$, then I will be forced to reject $X$. This revisability is, I think, crucial to our idea of activity: I am free to accept or reject conclusions in response to reasons. But the same is not true of motivation. Cases of motives conflicting with reasons, e.g., optical illusions, make this clear. In the Müller-Lyer illusion, I have compelling reasons to think that the lines are equal. I can thus revise the conclusion I drew from perception, namely that the lines differ in length, on the basis of new reasons. ${ }^{29}$ But I cannot so revise my perception. Motivation is closed (or rather, at most partially open) to the giving and

\footnotetext{
${ }^{29}$ Note that I am not specifying whether or not one's reasons are correct. One might colloquially call a reason which is in error "irrational." However, here, I treat anything as a reason which operates according to the norms and practices of reason. Thus, even reasons which are "irrational," i.e., mistaken, I will call reasons, because they are properly governed by the laws of reason, i.e., are meant to be judged correct or erroneous by the norms of reason and these norms are not external to their space of operation (as I claim the norms of reason are to motives).
} 
taking of reasons. Thus, whereas reasons are active, motives are spontaneous. Motives are not reasons. ${ }^{30}$

\section{Conclusion}

In this chapter, I have explained what it means to take motivation as an epistemic ground by defending 10 theses about motivation. I have shown how motivation can serve as an epistemic ground and, in my final thesis, I showed that motivation cannot be reduced to a species of causality or reason. Whereas causes do not operate in virtue of their meanings, and reasons operate in virtue of explicit meanings, motives operate in virtue of implicit meanings; whereas causes ground non-normatively and passively, and reasons ground normatively but actively, motives ground normatively but spontaneously. Finally, both reason and causality ground with necessity, whereas motives do not. In this way, motivation provides a way to understand how grounding can be a process of transcendence. In the following chapters, I will show how introducing motivation as an epistemic ground can solve long-standing epistemological problems.

\footnotetext{
${ }^{30}$ One might object that the above example can be accommodated by the view that motives are implicit reasons, by treating the conflict as one between two kinds of reasons. Certainly, we at times have conflicting reasons, so there is no prima facie reason to conclude from the conflict of motivation and reason that motives aren't a kind of reason. But notice that in the case of the Müller-Lyer lines, not only are motivation and reason in conflict, but it is not at all clear how one would even go about describing one's motives in terms of reasons. In other words, not only is one's motive for seeing one line as longer than the other as a contingent matter of fact implicit, it is not even clear how one could go about making one's motive explicit. Thus, psychologists can speculate about the "reasons" one has for seeing one line as longer than the other: perhaps the arrows make one line look like a protruding edge and the other like a recessed edge, such that the length of the line is interpreted differently. But this is really speculation, rather than an explication of an as yet implicit reasoning, and moreover this "reason" dissolves the moment it is actually treated as a reason (we can't take it seriously as a consideration in favor of).
} 

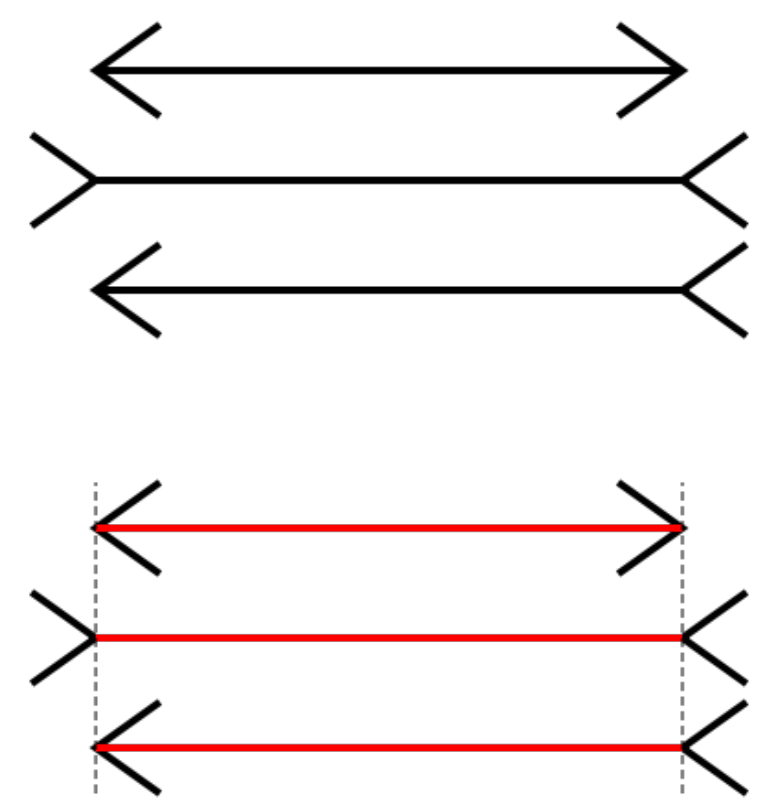

Figure 1.1. The Müller-Lyer Lines. Reprinted from Müller-Lyer Illusion, In Wikipedia. Retrieved August 9, 2017, from https://en.wikipedia.org/wiki/M\%C3\%BCllerLyer_illusion. 2007 by Fibonacci. Reprinted with permission. 


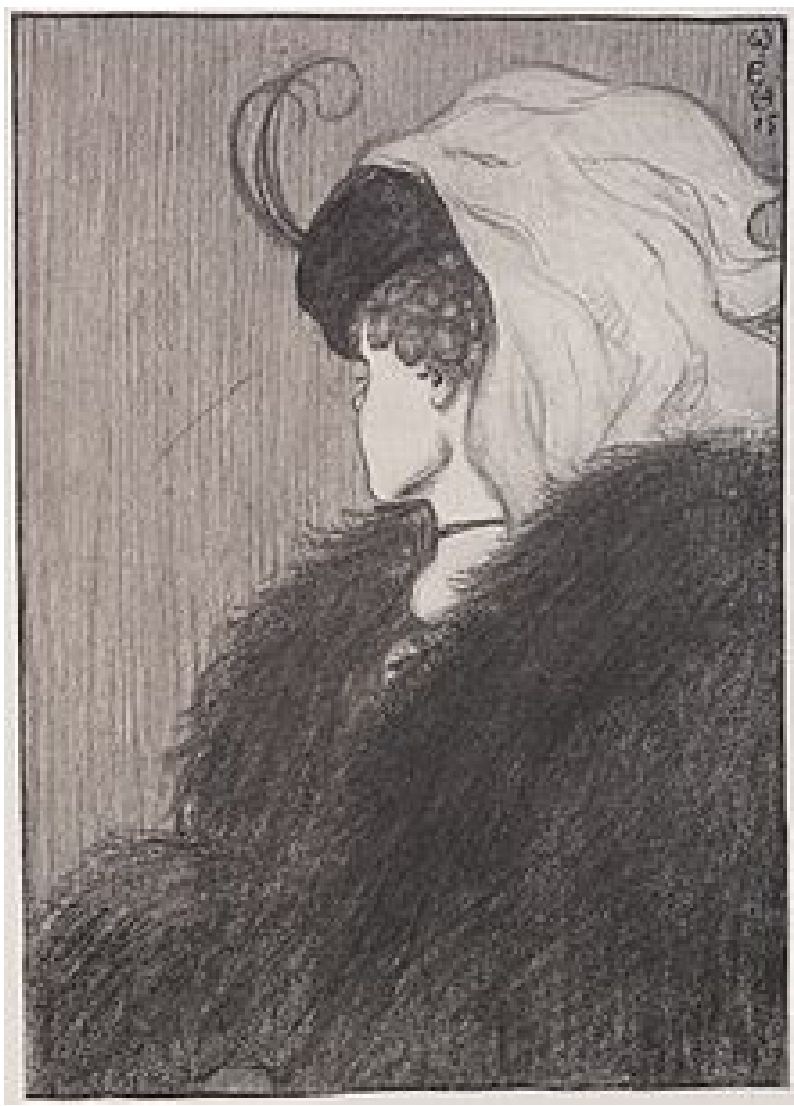

Figure 1.2. “My Wife and My Mother-in-Law.” Reprinted from My Wife and My Mother in Law, In Wikipedia. Retrieved August 9, 2017 from https://en.wikipedia.org/wiki/My_Wife_and_My_Mother-in-Law. 1915 by William Hill. Reprinted with permission. 


\section{CHAPTER 2. EXPERIENCE AND JUDGEMENT}

In the previous chapter, we saw that perceptual experience presents us with a spontaneous sense that is not well accounted for in terms of reason or causality. Instead, we need to employ a novel form of epistemic grounding, namely motivation, in order to understand the genesis of perception. My broader thesis is that motivation is the form of grounding pertinent to the relation between perception and knowledge. I now begin arguing for this position. My analysis will have two parts. In this chapter, I ask how experiences can ground judgments at all. Then, in chapter 3, I will turn to more general considerations about the relation of experience to judgments that are not directly of experience: universal judgments and, ultimately, a priori judgments.

There is no doubt that our judgments about experience are grounded in experience. If you were to ask me why I think that the sky above is cloudy or the pavement wet, I could appropriately reply, “Because that’s how it looks to me.” In other words: “Because I experience it so.” With this response, I would indicate that my judgment is grounded in my experience, or in other words that experience answers questions about why I judge as I do. And yet it is not so obvious how this grounding should be understood: philosophically, there is no agreement about how to characterize the relationship between experience and the judgments to which it gives rise. Evidently there is some manner in which experience grounds judgment and yet articulating this manner of grounding presents a challenge.

Two ways of thinking about this relation have been given expression in the work of Davidson and McDowell. Davidson has argued that experiences cause beliefs. He claims that “nothing can count as a reason for holding a belief except another belief,” and because experiences aren't beliefs, or any other sort of propositional attitude, they can't stand in a logical relation to beliefs (Davidson, 1986, p. 310). This leaves Davidson with the thought that experiences stand in a merely causal relationship to beliefs, and consequently, that experiences can’t justify beliefs. McDowell, in contrast, has argued that experiences can justify beliefs. In Mind and World, McDowell claims that experiences have conceptual content, and that because 
conceptually articulated contents can stand in a logical relation with judgments, experiences can count as reasons for judgments. These two ways of thinking about the relationship between experience and judgment continue to shape contemporary epistemological literature, and the debate between them has not been decisively settled.

In this chapter, I argue that this impasse is due to an insufficient phenomenology of the kind of grounding pertinent to the relation between experience and judgment. In fact, neither reason nor causality correctly describes this relation. What stymies the debate between McDowell and Davidson is that both accept the dichotomy of reason and causality. But we have seen that this dichotomy is a false one: motivation is a third kind of epistemic ground. Here, I show that motivation provides a new and better means of describing the relation between experience and judgment. ${ }^{31}$ Doing so will open a new avenue for thinking about knowledge, which avoids both Davidson’s “coherentism” and McDowell’s unique form of “minimal empiricism.”32

\section{Davidson and McDowell}

Davidson, in his “A Coherence Theory of Truth and Knowledge,” lays out a puzzle for empiricist accounts of knowledge. Empiricists think that our knowledge is justified by our experience. But, argues Davidson, experiences are not the kinds of things that can justify knowledge. Knowledge is propositional (i.e., its object is the referent of a that-clause). ${ }^{33}$ For example, I know that the tree is shedding its leaves. But experiences are not propositional. For example, I perceive a tree shedding its leaves. And here lies the problem: surely only a belief (i.e., something with propositional content) can serve as a reason for holding another belief. According to Davidson, we can only justify our beliefs in virtue of other beliefs. For example, if you ask me

\footnotetext{
${ }^{31}$ This thought is suggested by Mark Wrathall at the end of his essay “Motives, Reasons, and Causes," but not fully worked out there (not being the central point of his essay) nor sufficiently argued (as I will explain later).

${ }^{32}$ See McDowell 1996 (p. xii) for this designation.

${ }^{33}$ There are certainly different ways of specifying what this means, and I don't want to get bogged down in discussions about the nature of propositional content. For the sake of simplicity, I accept something like: Contents are propositional if they are referents of that-clauses.
} 
why I think it has rained, I will respond: “Because I think that the street is wet,” i.e., in virtue of some propositional content. But experiences are not beliefs, and so it seems that they cannot serves as reasons for - they cannot justify - knowledge. But since our experiences do evidently ground our judgments, but cannot do so in the mode of reason, they must instead cause our judgments. This leads Davidson to a coherentist position, according to which experiences cause beliefs and our beliefs are justified with respect to their degree of coherence with the full body of our beliefs.

McDowell's Mind and World aims, in part, to solve this puzzle. ${ }^{34}$ McDowell has his own way of formulating the puzzle: in terms of two conflicting philosophical pressures, which Mind and World aims to reconcile. On the one hand, knowledge seems to entail answerability to the empirical world (McDowell, 1996, p. xii). The ultimate verdict on our judgments and beliefs, according this minimal sort of empiricism, comes from the "tribunal of experience." Without this responsibility to the world of experience, our judgments ultimately fail to gain traction. The threat is that we have perfect freedom in judgments, in a way which leaves them ungrounded in anything outside of our freedom. Thus, if we are really to have knowledge at all, our judgments must be justified by experience.

On the other hand, a necessary condition of knowledge is justification: a belief which isn't supported by good reasons can’t count as knowledge. As Sellars puts it, in his attack on “The Myth of the Given," "In characterizing an episode or a state as that of knowing, we are not giving an empirical description of that episode or state; we are placing it in the logical space of

\footnotetext{
${ }^{34}$ McDowell's question, then, is really: How is knowledge possible? Because this is McDowell's guiding question, his interest in experience extends only to its ability to ground knowledge. Rouse has formulated this insight by arguing that McDowell's interest in experience is normative rather than descriptive, i.e., in whether experience can be assessed in certain ways rather than whether it actually is certain ways (Rouse, 2013). Rouse thus thinks McDowell's interests are orthogonal to those of phenomenology, such that it's not quite right to put them in dialogue. I think this formulation is too strong: McDowell really is interested in claiming that experience is, e.g., conceptually articulated. His interest in experience is just transcendental rather than phenomenological (i.e., in what experience must be like in order for knowledge to be possible, rather than in what experience is actually like), but both interests require giving an account of experience. Thus, there is room for genuine dialogue between the two approaches.
} 
reasons, of justifying and being able to justify what one says” (1997, p. 76). McDowell, following Sellars, contrasts the "logical space of reasons" (what I have simply called "reason”) with the "logical space of nature” (what I have called “causality”) the space in which the natural sciences function. Natural sciences explain rather than justify; knowing a cause helps to explain an effect, but it would be a category mistake to take a cause as a warrant or justification for an effect. As I put it in chapter 1, the presence of Socrates' body in the prison is the material condition for his being there, but it is not the reason for his being there. The logical space of nature is, in other words, lawful but not normative. But experience is customarily thought to belong to the logical space of nature: sensations or "impingements" are lawfully caused according to natural processes. And if our experience is caused, it can't figure as a justification for knowledge, because it doesn’t belong to the kind of logical space that involves justifications, i.e., the logical space of reasons. If our experiences belong only to the logical space of nature, they can serve at best as exculpations of our beliefs, but not as justifications (McDowell, 1996, p. 8). Conventional empiricism (the "Myth of the Given”) depends on a conflation of the two logical spaces, such that experiences can seem to be both caused and to serve as justifications for beliefs.

McDowell thus claims that for knowledge to be possible, both a) our judgments must be responsible to experience, and b) experience must be the kind of thing that can justify our judgments. McDowell's question is how we must conceive experience in order to accommodate both of these demands. In other words, what kind of thing must experience be, if knowledge is to be possible?

According to McDowell, as long as we conceive experience as purely receptive, as belonging squarely to the logical space of nature, it will be impossible to accommodate these two pressures. Instead, we must understand experience as belonging within the logical space of reasons, i.e., as constitutively shaped by our activity, or more specifically, by the capacities exercised in judgments. Further, McDowell understands this active shaping of experience in terms of conceptual capacities. In this chapter, I won't be interested in this aspect of McDowell's 
thinking (his attribution of conceptuality to experience), but only in his claim that the bond between experience and belief must fall within the space of reason if we are to have justified knowledge. In these terms, the Myth of the Given is that experience can be outside the boundary of activity and yet serve to justify judgments. McDowell's point is that experience can justify judgments, i.e., belong to the space of reasons, only if it is constitutively shaped by our rationality (specifically if it is organized by concepts).

Davidson lays out a genuine puzzle: How can non-propositional experiences justify propositional judgments? But I don’t buy Davidson’s conclusion, namely, that experiences cause judgments and so what we need is a coherence theory of knowledge. On the other hand, McDowell's instinct is right: experiences must ground judgments in some more-than-causal fashion. But McDowell’s solution won’t work. Experiences, as I will argue, cannot serve as reasons for judgments. What is needed here is a third form of grounding: motivation. In the following two sections, I will explain how I understand the difference between experience and judgment, and how motivation can be used to think about the relation between them. ${ }^{35}$

Subsequently, I will argue that neither causality nor reason adequately describe this relation.

\section{Experience and Judgment}

Noting a couple features of experience and judgment will help us understand the relation between the two. First, we are active in judgment to an extent that we are not in perceptual experience. As I have already said, perceptual experience draws on our spontaneity, whereas judgment responds to our active thinking. Merleau-Ponty notes this distinction, for example, in writing that

Between sensing and judging, ordinary experience draws a very clear distinction. It understands judgment to be a position-taking .... . It takes sensing, on the

\footnotetext{
${ }^{35}$ For Husserl's and Merleau-Ponty's descriptions of the relation between experience and judgment in terms of motivation, see, e.g., Husserl (1973, p. §§68 and 71) and (1989, p. §56); Merleau-Ponty (2012, pp. 33-7, 210, 395).
} 
contrary, to be the giving of oneself over to the appearance without seeking to possess it or know its truth (2012, p. 36). ${ }^{36}$

Judgment is subject to the norms of reason in way that experience is not: I can revise my judgments under pressure from conflicting reasons, but I cannot so revise my experiences.

Second, in experience contents are given to us, whereas no content is directly given in judgment. As Husserl writes, "Experience in the first and most pregnant sense is accordingly defined as a direct relation to the individual” (1973, p. 27). In contrast, one can easily make judgments for which no content is given, e.g., if I experience the sky as blue but arbitrarily form the judgment, "The sky is green today."

Finally, I take it that whereas judgment is propositional, experience is not. Or, in the terms of the phenomenological tradition, judgments are predicatively structured, whereas experiences are pre-predicative. As Husserl puts it, experience is "single-rayed": it is simply directed toward its object. In contrast, judgments synthesize two "rays of attention": it is directed toward both the subject and the predicate. While this claim about propositional structure is accepted by all parties to the present debate, it is not universally accepted. ${ }^{37}$ I'll briefly explain my reasons for holding it.

\section{A. Propositional Content}

Like McDowell and Davidson, Merleau-Ponty maintains that the content of perception is non-propositional. The language of "propositional contents” is not Merleau-Ponty’s, but I think that terminology does name something that Merleau-Ponty is genuinely interested in. Following Husserl, Merleau-Ponty describes perceptual experience as pre-predicative, i.e., as possessing a

\footnotetext{
${ }^{36}$ McDowell too notes this difference, writing that while in judgment one is free to make up one's mind, in experience "one finds oneself saddled with content" (1996, p. 10).

${ }^{37}$ See Davidson 1986 (p. 310). While McDowell did claim in Mind and World that experience has a sort of propositional content, namely that "things are thus and so," (1996, p. 9) he has since retracted this claim (2008). Merleau-Ponty's Phenomenology of Perception describes experience as "pre-predicative" throughout.
} 
structure different from and prior to that of predicative propositions. ${ }^{38}$ Merleau-Ponty writes, for example, that "the being of the perceived is the pre-predicative being toward which our total existence is polarized” (2012, p. 336).

I think it is right to distinguish propositional from experiential content, first, because our propositional knowledge is poor relative to our experience. Attend to your current perceptual state. Now attempt to express it, completely, in propositional form. ${ }^{39}$ The task is an immense one - in fact, it isn't clear that it has any precise limits. How many propositions would one need to complete the job? The question cannot be answered. Or, what is my experience like, e.g., as I cross the floor of the coffee shop? I maneuver between tables, chairs, customers and I mind these things and many others. It would be absurd to suggest that therefore the stream of my experience takes the form: "Now there is the table ... And now there is the chair ... And now there is the customer heading my way." What makes this suggestion ridiculous is that my experience is rich and my propositional knowledge is poor. The latter is not poor, however, in its quality, for in quality it achieves a determinacy and permanence that my experience does not. It is poor, instead, in what it manages to portray. The propositional expression (even if only internal) of my experience crystallizes some definite content out of the indefinite array of my experience, isolating only the most salient chunks of experience.

A propositionalist about experience will object that I have mistaken their position: I have understood "propositional content” in terms of explicitly formulated propositions - whether expressed or remaining internal - whereas in fact we should think of experience as propositional all the way down, including the implicit dimensions of experience.

My response to this objection is basically the same I gave to the objection that reasons can be implicit in chapter 1: the objection misses the transformative nature of attention. If this

\footnotetext{
${ }^{38}$ The idea that the structure of experience is not that of predicative judgments is a central idea of Husserl's Experience and Judgment, which turns around an analysis of the difference between predication and prepredicative experience. See Husserl 1973 (p. 27).

${ }^{39}$ I borrow this sort of experiment from Heck (2000, pp. 489-90).
} 
propositionalist objection were correct, how could formulating a proposition clarify anything in

experience, as it does when, for example, I begin to describe my experience of a taste, of a song,

or of a scene? Equally, how could we experience difficulty in raising our experience to

propositional expression, in giving a formulation to the ambiguous contours of experience, as I

surely do when I am made to describe a novel experience ${ }^{40}$

Finally, there are structural differences between experience and propositions. Whereas a

proposition is singular and determinate, experiential content lacks such precise contours. In a

working note for The Visible and the Invisible, Merleau-Ponty writes,

Yet there is a world of silence, the perceived world, at least, is an order where there are non-language significations - yes, non-language significations, but they are not accordingly positive. There is for example no absolute flux of singular Erlebnisse; there are fields and a field of fields, with a style and a typicality (1968, p. 171).

Our experiences, then, do not have the definite boundaries that our propositional descriptions of them do. ${ }^{41}$ This is why the task of giving experiential content propositional form is so

${ }^{40}$ Of course, some propositional content can always be summoned for experience. A novice wine drinker sampling for the first time a Barbaresco, when asked to describe the experience can always state vacuously, "This tastes like Barbaresco." But this expression is a mere tautology and so leaves out any meaningful content of my experience. As an expression, it is undoubtedly poor. Thus, while it is evident that any experience can be given propositional form, this does not prove that experience is propositional.

${ }^{41}$ This is, for example, Roquentin's point in Sartre's Nausea about telling the story of one's life: "You have to choose: live or tell. ... Nothing happens while you live. The scenery changes, people come in and go out, that's all. There are no beginnings. Days are tacked on to days without rhyme or reason, and interminable, monotonous addition. ... Neither is there any end: you never leave a woman, a friend, a city in one go. And everything looks alike .... . There are moments - rarely - when you make a landmark, you realize you are going with a woman, in some messy business. The time of a flash. After that, the procession starts again ... . That's living. But everything changes when you tell about life; it's a change no one notices ... . You seem to start at the beginning: 'It was a fine autumn evening in 1922. I was a notary's clerk in Marommes.' And in reality you have started at the end. It was there, invisible and present, it is the one which gives to words the pomp and value of a beginning. ... The end is there, transforming everything. For us, the man is already the hero of the story. His moroseness, his money troubles are much more precious than ours, they are all gilded by the light of future passions. And the story goes on in the reverse: instants have stopped piling themselves in a lighthearted way one on top of the other, they are snapped up by the end of the story which draws them and each one of them in turns, draws out the preceding instant .... We forget that the future was not yet there; the man was walking in a night without forethought ...” (2007, pp. 39-40). The ordinary flow of experience, then, is without stark boundaries: without beginnings or ends, or at least, when experience makes beginnings and ends, these are not definitive, for they engage generalities that persists beneath the boundaries. But when we set about telling of our experience we necessarily demarcate a before and after, i.e., we determine a beginning. Ronquentin goes on to point out that this marks a rupture in the temporality of an event: in isolating an experience, we define a whole, within which the parts define each other, such that the beginning is already defined by the end. But for my current purposes, all I wish to point 
interminable: there are myriad ways in which one can carve up this content into precise form.

This is also what makes the task difficult: it's often unclear what is the right way to put experience into propositional form. I will return to this point and make it more thoroughly in section 6 of this chapter. For now, I only mean to note that while experience is open to being put in propositional form, it also resists this transformation, and this resistance suffices to show that experiential content is different in form from propositional content.

\section{B. Conclusion}

In this section, I've sketched the contours of the distinction between experience and judgment. The view I have adopted is Merleau-Ponty's, which in large part agrees with views adopted by McDowell and Davidson. All three agree, for example, that experience is nonpropositional, whereas judgment is propositional. It's worth noting that there are significant regards in which they disagree. For example, they disagree about whether the content of perception is conceptual, McDowell holding that it is and Merleau-Ponty and Davidson holding that it is not. ${ }^{42}$ However, Merleau-Ponty is quite far from landing in Davidson's camp here.

Davidson views experience in terms of causality, and thus leaves spontaneity out of his picture of experience. Like McDowell, Merleau-Ponty thinks experience is organized by a kind of “spontaneity” in receptivity, but differs from McDowell in his description of this spontaneity: for McDowell, spontaneity signifies the deployment of conceptual capacities, while for MerleauPonty, spontaneity signifies that experience is meaningful. Thus, McDowell’s paradigm of spontaneity is active thinking (judgment), and passive experience is spontaneous only to the

out is that putting experience into language, into propositional form, entails determining the boundaries of an experience that in itself was indeterminate.

42 There is some question about whether Merleau-Ponty is as strongly opposed to McDowell on this issue as he seems to be. Dreyfus, Kelly, and Alweiss, for example, take Merleau-Ponty to think that the content of experience is non-conceptual (see Dreyfus (2007) \& (2013), Kelly (2001), and Alweiss (2000)). However, Berendzen has contested this claim (2009) \& (2010). It seems to me that while the nonconceptuality of perceptual content in Merleau-Ponty is at times overstated in the literature, a careful reading of Merleau-Ponty cannot ignore his description of certain kinds of non-conceptual content. He writes, e.g., that "Living thought ... does not consists in the act of subsuming under a category" (2012, p. 130). While I think that experience has non-conceptual content, my argument in this section does not rely on this position and so should be acceptable even to a conceptualist. 
extent that it involves the capacities exercised in active thinking (conceptual capacities). In contrast, for Merleau-Ponty, experience is organized by a spontaneity that is sui generis, i.e., isn't defined by discursivity.

\section{Motivation}

In the previous section, I distinguished between perceptual experience, in which one spontaneously grasps meaning, and judgment, in which one actively takes a propositional stance with respect to that meaning. A similar distinction between experience and judgment is drawn by McDowell and Davidson, though different parties construe the boundaries of this distinction differently. Now that I have clarified what Merleau-Ponty means by experience, and how his position stands with respect to McDowell's and Davidson's, I can turn to the question of how we should conceive the relation between experience and judgment. Whereas Davidson conceives this relation in terms of causality, and McDowell conceives it in terms of reason, Merleau-Ponty conceives it in terms of motivation. In this section, I explain what it means to claim that perception motivates judgments.

I think we can describe the motivational relationship between experience and judgment basically as follows. If judgment is propositional, and experience is nonpropositional, judgment is obviously not reducible to, or in any sense contained in, experience. Instead, judgment responds to nonpropositional experience by determining it propositionally. On the other hand, judgment isn't autonomous with respect to experience: experience demarcates and norms a field of possible judgments (propositions), establishing some propositions as better or worse responses to itself. Propositions are normed by experience in terms of how well they express the content of experience. In this sense, propositions are responsible to experience.

This account of the relation between perception and judgment allows us to acknowledge Davidson's puzzle without giving up the normativity of experience. Because the outputs of motivation transcend their inputs, it is possible for non-propositional content to motivate 
propositional content. And because motivation is normative, this non-propositional content norms the propositions that can be made of it.

Further, we can specify the notions of norming and responsibility here in terms of the phenomenological concept of evidence. Husserl uses the term 'evidence' to describe 'the giving of something itself' (1969, pp. 157-8). ${ }^{43}$ A judgment has evidence when it is intuitively fulfilled, e.g., in experience. While I am in the hallway, I can judge for myself that the room I will enter is full of people, but the judgment is empty (unfulfilled) until I walk into the room and see and hear for myself. In entering the room, my judgment becomes evident. Experiences norm judgments in the sense that they evidentiate them: seated across from my friend, I can judge 'My friend here is a human’ or I can judge ‘My friend here is a heron.' But only one of these judgments will be evidentiated by experience.

I will thus understand the claim that experience motivates judgments to mean that experience evidentiates judgments. The notion of evidence allows us to see how experience grounds judgments, without itself containing propositions. ${ }^{44}$

Importantly, we are not active with respect to evidence. I can actively form judgments at will, e.g., I am free to form the judgment "This room is full of people" in the hallway, and even if as I walk in I find no one there. But I cannot actively make a judgment evident. Alone in the room, I know too well that no amount of willpower can fulfill my judgment. At most I can put myself in the right circumstance for a judgment to be evidentiated (e.g., I cannot will my

\footnotetext{
${ }^{43}$ Naturally, Husserl is not suggesting that evidence in this sense is a sort of sense-datum or 'Given' (in the mythical sense), minimally because (in the same passage) Husserl is clear that the giving of evidence draws on our spontaneity (in Husserl's terms, on an 'intentionale Leistung').

${ }^{44}$ Walsh (2013) has pointed out that Husserl's notions motivation and evidence in the Logical Investigations are distinct. For example, the sight of smoke can motivate the thought of fire, even though it in no sense makes the fire evident to me. But, while it seems plausible to me that not all motivational relationships are evidential, this does not entail that no motivational relationships are evidential, nor that evidential relationships are not motivational. For example, in an Appendix II to Experience and Judgment, Husserl describes the way in which the evidence of a judgment of probability (and not just the judgment of probability itself) is motivated $(1973,394)$. Consequently, at least on Husserl's terms, nothing speaks against allowing that there are motivational relationships that are not evidentiating while at the same time holding that the evidential relationship connecting experience and knowledge is a motivational relationship.
} 
judgment "It is hot outside" into fulfillment, but I can walk outside into the heat). Thus, just as I am not active with respect to experience itself, neither am I active with respect to evidentiation by experience.

4. Reason

What makes my account of the relation between experience and judgment preferable to Davidson's causal account or McDowell's rational account? In this section, I argue that the relation between experience and judgment cannot be understood in terms of reason. In the next section, I will explain why causality won't work either. In short, my argument here is that McDowell cannot describe the grounding relation between experience and judgment in terms of reason, because to do so would entail that this relation is at the disposal of our active thinking, which it is not.

First, let me explain McDowell’s position in a little more depth. McDowell thinks that the conceptual capacities engaged in experience put us in a position to be justified in knowledge. The idea is that our judgments are ultimately justified by appeals to experience, by claims like: "It seems this way to me,” or “It looks like ...," or "It appears that ... ." ${ }^{45}$ For example, on a walk along the coast, I say to my companion, “Look! There’s that osprey!” If she then asks me why I say that that is the osprey - thinking herself that it is an eagle - it would be natural for me to say: “Well, because it looks that way to me.” In this way, experiences are our ultimate reasons for holding certain beliefs, because they immediately put us in a position to know certain propositions to be true or false. McDowell's view is thus that the nonpropositional content of experience justifies propositions, i.e., judgments: the former is a reason for holding the latter. But, according to McDowell, experience is a noninferential reason. In other words, we shouldn't think of experience as providing a premise for a conclusion (i.e., a judgment). Instead, experience immediately puts us in a position to know things, to know that certain propositions are true or

${ }^{45}$ See, e.g., McDowell (1996, p. 165) \& (2008, pp. 3-4). 
false (McDowell, 2008, pp. 12-13). When I reply to my friend that "It seems that way to me,” I am not using this appearance as a premise, for which "That's an osprey” is the conclusion; I am pointing out that my experience puts me in a position to know noninferentially that that is an osprey. ${ }^{46}$

I want to be clear about what justifications like "it seems that way to me” actually mean. If experience were propositional, then we might understand such claims as follows: "I experience that 'That is an osprey',” or, “The content of my experience is that 'That is an osprey'.” And then it might seem to be an obvious and reasonable step from the experience that "That is an osprey" to the judgment “That is an osprey.” But if experiences are non-propositional, as I and McDowell think, then phrases like "It seems to me that 'That is an osprey'," or "It looks that way [as if 'That is an osprey']" are misleading, for taken literally they suggest that what one sees in experience are propositions, thereby saddling experience with propositional content that it doesn't possess. Instead, according to McDowell, such phrases are best understood as meaning that one’s experience "inclines” one to say that, e.g., “That is an osprey.” McDowell writes that "Such locutions ... accept, in their 'that' clauses, specifications of things one's experience puts one in a position to know noninferentially” (2008, pp. 3-4). It seems to me that to say that experience "inclines" one to make a judgment or that experience "puts one in a position to know" are other ways of referring to what I have called evidentiation; I think justifications like "It looks that way to me” mean that experience evidentiates my proposition or judgment, in the sense that I don't

\footnotetext{
${ }^{46}$ Wrathall has argued against McDowell on the grounds that the motives of our experiences are often unavailable for use as reasons for judgment: "An experience is able to provide rational grounding to the extent that it is available for use in inference and justification. Thus, we can conclude that if the experience that gives rise to the thought is not available for use in inference and justification, then the thought is not rationally grounded. ... It is often the case that we are motivated by some features of our perceptual experience that are not available for use in thought but that nevertheless dispose us (rather than cause us) to have the thoughts that we do. Thus, motives stand to the thoughts they motivate not in a way that justifies or supports them, but rather in that they impel us toward having them” (2005, pp. 122-3). But I think this mistakes McDowell's case. For McDowell does not claim that every feature of experience that influences the way we see things is a rational ground for our judgments. Rather, McDowell claims that how we see things, our experience (however it is grounded in the various features of experience), is available for thought, and so can rationally ground a judgment. While the reflection in the eye may not be available for use in judging that the portrait is lively, the experience of the portrait as lively is.
} 
utter the proposition emptily (as I would if, e.g., I had said "That is an osprey” while walking down an empty, enclosed corridor, that appeared to me as such). ${ }^{47}$ Thus, if I reply that "it looks that way to me,” I don’t mean that I literally see the proposition, but that my experience makes that proposition evident. Again, if experience is nonpropositional (as I think it is), then we should think of experience as norming a field of possible propositions one could make in response to experience, such that no propositions are given in my experience, but my experience yet makes some propositions better than others.

This way of construing the bond between experience and judgment as rational, I now argue, will not do. Justifications like "Because it seems that way,” the kind McDowell uses to describe the justification of judgment by experience, are not really satisfactory as rational grounds for judgment. And the reason for this is that we cannot fully take responsibility for them, or in other words, the relation between experience and judgment isn't active in the sense McDowell requires to count it as justification (McDowell, 1996, p. 53). ${ }^{48}$

What would it take for the relation between experience and judgment to be rational? McDowell has provided an - I think good - answer to this question in his criticism of Evans. Evans claimed that experiences can have nonconceptual content and yet stand in a rational relation to judgments. McDowell criticizes this position on the grounds that any account that puts experience and judgment on opposing sides of a "conceptual boundary" (a boundary between conceptual and non-conceptual content), leaves experience outside the sphere of our spontaneity,

\footnotetext{
${ }^{47}$ I am putting McDowell's ideas in terms of the phenomenological concept of evidence in order to facilitate a conversation. However, if someone in McDowell's position had good reason to reject my assimilation of experience's “inclining” one so to judge in terms evidence, then I don't think my argument in what follows will be damaged. My argument depends on the fact that we can't freely revise how our experience evidentiates, but this is just as true of how experience inclines one to think. ${ }^{48}$ What I am arguing is that the relation itself doesn't come under the self-scrutiny of active thinking, and thus can't be considered as rational. Notice how I equally disagree with Evans and his defenders here (see, e.g., Heck (2000) or Lerman (2010), for a defense of Evans's position on this exact issue). I agree with McDowell, against Evans, that if experience is outside the boundary of spontaneity (in McDowell's sense, i.e., "the space of reasons"), then it cannot stand in a rational relation to judgment. But I disagree with McDowell that we should think of the relation between experience and judgment as rational, as being able to "come under the self-scrutiny of active thinking."
} 
and any account that leaves experience outside the sphere of spontaneity cannot treat the relation between experience and judgment as susceptible to active thinking. But, McDowell claims, only relations susceptible to active thinking can be considered as rational. As McDowell puts it,

If these relations [between experience and judgment] are to be genuinely recognizable as reason-constituting, we cannot confine spontaneity within a boundary across which the relations are supposed to hold. The relations themselves must be able to come under the self-scrutiny of active thinking.

Further, McDowell understands "falling under the self-scrutiny of active thinking” in terms of being "liable to revision, if that were to be what the self-scrutiny of active thinking recommends" (McDowell, 1996, p. 52). Thus, McDowell takes it that for a relation to be rational, it must be liable to revision by active thinking.

But the relation between experience and judgment does not meet this criterion. I have claimed that not only are we not active with respect to our experience, we are not active with respect to the evidentiation of our judgments by experience (i.e., these are grounded spontaneously, in the sense I articulated above). In other words, we are not free to revise or alter this relation under the recommendation of active thinking. Take again the case of my ornithological dispute. Suppose I am inclined to trust my friend's eyesight over my own, and so judge that what appears to me as an osprey is in fact an eagle. While I am free to form this judgment, I am not free to revise the way in which experience evidentiates my judgments: my experience continues to fulfill the judgment that the bird before us is an osprey, and not to fulfill the judgment that it is an eagle. Thus, we ought to say that while we are active with respect to our judgments, the relation between experience and judgment is spontaneous. But if this is so, then on the criterion McDowell has given, the relation is not rational.

Let me be more precise. It is true that our empirical judgments are revisable. In fact, they are revised in one of two ways: either a) experience evidentiates a new, different judgment, or b) one has reasons independently of experience for revising one's judgment. But neither of these two modes of revision can give McDowell what he needs in order to count the relation as rational. 
In the first case, the revision is not by the recommendation of active thinking. It is, in fact, totally spontaneous: the new evidentiation either falls into view, or it does not. In the second case, the relation between experience and judgment is not revised - it is simply ignored. The relation between experience and judgment is thus revisable only in the sense that one can always withhold affirmation from the evidentiation provided by experience. Even if experience fulfills a judgment, I need not affirm that judgment. I may have other reasons for doubting the testimony of experience (e.g., my friend's superior eyesight). I may even be embarking on a Cartesian project of radical doubt. Whatever the case, whereas the evidentiation provided by experience is spontaneous (and not actively revisable), I am active with respect to judgments, for I have the capacity to affirm or deny any judgment. In this sense, my judgments do genuinely fall under the "self-scrutiny of active thinking.” But the bond between experience and judgment is not thereby revised, but severed. The important point is that this power only tells us about judgment, and not about the relation between experience and judgment, which is what McDowell needs it to do.

Illusions make this distinction between activity and spontaneity particularly clear. For example, in Zöllner's illusion, parallel lines appear convergent (see Figure 2.1). Despite the fact that one knows that the lines are parallel, one cannot help but see them as convergent. Not only does one lack active control over one's experience here, but one lacks active control over what experience evidentiates: experience fulfills the proposition that the lines are convergent, but not the proposition that the lines are parallel. ${ }^{49}$ But my judgment is different, for I am free to deny the evidence of experience. Perhaps I have measured the distance between the lines at various points, and found these distances equal. So, I have good reason to deny the proposition that the lines are

\footnotetext{
${ }^{49}$ In reference to Zöllner's illusion, Merleau-Ponty writes, "We must recognize that in taking on the auxiliary lines, the principle lines have ceased to be parallel, that they have lost this sense in order to acquire another, and that the auxiliary lines import into the figure a new signification that henceforth clings to it and that henceforth can no longer be detached from it. This signification adhering to the figure, this transformation of the phenomenon motivates and is, so to speak, behind the false judgment” (2012, p. 37). Notice that neither can the bond here be understood simply in terms of passivity (causality), because sensory impacts upon the eye obviously do not give the lines as convergent: this signification is spontaneously produced in our perception.
} 
convergent. But whereas my denial is active, the bond itself is spontaneous: experience stubbornly fulfills the judgment that the lines are convergent, despite my knowledge to the contrary. No argument, no host of reasons, will alter this testimony of perception; though reason may well sever or bracket the bond between experience and judgment, it persists beneath my active refusal of it. Consequently, the fact that reason can grant or withhold approval from this bond does not make the bond itself rational.

I have argued that the bond between experience and judgment shouldn't be understood as rational, because it doesn’t meet the criteria McDowell rightly sets for rational relations: that they belong within the scope of active thinking. Before concluding this section, I will address one important objection to my position.

I have argued that the primary bond between experience and judgment is motivation, rather than reason. But one can take the motivational bond between experience and judgment as a reason. Active thinking can survey the motivational bond between experience and judgment, and affirm it as a reason for judgment. ${ }^{50} \mathrm{I}$ can take, for example, the proposition "I experience that the lines are convergent” as a reason for the judgment "The lines are convergent,” a reason which in this case is simply overruled by other reasons. This is not exactly the relation McDowell claimed to hold between experience and judgment (insofar as it is inferential), but it does seem like a legitimate sense in which experience serves as a reason for judgment. Thus, there seems to be a perfectly good reason for saying that there is a bond between experience and judgment which is rational. However, this move won't secure the kind of relation that McDowell wants.

\footnotetext{
${ }^{50}$ Notice that such acts of reason taking would be completely dependent upon the motivational bond. Husserl makes this point (in a slightly different context) in Experience and Judgment: “... Acts of positiontaking are completely dependent insofar as they have their motivational foundation in what takes place in the perception itself, in its proper and perhaps purely passive course. Perception has its own intentionality, which as yet involves nothing of the spontaneous activity of the ego and its constitutive function, since this intentionality is, on the contrary, presupposed if the ego is to have something for or against which it can decide” (p. 289).
} 
This strategy relies on a subtle ambiguity. Ginsborg has distinguished two senses of reason (Ginsborg, 2006). In one sense, we take facts as reasons, and it seems wrong-headed to even consider psychological states, like beliefs or judgments, as reasons. As Dennis Stampe puts it,

If I believe it has rained because the streets are wet, it is the fact that the streets are wet, not the fact that I believe them to be, that comprises my reason for believing that the streets are wet (1987, p. 343).

I take the fact that the streets are wet, not my belief that they are wet, as my reason for believing that it has rained. But in another sense, it is natural to take psychological states, like beliefs or judgments, as reasons. For example, someone attempting to reconstruct my reasons for judgment will cite my other judgments or beliefs as reasons: "His judgment that it had rained followed from his judgment that the streets were wet." This is the sense in which Davidson has claimed that experiences can’t count as reasons for belief. Reason in the first sense names "the fact which presents itself to the subject as favoring the belief" (Ginsborg, 2006, pp. 289-90). Reason in the second sense names the psychological state justifying the judgment. More generally, we can distinguish between grounds in the first sense and grounds in the second sense.

In considering the relation between experience and judgment, we have been considering reason in the second sense. McDowell's claim is that the kind of psychological state justifying one's judgments of experience is experience. But I have argued that reason does not describe the manner in which experiences ground (in the second sense) judgments, because of our passivity to this grounding. If one now takes the tack, in response, of claiming that we do take experiences as grounds of judgments (and thus this grounding is not merely passive), one has subtly shifted focus from the second form of grounding to the first. This response takes one's experience as a fact which serves as a reason, in the first sense, for one's judgment. But in the second sense, it is no longer the experience itself, but a judgment about experience (i.e., "I experience that ..."), that grounds one's judgment. And this merely pushes back the question about the relation between experience and judgment, because one must now explain how one arrives at the judgment about 
experience, the "I experience that ...", in the first place. Thus, this response does not make experience the ground of judgment in the sense that is relevant to McDowell, though it does describe a perfectly legitimate sense in which experience can be taken as a reason for judgment. This distinction allows me to preserve Davidson's insight that only a proposition can count as a reason for a belief, without denying experience a kind of justificatory role in our judgments of experience, though a very different one from that McDowell claimed to exist.

\section{Causality}

In the last section, I argued that the relation between experience and judgment isn’t rational. In this section, I claim that neither is it causal.

There are two main reasons that I think this, namely that the bond between experience and judgment is meaningful in a way that causality simply can't describe. First, it is the meaningful features of experience that evidentiate judgments. I am inclined to think that the bird before us is an osprey because I am familiar with the white patches on the chests of osprey - the coloration has a meaning for me, even without my pausing to reflect on it. Likewise, the reflection in the portrait's eye means liveliness to me: it isn't that the white patch causes me to judge the painting as lively, but the white patch in its meaning of "the reflection in the eye" makes the judgment of liveliness evident to me. Second, experiential judgments are normative: I find myself right to judge so, and others wrong not to judge so. But it is not clear how a causal relationship could instigate this kind of normativity. One is not right or wrong to have been caused such as one has, ultimately because one cannot take responsibility for this causation. In other words, I think McDowell is right that relations that are purely receptive cannot be normative and agree with him that nonpropositional experience and the grounding of judgment by experience cannot be understood simply in terms of receptivity. I just disagree with McDowell about how to understand this more-than-receptive type of grounding.

Thus, I think that a description of the bond between perception and judgment in terms of motivation is truer to the phenomena than either alternative. Understanding the bond in terms of 
reason fails to capture its passivity, and understanding it in terms of causality fails to capture its normativity. ${ }^{51}$

\section{Expression and Motivation}

One, especially if one is a trained philosopher, may not struggle to understand the relation between experience and judgment in terms either of reason or causality. In contrast, one may have little intuitive sense for what it means to think of this relation in terms of motivation. This lack of familiarity makes my account difficult to adopt. In this section, I will challenge these familiar modes of thinking about experience and judgment by analyzing the phenomenon of original expression. By expression I mean the act in which an experience is articulated in propositional form. In particular, I want to draw attention to original acts of expression, cases in which an experience cannot be expressed in a familiar or cliché manner and so requires a novel judgment. ${ }^{52}$ Original expression is a species of the relation between experience and judgment (and one of which every familiar expression is ultimately derivative), but it has not yet been used to analyze this relation. This is a shame, I think, because this species of the relation has the potential to reframe our ways of thinking about its genus.

Take, for example, a novice wine drinker sampling a novel wine. She will be hard pressed to find the right means to express her experience. Of course, she can form some

\footnotetext{
${ }^{51}$ An additional consideration clarifies the relation between the three modes of grounding. One way to see that motives aren't causes is to notice that motives are in principle open to being taken as justifications by rational reflection. Because motives operate in virtue of their meaning, they are the kind of thing that can be taken as justifications. The reflection in the portrait's eye really is a consideration in favor of the painting's quality of liveliness, and it justifies a judgment of liveliness, but only in the register of reflection. Prior to reflection, the light in the eye moves us by tacitly drawing on our recognition of its significance. The coloration on the bird's chest really is a consideration in favor of believing it to be an osprey. But prior to reflection, it is only part of my tacit familiarity with osprey; not taken up by me for itself, it is not taken up as a consideration in favor of my judgment. Yet, it would be a mistake to assimilate motives to rationality merely because the motives of our experience are open to being treated as reasons for judgment. As we saw in chapter 1, motives resist being treated as reasons, and we must say that motives are only relatively open to being treated as reasons.

${ }^{52}$ By original expression I mean something much like what Merleau-Ponty calls “speaking speech" as opposed to "spoken speech" (2012, pp. 202-3), where the latter names the already constituted system of familiar "means of expression," and the latter names a "meaningful intention in a nascent state" that must create a means to express itself by taking up and transforming already existing language.
} 
judgments, e.g., "This tastes like wine," and maybe even, "The wine is sweet." But she wants to do better, to articulate beyond these commonplaces the nuance of her experience. So, she searches for the right words. She tries on various options for size, but can't quite find anything that fits. Likely, she can't find any definite contour in the taste onto which she can hold. It isn't that she has some definite idea of the taste for which she just can't find the word. Instead, she isn't even totally sure what the taste is or if there is a word for it: the taste is vague or ambiguous. She runs through the experience trying to fix just what she has experienced, until suddenly she strikes upon a proposition which suits the taste: "The wine is acidic."

If we think through the novice wine drinker's act of expression closely, there is something puzzling about what has happened in it. On the one hand, her gustatory experience of the wine grounds her judgment: she only recognizes the judgment as true because it has been evidentiated by experience. The experience, as I said previously, norms the field of possible propositions, making this particular judgment a good one. On the other hand, the experience did not itself contain the proposition. If it had, this budding oenophile would not have had to search for the right words to fix her experience; she would only have been struggling to remember the words. Instead, the experience was vague and indeterminate, and if we remember her first taste we recall that it did not contain the acidity or exclude other qualities, e.g., tannin. It was too vague for this. But the judgment determines the experience, fixing it as acidic and not tannic. What is puzzling is that the experience did not contain the proposition "The wine is acidic," and yet when the proposition is suggested she recognizes her experience in it immediately. More, the experience itself is determined through the judgment. The content of the experience is actually enriched by the judgment, and when she returns to the wine the taste will mean something more to her than it did before. After all, this is how one becomes skilled or discerning in one's tastes: by enriching one's capacity for experience through articulation and expression. Or to use other terms, what is puzzling here is that the experience grounds the judgment, while itself being transformed by the judgment. 
This phenomenon only becomes more apparent when we look at less purely sensory experiences. Say that I am struggling to find the right words to describe our friend's behavior at the dinner table the other night. How would one describe him, exactly? Sure, he was acting oddly - but how exactly? Would you say he was despondent? Distracted? Joyless? None of these words quite do his behavior justice. Yet they are so many ways of getting at the same experiential content. In this case, I am trying to find the appropriate judgment to express the content of experience. But at the same time that my judgments are responsible to the experience they express, they give the experience a definite sense: in discerning between "despondent" and "joyless" we are deciding about the character of experience, and thereby determining it. I am trying to gesture here toward what Elena Ferrante has called "literary truth.” In speaking of sincerity in literature, she claims,

The most urgent question for a writer may seem to be, What experiences do I have as my material, what experiences do I feel able to narrate? But that's not right. The more pressing question is, What is the word, what is the rhythm of the sentence, what tone best suits the things I know? Without the right words, without long practice in putting them together, nothing comes out alive and true. It's not enough to say, as we increasingly do, These events truly happened, it's my real life, the names are the real ones, I'm describing the real places where the events occurred. If the writing is inadequate, it can falsify the most honest biographical truths. Literary truth is not the truth of the biographer or the reporter, it's not a pole report or a sentence handed down by a court. It's not even the plausibility of a well-constructed narrative. Literary truth is entirely a matter of wording and is directly proportional to the energy that one is able to impress on the sentence. And when it works, there is no stereotype or cliché of popular literature that resists it. It reanimates, revives, subjects everything to its needs (Ferrante, 2015).

Ferrante distinguishes the writer's material, the experience, from the form of the expression, the words, rhythm, and tone. This distinction allows us to see that what makes the writer's expressions "alive and true" is neither the experience to be expressed (the "material”), without which the expression is empty, nor the expression, without which the experience remains cliché. It is rather the intimate bond of the two. If we are to understand the form of grounding which occurs in expression, we must then appreciate the complexity of this grounding: the experience motivates the expression, but the expression opens up the experience. 
Once we appreciate the complex manner in which expressions are grounded, the dichotomy of reason and causality is far less tempting. In the case of the wine drinker, the experience cannot have been a reason for the judgment, because the experience is only determined through the judgment. Of course, if after making the judgment the wine drinker is asked why she thinks the wine is acidic, she will reference her experience, saying "Because its tastes acidic." The problem with this response is that she could not have said it prior to judging the wine acidic, because her experience is only determined as acidic through the judgment. The response "Because it tastes acidic" is thus a reconstruction of the actual ground of her judgment, one only possible in light of the judgment. In taking the experience to be the reason for the judgment, one has thus understood the process of expression in terms of its result. Neither can the grounding here be understood as causality. If the expression were simply caused by the experience, it would not require the labor of expression, nor could it introduce new content into the experience - there would be no normativity here, and so the wine drinker wouldn’t need to struggle. Just like reason, causality mistakes the process of expression in terms of its result: the experience only has the sort of content that could cause the judgment as a result of the process of expression.

These conclusions are also found in the case of literary expression. Ferrante distinguishes the form of an expression (the proposition) from its material (the experience). In seeking to achieve truth in her statements, the author is concerned primarily with the former. But if this is true, then there is no good way to make sense of the idea that the author's judgment is grounded either causally or rationally by her experience. On the one hand, this grounding cannot be understood in terms of causality. If the grounding was causal, the writer would passively receive the expression. But understanding literary expression in terms of passivity overlooks both the writer's craft and the normativity inherent in her task - the whole negotiation between her capacities and the demands placed upon her by the experience if she is to be true to it. On the other hand, neither can the author's expression be grounded in terms of reason. On McDowell's 
model, when the writer is asked why she formed this particular judgment, she will answer, “Because I experienced it thus.” But, no less than causality, this answer overlooks the author's craft, because it assimilates the expression to the experience. If Ferrante is right that the form of the expression cannot be reduced to its matter, then the writer can only say "Because I experienced it thus” after having formed the expression. Expression is not formed by reason of experience; instead, it creates experience as its reason. ${ }^{53}$ Neither reason nor causality can allow for the originality introduced by the form of the expression. Thus, we must say that the experience (as the theme or motif of expression) motivates the expression, norming the field of possible expressions without itself containing them.

What makes it so easy to think of the relation between experience and judicative expression in terms of reason and causality is that we tend to think in terms of experiences and judgments with which we are entirely familiar. In this section, I have tried to reorient our habitual ways of thinking about the relation between experience and judgment by calling attention to a unique form of this relation, namely, original expression. Of course, not all expressions are original (though all familiar expressions were at some point original, and so familiar judgment is a derivative mode of expression). But, as I have showed, an analysis of the phenomenon of original expression does require a reorientation in our habitual modes of thinking about the relation between experience and judgment.

\section{Conclusion}

In this chapter, I have argued that motivation, and not reason or causality, describes the relationship between perceptual experience and judgment. First, I described the specifically phenomenological concept of motivation, as a form of grounding distinct from reason and causality. I explained what it means to say that experience motivates judgment, in terms of the phenomenological concept of evidence. Experience, I then argued, cannot be understood as either

\footnotetext{
${ }^{53} \mathrm{Cf}$. Merleau-Ponty claims about original perception that it "cannot yet know its reasons, since it creates
} them" (2012, p. 46). 
a reason or cause for judgment, because the former would miss the passivity of the bond between experience and judgment and the latter would miss its normativity. Finally, I attempted to shift the parameters of this debate by considering the phenomenon of original expression. Now, in concluding this chapter, I'd like to consider the consequences of introducing motivation as a form of epistemological grounding. Ultimately, I suggest, it requires us to provide an account of knowledge that challenges the dichotomy between the unique form of empiricist foundationalism found in McDowell and Davidson's coherentism.

Within the domain of reason, we are concerned to justify our beliefs. But, as McDowell points out, if our beliefs are caused, then we can't speak of them as justified. Causes function as exculpations, rather than justifications (McDowell, 1996, p. 8). What about motives? One might think that if motives aren't reasons for belief, then they are at most exculpations for our beliefs. But I will show that motives, not belonging to the dichotomy of reasons and causes, can't be understood in terms either of exculpations or justifications.

Motives don’t justify: as we have seen, motives ground our expressions without offering the intermediary of a reason. On the other hand, it would be a mistake to think that, because motives aren't justifications, they ought to be lumped in with exculpations. Motives, unlike causes, which force us into outcomes, draw on and solicit our spontaneity. As I argued in the first section of this chapter, perceptual experience is shaped spontaneously (not actively or passively) and only motivation is in a position to describe this kind of spontaneous grounding. But if motivation is a form of grounding which draws on our spontaneity, then it cannot count as mere exculpation; our acts of expressions may not be justified, but neither may we be excused for them.

We might see the distinction here more clearly by considering it in analogy to Aristotle's distinction between voluntary action, involuntary action, and decision. Voluntary and involuntary action differ essentially in the locus of the principle of motion: within the agent or outside of the agent, respectively. Voluntary action differs from decision in that the latter is a product of 
deliberation, the difference clearly seen in that children and animals are capable of voluntary action, but not decision. ${ }^{54}$ We are certainly excused for our involuntary actions: that someone else pushed my hand onto the button that instigated the crime excuses me from guilt - it is an exculpation. But we are guilty (or responsible) with respect to our voluntary actions, for our voluntary actions manifest our character as virtuous or vicious, though according to Aristotle not as clearly as does decision, in which we are concerned to justify our actions. Motivated actions draw on our spontaneity, and so are importantly voluntary, insofar as the principle of motion is within the agent; because motivated actions aren't involuntary, motives don't count as exculpations. On the other hand, motivation needn't be the result of deliberation, and so motivated actions do not belong with decision. Consequently, motives don’t count as justification. ${ }^{55}$

But this alternative between exculpation and justification is at the heart of Davidson's coherentism and McDowell's brand of empiricism. McDowell is right to point out that it is because Davidson can see experiences as no more than exculpations for belief, such that beliefs can only be justified by other beliefs, that he adopts a coherentist stance. On the other hand, McDowell's sort of minimal empiricism is grounded in his belief that experiences justify judgments. A careful phenomenology of the bond between experience and judgment makes either of these alternatives unacceptable. But if neither exculpation nor justification adequately describe the relation between experience and judgment, a new way of thinking about knowledge will be needed. Phenomenology can supply this account of knowledge by beginning from the experience

\footnotetext{
${ }^{54}$ See Aristotle’s Nichomachean Ethics, Book III, chapters 1 \& 2.

${ }^{55}$ On the other hand, McDowell doesn't think that all justified action is deliberate, or the product of decision. McDowell's claim would thus be that the sphere of voluntary actions belongs within the sphere of reasons, insofar as an agent is always prepared to justify her spontaneous actions with reasons (or at least is rightly expected to be so prepared). And if this were true, motivation would either describe the sphere of involuntary actions, or would be a species of reason-giving. But by now it should be clear that from the fact that an agent can give reasons for her spontaneous actions or judgments, it doesn't follow that her actions or judgments were grounded in reasons. I have argued that the space of motivations is partially open to the space of reasons, but conflating the two ignores the transformation that our grounding undergoes when we give an account of our actions and beliefs.
} 
of evidence, in which our experiences motivate our judgments. This is much the sense in which Husserl has defined knowledge as

The consciousness of the 'agreement' between an empty anticipatory belief, in particular a predicative belief (empty, or not genuinely given), and the corresponding experience which gives at first hand the object of this belief - the object judged in the predication - as the experience of its self-givenness ... . From another perspective: there is agreement between the mere judgment, between what is posited in the predicative sense, and the experience of this sense in the mode of 'it itself' (1973, p. 283).

In this way, phenomenology will allow us to understand knowledge (as Ferrante puts it) in its "life and truth."

This, in brief, will be the aim of chapter 3 . Whereas in the present chapter I have described the relation between experience and empirical judgment in terms of motivation, in the following chapter I will consider how experience grounds knowledge generally, i.e., how it grounds universal and ultimately a priori judgments. Again, I will argue that motivation provides the best description of this grounding relation. 


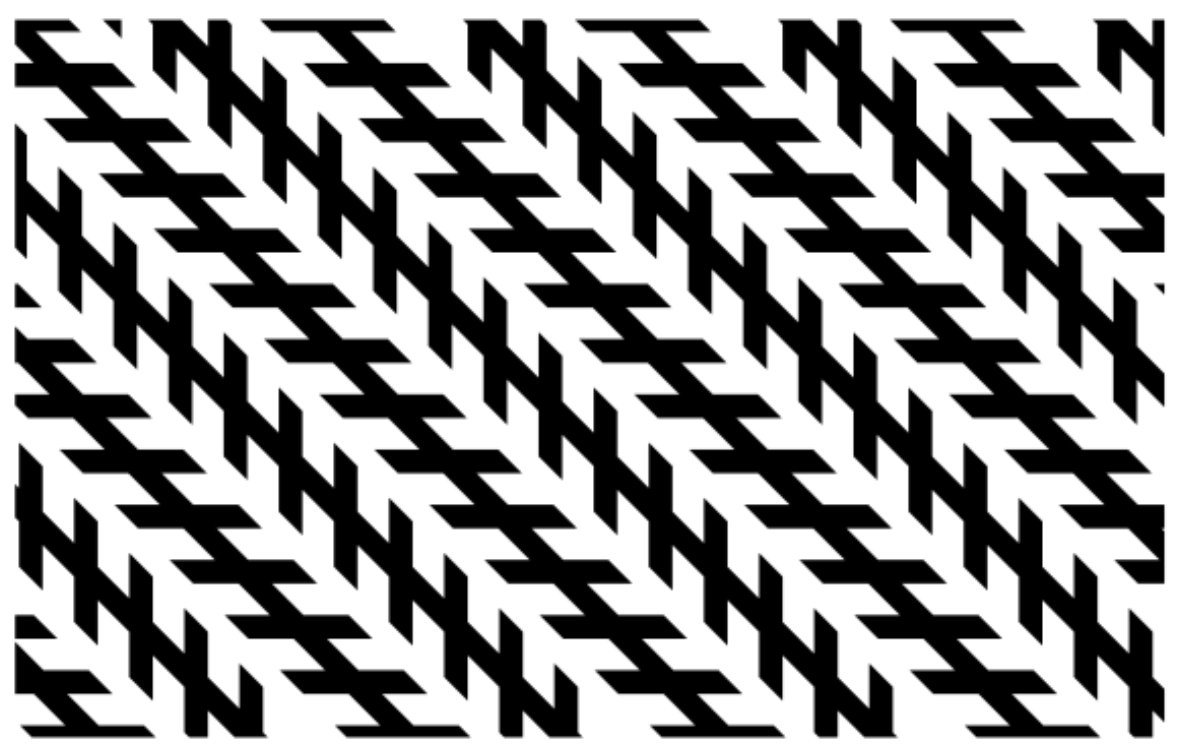

Figure 2.1. Zöllner Illusion. Reprinted from Zöllner Illusion, In Wikipedia. Retrieved August 9, 2017, from https://en.wikipedia.org/wiki/Z\%C3\%B6llner illusion. 2007 by Fibonacci. Reprinted with Permission. 


\section{CHAPTER 3. THE PRIMACY OF PERCEPTION}

From the moment we reflect on the relation between experience and knowledge we are caught in an antinomy - the antinomy which gives life to both rationalism and empiricism. On the one hand, it seems that our knowledge must be grounded in experience. If it were not, how would we distinguish the real from the imaginary? The law of non-contradiction shows some propositions to be false independently of experience, but it does not yet give us knowledge of the real; independently of experience, our beliefs are at best consistent, but not yet true. On the other hand, it seems that experience cannot ground our knowledge. Experience teaches us particular facts about the world: experience can teach us that "This swan is white,” but not that "All swans are white.” Moreover, experience is contingent. Even if experience could teach us “All swans are white,” there would be nothing necessary about this judgment. Consequently, experience cannot teach us a priori truths, e.g., “All shape has extension.” But we know (among other things) truths which are universal and necessary, for example, that all shape has extension. What experience, delivering a contingent particular, could teach us such a truth?

There is, consequently, an antinomy about experience and a priori knowledge. Universal, and especially a priori, knowledge - that is, universal knowledge that holds with necessity, e.g., “All shape has extension,” but not “All swans are white” - cannot be founded on experience. On the other hand, a priori knowledge must be founded on experience. Broadly speaking, the former is a rationalist point and the latter an empiricist point. If there is truth in this antinomy, then we cannot see how we have a priori knowledge at all.

In this chapter, I seek to resolve this antinomy by describing the relation between experience and knowledge in terms of motivation. I argue, following Merleau-Ponty, that experience grounds knowledge in the mode of motivation. To reach the conclusion that experience grounds knowledge, I will have to meet two key challenges. First, the contingent is supposedly insufficient to ground the necessary. Second, to the extent that knowledge exceeds 
experience, knowledge of the real supposedly cannot be distinguished from the imaginary. I show how motivation can meet both challenges.

While my account is aimed at what I see as the basic historical motives of rationalism and empiricism, in the final sections of this chapter I will address how motivation can be used to resolve contemporary rationalist and empiricist debates in philosophy and cognitive science.

\section{Rationalism and Empiricism}

First, I need to clarify what the rationalist and empiricist positions are. The debate between the two centers around two terms, which correspond to what Husserl would call meaning-intention and meaning-fulfillment, or what I have been calling meaning and evidence. The empiricist holds the propositions:

E1) All knowledge is definable in terms of experiential content.

E2) The evidence for all knowledge is ultimately (immediately or mediately) experiential. In contrast, the rationalist holds that experience is insufficient to license these propositions, and holds instead:

R1) There is some knowledge that could not have gotten its meaning from experience (i.e., not all knowledge is definable in terms of experiential content).

R2) There is some knowledge that, because it cannot be evidenced by experience, must be self-evident.

E1) is perhaps the core tenet of empiricism, already espoused by Locke in his Essay Concerning Human Understanding. There, Locke argues that there are no such things as innate ideas. All our ideas, instead, are received through experience, or more specifically, through sensation (experience of external objects) and reflection (inner sense). These two sources directly give us all our simple ideas (e.g. color, extension, succession). With respect to such simple ideas, we are passive; we do not choose whether and when we will receive them. On the basis of such simple ideas, we can construct complex ideas (e.g. duration, power, substance). Complex ideas are actively (voluntarily) made. They are produced, claims Locke, according to three operations 
which the mind can perform: combination, comparison, and abstraction. Such acts are performed on the simple ideas that the mind passively receives from experience. Simple ideas, then, are the material out of which all our ideas are constructed. Importantly, the operations of which the mind is capable cannot introduce any new content into our minds. Instead, they only combine, compare, or abstract from given contents. As Locke puts it, the mind cannot "have any idea which does not wholly consist of [simple ideas]” (2009, p. 340). When I say that the mind cannot introduce any new content, I mean just this: all our ideas wholly consist of simple ideas.

Hume formulated a version of the second empiricist proposition - that all evidence is ultimately experiential - when he claimed that we can hold no idea valid to which no impression corresponds. It emerges in another way in the verificationist attitude prevalent in early $20^{\text {th }}$ century analytic philosophy, namely that only empirically verifiable statements are cognitively meaningful. ${ }^{56}$ The common thread is the thought that experience is the ultimate touchstone of our propositions, establishing some as knowledge and others as false. Without experience, we would have no means of distinguishing between the real and the imaginary, and so no means of distinguishing between true and fictitious propositions. It is experience, then, that establishes the truth-value of our propositions, in the sense that it is a condition of statements having veridical import at all. In defining the second empiricist proposition in terms of evidence, I am admittedly giving the sense of "truth" here a phenomenological spin. In phenomenological terms, the empiricist position would be that all meaning-fulfillment is composed out of experiential meaning-fulfillments; what the first empiricist proposition said of meaning-intention, the second says of meaning-fulfillment.

The rationalist position denies both empiricist propositions. The first rationalist proposition denies that all knowledge can be defined in terms of experiential content. The

\footnotetext{
${ }^{56}$ Note that few empiricists, prior to Quine, are as rigorous about evidence as the principle E2 would demand. Most hold that there is some form of a priori justification, e.g., even Hume holds that we know "relations of ideas" independently of experience.
} 
rationalist holds that there is an incommensurability between our experience and our knowledge, such that our knowledge cannot simply be composed out of our experience. It is unclear, for example, how terms as diverse as "quark," "chiliagon," "modus ponens” could be defined in perceptual terms. One way to see this is in terms of the sorts of propositions experience is able to provide with intuitive content: I cannot perceive a chiliagon (all I see is “a many-sided figure”) nor a universal law. Experiential content might figure in the definitions of such intellectual items, but one cannot define the latter solely by operating on the former. The rationalist concludes that such meanings must be innate.

The second rationalist proposition denies that experience is the sort of thing that could serve as evidence for certain kinds of knowledge, in particular, a priori knowledge. A priori knowledge is universal and necessary, while experience is particular and contingent. As Leibniz puts it,

Although the senses are necessary for all our actual knowledge, they are not sufficient to provide it all, since they never give us anything but instances, that is particular or singular truths. But however many instances confirm a general truth, they do not suffice to establish its universal necessity; for it does not follow that what has happened will always happen in the same way. ... From this it appears that necessary truths, such as we find in pure mathematics and particularly in arithmetic and geometry, must have principles whose proof does not depend on instances, nor consequently on the testimony of the senses, even though without the senses it would never occur to us to think of them... (2000, p. xlviii).

At least some of our knowledge cannot be “established” by experience, because experience gives only instances, and instances do not suffice as reasons to hold any truth with necessity. Since some of our knowledge is necessary, it cannot be established by experience. Hume, of course, makes a similar point about our causal propositions. But whereas Hume concludes that propositions that cannot be licensed by experience are fictitious - the product of habit or sentiment - the rationalist concludes that a priori knowledge must be self-evident. Descartes, for example, holds that certain propositions are indubitable because they appear clearly by the natural light. 


\section{Arguments against Rationalism and Empiricism}

In this section, I argue against the rationalist and empiricist positions.

First, I endorse the rationalist argument against empiricism: perception and the intellect are incommensurable. Indeed, many intellectual structures are not transposable into perception, and conversely, there are many intellectual contents which are not definable in terms of perceptual contents. Take, for example, number. I cannot imagine a chiliagon, nor will I perceive a pile of 1,000 toothpicks as numbering 1,000. Yet, “1,000” has a meaning for me in virtue of the intellectual structure of natural number: its place in the count sequence relative to the other numbers, which distinguishes it from 999. Perception can distinguish between 800 and 1,000, but not between 999 and 1,000; the intellect can draw both distinctions, and to draw the latter, it relies on a sophisticated concept of number that perception does not possess. As I will argue later, it would be a profound underestimation of the difficulty of acquiring the concept " 1,000 " to think it could be defined simply in terms of operations on perceptual content. Again, perception does not yield the scientific description of time; perception presents us with distant simultaneity (gives us spatially separate events as occurring simultaneously), whereas on the scientific conception the simultaneity of distant events is relative to frames of reference. Thus, the intellect is capable of disclosing the world in ways which exceed our perception.

Further, the intellect has access to a genre of being which is non-perceptual: universals. I can perceive numerous instances of equality, but not equality itself. This is not to deny that perception has general structures. Indeed, a central aim of the present chapter is to describe how perceptual structures can be leveraged into the development of intellectual structures. But perceptual structures are ways of construing the concrete world of particulars we inhabit by our bodies; perceptual structures allow us to perceive particulars and so it remains true that one can think universals whereas one cannot perceive them. Moreover, universals are not definable in terms of operations performed on particulars. As Husserl pointed out, abstraction conflates a property as an individual moment and as a universal, for even when we remove every 
distinguishing feature of a particular instance of a property - even when we abstract the property from the particular to which it belongs - it yet remains a particular instance of the property (2001, p. 253).

In this way, perception and the intellect are incommensurable. Intellectual meanings cannot be defined solely in terms of perceptual meanings, and a fortiriori, neither do the latter suffice to evidence the former; where a meaning-intention is insufficient, a meaning-fulfillment will be so as well.

The case I want to make against rationalism is more complex. I intend to argue that even a priori knowledge must be founded on perceptual experience, in terms of evidence and meaning. ${ }^{57}$ I'll proceed in two steps. First, I explain Merleau-Ponty's argument that we have no absolute knowledge. Second, I explain Husserl’s argument that the evidence we have for our knowledge (intellectual evidence) is founded on experiential evidence.

The second rationalist proposition holds that our a priori knowledge, not being grounded in experience, must be self-evident. Merleau-Ponty contests this point by arguing that evidence (like perception) relies on a foreground/background structure, such that any proposition can only appear evident in virtue of a background set of beliefs that are not being raised to explicit awareness. I now consider Merleau-Ponty’s argument, from the “Cogito” chapter of Phenomenology of Perception, that we have no apodictic evidence.

\footnotetext{
${ }^{57}$ Merleau-Ponty at times writes as if he wishes to eliminate the distinction between the $a$ priori and the empirical altogether. For example, Merleau-Ponty writes that "From the moment in which experience - that is, the opening onto our factual world - is recognized as the beginning of knowledge, there is no longer any means of distinguishing between a level of a priori truths and a level of factual ones ...” (2012, p. 229). One might, on the basis of these claims, think I am mistaken in even thinking that there is such a thing as an a priori to be based on experience for Merleau-Ponty. Yet only a matter of lines after the previously cited passage, Merleau-Ponty claims that the diversity of the senses is an a priori truth, and on the next page distinguishes the a priori and the $a$ posteriori as follows: "The $a$ priori is the fact as understood, made explicit, and followed through into all of the consequences of its tacit logic; the a posteriori is the isolated and implicit fact” (2012, p. 230). As Hall points out (1979), Merleau-Ponty does not wish to eliminate the distinction between the a priori and the empirical, but to reconfigure the distinction, such that the two are not independent of each other but, so to speak, two sides of a coin.
} 
When Merleau-Ponty writes that no evidence is apodictic, he means that no evidence has necessity or indubitability. Husserl, for example, defined apodicticity as "absolute indubitability" or "the absolute unimaginableness (inconceivability) of [the state of affair's] non-being" (1999, pp. 15-6). There is an obvious sense in which no perceptual evidence is absolute or apodictic: in virtue of the perspectival nature of perception, we are never fully given the object of perception (any side seen implies a side unseen and there is always the possibility that upon further investigation we will discover that our apprehension of the perceptual object has been mistaken). ${ }^{58}$ Much more difficult to see is how it could be the case that no evidence, including intellectual evidence, is apodictic. How, for example, could the logical truth “A or not A" be other than apodictic?

In the "Cogito" chapter, Merleau-Ponty argues that there is no certainty that cannot be doubted, claiming that "certainty is doubt" (2012, p. 417). Merleau-Ponty does not, of course, mean that certainty and doubt are identical, only that they are two moments of a shared structure, the structure of evidence. The one cannot appear unless it contains a germ of the other, and consequently can never eliminate the other. ${ }^{59}$ Here is the argument in brief:

It is no accident that even evidentness can be thrown into doubt; it is because certainty is doubt, being the taking up of a tradition of thought that cannot condense itself into evident 'truth' without my renouncing the attempt to make it explicit. An evident truth is irresistible in fact and yet always open to doubt for the very same reasons: and these are two ways of saying the same thing: it is irresistible because I take for granted a certain acquisition from experience and a certain field of thought, and precisely for this reason it appears to me as evident for a certain thinking nature whose use I enjoy and that I carry forward, but that remains contingent and given to itself. The consistency of a perceived thing, of a geometrical relation, or of an idea is only obtained if I give up the attempt to make it explicit everywhere, and if I come to rest in it. From the moment I have entered the game, or engaged in a certain order of thought - whether it be, for example, Euclidean space or the conditions of existence for some society - I discover evident truths, but these are not irrevocable evident truths, since perhaps this space or this society are not the only possibilities (Merleau-Ponty, Phenomenology of Perception, 2012, p. 417).

\footnotetext{
${ }^{58}$ See Merleau-Ponty 2012, "The evidentness of perception is neither adequate thought nor apodictic evidentness" (p. lxxx).

${ }^{59}$ Note that Merleau-Ponty uses "absolute evidence" interchangably with "apodictic evidence," and in fact it is the former which appears in the "Cogito" chapter.
} 
This argument contains two main steps: 1) apodictic or absolute evidence is presuppositionless, and 2) we have no presuppositionless evidence. I'll treat these two steps in turn.

First, apodictic evidence is presuppositionless. According to Merleau-Ponty, the very presuppositions which make evidence possible also leave it open to doubt. It is only because, to some extent, I agree to take certain presuppositions for granted that I can experience evidence, for if all my presuppositions were constantly thrown into doubt then my ideas would lose their evidence. But to the extent that I do not throw my presuppositions into doubt, they remain contingent: they are only possible (perhaps among other possibilities), not yet necessary. These presuppositions, being contingent rather than necessary, leave evidence open to doubt. ${ }^{60}$ Euclidean geometry, for example, depends on a certain intuition of space, i.e., on a presupposition about space. One can only derive the theorem that the interior angles of a triangle are equal to two right angles through a construction presupposing a certain intuition of space. ${ }^{61}$ As long as this presupposition is not interrogated, the evidence for this theorem is irresistible; its evidence appears apodictic. However, when it is revealed that Euclidean space is "contingent," i.e., only one possible space, the theorem loses this apodictic evidence: it is true only for particular kinds of space. Merleau-Ponty’s point with this example is that we experience the evidence possessed by Euclidean geometry as certainty only to the extent that we agree to leave certain presuppositions

\footnotetext{
${ }^{60}$ One might object that propositions known analytically, i.e., in virtue of the principle of noncontradiction, are presuppositionless. Indeed, it is in terms of something like this principle that Husserl defined apodicticity above: we know something apodictically when its negation is inconceivable - Schmid has even argued that apodictic evidence is not given in "transcendental experience" for Husserl, but in "reflection," when one attains the insight that the supposition of the non-existence of a being in fact implies its existence (2001). But first, this argument would depend on knowing the principle of non-contradiction entirely without presupposition. And second, I think Merleau-Ponty would follow Husserl here in distinguishing between "consequence logic" and "truth logic" (Husserl, 1969), where the former is governed by the principle of non-contradiction, and the latter incorporates the experience of truth, i.e., evidence. We may be able to rule certain propositions out solely in virtue of their form, but we are not actually concerned with truth until we are concerned with evidence.

${ }^{61}$ See Kant's Critique of Pure Reason B 741-7 and Merleau-Ponty 2012 (pp. 403-8). For more on MerleauPonty's thinking about geometry, see Hass \& Hass (2000).
} 
out of the question (e.g., the parallel postulate) ${ }^{62}$ Because presuppositions are open to doubt, apodictic evidence (which cannot be open to doubt) must be presuppositionless.

Second, according to Merleau-Ponty, our experience of truth always depends on a body of presuppositions. Presuppositions are unthematized or implicit grounds. If grounds are thematized, they can be either affirmed or denied on the basis of justification, i.e., they can be treated as reasons. But, as I argued in chapter 1, as long as grounds are unthematized, they can't properly count as reasons, but only as motives. This is not that our knowledge cannot at all be grounded in reasons, only that it can never be fully grounded in reasons. Merleau-Ponty's claim, then, is that all of our truths are at least partially grounded not in virtue of reason, but in virtue of motivation. As Merleau-Ponty puts it, "There are truths just as there are perceptions: not that we could ever fully lay out before ourselves the reasons for any affirmation - there are only motives ...” (2012, p. 415). Evidence is motivated, in part by our experiences, by our past, etc.. And these unthematized motives are the "situation" within which we experience evidence. Evidence is thus not free-floating, but depends on a situation (a past and a present) which motivates it. MerleauPonty writes, "We possess a truth, this experience of truth would only be absolute knowledge if we could thematize all of its motives, that is, if we ceased being situated" (2012, p. 416). This situation names the set of presuppositions on which our truths or evidence depend: when I perceive or when I have evidence, my past evidences contract into a background against which the new evidence can appear. ${ }^{63}$

\footnotetext{
${ }^{62}$ Analyses like this of Euclidean geometry are problematic. It is not clear that Euclidean geometry does not in fact do the best job of modelling real space. Specifically, it remains in question whether general relativity - the classical evidence that Euclidean geometry is contingent - requires that space be nonEuclidean. The central point I wish to preserve of Merleau-Ponty's, however, is that this is a question that cannot be answered simply by appeal to an a priori intuition of space, and must be settled by empirically. ${ }^{63}$ Evidence, in this respect, partakes of the same structure that Heidegger attributes to "guilt" in Being and Time §58. According to Heidegger, Dasein is a "null-ground," insofar as it both grounds itself qua project, and does not ground itself qua thrown. Dasein "is never existent before its ground but only from it and as it. Thus being the ground means never to gain power over one's ownmost being from the ground up.... Being a self, Dasein, as self, is the thrown being. Not through itself, but released to itself from the ground in order to be as the ground. Dasein is not itself the ground of its being, because the ground first arises from its own project, but as a self, it is the being of its ground. The ground is always a ground only for a being whose being has to take over being-the-ground” (Heidegger, 2010, p. 273). Just as practically we are concerned
} 
In other words, there is no immaculate evidence. Evidence is always situated. ${ }^{64}$ If, for example, I have an inferiority complex, then an endeavor that to a normal subject would read as a success may look to me like a failure. If I am religious, an experience that would otherwise read as a coincidence may look like a sign. Similarly, a wine connoisseur will be able to evidentiate propositions about wine that I cannot. The point is not just that we interpret our experience, but that experience evidentiates judgments only through the mediation of a motivational situation or context. At the most basic level, experience can only evidentiate judgments for me because I have a primordial faith in the contact of perceptual experience with a world: if I were through some derangement to become convinced that perception was necessarily illusory, then it would bear no evidential weight.

According to Merleau-Ponty, the fact that all our judgments depend on presuppositions is not merely a matter of practical limitations - that judgments are at times, excusably, made hastily. Instead, it is an essential necessity that judgment rest on certain presuppositions: if anything is to appear certain to me, it will do so because I "give up the attempt to make it explicit everywhere” and "come to rest in it." The structure of certainty is that whatever appears to me as certain does so against a background of uninterrogated beliefs. Wittgenstein makes a similar argument in On Certainty when he writes that if I wish to test a conviction, I can only do so by putting certain

with grounding our existence through our projects, so theoretically we are concerned to ground our knowledge through evidence. But, as we are thrown into our existence, so we are thrown into an evidential situation within which we have to ground our knowledge in truth. This is what the word presupposition signifies here: that we do not ground our knowledge before this evidential situation, but only "from it and as it". Within such an evidential situation we are responsible for transforming this situation, to the extent that we are concerned with truth (in the practical context, insofar as we "understand the summons" of the "call of conscience"). Descartes' project in the Meditations is possible because we are in this manner "thrown" into an evidential context. Only because we are thrown into a body of presuppositions do we need "once in life" to attempt a radical grounding of our knowledge. In this regard, Descartes' project is a sort of theoretical "wanting-to-be-a-conscience," albeit in the deficient mode of forgetting its finitude.

${ }^{64}$ The situation is analogous with respect to practical motivation: Sartre, in his analysis of Clovis' conversion, points out that there is no such thing as a motive in itself, but only a motive with respect to an end. One might say that Clovis is motivated to convert to Catholicism by the power of the episcopate in Gaul, but as Sartre points out "In order for the power of the episcopate to be revealed to Clovis as the cause of his conversion ... it is necessary first for him to posit as an end the conquest of Gaul” (1984, p. 575). Similarly, in order for a situation to be revealed as evidencing some judgment, an evidential context must first be in place. 
other convictions out of question, e.g., I must trust the apparatus by which I perform the experiment or the subject on which I experiment (Wittgenstein, 1972, p. 43). As Wittgenstein puts it, "If I want the door to turn, the hinges must stay put" (1972, p. 44). In other words, if some belief of mine is to change, then some other must remain the same. For example, I walk along the shore and discover what I thought was a row of birches is in fact a shipwreck. This change in convictions presupposes my belief that I am seeing the world as it is, that I am not possessed by a hallucination in which a row of birches can transform themselves into a shipwreck. If it was the latter, I would not say, “It was always a shipwreck, a fact to which I was blind,” but "By some magic, the birches have become a shipwreck.” My belief in the world is the hinge upon which turns the belief about what it is that I see. Every judgment, then, demands that something hold fast, and for this reason Wittgenstein concludes that “justification comes to an end” (1972, p. 27). Importantly, for Merleau-Ponty, the situatedness of all evidence is, in part, a historical situatedness. ${ }^{65}$ Ideas are given within a temporal horizon, i.e., there is a temporality of ideas. ${ }^{66}$

On the one hand, every present evidence depends on a horizon of past evidences. In Husserl's terms, evidence is sedimented: any actively constituted meaning becomes passively retained as a lasting acquisition, which then serves as a basis for future acquisitions. This is true even in cases of explicit reasoning. If I deduce the truth of some conclusion, $A$, then $A$ is available as a premise for us in drawing some further conclusion, $B$ : it has become an acquisition, the grounds for the truth of which I don't need to be attending to at the moment I am deriving the truth of $B$ (though if $B$ is to be rigorously grounded, I do need to be able to reactivate the grounds

\footnotetext{
${ }^{65}$ Dillon sees the a priori in Merleau-Ponty as "an historically emergent sense of the whole," grounded not in the structures of the mind, but in the phenomenal world (Dillon, Apriority in Kant and Merleau-Ponty, 1987, p. 420). Dillon emphasizes, however, that "the priority of the a priori is an historical priority" (1987, p. 418). But it seems to me important that we understand the historical situatedness of the a priori correctly, for it must not rule out that there are certain trans-historical structures of experience, e.g., historicality itself, as well as "figure and background," "thing and non-thing" and the horizon of the past (MerleauPonty, 2012, p. 24). On my reading, our apprehension of these structures will be historically situated, but this itself does not determine their historicality.

${ }^{66}$ As I stated in my Introduction, I am interested in the epistemological and not the ontological dimension of this claim.
} 
for A). Millikan, for example, can make use of Stoke’s law in the oil drop experiment without needing to verify it himself (though he is able to do so). The change of an electron thereby derived is afterwards an acquisition that can be used to derive many further results. In a process of sedimentation, then, a chain of evidences is built up between propositions, in which the evidence of the higher ultimately depends on the evidence of the lower, without the higher needing to be reactivated all the way down to the most fundamental levels in order to be used for further acquisitions. Here, the self-evidence actively being obtained in drawing new conclusions relies on a passively retained chain of evidence.

In this vein, Merleau-Ponty writes that tradition is the power to forget origins (1973, p. 68). In the context in which we are now working, the idea is that any active evidence, any evidence that I am explicitly attending to, relies upon a set of passively retained evidences that make it possible and that it covers over as a condition of appearing at all. I cannot hold a whole chain of evidence in mind as I draw the final conclusion, I can only retain each step as a background that enables a foreground conclusion. Of course, I must in principle be able to retrace my steps if the conclusion is to be rigorously grounded. But the point is that at the moment I draw the conclusion, each step must retreat into the background of my thinking. In this sense, then, it is a necessity that each present evidence relies on certain acquisitions made in the past, which it need not reactivate and cannot be reactivating at the moment it appears evident. Thus, there is a time of ideas as well.

On the other hand, every present evidence has a horizon of future evidences. Every present evidence is open to becoming the sedimented history in virtue of which future evidences will be able to appear. This future horizon is also apparent in the fact that present evidences are intrinsically open to alteration or cancellation in the future. This was the import of MerleauPonty's claim that certainty is doubt. We saw that Euclidean geometry, for example, depends on a contingent description of space, and so is revealed to be a situated truth: 
... Euclidean geometry is one day revealed as evident merely for a certain historical period of the human spirit; it merely signifies that men were able, for a time, to take a homogenous three-dimensional space as the 'ground' of their thoughts and to adopt unreflectively what generalized space will later consider to be a contingent description of space (Merleau-Ponty, 2012, p. 414).

Thus, just as there is a past-horizon of ideas, there is also a future-horizon, in which ideas are open to being utilized, to augmentation, but also to being subsumed within a more comprehensive truth. ${ }^{67}$ Thus, our ideas, as historically situated, passively depend on a set of presuppositions.

Let this suffice for an argument for the position that all our evidence depends on presuppositions. Given these two steps - that apodictic evidence is presuppositionless and that our evidence is never presuppositionless - Merleau-Ponty is licensed to conclude that evidence is never apodictic. Still, this by itself does not provide me with the conclusion I intend to reach, that all knowledge depends on experience. For one might think that some knowledge is justified independently of experience but is not therefore infallible. This, for example, is how Bonjour has defined his “moderate rationalism.” To reach this further conclusion, I turn to Husserl's argument that the evidence for all knowledge, including a priori knowledge, is founded in experience.

In Formal and Transcendental Logic, Husserl describes a hierarchy of evidence, running from prepredicative experience up to universal judgments. ${ }^{68}$ According to Husserl, experience has priority in terms of evidence to all other acts possessing truth value: "the truths and evidences that are first in themselves must be the individual ones" (1969, p. 205). Experience is the means

\footnotetext{
${ }^{67}$ This claim - that the evidence of our knowledge is given within a temporal horizon, in virtue of which our knowledge always possesses revisability - is admittedly one of the more contentious claims of this dissertation, for it seems to deny the obviousness of the most obvious beliefs. How, for example, could the law of non-contradiction be said to be open to revision? It might help to understand this claim by analogy to the revisability of our perceptions, for every perception too is in principle open to revision. And yet we typically reach a point in our perceptions in which, having attained a sufficient perceptual grasp on some object, we are satisfied with the perception. I am perceptually satisfied, for example, that my computer is resting on my desk. It would seem absurd in this case to tell me, "Well, but you can never be certain that your computer is resting on your desk." Nevertheless, here too, the perception is intrinsically open to the possibility of revision in light of new evidence, however unlikely such a revision may be. In terms of knowledge, my point should best be understood to be that certainty and doubt are moments of a whole, rather than that our knowledge is dubious, for I am not saying that our grasp of the world in knowledge, such as the law of non-contradiction, is dissatisfactory, only that it is in principle open to revision.

${ }^{68}$ A similar case is made in the Logical Investigations, when Husserl argues that categorial intuition is founded on sensuous intuition.
} 
by which individuals are given directly. ${ }^{69}$ On the basis of experience one can form an "individual" or "experiential" judgment (e.g., on the basis of my experience of the apple, I can form the judgment "the apple is red"), which as the sort of judgment most immediately related to experience, is the sort of judgment with the most original evidence. Empirical judgments obviously refer to experience, as both that which gives the "elementary cores" (the matters, the subject and the predicate) for judgment and as what gives the "data" that "give norms for the correctness of categorical judicial meanings at the lowest level concerning individuals" (Husserl, 1969, p. 209). Thus, the first step in the theory of evident judgments is "the genetical tracing of predicative evidences back to the non-predicative evidence called experience" (Ibid.). Universal judgments too are to be related back to experiences of individuals - though mediately rather than immediately - even though they do not contain individuals as parts (as individual judgments do). This works somewhat differently in the case of material and formal universal judgments. Material universal judgments draw content from experience, and so demand a return to intuitions of individuals (not any individuals in particular, only to some exemplar) (Husserl, 1969, pp. 212-3). Formal universal judgments (e.g., the principles of logic) need only some examples of categorialia (any sorts of logically structured judgments), and thus don't depend on any experiential content. Still, they refer to individual experiences for their "formal-ontological validity," i.e., for their applicability to "everything conceivably existing" (Husserl, 1969, p. 214). Thus, every conceivable judgment has relation back to individual objects, and we can speak of a reduction of all truths to the truth of experience (Husserl, 1969, p. 204). In this sense, Husserl writes, "In respect of its being, reality has precedence to every irreality whatsoever, since all irrealities relate back essentially to an actual or possible reality" (1969, pp. 168-9).

\footnotetext{
69 "Individuals are given by experience, experience in the first and most pregnant sense, which is defined as a direct relation to something individual" (Husserl, 1969, p. 206) and, "Experience is an evident seizing upon and having of either an immanent or a real individual Datum itself' (Husserl, 1969, p. 156).
} 
These conclusions might be formulated into an argument as follows. Intellectual meanings are expressed in judgments. Judgments can either be empirical (about particular objects of experience) or universal (about universal objects which cannot be directly experienced). Universal judgments can be material (i.e., have experiential content) or formal (have no experiential content). We can show that each of these three types of judgment - empirical, material universal, or formal universal - has its evidence in virtue of perception.

1. Individual Judgments

There is an obvious sense in which individual judgments, or judgments of experience, depend upon experience for their evidence. Such judgments include empirical particulars within themselves, and so one can't fulfill the judgment without fulfilling an intention of the individual. Since the mode of dependence between individual judgments and experience was the concern of chapter 2, I'll assume this point is familiar. However, as we have seen, general judgments do not contain individuals. So how is it that they refer to experience for their evidence?

\section{Material Universal Judgments}

Material universals are universals that include some material content, i.e., content garnered from experience, e.g., "Every sound has tone." Such universals rely on experience for their evidence. Husserl writes: "Every A Priori with a material content ... demands a return to intuition of individual examples - that is: to 'possible' experience - if criticism is to bring about genuine evidence" (1969, p. 213).

For example, take the proposition, "Every sound has a tone." This proposition is universal and necessary (it is an a priori truth), but material insofar as it has sensuous content (it refers to sound, which is not a logical category). ${ }^{70}$ At the same time, such a proposition can only be fulfilled through experience - without the possibility of sonorous experience, the proposition would be a set of empty significations. Obviously, no particular experience can establish the

\footnotetext{
${ }^{70}$ For this distinction between formal and material a priori, see e.g., Husserl 1969 (p. 29).
} 
necessity of this proposition. But it is not the individual per se that fulfills the judgment. The individual as an exemplar fulfills it. If I grasp the noise penetrating my apartment from the road, I can freely vary its tone or pitch in my imagination. However, I cannot imagine it as a sound that has no tone. Such a sound would not sound - it would be no sound. On the basis of this individual as exemplar then, I fulfill the judgment that "Every sound has a tone."

\section{Formal Universal Judgments}

Formal universals, such as the laws of logic, don't include any material content. Instead, they have purely categorial content. It might seem, then, that there is no clear sense in which such universals would demand supplementation by experience in order to have evidence: whereas material universals must ultimately be fulfilled through experience, formal universals can be fulfilled through any example of categorialia. But, as we have seen, Husserl argues that all categorialia (all judgments) are themselves fulfilled on the basis of experience. Thus, formal universals are mediately founded upon experienced individuals - insofar as they are founded on categorialia, which are founded on experience. Husserl writes,

The sense-relation of all categorial meanings to something individual, that is, on the noetic side, to evidences of individuals, to experiences, - a relation growing out of their sense-genesis and present in every example that could be used by formal analytics - surely cannot be insignificant for the sense and the possible evidence of the laws of analytics, including the highest ones, the principles of logic. Otherwise, how could those laws claim formal-ontological validity: united with their validity for every possible predicative truth, validity for everything conceivably existing? This conceivability surely signifies a possibility of evidence, which leads back ultimately, even though with formal universality, to a possible individual something or other and, correlatively, to a possible experience (1969, p. 214).

To test this point, let us try to think what it would be like to judge without having any experience. Suppose we were, by whatever means, familiar with all the significations we currently possess, but simply lacked all sensuous intuition or experience. What would our judgments be to us then? First, there would be no means by which to distinguish true from false individual judgments. Without experience, I could well judge "The apple is green," and I could just as well judge, "The apple is red," but neither of these judgments could I fulfill or thereby determine as true. My 
judgments would be constrained by the law of non-contradiction, but they would not thereby possess truth. Second, in the case of material universals, there would be no criterion by which to distinguish judgments with purely imaginative content from those with experiential content, i.e., one could not distinguish possible judgments from true ones. One can, for example, make as consistent universal judgments about unicorns as about horses. The mark that makes judgments about the latter have truth value is the possibility of experience.

What about in the case of a priori truths? Because such laws have necessity, they can be based on imaginative particulars as well as perceived particulars. For example, I can verify modus ponens for myself as easily in an imagined case as in an experienced case. So how is experience integral to the evidence of a priori universals? Faced with a parallel problem about the perception of universal ideas (as opposed to universal judgments, which I am considering) in Logical Investigations, Husserl distinguishes between assertive and merely contemplative universals (2001, pp. 293-4). If we intend a universal purely contemplatively, we suspend interest in its "'being' or 'non-being"' and consider only its "'possibility or impossibility" (Ibid., 294). In contrast, if we intend a universal assertively, we are concerned with its being or non-being, and in this we depend on a reference to the universal being "confirmed or refuted by adequate future perception" (Ibid., 293). In other words, if we are concerned not merely with a universal's possibility, but with its truth, then we are referring not just to imagination, but to experience. A universal is confirmed,

Whenever the universal meaning is fulfilled by an adequate percept, i.e., by a new consciousness of the universal which constitutes itself on the basis of a 'true' abstraction form the corresponding individual percept. The universal object is then not merely presented and posited, but is itself given to us (Ibid., 294).

Similarly, in the case of judgments we can distinguish between contemplative and assertive judgments. If we mean judgments assertively, if we affirm their truth, then we must be referring not merely to the imagination, but to experience, as the basis on which such judgments can be 
fulfilled. On the basis of imagination we can at most assert the possibility of such judgments, so that without experience we could not assert their actual truth.

Perhaps the best way to see this is to imagine a case in which the problem is not that we have no experience, but that we have an experience that disconfirms a universal judgment. For example, there is a well-known debate between realism and operationalism as to quantum logic and its divergence from classical logic, with regard to the distributive property of disjunctions. ${ }^{71}$ If the laws of classical logic were self-evident independently of experience, then no empirically derived results could put these laws into question - the debate would have no good sense. But it is no good to dismiss the debate as unreasonable on the grounds that the laws of logic cannot be drawn into question by experience, for this is merely begging the question. To be sure, I don't assert the realist position in this debate (that the laws of classical logic are violated by quantum mechanics). I assert only that the question here cannot be dismissed a priori, and so the evidence of the laws of classical logic is in fact not entirely independent of experience. My point is that the question can only be resolved by a correct interpretation of empirical results: to say whether these laws do not apply in the case of quantum mechanics, we have to wait for a certain kind of experience. This is why the mere fact that there is a question here for us tells us everything we need to know. This is one way of making the point that formal universal judgments depend upon experience for their validity with regard to beings: only empirical evidence can finally determine whether formal universal judgments are valid of the objects of experience. Thus, if we find a kind of experience that really does seem to throw formal judgments into question, we do not dismiss this experience outright, as we would have to if laws were a priori evident. Instead, we - with a certain reserve and due circumspection - listen to experience.

I conclude that both rationalism and empiricism are untenable. The rationalist is right that there is incommensurability between knowledge and perception. But the empiricist is right that

${ }^{71}$ See Putnam (1968) for an incipient text in this debate. 
our knowledge is not self-grounding and must be grounded in experience. Only experience can ground knowledge, and yet experience cannot ground knowledge. This is the antinomy at the heart of the genesis of knowledge.

\section{Motivation as a Ground of Knowledge}

I have claimed that Merleau-Ponty understands the relation between perception and knowledge in terms of motivation and that if we follow Merleau-Ponty in this regard, we will be able to resolve the antinomy that undergirds rationalism and empiricism. In this section, I explain why this is so.

Merleau-Ponty's approach to the relation between perception and knowledge might be best described under the heading: "the primacy of perception.” Perception has "primacy” in relation to knowledge, insofar as knowledge is founded on perception. Merleau-Ponty writes, for example, that "the certainty of ideas is not the foundation of the certainty of perception but is, rather, based on it” (1964, p. 13). The concept of foundation invoked to describe this relation is technical phenomenological term. Husserl defines foundation, Fundierung, as follows:

If a law of essence means that an $A$ cannot as such exist except in a more comprehensive unity which connects it with an $\mathrm{M}$, we say that an $A$ as such requires foundation by an $M$ or also that an $A$ as such requires to be supplemented by an $M$ (2001, p. 25).

To say that knowledge is founded on perception means, in this sense, that knowledge is a dependent moment, i.e., that it is not self-subsisting, but instead if there is knowledge, then there is also perception. Merleau-Ponty clearly relies on this definition, but gives the term a more narrow sense when he defines a Fundierung relationship as one in which

The founding term ... is primary in the sense that the founded term is presented as a determination or a making explicit of the founding term, which prevents the founded term from every fully absorbing the founding term; and yet ... the founded is not merely derived from [the founding], since it is only through the founded that the founding appears (Merleau-Ponty, 2012, p. 414).

The founding terms has primacy insofar as it is that which the founded determines and explicates. And yet, conversely, the founded is not reducible to the founding, since it is the founded that 
makes the founding appear explicitly and determinately. We can understand the primacy of perception, then, to mean that knowledge is dependent on perception insofar as knowledge is an explication and determination of perceptual experience. At the same time, the primacy of perception entails that knowledge is not reducible to perception, because it affects perception with a standard of determinacy that perception alone could not attain. And, indeed, this is precisely how Merleau-Ponty defines the relation between perception and knowledge:

The perceived object ... has a two-fold relation to what is understood. On the one hand, it is only the sketch or fragment of meaning which calls for a repetition [in the understanding] that fixes the perceived object and finally makes it exist. On the other, the perceived object is the prototype of meaning and alone accomplishes the actual truth of what is understood (Merleau-Ponty, 1973, p. 106).

Knowledge is founded on perception, because knowledge is just an explication and determination of perceptual meanings. But as an explication and determination of perception, knowledge is not reducible to perception, which ultimately offers a merely fragmentary meaning. Consequently, Merleau-Ponty can define the thesis of the primacy of perception as follows:

In speaking of the primacy of perception, have never, of course, meant to say (this would be a return to the theses of empiricism) that science, reflection, and philosophy are only transformed sensations or that values are deferred and calculated pleasures. By these words, the 'primacy of perception,' we mean that the experience of perception is our presence at the moment when things, truths, values are constituted for us; that perception is a nascent logos; that it teaches us, outside all dogmatism, the true conditions of objectivity itself; that it summons us to the tasks of knowledge and action. It is not a question of reducing human knowledge to sensation, but of assisting at the birth of this knowledge, to make it as sensible as the sensible, to recover the consciousness of rationality. This experience of rationality is lost when we take it for granted as self-evident ... (1964, p. 25)

The thesis of the primacy of perception, then, carves out a space between rationalism and empiricism. It is not an empiricist thesis, because it holds that knowledge transcends perception, or in other words, that intellectual meanings and evidence ${ }^{72}$ are not reducible to (definable in

\footnotetext{
${ }^{72}$ Merleau-Ponty writes, "We are not reducing mathematical evidence to perceptual evidence. We are certainly not denying, as will be seen, the originality of the order of knowledge vis-a-vis the perceptual order. We are trying only to loose the intentional web which ties them to one another, to rediscover the
} 
terms of) perceptual meanings and evidences. ${ }^{73}$ On the other hand, it is not a rationalist thesis, because it denies self-evidence to reason and seeks to describe instead how the "natural light" of reason comes to birth within the perceptual field. ${ }^{74}$ As Merleau-Ponty puts it, "The perceived world is the always presupposed foundation of all rationality, all value and all existence. This thesis does not destroy either rationality or the absolute. It only tries to bring them down to earth" (1964, p. 13). ${ }^{75}$

It seems to me that it is only possible to get this thesis of the primacy of perception properly into view in virtue of Merleau-Ponty's concept of motivation. Perception is supposed to found knowledge, but it cannot cause our knowledge, for the content of knowledge transcends the content of perception. Further, as the rationalist shows, perception does not suffice as a reason for knowledge. Consequently, we can only understand the sort of grounding with which perception furnishes knowledge in terms of motivation.

It must be noted that reading Merleau-Ponty's thesis of the primacy of perception in terms of motivation is not standard. Merleau-Ponty does little to connect these two concepts, and a central innovation of this dissertation is to use the later concept to clarify the former. Nevertheless, Merleau-Ponty’s descriptions of the relation between perception and knowledge support my reading of it. Consider the following two quotes:

1) 'We call this level of experience [namely, perception] 'primordial' - not to assert that everything else derives from it by transformations and evolution (we have expressly said that man perceives in a way different from any animal) but rather that it reveals to us the

paths of the sublimation which preserves and transforms the perceived world into the spoken world" (1973, pp. 123-4). Or, he writes that intelligible being "has its own evidence" (2010, p. 12).

${ }^{73}$ Rockmore seems to me decisively to misunderstand this point in classifying Merleau-Ponty's account of the primacy of perception as "a nonstandard form of the empiricist claim familiar in Kant's view that knowledge of any kind begins in experience" (Rockmore, 2011, p. 202). Of course, Merleau-Ponty does think that knowledge begins with experience. But he thinks this "beginning" in a way radically different than the empiricist - who entirely misses the transcendence involved in the transition to knowledge - and the rationalist - who, like Kant, thinks that experience is a merely occasioning cause of our knowledge. But I have argued that knowledge cannot be reduced to experience, in the manner to empiricist intends, or separated from experience, in the manner the rationalist intends.

74 "The perceived object is the prototype of meaning and alone accomplishes the actual truth of what is understood" (Merleau-Ponty, 1973, p. 106).

${ }^{75}$ Or again, "There is thus no destruction of the absolute or of rationality here, only of the absolute and the rationality separated from existence" (Merleau-Ponty, 1964, p. 27). 
permanent data of the problem which culture attempts to resolve” (Merleau-Ponty, 1964, p. 25).

2) As we saw above, Merleau-Ponty writes that the perceived object is a "sketch or fragment of meaning which calls for a repetition [in the understanding] that fixes the perceived object and finally makes it exist” (Merleau-Ponty, 1973, p. 106).

Perception poses the "problem" to which knowledge responds; it calls for knowledge. This is the language of solicitation, which I described in chapter 1 as a kind of motivation. So, it seems to me that my reading has initial plausibility on this basis. My primary support for this reading, though, will derive from how well it will be shown to describe the primacy of perception in what follows.

What does it mean to say that perception motivates knowledge? Following the features of motivation laid out in chapter 1 , it means that the relation is between two meanings, need not be explicit, is spontaneous, is internal and reciprocal, and tends to equilibrium. Further, perception does not ground knowledge with necessity and yet our knowledge is normed by perception. Finally, it means that knowledge transcends perception. I’ll emphasize a few points here.

First, the fact that the relation is internal means that the two are inseparable. The former cannot serve as a mere occasion for the latter, because the latter owes its meaning (and not just its existence) to the former - motivation is a Fundierung relation. This does not mean that the latter can only exist as long as the former exists, only that the latter would not have the meaning it does if the former had never been apprehended. Conversely, this means that we shouldn’t expect perception to be strictly unaltered by knowledge. The way we perceive (perceptual meanings) will presumably be at least partially altered by our knowledge. For example, the acquisition of natural number augments our capacity to perceive number.

Second, the move from perception to knowledge aims to achieve a higher degree of stability or equilibrium in a system by explicating and determining that system. Much as in Plato's description of thought summoners, perception is unstable: it lacks the resources to resolve the contradictions it engenders. Such contradictions must be resolved by transitioning to a higher level, i.e., the more determinate system of structures that knowledge provides. For example, 
children tend to have an undifferentiated concept of air and nothing: they fail to distinguish between the two (Carey, 2009, pp. 403-4). This is because air “looks" empty - perception tends not to discriminate between the two. Nothing is stranger to the child than to imagine air as full, as suddenly becoming itself visible, for how then could one see? The child imagines one would be immersed in an impenetrable cloud and, further, traversing space would present the same difficulty as traversing water. But this undifferentiated concept of air/nothing results in contradictions with the other beliefs that children hold, e.g., that they can feel air move across their skin (wind) and fill or empty their lungs (breath), and that one cannot breathe in space, where there is in fact nothing. The child is led to these difficulties because she draws a strict distinction between the "full” (substance) and the "empty" (nothing). The child's education must teach her that this distinction does not hold: in fact, "full” solids and "empty" air are both states of matter; in fact, neither is full or empty, for both are different arrangements of particles moving in the void. This resolves the contradictions the child's beliefs faced: if air is not nothing, then it makes sense that it moves and that one cannot breathe in space. This contradiction is only resolved by transitioning to a new level, one which describes air in a manner that perception did not. Knowledge resolves the contradiction present in perception by transition to a new and more determinate level (a conceptual or structural system that can distinguish between air and nothing), which results in a greater degree of stability.

Third, motivation makes use of the best points of both rationalism and empiricism. Motivation accommodates the rationalist point that there is incommensurability between experience and knowledge, because motivata transcend their motives in the sense that the former is not definable in terms of the latter. As Merleau-Ponty puts it, in the transition to knowledge:

We are dealing with transcendence and not a static identity, and here ... truth is not an adequation but anticipation, repetition, and slippage of meaning. Truth allows itself to be reached only through a sort of distance. The thing thought is not the thing perceived. Knowledge is not perception ... (1973, pp. 128-9). ${ }^{76}$

\footnotetext{
${ }^{76}$ It seems to me that Low's conception of an "empirical a priori” to be found in Merleau-Ponty is mistaken on this point, since it takes the a priori as something “directly drawn from experience” (Low, 2013, p. 281).
} 
But it also accommodates the empiricist point that knowledge is grounded in experience (Merleau-Ponty's thesis of the primacy of perception) because it holds that motivation is normative. Thus, on my account, perception norms the very knowledge that transcends it.

Fourth, motivation can make use of the best points of rationalist and empiricism because it doesn't think of the relation between experience and knowledge in terms of causality and reason. In other words, I am arguing that perception neither causes nor justifies knowledge. Experience can’t cause knowledge, because even if we assume that experience affects us causally, it can at most cause particulars to enter our awareness, not universals. Similarly, Benaceraff has argued that experience can only cause knowledge of concrete objects, but universals (specifically, mathematical entities) are abstract, and so mathematical entities cannot be causally produced in us (Benacerraf, 1983). But because Benaceraff believes that the only justification for beliefs is causal production of them in us, he holds that beliefs about such objects are unjustified. But neither does experience justify our knowledge, for our knowledge is richer than what experience can justify. Further, if the very rules of reasoning are founded in perception, then perception cannot primarily be related to our knowledge in the mode of reason (more on this point later).

Finally, motivation encounters profound challenges from both rationalism and empiricism. The empiricist holds that any idea of which we have no impression is indistinguishable from fiction. But we have no perceptual impression of much of our knowledge, because knowledge transcends perception. On the other hand, the rationalist holds that perceptual experience is insufficient to ground a priori knowledge. But motivation holds that perceptual

Low conceives this direct drawing as follows: "A certain aspect of experience is given so routinely and regularly (all perception is spatial, for example) that it deserves to be called an empirical $a$ priori; it deserves to be called a transcendental condition, a condition in whose absence experience simply would not take place" (Ibid.). But I have argued that Merleau-Ponty does not conceive of the $a$ priori as something given in experience, but rather as transcending experience. As I will argue in what follows, the spatial character of perception is not directly given in experience, but an accomplishment of synthesizing the sensory modalities of space. 
experience norms, i.e., grounds, a priori knowledge. If my account is going to work, it needs to address these two challenges. I will now contest the two claims at the core of these challenges, by arguing that a) the contingent can ground the necessary and b) knowledge can transcend its ground without being indistinguishable from fiction.

\section{A. The Contingent Can Ground the Necessary}

Rationalists argue that perceptual experience cannot ground knowledge, because perceptual experience is contingent whereas knowledge is necessary; there is an ontological difference between the content of experience and the content of knowledge that makes the former unsuitable to ground the latter. I argue that motivation allows us to make a seemingly contradictory claim: the contingent can ground the necessary.

The rationalist objection, as I put it, harbors an ambiguity. On the one hand, necessary knowledge can mean knowledge of a proposition which is to hold necessarily. On the other hand, necessary knowledge means knowledge that is known with necessity. In the first case, the necessity is a quality of the intended proposition (the known). In the second, it is a quality of the knowledge itself. Leibniz is right that no perceptual evidence, being contingent, can serve as a sufficient reason to hold an intellectual evidence with necessity: a universal truth cannot be deduced from a fact. This distinction allows me to make two points.

First, Leibniz shows that perceptual evidence cannot establish necessary knowledge in the second sense. But I, following Merleau-Ponty, already argued that not only can perception not establish such knowledge, but we have no such knowledge, i.e., there is nothing that we do know with necessity or in his terms, with absolute evidence. Thus, the objection that perception does not allow us to know with necessity will get no traction with my line of thinking, because I hold that there is no such thing as absolute evidence.

Second, the fact that perception cannot establish knowledge with necessity does not mean that it cannot establish knowledge that is to hold with necessity: particular experiences can motivate knowledge which is intended as universal and necessary. For example, already my first 
encounter with a person engenders a sense of who they are: it carries me beyond this particular encounter and toward the person. My feeling for the person is already universal in the sense that it concerns not just the way the person acted in the particular encounter, but the person's style which will manifest itself in all their deeds. Of course, this feeling may be disconfirmed by future encounters, and in this sense was not universal at all. Yet it intended not the particular but the universal. At the same time, it is the particular, the first encounter, that keys us into the universal. The particular motivates a universal that cannot be deduced from it. Take instead the example of a scientific law. A scientific law is grounded in experiments, that is, in particular cases. From these particular cases, the scientific law cannot of course be deduced with necessity. Yet a necessary law is intended in the particular, and thus scientific laws can be knowledge necessary in the first sense but not the second.

In fact, both empiricism and rationalism misconstrue the relation between the perception of a particular fact and the intellection of a universal essence. Leibniz' argument for the insufficiency of experience to establish universal truths joins up with Hume’s critique of causality in sharing a false idea of induction. In "Phenomenology and the Sciences of Man,” MerleauPonty argues against an empiricist conception of induction as "a process by which, in considering a group of facts, we discover a common character and set it apart by abstraction” (1964, p. 68). We do not start from a set of isolated particulars and then abstract a common character which is already contained in each. Merleau-Ponty adduces as evidence against this conception of induction the process by which Galileo arrived at his conception of the fall of bodies. Galileo could not have proceeded by abstracting a common character found in the many experiences of falling bodies, because his conception starts from the pure case of a freely falling body, of which we have none in experience (every falling body that we experience is affected by factors such as wind resistance). Thus, "the conception of the fall of bodies which guides his experiment is not found in the facts. He forms it actively; he constructs it” (Ibid., 69). Having constructed the pure case of the freely falling body, Galileo can then explain the "confused facts" through the 
introduction of additional considerations (e.g., resistance). Galileo’s law is not contained in or derived from particular cases; it is creative, original. And yet it is only such cases that can serve to motivate Galileo's construction, through the meaning they make available and the problems they pose.

To put the argument in other terms, we do not derive a universal connection from a set of distinct particular connections, as follows:

$$
\begin{aligned}
& \mathrm{A}_{1} \rightarrow \mathrm{B}_{1} \\
& \mathrm{~A}_{2} \rightarrow \mathrm{B}_{2} \\
& \underline{\mathrm{A}_{3}} \underset{\longrightarrow}{\rightarrow B_{3}} \\
& \mathrm{~A} \rightarrow \mathrm{B}
\end{aligned}
$$

Instead, with the experience, " $A_{1} \rightarrow B_{1}$ " there may already be initiation into the insight " $A \rightarrow B$ ". Each further experience gives evidential weight to the universal. It's not that I build up the general out of particulars, but that the general is vaguely present with the first particular and each particular evidentiates it further. As Husserl puts it,

It is from this that Hume ought to have started, from self-evidence: the fact that in circumstances $U$, a $W$ appears, in and of itself already lends something like weight to the assertion 'In general, in circumstances $U, W$ appears'; and this weight increases with the number of cases experienced (1973, p. 394).

On this conception, the universal is neither caused (i.e., content is abstracted from a number of impressions) nor justified (i.e., is deduced from the particulars). It is instead evidenced in each particular experience. The knowledge of such a universal will not be necessary in the sense of being known with necessity, but such a universal is always evidenced precisely as necessary (is intended as necessary). This, as Husserl puts it in the same passage, is "the motivating power of experience” (Ibid.). In this manner, the concept of motivation allows us to accept the arguments against empiricism proposed by Hume and Leibniz without accepting their conclusions: Hume, holding that we have some ideas that cannot be caused by the world in perception, draws the skeptical conclusion that such ideas are mere fictions; Leibniz, holding that we have some 
knowledge that cannot be justified by perception, draws the rationalist conclusion that we have innate knowledge. Merleau-Ponty claims instead that perception motivates the intellect's grasp of it, and thus grounds beyond what it contains.

\section{B. Knowledge can transcend its ground without being mere fiction}

Hume formulated a version of the challenge here when he claimed that we can hold no idea valid of which we have no impression. Because we have no impression of many of our ideas - personal identity, substance, necessary connection (causality) - Hume concluded that these ideas are fictions, grounded in habit and sentiment. In other words, Hume concluded that because these ideas are not produced in us by causal impacts of the world on our senses, and no sufficient reason can be adduced for establishing them, they must be produced by the imagination. Hume thus reaches a skeptical position regarding these ideas.

The core of the challenge is that to the extent that an idea or proposition exceeds its ground it is a mere fiction. Motivation allows us to see how this is not so. As I described in chapter 1 , a motive delineates and norms a field of possible responses to it. These responses are not contained in the motive; instead, they exceed the motive. But they are normed by the very motive they exceed. The input of motivation grounds the output, even while the output exceeds the input.

There is a kernel of truth to Hume’s invocation of “fiction” and "imagination,” because motivation is creative in the sense that it engenders a product which is original (another way of saying that it exceeds its ground). But “fiction” doesn’t capture the process of motivation, because describing our knowledge as fictitious suggests that it isn't responsible to reality, whereas describing our knowledge as motivated suggests that it is. Our knowledge is normed by experience, and this means that it is responsible to that experience; knowledge has a different kind of purport than fiction. Because it is normed, knowledge is grounded in a way that fiction isn't. 


\section{Examples}

In this way, motivation can avoid the challenges posed by both rationalism and empiricism. I now illustrate how motivation works through several case studies.

\section{Space}

I draw my first example from Merleau-Ponty’s analysis of space. Merleau-Ponty argues that the contingent modes of access to space provided by the senses are inseparable from the meaning space has for us. This might seem unlikely, for the intuition of space, being unique and common to each of the senses, must be a priori. Space is the universal form to which each of the senses lend their particular matter. Vision, touch, and hearing all disclose the same space, which is why the tactile experience of space can be coordinated with the visual experience of space. Consequently, with respect to space, each of the senses are contingent. If both vision and touch disclose the same space, neither of them are an inseparable part of the intuition of space; neither the blind person nor the hypoesthesiac lacks an experience of space, and thus each sense is accidental to the experience of space. The senses are contingent and subjective modes of access to the necessary and objective intuition of space.

But, on the other hand, space only has the meaning it does for us in virtue of the senses that disclose it. For it is not true that each sense discloses space in the same manner. Vision and touch, despite disclosing the same world, each give the world with a structure that is not transposable into the other. Take, for example, Jonathan Franzen's description of a child’s experience of the underside of the table he has been sentenced to remain at until he finishes his dinner:

Even the most extreme boredom had merciful limits. The dinner table, for example, possessed an underside that Chipper explored by resting his chin on the surface and stretching his arms out below. At his farthest reach were baffles pierced by taut wire leading to pullable rings. Complicated intersections of roughly finished blocks and angles were punctuated, here and there, by deeply countersunk screws, little cylindrical wells with scratchy turnings of wood fiber around their mouths, irresistible to the probing finger. Even more rewarding were the patches of booger he'd left behind during previous vigils. The dried patches 
had the texture of rice paper or fly wings. They were agreeably dislodgable and pulverizable.

The longer Chipper felt his little kingdom of the underside, the more reluctant he became to lay eyes on it. Instinctively he knew that the visible reality would be puny. He'd see crannies he hadn't yet discovered with his fingers, and the mystery of the realms beyond his reach would be dispelled, the screw holes would lose their abstract sensuality and the boogers would shame him, and one evening, then, with nothing to relish or discover, he might just die of boredom (Franzen, 2001, p. 267).

According to Franzen, vision has a power of distance which collapses space, whereas the proximity of touch expands it; vision surveys a realm in one glance, and having captured it, removes the mysterious quality of tactile space (the solicitation of which was irresistible to the probing finger), and so gives way to boredom; the materiality of the screw holes coalesces into a concrete meaning; what was so agreeable in the sensuality of the texture of dried boogers, in the light of the eye (as if in watching one were being watched, for vision transports us into the objective) turns to shame. This power of distance means that whereas touch can only give us simultaneity with a small extension (that of the body), vision can coordinate two distant events which touch can only traverse with time (Merleau-Ponty, 2012, p. 232). Thus, vision makes possible a distant simultaneity that touch could not. This is why a patient blind from birth, once their cataracts have been removed, can claim never to have had the experience of space prior to the operation (Merleau-Ponty, 2012, p. 231 \& 536). Of course, the patient is not rigorously correct in this claim: for he reaches to touch what he sees, attempting to palpate sunlight for example, and this is only possible if he locates vision and touch within a common spatial universe. And yet the patient could only experience the arrival of vision as an event, as a revelation, if vision gives space in a way that touch did not. The patient does not readily know how to coordinate vision and touch, and this is only possible if vision and touch do give the same structure of space. Space is not the same after the arrival of vision, and this means that space is not something "above" the senses, but rather a meaning produced by the synergy of the senses involved in normal perception of spatial objects. Only by this synergy between the senses does each particular sense become a contingent grasp of space, and thus space is not something 
separable from the senses, but only separable from each particular sense, just as the body exceeds each of its organs while being only the power of their synthesis.

The contingent senses are essential - and not accidental - not only to the a priori intuition of space, but also to our intellectual grasp of this space in geometry. This position seems impossible, because each sense is contingent to our grasp of geometry. Blind people are able to learn geometry, and this means that vision is a contingent mode of grasping the truths of geometry. But this fact does not hinder the sense of geometry from being transformed by the arrival of vision. The patient whose cataracts have been removed claims that the circle and square are not genuinely perceived by touch, but only recognized according to signs (the presence and absence of edges) (Merleau-Ponty, 2012, p. 233). The patient may well overstate the case. Yet the fact that the patient can be surprised by how a circle or square looks - that they are not what he had anticipated - shows that vision discloses geometry in a way different from touch. Both vision and touch disclose geometrical truths, and thus each is contingent with respect to these truths. But each gives these truths a unique sense, which the definition alone (e.g., a figure the radii of which are all equal) does not capture. The definition is perfectly transposable between the blind and the seeing geometer. And yet the sense it captures is different for each. Perhaps some other sense not yet imagined could give a new meaning to this definition. Perhaps one could perform many geometrical operations correctly without possessing either touch or vision. Yet without any senses these operations would have no meaning. In this case, the contingent is the inseparable ground of the necessary.

\section{Galileo’s Discovery of Kinematic Laws}

My second example, taken from Wertheimer and Merleau-Ponty, belongs to the history of science: Galileo’s discovery of the kinematic laws that underlie classical physics. Galileo’s laws significantly restructure the laws of motion that perception suggests. For example, Galileo’s laws unite under one law cases of motion that seem to be described by different laws. It is easy to determine perceptually that heavy objects fall downward, and pre-Galilean physics viewed this as 
evidence that the natural home of heavy bodies is the earth. Uniform rectilinear motion (i.e., horizontal motion in a line), on the other hand, was described by a different set of laws: the body will move until its vis impressa no longer acts on it. The distinction between these two kinds of motion seems perfectly obvious. Yet Galileo unites both cases under a single law.

I'll summarize Wertheimer's description of the process of structural reorganization that Galileo’s thinking undergoes (Wertheimer, 1945). It is perceptually available that heavy bodies fall, and that the longer they fall the faster they fall. Galileo sets out to determine how bodies fall more precisely. Since the speed of falling objects is great, exact measurements of time are difficult for Galileo to make. Instead, Galileo experiments with rolling objects down inclined surfaces: he conceives free fall as merely a special case of fall, fall at an angle of $90^{\circ}$. Experimenting with different angles of decline, Galileo finds that the lesser the angle, the lesser the object's acceleration; the closer to $90^{\circ}$, the greater the acceleration. It then occurs to Galileo that the converse is true of an object thrown upwards: it undergoes the greatest negative acceleration if thrown vertically upwards, and lesser negative acceleration the smaller the angle of incline. What about when the object is neither thrown upward or dropped, but simply rolled forward? Since the angle is zero here, the object will undergo no acceleration or deceleration. In other words, its motion is constant. This leads Galileo to the conclusion that a body in rectilinear motion moving at constant velocity will never come to rest, except under the influence of friction. Inertia replaces the view that the body will move until its vis impressa no longer acts on it: it is not that the body runs out of vis impressa, but that an external force - friction - acts on it. Galileo unites rectilinear motion and the acceleration of falling bodies under a single law, thereby transforming both.

In this way, Galileo's laws generalize, or move from particular cases to a universal law. Merleau-Ponty writes,

When Galileo succeeded in bringing under one signification the factors of uniform acceleration and deceleration - for example, the stone thrown in the air 
and the uniform rectilinear movement of a body on which there is no impinging force - these phenomena became variants of a single dynamic (1973, p. 105).

These phenomena, which for perception seem to operate according to distinct structures, are revealed to be coordinated by a common law. The law generalizes, because it makes these distinct structures into "variants of a single dynamic." The law provided by the intellect is not false of the perceived particulars. Instead, it clarifies them in a way that perception could not have imagined. The intellect draws out truths about the perceptual world that perception does not contain. Here, it determines and explicates perception through generalizing and formalizing. ${ }^{77}$

At the same time, the general law draws its meaning from the experiences it explicates. Merleau-Ponty writes of the signification developed by Galileo:

[It] can in principle appear only through the concrete shapes which it unified. That it appears to us on the basis of 'particular cases' is not an accident of its genesis with no essential effect. The signification is inscribed in its content, and if we tried to abstract the signification from the circumstances in which it appears, the signification would vanish before our eyes. The latter is not so much a signification over and above the fact which signify it as our means of passing from one fact to another or the trace of their intellectual generation (1973, p. 105).

In other words, it is only by gradual rearrangements of the perceptually available structures that Galileo’s conclusions have meaning or evidence for us. We do not experience a kind of motion which is as undivided between the two cases as the general is: we experience either the heavy body falling or the rectilinear motion. A motion that would be neither of these has no meaning for us. More, we do not experience inertia: all bodies perceptually available come to rest under the influence of friction, and consequently perception does not decide between an interpretation of an object expending its vis impressa or an object limited by friction that would ideally undergo constant motion. How do we make sense of Galileo’s conclusion, then? Only in virtue of a structural reconfiguration demanded by Galileo’s realization that deceleration decreases with the angle of incline and acceleration increases with the angle of decline. If we do not see this demand

\footnotetext{
${ }^{77}$ See also Merleau-Ponty 1964 (p. 69).
} 
for ourselves, then the idea of inertia is a mere placeholder for a meaning that belongs within a structure of other terms (motion, rest, acceleration, distance, space, etc.) and which I can perfectly well use to perform calculations but has no meaning for me. I only have reason to see the truth of Galileo’s laws when I see how they provide a more determinate and stable description of the perceptually available phenomena. Thus, it is only within and on the basis of the contingent that the more universal and necessary law is obtained; the former is not the mere occasion for the latter, it is its life source.

\section{Weight/Heft}

My third example I draw from Wiser and Smith's recent research on science education, which has explored the most effective means of encouraging conceptual change from children's initial conceptual system to the scientific conceptual system (Wiser \& Smith, 2016). Take one example: children have an undifferentiated concept of weight/heft. That is, children understand weight in terms of heft, resulting in incorrect beliefs, e.g., that very small objects have no weight. This engenders a contradiction, because very small objects have no heft independently of each other but do when added together: a grain of rice has no heft, but a bag of rice does. The child recognizes that no amount of null weight objects can sum to an object having weight, but is unsure how to resolve the problem. To account for this, knowledge discriminates between weight and heft, determining the latter as an imperfect mode of access to the former: small objects have a weight that perception cannot observe, because all mass has weight. Knowledge resolves the contradiction present in perception by transitioning to a new and more determinate level (a conceptual or structural system that can distinguish between weight and heft), which results in a greater degree of stability. Part of the difficulty of science education is encouraging children to adopt a conceptual system that contradicts the perceptual evidence available to them (e.g., that a grain of rice has no heft).

The scientific concept of weight significantly transcends the perceptual concept of weight: it enlarges the domain in which this concept applies, holding that all mass has weight, but 
also understands weight in terms that are unavailable to perception, defining weight as a measure of force exerted by gravity. This scientific concept of weight has no intrinsic evidence or meaning for the child. The problem, then, is how to move the child from her initial conceptual system to the scientific conceptual system. And the difficulty is that the child has no stock of meanings or evidence other than those available to perception with which to transcend the perceptual concept system for the scientific system.

Wiser, Smith, and Doubler outline a series of stepping stones that allow the child gradually to reconfigure their conceptual system (Wiser, Smith, \& Doubler, 2012). An initial step is to get children to believe that scales are more accurate measures of weight than hands. The child can easily see that objects affect scales according to their heft: a heftier object makes the scale go further down. And yet this belief conflicts with evidence available to the child. For example, it may occur that of two objects which for the child have the same heft, one makes the scale go further down than the other. The child learns that scales are more sensitive than hands. The child can also learn that the scale is more reliable than hands: her peers may report all different degrees of heft, whereas the scale is constant. A second step is to develop a concept of scale weight. Initially, objects can be qualitatively sorted by their relative effect on the scale. Then, they can be sorted quantitatively, by introducing units. The language used with the child to describe measurement serves to "scaffold" conceptual change: from "The Playdoh cube is as heavy as five teddy bears," to "The weight of the cube is the same as the weight of five teddy bears," to "The weight of the cube is five teddy bears," to "The weight of the cube is 25 grams" (Wiser \& Smith, 2016, pp. 40-1). The child now has access to an extensive concept of weight, i.e., that the weight of the whole is composed of the weight of the parts, through which a child can learn that all mass has weight (e.g., by a thought experiment in which the child continuously halves a weight - if the weight of the whole is composed of the weight of the parts, the mass can be divided indefinitely and each part should still have weight). 
Of course, more steps are required to obtain the full scientific concept of weight. But the important thing to see is how complicated it is to acquire this concept. It is, of course, possible that a child could be trained to operate perfectly correctly with the scientific concept of weight without understanding it at all. One can understand the formal relations of the propositions, "Weight is the measure of force exerted by gravity," "Gravity is a force of attraction between masses," "Mass is the amount of matter in an object," and "Matter is a substance that takes up space", without understanding their meaning at all, and further, without knowing whether they have any truth. Such propositions only have a meaning insofar as the perceptual concept system can be gradually manipulated or reorganized into the scientific concept system, and they are only evident insofar as perceptual evidence (in particular, the contradictions it poses) requires this reorganization. Again, the difficulty of science education is that these propositions aren't definable in terms of the child's conceptual system and are not directly evidenced by perception (indeed, they seem to conflict with perception), and yet the only resources the child has for giving meaning and evidence to these propositions is precisely her perceptual concept system.

The undifferentiated concept of weight/heft is incommensurable with the adult concept: from the adult perspective, it is confused and doesn't make sense. At the same time, weight only has its meaning as a determination or differentiation of the weight/heft concept. The child's grasp of weight is indeed contingent: it is only a subjective and in this sense arbitrary mode of access to the objective. And yet something like an objective and necessary grasp of weight is only possible within the space carved out by this confused concept. In this case, the contingent grasp of weight grounds the necessary grasp, and the necessary grasp is not therefore a mere fiction, for it is in fact more precise and determinate than its ground. 


\section{Natural Number}

My fourth example is taken from Susan Carey's research on the development of the concept of natural number in childhood. ${ }^{78}$ Children do not initially possess any concept of natural number. They do, however, possess some perceptual capacities related to number. Children can distinguish between a larger and a smaller set if the difference between the two is sufficiently large. Carey terms this capacity the analog representation of number, and finds that it operates on Weber's law, i.e., the ratio at which we can distinguish magnitudes is constant (I can distinguish 6 and 9 items, but not 18 and 19). Further, they are able to distinguish between and remember up to three objects. For example, if an infant sees two crackers being hidden in one jar and three crackers in another, they will preferentially move toward the jar with three crackers and will remove three crackers from it (since they are unable to store 4 distinct items in memory, they show no preference for a jar with 4 crackers over a jar with only 1). Neither of these capacities amount to a concept of natural number. For example, neither of the infant's numerical capacities can distinguish between 19 and 20, while natural number can. Further, neither has the resources to represent numbers like 7 or 1,152. Natural number possesses the crucial characteristic of relating numbers in a sequence defined by the successor function, i.e., that each number in the sequence is reached by adding 1 to the previous number. The child's perception of number involves no such capacity. Thus, natural number is not definable in terms of perceptual numerical capacities.

On the other hand, natural number only has its meaning in virtue of these perceptual capacities. Let us see how the child develops a concept of natural number. First, children learning natural number are taught a count list: “1, 2, 3 ...”. This count list is composed of explicit symbols that are intrinsically meaningless and initially have meaning only in virtue of their relation to each other (their place in the succession of symbols). As already mentioned, children

\footnotetext{
${ }^{78}$ See Carey (2009) and (2010)
} 
have a capacity to distinguish between 1,2 , and 3 objects. Once they have learned the count list and these numbers, they are in a position to perform the crucial induction: mapping their understanding of number onto the count list. This allows them to learn the meaning of numbers that they could not have learned otherwise.

While natural number transcends perceptual numerical capacities, it only acquires meaning on the basis of those capacities. The count list can only acquire a meaning insofar as the child learns to map their already available representations of 1, 2, and 3 onto the count list - the inductive step cannot be taken without this recognition. It is only because the child can leverage the numerical structures implicit in perception, that they can develop sophisticated cognitive numerical structures.

One might object: I have no innate capacity to represent 1,152, but I understand this number. But consider the meaning this number has for me. I cannot recognize a mass of toothpicks scattered on the floor as 1,152 toothpicks or a 1,152-sided figure as having that many sides. Instead, it has its meaning in terms of the position it occupies in the count sequence, in terms of its relations to other numbers: it is one more than 1,151 and one less than 1,153, and I could, through such addition or subtraction of units eventually arrive from 1,152 to any natural number. The meaning it has derives from the function of succession, which meaning arises out of a reconfiguration of our initial stock of perceptual meanings (1, 2, and 3). Moreover, it never loses the meaning it has for me in terms of elementary perceptual structures. The analog representation of number persists even in the adult's grasp of the verbal integer list, which is why adults are much faster to decide that 9 is more than 5 than they are to decide that 6 is more than 5 (Dehaene, 1997). There is nothing about natural number that is more conducive to the former than the latter decision (indeed, in learning natural number we become so familiar with the count sequence “ 4,5 , 6” that one might expect the opposite result), but the analog representation of number does explain this adherence to Weber's law. 
These four examples demonstrate that the contingent can ground the necessary and that what is grounded in this manner is not therefore mere fiction. The contingent is the inseparable manner of our access to the real; it grounds precisely in its groundlessness.

\section{A Priori Justification}

Contemporary debates between rationalism and empiricism treat the issues of meaning and justification separately. One debate, primarily among philosophers, concerns the justification of our knowledge. Most parties to this debate agree that we have some innate representations, but disagree about how our representations are evidenced. Empiricists hold that the only source of justification for our knowledge is experience, while rationalists hold that we have a capacity for rational insight in virtue of which some knowledge is justified independently of experience. A second debate, primarily within the field of cognitive science, concerns whether humans possess any meanings independently of experience. Most parties to this debate assume that all evidence is empirical, but disagree about how we acquire the meanings that experience evidences.

Empiricists hold that all representations are acquired from sensori-perceptual experience, while nativists hold that some representations are innate. I'll consider both these debates in turn.

The debate between rationalism and empiricism in philosophy concerns how our knowledge is justified. Analytic orthodoxy of the past century has held that the only ultimate source of justification is experience. Some of these empiricists are foundationalists about experience, holding that all our beliefs are indirectly justified by experiences, which are directly justified. Others are coherentists, holding that there is no such thing as direct justification and all our beliefs are indirectly justified by their relations to other beliefs, which are ultimately constrained causally by experience. In either case, the only ultimate source of constraint or justification is experience. According to this empiricist orthodoxy there is no such thing as $a$ priori justification. The past two decades have seen the emergence of a dissenting position. Rationalists, of whom I will take Laurence Bonjour as representative, hold that we have a 
capacity for "rational insight" in virtue of which some of our knowledge is justified independently of experience. I'll start by explaining Bonjour's position and the empiricist objections to it.

In his In Defense of Pure Reason, Bonjour defends what he terms a "moderate" rationalist position (1998). Like the classical rationalists (and indeed, many classical empiricists), Bonjour maintains that we have two sources of justification. Some of our knowledge is justified ( $a$ posteriori) by appeal to experience. And some of our knowledge is justified (a priori) by appeal to reason alone, independently of experience. Bonjour differs from the classical rationalists, however, in holding that rational insight - that in virtue of which some knowledge is justified $a$ priori - is fallible. Bonjour claims that nothing about the idea of experience-independent insight necessarily implies infallibility and moreover there seems to be enough evidence that none of our knowledge is infallible that the classical position is untenable.

Bonjour provides three main arguments for holding that there is a priori justification. First, Bonjour appeals to putative examples of knowledge that could only be justified a priori, e.g., "Nothing can be red all over and green all over at the same time," "If a certain person A is taller than a second person B and person B is taller than a third person C, then person A is taller than person C," "There are no round squares," and "Either David or Jennifer ate the cake, but Jennifer did not eat it. Therefore, David did." Propositions of this sort don't seem to need to be evidenced by experience, but seem to be intuitively self-evident. Bonjour argues that such propositions are apprehended in acts of rational insight, i.e., in a way that is both direct, immediate, non-discursive and intellectual or reason-governed. It is this rational insight that justifies one in believing such propositions to be true.

Bonjour's second and third arguments claim that the denial of a priori justification implies extreme skepticism. The second argument points out that the idea of empirical justification depends on having some rational insight. The contents of experience are particular and are limited by the narrow scope of what we can observe. But we hold many beliefs that exceed the scope of perceptual experience - beliefs about the past, the future, unobserved 
particulars, and not least of all, general claims. Either inferences from experiential beliefs to nonexperiential beliefs are valid - in which case they depend on rules of inference that cannot themselves be inferred from experience, because they are conditions for such inferences - or are invalid, in which case we are left with a pretty severe form of skepticism.

Bonjour's third argument claims that any argument depends on some a priori justification. All arguments involve an inference from some premises to a conclusion. We hold inferences to be valid when we have a reason to think that the conclusion is true if the premises are true. But reasons for holding inferences valid cannot involve appeals to experience. Suppose one were to justify an inference in this manner. The experience to which one appealed could itself be formulated as a premise, in which case the conclusion is either explicitly included in the premises, and so no inference is necessary, or it is not, in which case the inference goes beyond what can be derived from experience. Consequently, one must either hold some form of rationalism or an extreme skepticism which denies that there are valid arguments. Rejecting the skeptical position, Bonjour holds that we have some capacity for a priori justification.

Empiricists tend to object to Bonjour's position along two main lines. The first aims to remove the motivation for the rationalist position by showing how empiricism can account for the kinds of examples of knowledge that Bonjour considers. The second holds that the rationalist position is too obscure to be acceptable.

First, empiricists argue that there is a good way to construe our possession of seemingly $a$ priori knowledge without resorting to a priori justification. Michael Devitt, for example, proposes a coherentist picture that he thinks avoids Bonjour's objections (2005). Devitt argues that the kinds of examples invoked by Bonjour can be justified by experience; we just need a different understanding of how justification by experience works. Propositions are not justified independently of each other, but in a holistic manner, i.e., together with a set of other beliefs and background assumptions. A proposition like "Nothing can be red all over and green all over at the same time" is not justified through any particular experience, then, but as a part of general 
network of interconnected beliefs that allow us to make sense of experience. It is this network which is tested by experience, and if it passes the test, so do its parts.

Further, empiricists argue that accounts like Devitt's are preferable to Bonjour's, because the latter is obscure. How is it that we are able to perform a cognitive act that gives us immediate access to necessary truths? ${ }^{79}$ While there is question enough how we are able to have direct access to individuals in perception, there is at least some understanding that this involves a story about sensation, embodiment, and the organization of sensation into meaningful wholes. No analogous story is told about rational insight; it is only claimed that we indeed have such insight.

Once again, thinking in terms of motivation suggests a third position. It seems to me that Bonjour's description of a "rational insight" has a phenomenological weight that must be acknowledged. In the examples that Bonjour considers, we do apparently have direct insight into the truth of certain propositions, and this insight is not perceptual but rational. Something like this is implied by Merleau-Ponty's insistence that intellectual evidence is not reducible to perceptual evidence. ${ }^{80}$ But, phenomenologically, this description of the experience of insight is inadequate. As every intellectualist analysis is prone to do, it overlooks the internal relation between a foreground and its background. Every foreground, while it presents itself as immediately and directly accessible, is mediated by the background that it stands out against: tone is perceived in virtue of keynote, color in virtue of lighting. The same is true of rational insight. Rational insight presents itself as immediate, but in fact it is only able to appear in virtue of a background of sedimented truths. And, I suggest, these sedimented truths ultimately lead us back to perception. As long the rationalist does not acknowledge this background, the empiricist is right that the idea of $a$ priori justification is obscure. ${ }^{81}$

\footnotetext{
${ }^{79}$ See, e.g., Boghossian (2001).

${ }^{80}$ See, e.g., Merleau-Ponty's claim that he is not attempting to reduce mathematical evidence to perceptual evidence (1973, p. 123).

${ }^{81}$ Hass and Hass distinguish between intuitionism and Merleau-Ponty's line of thinking in a similar manner: "For Merleau-Ponty mathematical proof happens amidst a field of proliferate possibilities and takes shape through genuinely creative, transgressive insights - insights that once formalized, actually
} 
What makes the appearance of immediacy so convincing is that all of Bonjour's examples are deeply sedimented truths. Because they are so familiar, they present themselves with the character of self-evidence. What is needed is to attend to the acquisition of an a priori insight. Take Wertheimer's example of how a child discovers the formula for the area of a parallelogram.

Suppose a child has learned the formula for calculating the area of a rectangle, but when asked to calculate the area of a non-rectangular parallelogram is stumped. There are various methods by which a child can proceed, but all involve manipulation of perceptual structures and their knowledge of the formula for rectangles. In one method, a child first sees the parallelogram as a rectangle with a triangle protruding from either end. Second, the child reorients this figure, seeing the triangle on one side as a protrusion and the triangle on the other end as corresponding to a gap (as a rectangle with a triangular piece missing). The child then sees that the gap can be filled in with the triangular protrusion at the other end, such that the parallelogram can be transformed into a rectangle (see Figure 3.1). The child concludes that the area of a parallelogram is computed with the same formula as the area for a rectangle. The child now has this formula readily available and with time may come to think of the area of the parallelogram as an obvious truth. But this belief is belied by the child's initial situation, in which the formula is nowhere to be found. Of course, the child can be simply told that the relevant formula for a parallelogram is “Area equals width times height.” But the child only has rational insight into the truth of this formula - the formula only has meaning or evidence - if it is seen (intuited) in the rearrangement of the perceptual structure of the parallelogram.

We are able to extend this analysis back to Bonjour's examples. Even though nothing could be more obvious than the transitivity of height to us, let us try not simply to assume that the child is able immediately to see that from the facts that A is taller than B, and B is taller than C that it follows that A is taller than C. How will the child arrive at this insight about the transitivity

disguise the open character of the activity and the dramatically other potential lines of development” (2000, p. 183). 
of height, then? If she puts A, B, and C before her vision (or imagination) she will be able perceptually to observe that $\mathrm{A}$ is indeed taller than C. But this is a mere fact: she does not yet see the structural necessity involved in transitivity. But she can arrive at this necessity if she now tries to vary the height of these figures in imagination. She supposes that $\mathrm{C}$ is in fact very tall, expanding $\mathrm{C}$ in her imagination to be taller than $\mathrm{A}$, while leaving $\mathrm{A}$ taller than $\mathrm{B}$ and $\mathrm{B}$ taller than C. What results (see Figure 3.2)? If we assume that she has not yet had insight into the necessary implications of transitivity for height, there is nothing contradictory in this supposition. A contradiction only results if we apply transitivity to note that if B is taller than C, and C is taller than A, then B must be taller than A. This contradicts the first supposed premise, that A is taller than B. But, again, this contradiction results only if transitivity is presupposed, and therefore cannot justify transitivity. In contrast, the child's imaginative supposition makes the contradiction immediately evident. If the child tries to imagine $C$ taller than $A$, then she can see that $C$ will be taller than B, and this contradicts her suppositions. Perhaps she tries to fix this by now expanding the size of B in her imagination, so it is taller than C. But if she does this, then B will be taller than A, and this contradicts her presuppositions. In this way, she acquires insight into a perceptual structure: that height is transitive. Henceforth, the insight will present itself as an immediate rational insight. But it was not there in her original perceptual situation, nor in the original meaning of height, for as we saw, if she attempted to derive transitivity from a proof by contradiction, she could do so only by presupposing transitivity. The insight is therefore not arrived at by a logical arrangement of significations, but by insight into a perceptual structure, arrived at through the manipulation of a perceptual situation. The rationalist analysis, which attends only to the rational insight, is indeed obscure, for it leaves veiled the sedimented perceptual structure which supports the rational insight.

Bonjour proposes an important objection to my position, namely that for denying the immediacy of rational insight, it results in skepticism. According to Bonjour, if we do not have immediate insight into the rules for validly inferring from perception to knowledge, or more 
generally from premises to conclusions, then none of our knowledge is justified. For if these rules are not immediately justified, they will themselves be derived from experience, but being the rules for justified inference from experience, will not themselves be justified. And if these rules are not justified, nothing derived by them will be justified. It seems to me that this objection is devastating for the empiricist picture: if there are no such rules known a priori, there is no way that our knowledge can be justified by experience.

I think this objection cannot be avoided. Bonjour is right that on my position, none of our knowledge is ultimately justified. But Bonjour's criticism is already acknowledged and accepted in Merleau-Ponty's claim that our knowledge is ultimately supported not by reasons, but by motives:

There are truths just as there are perceptions: not that we could ever fully lay out before ourselves the reasons for any affirmation - there are only motives, and we merely have a hold on time, not a possession of it - but because it is essential to time to take itself up to the extent that it leaves itself behind, and to contract itself into visible things or into things that are evident at first glance. Every consciousness is, to some extent, perceptual consciousness. Were it possible to unfold at each moment all of the presuppositions in what I call my 'reason' or my 'ideas,' then I would always be discovering experiences that have not been made explicit, weighty contributions of the past and of the present, and an entire 'sedimented history' that does not merely concern the genesis of my thought, but that determines its sense (Merleau-Ponty, 2012, pp. 415-6).

This move from reasons to motives allows us to see something important. Bonjour simply assumes that the only normative relation between beliefs is reason. This assumption is false: I have argued that motivation is a normative relation. Moreover, it is a property of motivation that its output can transcend its input, and so it can move from the contingent to the necessary, from the a posteriori to the a priori. In the manner we saw above, the contingent grasp of the heights of three individuals can motivate a structural insight. Because Bonjour does not see motivation as a possible ground for the rules of inference, he does not see how justification can arise out of our initially unjustified access to the world. Certainly, on my picture, there is no apodictic justification: our beliefs have a temporal horizon in virtue of which they are open to being revised in the future. But neither is there apodictic justification on Bonjour's "moderate" rationalism. 
Moreover, it is not clear that the lack of immediate insight into rules of inference from experience to knowledge is a defect of my position. As Devitt has pointed out, our evidential practices have changed significantly over the past centuries, e.g., with the rise of statistical methods. It seems more likely to me that we build rules for inference at the same time that we build knowledge on the basis of inference. Thus, my position does not culminate in skepticism; it simply denies an untenable account of justification, which the empiricist and the rationalist share.

\section{Empiricism and Nativism}

I now turn to the question whether we have any innate cognition, and if so, what character it has. Nativism plays the rationalist part in this debate, holding that we do have innate cognitions. In contrast, the empiricist position holds that we have no innate cognitions. The question is whether all meanings are ultimately perceptual meanings, i.e., can all knowledge be formulated in perceptual terms?

First, I should clarify some terms. This debate understands perception in a manner that Merleau-Ponty would find impoverished, namely in terms of qualities available to sensation, such as color, size, shape, and motion. Some sensory/perceptual qualities (e.g., shape and depth) are the output of innate sensory/perceptual analyzers. But such representations as object, cause, magnitude, and agency are thought not to be perceptual. Clearly, this debate does not understand the same thing by perception that Merleau-Ponty does. For Merleau-Ponty, perception is rich enough to include meanings such as object, cause, magnitude and agency. This is because Merleau-Ponty understand perception as the embodied experience of particulars, engendered by a set of passive synthetic processes.

Next, to say that a cognition is innate does not mean that one has a mental representation of that cognition prior to experience. For example, if the concept red is innate, this does not necessarily mean that one has a representation "red” prior to experiencing red things. Modern models of perception are a bit like certain classical rationalists in holding that we have innate mechanisms that analyze perceptual inputs to produce representations like depth, but unlike those 
rationalist insofar as they "do not require that the representations that enter into modular perceptual computations be consciously accessible” (Carey, 2009, p. 31). Nor does it mean that one is born with such a representation, for it might emerge as part of normal maturational processes. Instead, to say that a concept is innate means that it is not learned from experience. Generally speaking, the empiricist position is that we have no innate cognitions. This position is usually maintained according to at least one of two premises. First, a strong formulation of the position holds that all meanings are ultimately perceptual. As Locke would have it, all our ideas are constructed out of the simple ideas received through experience. To put this idea in more contemporary terms: all our knowledge can be formulated in terms of perceptual primitives (e.g. causality as the succession of two sensations). A somewhat weaker premise, which still supports the conclusion that we have no innate cognition, is that our only innate representations are perceptual. On this view, all our knowledge is achieved on the basis of language and other cultural educative practices which are discontinuous with innate perceptual mechanisms (Quine advocates something like this view), or some other mechanism (for example, Piaget's stage theory). Thus, the empiricist holds that we have no innate cognitions, though this leaves open whether we have innate perceptual representations (which is likely). I will be primarily interested in the strong empiricist premise, that all knowledge can be formulated in terms of perceptual primitives.

Nativists hold that we have at least some innate cognition. Following Chomsky's work on language acquisition, a large body of research has developed that supports this conclusion. Chomsky's work argued that the complexity of language and the readiness with which children learn it indicate that language is guided by innate syntactical structures. Since then, many studies have shown that very young infants are capable of having more than sensory representations, e.g., representing objects that are placed behind a screen (Baillargeon, Spelke, \& Wasserman, 1985) (Xu \& Carey, 1996). There are a number of other non-perceptual representations (e.g., number, cause, agent) that very young infants possess but are not likely to have been learned. In response 
to such results, Spelke and others have posited that humans have a system of innate "core knowledge” or “core cognitions.” Perhaps the most radical formulation of the nativist position was given by Fodor, when he argued that concept learning is in fact impossible (Fodor, 1975). This is not a necessary feature of the nativist position, and of course it is implausible that concepts such as terrier or jet engine are innate. A more conventional formulation of the nativist position is that we have at least some innate cognition, and this cognition constrains our acquisition of non-native knowledge.

Both positions are incompatible with Merleau-Ponty's account of the genesis of intellectual meanings or cognitions. The strong empiricist premise reduces intellectual meanings to perceptual meanings (indeed, to what Merleau-Ponty would consider sensory meanings). On the other hand, the nativist position loads all of knowledge into innate cognitions, in claiming that the former is constrained by the latter. Neither allows for the genesis of meaning that is central to Merleau-Ponty's account, the former holding that all knowledge is formulable in terms of perceptual primitives, the latter holding that all knowledge is formulable in terms of innate cognitive primitives.

I am more interested in how each position accounts for development than in how each describes our initial cognitive situation, i.e., whether we have innate perceptual representations or innate cognitions. Merleau-Ponty’s position is not that we have no biologically innate mechanisms that figure in the constitution of perception (in the rich sense). In fact, MerleauPonty's position, it seems to me, is much closer to the nativist's in this regard. The empiricist description of perception is too bare, on Merleau-Ponty's view, to provide a good description of our initial cognitive situation. The claim that we have core cognition, on the other hand, is compatible with Merleau-Ponty's account of perception. Not only do the contents of core cognition (e.g., agent, cause, etc.) figure into the content of perception, according to MerleauPonty, but like perception, core cognition is not an explicit theory. Core cognition of number, for example, includes no explicit representation of the axioms of arithmetic (Carey, 2009, p. 135). 
Further, the outputs of core cognition are particular perceptions (e.g., "That moving object, $X$, has object $Y$ as its goal”), not universal judgments (e.g., “Only agents have goals”). These outputs are passive, in the sense that they are not revisable; in Fodor's language, they are “encapsulated.” In short, this account of core cognition leaves very little that Merleau-Ponty would disagree with. Merleau-Ponty would object to the claim that we have core cognition in the sense that we have innate conceptual/theoretical knowledge of the world which is therefore not founded on experience, but contemporary theories of core cognition do not posit such knowledge.

Merleau-Ponty's position is that all intellectual meanings are motivated by the stock of meanings involved in perception. This position requires two claims: a) intellectual meanings transcend the initial stock of meanings involved in perception (i.e., the former is not definable in terms of the latter), but b) the former are founded on the latter. As I pointed out above, neither empiricism nor nativism can countenance the first claim, and so neither can countenance the idea that intellectual meanings are motivated. However, these are not the only positions that developmental cognitive scientists take. Indeed, an emerging body of research, spearheaded by Susan Carey, supports the two claims I have just attributed to Merleau-Ponty. In the remainder of this section, I explain Carey’s position and how it supports Merleau-Ponty’s claims.

In her The Origin of Concepts, Carey lays out three theses that define her view. First, that we possess some innate cognitive structures, which she calls core cognition. Second, that humans have a unique capacity to create cognitive systems that "transcend sensory representations and core cognition” (Carey, 2009, p. 18). These cognitive systems transcend core cognition in the sense that they are discontinuous and locally incommensurable with core cognition. Third, that we create such cognitive systems in virtue of what she calls “Quinian Bootstrapping.”

First, Carey argues that we have an innate cognitive structure that she calls core cognition. Core cognition differs from sensory/perceptual representations systems, insofar as it plays a rich conceptual, inferential role. But it also differs from theoretical conceptual knowledge, insofar as it consists of "modular innate perceptual-input devices” - in my terms, insofar as it is 
passive (“encapsulated”), has sensory input and produces the rich perception of the world that Merleau-Ponty describes phenomenologically (Carey, 2009, p. 11). Carey’s point is that we have innate systems for representing the world that are not merely sensory, such as object, magnitude, causation, agency (goal-directedness). Such representations cannot be defined in terms of sensation. But they are also not explicit theories: they do produce explicit representations of particulars, but the manner in which they do so is not consciously accessible, and much of their conceptual content is inaccessible. They are also not theories (intellectual meanings in MerleauPonty's sense), because their outputs are representations about particulars, whereas theories represent universals.

Second, our cognitive systems are not continuous over our lifespan, i.e., we develop cognitive systems that are discontinuous with core cognition. In other words, it is not the case that "the resources needed to express all concepts humans can represent are available throughout development, even at the beginning” (Carey, 2009, p. 248). Recall, this is a nativist thesis, insofar as the nativist holds that all concepts that humans can represent are innately available (or at least, the resources for these concepts are). For example, we develop representations of magnitude, namely natural number, which core cognition cannot capture. According to Carey, the cognitive systems we develop as adults are discontinuous and incommensurable with core cognition. In other words, the shift to adult cognitive systems involves not just as amplification of core cognition, but fundamentally changes representations like number, object, cause, agent, etc. This means that parts of core cognitive systems appear incoherent from the perspective of adult cognition or cannot be expressed in terms of adult cognition. Children, for example, have an undifferentiated concept of subtraction and division, yielding something like "an operation that makes a number smaller” (Carey, 2009, p. 355). Thus, they hold that if you divide the number 1 a sufficient number of times, you will get to 0 . Or again, they have an undifferentiated concept of weight and density (Carey, 2009, p. 389). Such undifferentiated concepts are incoherent from the adult perspective: how could the child coherently think in terms of a concept that is in fact two 
distinct concepts? The child's cognitive system is incommensurable with the adult's cognitive system in this sense: the child's concept does not coherently translate into the adult's cognitive system. But, according to Carey, such incommensurability is always "local," i.e., there is incommensurability between only some portion of the two cognitive systems. For example, in the move from the child's first grasp of natural number to the sophisticated adult grasp of number, there is indeed incommensurability, but both are cognitions of number, both represent natural number, etc.

Third, we create new cognitive systems in virtue of what Carey calls “Quinian bootstrapping." The term "bootstrapping” is meant to capture what is puzzling about this process, namely that it is a process of "creating new representational resources that are not entirely grounded in antecedent representations” (Carey 20). Basically, Quinian bootstrapping works by posing a set of explicit symbols which are intrinsically meaningless, which serve as placeholders for new meanings. For example, in the acquisition of natural number, the child initially learns the intrinsically meaningless set of symbols in the count sequence. Carey attributes the following characteristics to core cognition:

1) relations among symbols are learned directly, in terms of each other; 2) symbols are initially at most only partly interpreted in terms of antecedently available concepts; 3) symbols serve as placeholders; 4) modelling processes analogy, inductive inference, thought experiment, limiting case analyses, abduction - are used to provide conceptual underpinnings for the placeholders; 5) these modeling processes combine and integrate separate representations from distinct domain-specific conceptual systems; and 6) these processes create explicit representations of knowledge previously embodied in constraints on the computations defined over symbols in one or more of the systems being integrated (Carey, 2009, p. 418).

I don't want to pursue the details of Carey's description of the bootstrapping process. What interests me is how it provides an alternative to empiricism and nativism that is very close to the one I have been proposing. On the one hand, the output of Quinian Bootstrapping is not definable in terms of its input. But on the other, the output only has a meaning by leveraging the stock of meanings present in the input. As discussed above, the count sequence by itself would remain 
totally meaningless: an arbitrary sequence which we can reproduce, but doesn’t have any sense. It is only when the child maps her capacity to perceive 1,2 , and 3 objects onto the count sequence that it is, as it were, gradually illuminated and becomes a means of organizing the world.

Carey thus proposes an account of cognition that resists both a strong empiricism and a strong nativism, because it is an account of the genesis of knowledge, i.e., of the development of knowledge out of structures that it transcends. In doing so, it supports Merleau-Ponty's two claims about the genesis of knowledge.

\section{Conclusion}

In this chapter, I have argued that the grounding relation between perception and knowledge should be understood in terms of motivation. Understanding the relation in this way allows us to resolve the antinomy at the heart of rationalism and empiricism: perceptual experience must ground our knowledge, and yet our knowledge is incommensurable with perception.

One key feature of thinking in terms of motivation is that it requires the contingent to ground the necessary. On this picture, the contingent is not a mere occasion for acquiring a necessary truth, but is an inseparable feature of the necessary. It is because our a priori truths are founded on our contingent modes of perception that, as Merleau-Ponty puts it, "certainty is doubt," or in other words, the a priori has a temporal horizon: a past out of which it arises and a future within which it may be overturned. This account, while it posits a Fundierung relation between perception and knowledge, is not for that reason foundationalist. For the foundation provided by perception is contingent, and it is the very inadequacy of this ground that propels knowledge toward the necessary. This distinguishes motivation from empiricism, because the former does not claim that the structures of experience are a sure foundation - indeed, in our progress toward the true, they must be overturned, precisely while they are in another sense maintained. 
On the other hand, motivation distinguishes this account from the sort of antifoundationalism defended by Varela, Thompson, and Rosch in their Embodied Mind. There, they propose an enactivist view of cognition, according to which "cognitive structures emerge from the recurrent sensorimotor patterns that enable action to be perceptually grounded” (1991, p. 173). This position holds that subject and object are codependent, and consequently that the world can only be understood as something enacted in our contingent bodily modes of engaging it. This leads them to conclude that our cognition has no sure foundations. Thus far, the conclusions of Embodied Mind are compatible with the position I have been describing. But Varela, Thompson, and Rosch go on to argue that the appropriate reaction to the groundlessness of our cognition is to give up our grasping after grounds and instead to embrace groundlessness. In contrast, I argue that the progress of knowledge, both historically and within the life of the individual, is the accession to surer grounds. ${ }^{82}$ Varela, Thompson, and Rosch are right that we do not leap from out of our subjective modes of access to the world into objective determinations of the world. Yet, the genesis of knowledge provides us with a more stable and determinate grasp of the world. We approach the necessary, but only within the contingent. Indeed, this move from within the groundless toward the surer ground is an essential structure of existence that Merleau-Ponty calls transcendence:

Existence is the very operation by which something that had no sense takes on sense, ... by which chance is transformed into reason ... . 'Transcendence' is the name we shall give to this movement by which existence takes up for itself and transforms a de facto situation. ... Everything is necessary in man .... And everything is also contingent in man ... (Merleau-Ponty, 2012, p. 174).

\footnotetext{
${ }^{82}$ Dillon puts it well in writing that "The argument that proceeds from the rejection of all absolutes [i.e., ultimate grounds] to the rejection of all grounds (and hence all truths) is specious. There are finite grounds, finite truths. It is on the finite ground on which we stand that we must base the truth that we need in order to live as long and as well as we do" (1987, p. x). See also the conclusion to Dillon 1987, "Abyss and Logos.”
} 

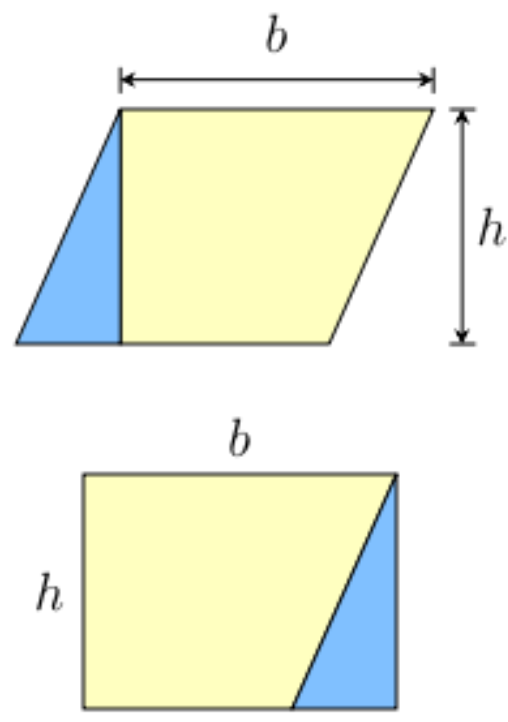

Figure 3.1. Area of a Parallelogram. Reprinted from Parallelogram, In Wikipedia. Retrieved August 14, 2017, from https://en.wikipedia.org/wiki/Parallelogram. 2010 by Jim.belk. Reprinted with permission. 


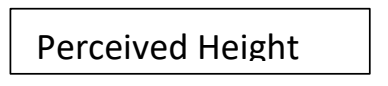

\begin{tabular}{|l|}
\hline Imaginative \\
Variation 1 \\
\hline
\end{tabular}

\section{Imaginative}

Variation 2
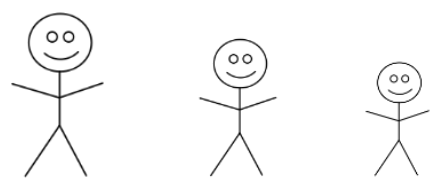

A
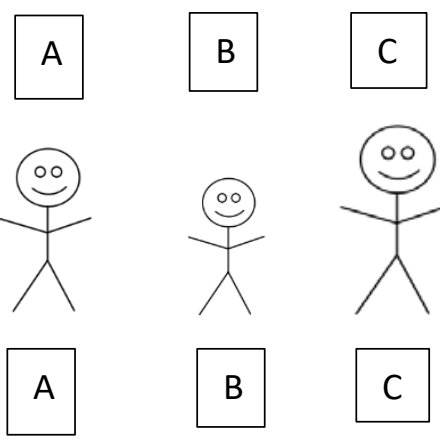

$\frac{0}{1}$

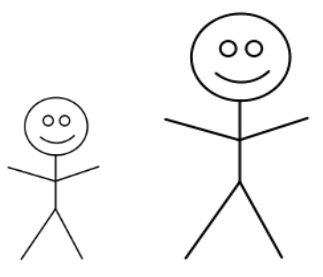

A
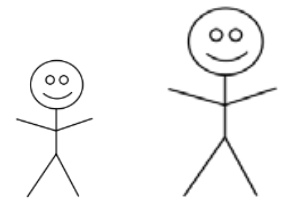

C

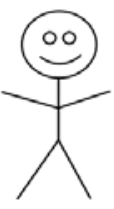

B

C

Figure 3.2. Transitivity of Height. 


\section{CHAPTER 4. MERLEAU-PONTY AND KANT}

In chapter 3, I explained how Merleau-Ponty, and phenomenology generally, provides an alternative to the rationalist and empiricist conceptions of the relation between experience and knowledge. But Merleau-Ponty does not provide the only or the first such alternative. Indeed, Kant's project could be described in these same terms. Kant is not an empiricist about knowledge, insofar as he thinks a priori knowledge is possible and that an empirical deduction of the categories cannot secure their validity. Nor is he a rationalist, because he grounds a priori knowledge on the possibility of experience; his project is well described as a critique of pure reason. Further, Kant's transcendental idealism advances beyond the empirical idealism of early modern philosophy onto the same terrain as phenomenology, both attempting to describe, in Merleau-Ponty’s terms, an “in-itself-for-us” or, in Kant’s, an “appearance itself.”

At the same time, Kant's resolution of the antinomy of empiricism and rationalism seems to be incompatible with Merleau-Ponty's, in at least two ways. First, Kant seems to describe the conditions for the possibility of experience in terms that Merleau-Ponty would consider intellectualist. ${ }^{83}$ Indeed, Merleau-Ponty provides good reasons to think that the conditions Kant considers are not in fact conditions for the possibility of perception, or so I will argue. Second, Kant develops a sense of the a priori which is incompatible with the description I gave in chapter 3 of an a priori founded on experience. ${ }^{84}$ Kant develops a line of argumentation, namely transcendental argumentation, according to which certain structures of the understanding can be known or justified a priori. These structures are not to be justified by having been gathered from actual experience. Instead, they are justified as conditions for the possibility of experience. Consequently, knowledge of these structures is a priori knowledge. For Kant, in other words,

${ }^{83}$ The literature on the relation between Merleau-Ponty and Kant focuses on accusations of intellectualism. See, e.g., Matthews (2006, p. 31), Longuenesse (1998, pp. 204, 271, 395), or see Melnick (2013) for a more detailed examination of such accusations.

${ }^{84}$ Merleau-Ponty himself clearly distinguishes his sense of the a priori from Kant's (2012, pp. 229-30). See Dillon (1987) for a discussion of the differences between the a priori as it is in Kant and Merleau-Ponty. 
knowledge is a deduced as a condition for the possibility of experience, not as motivated in the course of actual experience.

My general thesis in this chapter will be that, contrary to appearances, the philosophies of Kant and Merleau-Ponty are largely compatible. ${ }^{85}$ This, I will argue, is because the two aim their projects at different levels of experience. What Merleau-Ponty means by perception is a level of experience that might be described as pre-predicative or pre-objective. In contrast, for Kant experience means empirical judgment. Further, these different senses of experience are accompanied by different senses of the sort of normativity involved in experience. Whereas Kant approaches experience with the standard of justification, Merleau-Ponty approaches it with the standard of motivation. But my contention, as well as Merleau-Ponty's, has not been that other forms of grounding, namely reason and causality, don’t have spheres of legitimate application, only that they are not exhaustive of the forms of grounding and that they are not well applied to perception and the primary bond between experience and knowledge. In this sense, Kant's and Merleau-Ponty's projects are not only largely compatible, but also complementary, describing different levels of experience and normativity that together provide a complete description of experience. However, I will also argue that Merleau-Ponty’s description of a pre-predicative sphere of experience places limitations on Kant's account of the $a$ priori. In particular, I will argue Kant's account of a priori justification relies on an insight into the general structure of experience, which cannot be justified a priori in the manner Kant lays out. Instead, these structures must be described as a priori in the sense I defined in chapter 3, namely as motivated in the course experience.

\footnotetext{
${ }^{85}$ In what follows, I will generally leave aside Merleau-Ponty's own reading of Kant, which while interesting can obscure the philosophical issues at hand. For a good discussion of Merleau-Ponty's treatment of Kant, see Matherne (2016, pp. 207-211) or, for a markedly different take, chapter 6 in Rockmore (2011).
} 


\section{Kant on Experience}

In this section, I will explain Kant's account of the epistemological role of experience. One place where this role can be readily seen is in Kant's description of the method of transcendental deduction. But to identify what a transcendental deduction is, we will first have to determine what a deduction is and what makes Kant's deduction a transcendental one.

In his account of the deduction, Kant famously distinguishes between questions concerning fact (the quaestio facti) and questions concerning right (the quaestio iuris). Whereas the former is concerned with establishing what is actually the case, the latter is concerned with establishing a right or entitlement, i.e., a justification. It is the latter sort of question with which a deduction is concerned. A deduction of the categories means a demonstration that we are justified in using the categories. We are justified in using categories if they are objectively valid, i.e., if they can be used to cognize objects. Whereas with regard to the categories the quaestio facti would only be concerned to demonstrate that we do possess a priori concepts, the quaestio iurus is concerned to demonstrate that we are justified in using these concepts.

A transcendental deduction aims to justify a concept $a$ priori. A priori, as I am using it here, refers not to the innateness of a concept (although Kant is also interested in this), but to the sort of justification it possesses. One might attempt to justify a concept's use by showing how that concept is derived from experience or can be identified within experience. For example, Kant claims that we can always use experience to prove the objective reality of our empirical concepts (p. B 117). A transcendental deduction aims to provide a different sort of justification, namely, one which does not rely on experience. For Kant, it is important to justify the categories a priori, because experience cannot justify the categories with the necessity that cognition of them entails, and because the categories are not derived from experience. An empirical deduction of the categories could not properly count as a deduction, because it would demonstrate not the legitimacy of the concept, but only the factual situation whereby we come to possess that concept. Thus, according to Kant, any attempted empirical deduction of the categories would amount only 
to an answer to the quaestio facti. Such attempts are useful only in their proper sphere, namely, that of the "explanation of our possession of a pure cognition” (p. B 119). ${ }^{86}$

The idea of a transcendental deduction, then, turns on the distinction between justification and explanation which is at the core of this dissertation. Experience, according to Kant, can at most serve as an explanation of our possession of the categories; it does nothing to justify our use of them.

Nevertheless, experience does play a critical role in the justification of the categories, for it is only on the basis of experience that the categories can be shown to have objective validity. As Kant puts it, "the transcendental deduction of all a priori concepts has a principle to which the entire investigation must be directed: viz., the principle that these concepts must be cognized as $a$ priori conditions for the possibility of experience” (p. B 126). More generally, experience plays a critical role in the justification of our a priori synthetic knowledge, just not with respect to its actuality (the fact of experience): Kant, unlike his rationalist predecessors, grounds metaphysical knowledge on experience. Thus, Kant writes,

Experience, as empirical synthesis, is in [regard to] its possibility the only kind of cognition that provides reality to all other synthesis. By the same token, this latter synthesis, as a priori cognition, has truth (agreement with the object) only because it contains nothing more than what is necessary for synthetic unity of experience as such (pp. B 196-7).

What makes a priori synthesis possible, according to Kant, is experience in regard to its possibility. How does Kant reach this conclusion?

Analytic judgments are licensed simply in terms of the concepts of the subjects of those judgments. According to Kant, in judging that "All bodies are extended" I am merely elucidating

\footnotetext{
${ }^{86}$ With regard to our possession of a priori concepts, experience should be thought of as an occasioning cause. As Kant puts it in the introduction to the B-edition, "Even though all our cognition starts with experience, that does not mean that all of it arises from experience" (p. B 1). Experience, according to Kant, is temporally our first cognition, for it is sensation that "arouses" the understanding. Nevertheless, this does not entail that all the content of our cognitions is derived from experience, because the understanding is a condition for the possibility of experience, and so any content added to experience by the understanding will be derived not from experience but from the understanding, experience merely serving to awaken this content.
} 
a content of the concept "body." In contrast, synthetic judgments are "ampliatory," they require something outside of the concept itself in order to be licensed. ${ }^{87}$ In the case of empirical truths, such as "It's raining," this "something else" is clearly my experience of the weather. But what is this something else in the case of a priori synthetic judgments? Clearly, the formal condition of truth, non-contradiction, is not enough to answer this question (as it was in the case of analytic judgments), because a synthetic judgment can both be non-self-contradictory and fail to agree with its object (there is nothing contradictory about my judging that it's snowing - it is simply wrong to do so) (p. 84). And experience can license only particular judgments, not necessary and universal judgments. Thus, Kant's guiding question in the Critique of Pure Reason is "How are synthetic judgments possible a priori?" (p. B 19).

Kant answers, as we have seen, in terms of experience not with regard to its actuality (which licenses only a posteriori judgments), but with regard to its possibility: "the possibility of experience is what provides all our a priori cognitions with objective reality" (p. B 195). Kant's reasoning is that certain cognitions are necessary conditions for the possibility of experience, and because we have experience, we know these cognitions (because they are necessary conditions) to be true necessarily. Cognitions which are necessary for the possibility of experience can be $a$ priori, because they are not derived from experience but instead make experience possible, and synthetic, because they are licensed by a "something else," namely, the possibility of experience. One of the central aims of the Critique of Pure Reason is to justify a variety of a priori judgments, in particular the "synthetic principles," on the grounds that they are conditions for the possibility of experience.

There is a core move, common to the transcendental aesthetic, the transcendental deduction of the categories, and Kant's account of the synthetic principles: each justifies a certain

\footnotetext{
87 "In synthetic judgments, where the predicate does not lie within the concept of the subject, I must have besides this concept something else $(\mathrm{X})$ on which the understanding relies in order to cognize nonetheless that the predicate belongs to the concept" (p. A 8).
} 
sort of cognition as a cognition of a structure that is a condition for the possibility of the experience that we do actually possess. This move is the characteristic feature of transcendental arguments. A transcendental argument, beginning with the given features of ordinary experience, deduces the transcendental conditions of these features; it moves from the conditioned (our experience) to its condition (transcendental laws); from what is first for us (experience) to what is first in itself (the transcendental).

\section{Kant on Justification}

The central question in the justification of the categories and the synthetic principles is "How is the experience of objects possible?” This question differs importantly from the kind of skeptical question Descartes had considered, i.e., "How can we know that our experience of objects is correct?” Kant is not asking how we can infer reliably from representations within our minds to states of the outer world. Properly speaking, Descartes’ question only arises for the transcendental realist. ${ }^{88}$ For the transcendental realist, perception is only a set of inner representations, causally produced in the mind by the impact of the world outside oneself in space. Because such representations are caused, the transcendental realist can infer the existence of outer objects. But this inference is unreliable: it leaves undetermined whether the cause is actually in the world or merely in us (as in a dream). For this reason, Kant argues, the transcendental realist ends up an empirical idealist (p. A 369). In contrast, Kant’s transcendental idealism allows him to be an empirical realist. What we have in experience, according to Kant, is the real itself, directly given in outer sense. However, this real cannot be understood as anything "outside us," because it is in space and time, and space and time are nothing but the forms of our intuition. Certainly, the real is outside of any given empirical subjectivity, but this is because any empirical subjectivity is itself something located within space and time. Kant's transcendental

\footnotetext{
${ }^{88}$ See the Fourth Paralogism in the A edition.
} 
idealism does not imply an empirical idealism; there is, on his account, such a thing as "the appearance in itself” or an object of experience.

And yet, insofar as everything in space and time is, in the transcendental sense, an appearance or presentation, it is not immediately obvious how there can be such a thing as an object of experience. The general problem is that if in experience we have only to do with our presentations, then there is nothing outside our presentations with which to compare our presentations. And if this is the case, it seems that there can be no such thing as empirical truth, for truth as the tradition has understood it is just correspondence between our presentations (cognitions) and the object outside of our cognitions. Kant's solution to this problem is that there is only an object of experience insofar as our presentations are governed by rules, and that empirical truth will be defined as correspondence between our presentations and those rules. Thus, in the A deduction, Kant writes,

When we have brought about synthetic unity in the manifold of intuition - this is when we say that we cognize the object. This unity is impossible, however, unless the intuition can be produced according to a rule through a [certain] function of synthesis, viz., a function of synthesis that makes the reproduction of the manifold necessary a priori and makes possible a concept in which this manifold is united. ... This unity of the rule determines all that is manifold, and limits it to conditions that make possible the unity of apperception. And the concept of this unity is the presentation of the object $=x$ (pp. A 104-5).

Again, Kant's problem is not the skeptical problem, about how we can infer outer the states of the world from our inner presentations. For Kant, we are directly referred to the real through outer sense. ${ }^{89}$ However, all we are given through outer sense is a manifold of intuition and this manifold can be synthesized in all manner of ways. The question is how we can distinguish

\footnotetext{
${ }^{89}$ Rockmore (2010) has accused Kant of inconsistently endorsing both constructivism (according to which the subject "constructs" its object, i.e., the phenomenon) and representationalism (according to which appearances are internal representations of objects in themselves). Only with Fichte's elimination of the thing in itself, according to Rockmore, does philosophy properly move from representationalism to constructivism. While it may be that Kant's account of the thing in itself entails a sort of representationalism, Kant's question about how there can be an object of experience does not entail any sort of representationalism: the problem here is not moving from internal representations to external objects (as Kant's language sometimes suggests), but from a subjective to an objective arrangement of the directly given world of phenomena.
} 
between objective and merely subjective synthesis of this manifold. In the Second Analogy, Kant writes,

What, then, do I mean by the question as to how the manifold may be combined in appearance itself (which, after all, is nothing in itself)? Here what lies in the successive apprehension is regarded as presentation; but the appearance that is given to me, despite being nothing more than a sum of these presentations, is regarded as their object, with which the concept that I obtain from the presentations of apprehension is to agree. We soon see that, since agreement of cognition with the object is truth, the question can only be inquiring after the formal conditions of empirical truth; and we see that appearance, as contrasted with the presentations of apprehension, can be presented as an object distinct from them only if it is subject to a rule that distinguishes it from any other apprehension and that makes necessary one kind of combination of the manifold. The [element] in the appearance which contains the condition of this necessary rule of apprehension is the object (p. B 236).

In this regard, the problem of empirical truth is reformulated: given that we receive through intuition only a manifold, with what is our apprehension of this manifold to correspond so as to be true? Kant's answer, again, is that our apprehensions can only be objective if the manifold received in intuition is bound by rules; it is to these rules that our apprehension must correspond if it is to be true.

Before turning to this solution, we need to be more precise about how this problem arises for Kant. Again, the basic issue is that the manifold of intuition does not determine any particular synthesis or organization of itself. In the "Stufenleiter" Kant presents a taxonomy of the genus "presentation," writing,

Under [the genus "presentation"] falls presentation with consciousness (perceptio). A perception that refers solely to the subject, viz., as the modification of the subject's state, is sensation (sensatio); an objective perception is a cognition (cognitio). Cognition is either intuition or concept (intuitus vel conceptus) (p. B 376).

Thus, according to Kant, both intuitions and concepts are perceptions that refer to objects.

However, while intuition is perception referring to the object, it by itself can only give a manifold, not a unitary object, and not a unity of experience as a whole; as Kant claims at the beginning of the B-deduction, "a manifold's combination (conjunctio) as such can never come to us through the senses" (p. B 129) and so "combination is an act of the understanding" (p. B 130). 
Through the application of concepts and the synthesis of cognitions through the categories, i.e., through the understanding, the manifold of intuition is synthesized into unitary objects and ultimately into a coherent whole of experience concordant with the transcendental unity of apperception. So, cognitions refer to objects in virtue of the understanding.

However, there is a threat to this straightforward argument. Intuitions, or cognitions generally, can be synthezised by the understanding in judgments, but also by the imagination in associations. Kant distinguishes these options in section $\S 19$ of the B-deduction, writing,

Suppose that I inquire more precisely into the reference of given cognitions in every judgment, and that I distinguish it, as belonging to the understanding, from the relation in terms of laws of the reproductive imagination (a relation that has only subjective validity). I then find that a judgment is nothing but a way of bringing given cognitions to the objective unity of apperception. This is what the little relational word is in judgments intends [to indicate], in order to distinguish the objective unity of given presentations from the subjective one (p. B 142).

Kant specifies that it is only because a judgment is referred to the necessary unity of apperception (i.e., the original or transcendental, as opposes to the empirical) that it is valid objectively. In contrast, the imagination combines presentations according to laws of association, which are empirical, and so have only subjective validity. What is given empirically will, as a matter of fact, be combined in a variety of different ways: "One person will link the presentation of a certain word with one thing, another with some other thing" (p. B 140). Whatever laws of association an individual applies in their reproductive imagination to associate two presentations is contingent, a habit they have developed empirically through repeatedly finding one presentation linked with another. Thus, this empirical unity is a subjective unity which is only "a determination of inner sense," and "through association of presentations, itself concerns an appearance and is entirely contingent" (pp. B 139-40). So, it is only through the understanding, and the necessity it provides through rules, that we can present an object, i.e., that our experiences can have objective purport. This, according to Kant, is the significance of the copula in judgments: in judgment we can say, "Bodies are heavy," but all we can say according to the imagination is, "When I support a body, then I feel a pressure of heaviness" (p. B 142). In other words, the reproductive imagination is 
capable only of a subjective validity because it can only combine presentations in perception of the "subject's state" (p. B 142): when I support the body I have the sensation - a perception of my subjective state - of heaviness.

What judgment, and the categories generally, establish is not that our presentations are correct, but that they have objective purport at all. Kant writes that,

The reference to [the necessary unity of apperception] is there even if the judgment itself is empirical and hence contingent - e.g., Bodies are heavy. By this I do not mean that these presentations belong necessarily to one another in an empirical intuition. Rather, I mean that they belong to one another by virtue of the necessary unity of apperception in the synthesis of intuitions (p. B 142).

In particular, empirical judgments - made by particular, empirical subjects - presentations do not come together in any necessary way, and so such judgments are open to being incorrect.

However, in particular, empirical judgments, presentations do belong to one another according to necessary laws (ultimately, the unity of apperception), and so have objective purport.

In other words, I agree with the line of interpretation given by Longuenesse, who distinguishes between two senses of objectivity at play in Kant's discussion of the objective unity of apperception: a first, according to which a unity of apperception "conforms to an object” (i.e., forms a true representation) and a second, according to which a unity of apperception relates our representations to an object (i.e., forms a representation that tends to truth, or has truth value, though it may be true or false) (Longuenesse, 1998, p. 82). If I think I am seeing a rock jutting up from the sand on the beach, but it turns out to be driftwood, my cognition was objective in the second sense (insofar as it was referred to the object), but not in the first (insofar as it did not present the object correctly). According to Longuenesse, it is this second sense of objectivity that the categories allow for. This seems right to me - Kant is aiming to explain how we can make empirical judgments, statements with objective purport, in the first place. He effectively says as much in writing that he does not mean that presentations belong necessarily to each other in empirical intuition and that empirical judgments are contingent. 
In this sense, the categories and the synthetic principles are justified insofar as they are conditions for the objects of experience: without them, experience would (per impossibile) not have objective purport and nothing like empirical truth would be thinkable. Kant's second analogy provides a good example of this line of thinking.

In the Second Analogy, Kant argues for the "principle of temporal succession according to the law of causality," namely that "All changes occur according to the law of the connection of cause and effect” (p. B 232). It is a feature of experience that it delivers to us objective time orders. When - to use Kant's example - I see a boat floating down river, I take it that the boat itself has over time moved from one position to the next; that this succession is not merely a contingent, and so subjective, feature of my apprehension of the boat. Further, in experience we distinguish between objective temporal succession (succession that is in the object, like the boat floating downstream) and subjective temporal successions (succession that is only "in me," for example, my perspectival apprehension of a table as I walk around it). In the second analogy, Kant asks how it is possible that we experience objective time orders. For what we are given through intuition is a temporal manifold, which can be organized in a variety of manners. Under what conditions can an organization be called objective, or rather, under what conditions can we make claims as to the objectivity of temporal orders? ${ }^{90}$

According to Kant, the imagination does not suffice to provide objective time order. Because the imagination organizes the manifold of intuition according to laws of association, the organization it produces is contingent (pp. B 223-4). The imagination could just as well present

\footnotetext{
${ }^{90}$ To be clear, when I talk about an objective temporal succession, I am talking about objectivity in the second sense proposed by Longuenesse: objective purport. In the Second Analogy, Kant is not attempting to establish how we can guarantee the certainty of our judgments about time orders, but how we can make judgments about time order with objective purport at all. Guyer and others, it seems to me, get this backwards (Guyer, 1987). For a good discussion of the relative strengths and weaknesses of Guyer's and Longuenesse's positions see Osborne (2006). And for a defense of the line of interpretation I think is shared by myself and Longuenesse, see Allison (2004, pp. 256-60). The decisive consideration pointed to by Allison, I think rightly, is that interpretations like Guyer's, which take Kant to establishing how we can make correct judgments, in effect elevate empirical laws into necessary conditions of experience, a consequence which does not sit well with Kant's project (2004, p. 257).
} 
the boat floating upstream, or jumping back and forth, for that matter. Consequently, the imagination cannot distinguish between succession that is in the object and succession that is only in the subject. At the transcendental level, imagination does not suffice to provide our experiences with objective purport.

Since neither intuition nor imagination can provide for this objective purport, the understanding must. It does this by providing the rules for the organization of the temporal manifold, namely, that all changes occur according to the law of cause and effect. If a succession is governed by a causal law, then the succession has a necessary sequence. Because the boat is caused to float downstream by the force of the river, the temporal sequence must portray the boat as being further upstream in a prior moment and further downstream at a later one. At the transcendental level, the fact that any experience of change will be governed by causality is what allows our experience to be of objects, i.e., to have objective purport. As we saw Kant put it above, the condition of empirical truth is correspondence to a rule:

Appearance, as contrasted with the presentations of apprehension, can be presented as an object distinct from them only if it is subject to a rule that distinguishes it from any other apprehension and makes necessary one kind of combination of the manifold. That in the appearance which contains the condition of this necessary rule of apprehension is the object (p. B 236).

In this section, we've seen that for Kant it is judgment and its structures that allow for the objects of experience. Part of what enables this conclusion to come into focus is the fact that Kant approaches experience with the dichotomy of justification and explanation. For example, in the Second Analogy, Kant claims that through imagination I can be "conscious only that my imagination places one state before and the other after, but not that the one state precedes the other in the object” (p. B 233). In other words, imagination and its laws of association only explain how I apprehend a succession in a given order; they do not justify this apprehension. In this light, Kant's claim is that as long as we are dealing with explanations and not justifications we cannot, at the transcendental level, distinguish between objectivity and subjectivity at all. It is only by invoking the understanding, and its standard of justification, that something like an object 
of experience (an appearance in itself) becomes possible. As Kant puts it, “... the mere succession in my apprehension, if it is not determined by a rule by reference to something preceding it, justifies no succession in the object” (pp. B 240, my emphasis). ${ }^{91}$ Kant's point, on my interpretation, is that the objective purport of experience is only possible due to laws that entitle (or justify) us to distinguish between objective and subjective successions. If, absent such entitlement, one still took one's apprehension to refer to an object, one would be dreaming:

... If I posited what precedes and the event did not succeed it necessarily, then I would have to regard this event as only a subjective play of my imaginings; and if I still presented by it something objective, then I would have to call it a mere dream (p. B 247).

For Kant, claims to objectivity are either to be explained (as in the case of a dream in which there is no normativity and so the only question to consider is how the dream arose as it did) or justified (as occurs in waking experience, in which normativity is determined by the necessity of rules and so the reference to objects is guaranteed by the necessity of causality).

\section{Kant and Merleau-Ponty on Perceptual Experience}

There seems to be an obvious sense in which Kant's thinking and Merleau-Ponty's disagree. For Kant is posing conditions for the possibility of experience, but throughout the Phenomenology of Perception Merleau-Ponty argues that the sort of conditions posed by Kant misconstrue experience: these conditions “intellectualize” perception, are not conditions for perception as it is lived, and are only a reflective reconstruction of perception. Indeed, MerleauPonty criticizes Kant for intellectualizing perception. ${ }^{92}$ In this section, I'll explain and defend the good grounds Merleau-Ponty has to deny that the conditions Kant attributes to experience are in fact conditions for perception. However, I do not think that this denial puts Merleau-Ponty’s project in conflict with Kant's. Instead, I will argue that Merleau-Ponty and Kant are describing

\footnotetext{
${ }^{91}$ See also "... The objective succession will consist in the order of the manifold of appearance whereby the apprehension of the one item (viz., what occurs) succeeds the apprehension of the other (viz., what precedes) according to a rule. This alone can entitle me to say of the appearance itself, and not merely of my apprehension, that a succession is to be found in it ...” (p. B 238).

${ }^{92}$ See Merleau-Ponty 2012 (pp. lxxvii, 107, 131, 228, 315).
} 
two different levels of experience and so their projects are compatible, even complementary.

Whereas Merleau-Ponty is interested in describing pre-reflective experience - what he calls

perception - Kant is interested in describing empirical judgment. I take it that this description of

Merleau-Ponty's project is non-controversial. My description of Kant's project, though, bears

some comment, for many commentators take Merleau-Ponty and Kant to be working on the same

level. ${ }^{93}$ For Kant, experience, in the proper sense, is a cognition of an object. But experience only

functions as a cognition (in the proper sense) if it is understood as an empirical judgment. For

example, in the following passage from the second analogy, Kant explicitly defines the

perception of an object as an empirical judgment:

... If my perception is to contain the cognition of an event, i.e., of something's actually occurring, then it must be an empirical judgment in which we think of the consequence as determined, i.e., as presupposing in terms of time another appearance that it succeeds necessarily, or according to a rule (pp. B 236-7).

The reason for this, as we saw explained in the B-deduction, is that only at the level of judgment do our perceptions have objective purport. Thus, if we are speaking of the experience of objects, we are speaking of empirical judgments. ${ }^{94}$ Consequently, when Kant is talking about the conditions for the possibility of experience, he is talking about the conditions for the possibility of

${ }^{93}$ Disagreements about how much Merleau-Ponty shares with Kant make this assumption. Both those who hold Merleau-Ponty and Kant offer competing accounts of perceptual experience - for example Melnick (2013) and Longuenesse (1998, pp. 204, 271, 395) - and those who hold that their accounts in fact share a great deal - for example Matherne (2016) -make this assumption. For what it's worth, it seems to me that even were they operating at the same level, the two would share more than is frequently admitted. Matherne has provided a compelling account of the connection between Kant's schematism and MerleauPonty's account of the body schema via the work of Pierre Lachièze-Rey, a major influence on MerleauPonty's reading of Kant. Nevertheless, it seems to me that the two accounts would ultimately be at odds, for as I will argue, what Kant calls conditions for the possibility of experience cannot be conditions for the possibility of perception.

${ }^{94}$ This is something of an overstatement. Kant admittedly does still wish to distinguish judgments from intuitions, writing for example that it is the same function which gives unity to both judgments and intuitions (pp. B 104-5) - clearly implying that while the two rely on the same function, they are not therefore the same. On the other hand, Kant is clear that bringing a manifold of presentations under one apperception is the logical function of judgments, and the categories are these logical functions (p. B 143). It is because categories are logical functions of judgments, I take it, that Kant writes in the Second Analogy that if a perception is to be objective - i.e., a cognition and not a sensation (p. B 376) - then it must be an empirical judgment. Kant is interested in experience as empirical cognition (cf. A 125), and this means experience organized by the functions of judgment. In contrast, Merleau-Ponty is interested in describing a kind of experience, namely perception, which does not in this qualify as empirical cognition. 
empirical judgment. But not only is it not immediately obvious that conditions for the possibility of empirical judgment are conditions for the possibility of pre-reflective experience, MerleauPonty gives us good reason to think that they aren't.

Further, the standards of empirical judgment are not those of pre-reflective experience. In other words, corresponding to the two senses of experience employed by Merleau-Ponty and Kant, the two have different senses of normativity. Kant understands normativity in terms of justification, because justification is the proper standard by which to measure judgments. But justification is not the standard on which pre-reflective experience operates. As I have argued in this dissertation, the standard on which pre-reflective experience operates - the sort of normativity to which it responds - is motivation. Kant does not acknowledge this sort of normativity; he approaches experience with the dichotomy of explanation and justification. Thus, he thinks that the imagination can only explain how we order a succession, and that if we persist in attributing objectivity to this order, we are no more than dreaming. But in this dissertation, I have shown how Merleau-Ponty carves out a space of grounding between explanation and justification, between necessity and mere dreaming. This is the space of motivation. In virtue of motivation, Merleau-Ponty can point out that experience has objective purport without relying on the standard of justification. From this it does not follow that experience is a mere dream and the reason for this is that experience, while not justified, is nevertheless normed, namely, in the manner of motivation.

I'll now proceed to a more detailed discussion of these points. I'll begin by demonstrating how the distinctions I have just laid out operate with respect to two particular examples, the second analogy and the axioms of intuition, and then I will move to a general discussion of objectivity and normativity in Kant and Merleau-Ponty.

First, while the second analogy does show that the principle of sufficient reason is a necessary condition for empirical judgments about objective time order, Merleau-Ponty gives us good reason to think that it is not a necessary condition for pre-reflective experience of objective 
time order. That is because Merleau-Ponty gives an account of how our organization of temporal succession is normed by a passive temporal synthesis. As a consequence of this account of time order, Merleau-Ponty denies that we face the problem about the constitution of objective experience that Kant solves with the principle of sufficient reason.

For Kant, the problem is to know how we think of a given time order, A - B - C - D - E, as objective, or how it is that we can distinguish objective and subjective time orders. The manner in which these representations come together in the imagination is contingent, and the imagination could just as well represent the order as E - D - C - B - A. So, our apprehension of this order has objective purport if the time sequence is thought as having a necessary order, such that it is necessarily the case that A - B - C - D - E. Importantly, this problem arises only if we think of the moments, A, B, C, D, E, as independent of each other, i.e., as possessing a content or meaning which is in not determined by the other members of the sequence. Because each moment is independent of the others, they can be arranged in any order, e.g., the boat flowing upstream, downstream, or jumping back and forth.

Merleau-Ponty's response to this problem would be to point out that there are no independent moments given in experience. Every moment is given as possessing a temporal horizon of past and future which figures in its meaning or content. In the language I used in chapter 1 , each moment is internally related to the other moments of a sequence. In experience, we are not given the independent moments, A, B, C, D, E; rather, the smallest unit we could find would be b - C - d, or c - D - e, where the lower-case letters indicate the temporal horizon which figures in the meaning of each moment. In this case, each moment is given in virtue of its relation to the temporal whole, i.e., the sequence, and for this reason the problem that Kant means to solve by invoking the principle of sufficient reason does not arise at the level of pre-reflective experience. Our apprehension of the temporal whole is normed by the temporal horizon definitive of each moment: given that the smallest unit of temporal experience has the form $b-C$ - d, it would be a violation of the meanings of the moments to organize the sequence: E - D - C - B - A. 
No causal law is needed to norm this succession: the normativity arises from the meaning of the moments themselves. This normativity does not have the force of justification, but because it is normative it also does not count as mere explanation. Instead, the sort of normativity at play here is motivation.

This idea needs to be illustrated. In apprehending a melody, for example, I apprehend a sequence of notes, A - B - C - D - E. The sense of each note is apprehended in terms of the whole melody to which it belongs. When I hear E, I hear it as the culmination of an ascending scale. Conversely, already with A there is a readiness for further notes to follow, even though there is very little determination of what will follow. That is, each note is given with a temporal horizon. In virtue of this horizon, I experience the order in which I apprehended the notes as normative. If I imagine playing the sequence backwards, E - D - C - B - A, I get the sense that this is not how the sequence actually occurred. Thus, I find myself constrained in experience by the motive force of the sense of the melody. Or, for example, take our apprehension of the motion of a rolling ball. Let us say that in a series of moments, A - B - C - D - E, the ball occupies the positions 1 - 2 - 3 4 - 5, respectively. The primary content of experience here is not a set of discrete momentposition coordinates. Instead, the primary content of experience is the direction of motion (from 1 to 5). It is possible to analyze this motion into discrete moment-position coordinates, but only at the price of abstracting from the actual content of experience, which has as its smallest unit, for example, the ball at C-3 moving toward D-4 and coming from B-2, i.e., the moment immersed in a temporal and kinetic horizon.

In other words, we find that in pre-reflective experience the sequence - the whole - is prior to the moments - the parts. Consequently, our apprehension of a sequence is normed, and so not a mere dream. However, the sort of normativity that this pre-reflective experience involves does not meet the standard of justification: it does not provide the organization with necessity, but only with actuality. It remains possible that the temporal horizon which constitutes the sense of each moment is a subjective feature of the sense of that moment, for the horizonal aspect of this 
sense may be merely subjective. To respond to such skeptical worries, reflective analysis is compelled to abstract each moment from its temporal horizon and treat each as an independent moment in virtue solely of its non-horizonal content (e.g., the mere position of the ball abstracted from the direction that animates the position). Once this has been done, it is the case that the independent moments can be ordered in any fashion and merely asserting that they take the order they did in experience would lack all justification: the passive synthesis of temporality now seems only to explain the order in which we apprehended the sequence, not to tell us anything about the sequence in the object. And now for there to be any normative organization of the moments there must be a causal law governing the contents of the moments and so justifying the order of apprehension. In this regard, we can see that pre-reflective experience is unstable and collapses when faced with the standards of justification. But it also has its own sort of normativity motivation - for the possibility of which the necessity of causal laws is not a condition. The problem that Kant solves with the synthetic principles arises only at the level of empirical judgment, even while the seeds for this problem are present within pre-reflective experience. ${ }^{95}$

I'll take as a second example Kant's axioms of intuition. Since we have not yet encountered the axioms, I'll say a couple words about them. This principle holds, "All intuitions are extensive magnitudes" (p. B 202). Kant's argument for this principle runs as follows: every intuition has the form of space and time, and any intuition in space and time contains a homogenous manifold, so no intuition can be apprehended except through the synthesis of a homogenous manifold. In other words, no appearance can be apprehended except as the synthesis of a homogenous manifold of intuition. But, according to Kant, the consciousness of such a synthesis is the concept of magnitude, and so no appearance can be apprehended unless it is

\footnotetext{
${ }^{95}$ It is important to bear in mind throughout this discussion that we are considering not how particular empirical judgments can be reliably made, but only the transcendental conditions of particular experiences (i.e., empirical judgments). My point here is not that the passive synthesis of the imagination suffices to provide particular experiences of objectivity but that it suffices to provide experience with the overall form of objectivity: no further transcendental condition is needed than this passive synthesis.
} 
thought through the concept of magnitude. This magnitude is extensive, because it is one in which the parts make possible, and so precede, the whole: any intuition is an aggregate of spatial or temporal parts.

Kant's conclusion is undeniable: there is no pointilistic intuition, every intuition has some spatial or temporal extension. But while quantity is an appropriate category by which to approach empirical judgment, it is not the appropriate category by which to approach perception.

I think one could respond in a Merleau-Pontian vein to Kant's argument here as follows: Perception in fact cannot make use of the concept of extensive magnitude in order to synthesize an intuition. Any extensive magnitude is an aggregate of units. But there are no units in experience prior to the synthesis of an intuition. It is not the case that perception begins with a collection of parts and must assemble these into a coherent whole, as if perception were a jigsaw puzzle. If perception did begin with parts, then we would run into the problem that these parts are themselves extensive magnitudes, and so would have to be assembled out of prior parts. This assumption obviously results in a regress, where any immediately given part is mediated by itself being the aggregate of prior parts. Consequently, a whole must be given first, which afterwards can be analyzed into parts. These parts can then be treated as wholes, as units, out of which the whole can be composed. But this analysis necessarily comes after the fact: there must first be a one, a whole, which can be analyzed into parts or itself treated as a part and assembled into a larger whole. Thus, synthesis does not depend on extensive magnitude: instead, it makes extensive magnitude possible.

Let us think this argument through phenomenologically. What is the incipient moment of perception like? Merleau-Ponty analogizes this incipient moment to a nebula.

If I am waiting for someone at the door of a house on a poorly lit street, each person who comes through the door appears momentarily under a confused form. Someone is leaving the house, and I do not yet know if I can recognize this person as the one I am waiting for. The well-known silhouette will be born from this fog like the earth from its nebula (2012, p. 338). 
Of course, this example is not primordial: it describes the move from recognizing "someone" to recognizing a particular individual. And yet it gets to the precise issue I am pursuing, namely, the advent of determinacy. Prior to the whole, perception does not give us discrete units, but a nebula within which a form can coalesce. The proof of this is that I do not in this case perceive precise features of the other's face and then draw a conclusion about who it is. For the parts themselves are not yet determinate. Rather, as the other comes into view, this nebula begins to acquire determinacy until suddenly I recognize the one who is leaving. Once this person has been identified, the parts are transformed, they acquire a determinate character: I know the eyes, the hair, etc. Only in very unusual cases, e.g., in perceptual disorders, do we work from the parts to the whole. Chuck Close, who suffers from prosopagnosia ("face blindness"), is famous for his style of decomposing faces into parts and then assembling these parts into a single image. Consider his description of why and how he paints portraits:

It's not so strange that I ... made portraits. I was driven to make portraits. I was trying to understand the faces and commit them to memory, of people that I know and love. And for me it has to be flattened out. Once it's flattened out, I can commit it to memory in a way that I can't if I'm looking at you. If you move your head half an inch it's a whole new head I haven't seen before. But once it's flat ... I have no trouble seeing that was a face because I can see flat patterns of face. ... I'm overwhelmed by the whole. I can't make a decision. I've broken [the image] down into small bite size incremental units. And the degree to which I can move from incremental unit to another and build clusters that stack up to make something is because I am profoundly interested in artificiality (Close, 2012).

Close cannot see the face as it presents itself to a subject without prosopagnosia, i.e., as a whole in its mobility and depth. Instead, he must first flatten the image and attend to abstract features of the face (patterns). For us, the essential point is that he does not look to the face as a whole, because to do so would be blinding, i.e., he could not find any meaning there: the whole is "overwhelming." Instead, he attempts to see the face through its parts. What is important for us to see is how different the result is from how those without prosopagnosia see faces, and indeed how Close perceives things other than faces. For the result of this style is that while from a distance the portrait present a coherent figure, the closer one gets the more it decomposes into distinct 
pockets of materiality. Precisely because the whole is in this manner built out of the parts - rather than being generated in the organic interaction of whole and part - it acquires the air of artificiality. Here, even the reflection in the eye, seen from up close, is on the verge of dissolving into mere color (see Figure 4.1)

If prior to the arrival of a one - the whole - perception does not give us a set of distinct units, then what is it like? For the normal subject, prior to the form, perception gives only a nebula, an indeterminate fog which coalesces into a whole with the advent of determinate unity. It is tempting to take cases of Gestalt reversibility, like the Rabbit-Duck, as indicating that perception delivers us a matter on which we impose a form. One reasons: if the same sensibilia can be both a duck and a rabbit, it must in reality be neither. Perhaps we even, by refusing to focus on the image, manage to see it as neither, but as a mere shape. And yet this would be wholly to mistake the significance of such figures for perception. For perception, the figure is not mere matter, indifferent to form. On the contrary, it calls alternatively for both forms. The figure is not too poor, but too rich. Prior to the whole, the matter does not have determinate parts, and there is nothing in it resembling a one, a unit. It is instead a chaos, but a chaos straining toward form, i.e., a nebula. This nebula is intrinsically oriented toward form, which is why with the arrival of unity, this nebula vanishes like a phantasm at dawn.

Extensive magnitude is, then, not a condition for the possibility of the experience of a unity, because the whole must precede its parts and is what makes its parts be parts (determinate unities) in the first place. What is true is that extensive magnitude must be able to accompany all our experience of unities, because it is true that every perception arises out of the nebulous generativity of sense and in this way there is no simple (rather than complex) perception. For this reason, every form can always be decomposed into parts from which it can be recomposed. But in this case we must say that extensive magnitude is licensed by perception and not its condition. On the other hand, none of this means that extensive magnitude is not a condition for empirical judgment about intuitively given manifolds. It is plausible that empirical judgment requires us to 
attend to the parts as fully constituted, i.e., discrete and limited, parts out of which the whole can be aggregated.

We can now raise this analysis to a more general level. Kant's general question is how is it that there is for us an object in experience. Kant's answer is that there is an object for us only insofar as our presentations are rule-governed. But this is actually a condition for there being an object of empirical judgment, not an object of pre-reflective experience. ${ }^{96}$ The reason for this, again, is that the problem Kant solves with rule-governedness in fact only arises once one has accepted the terms of reflective analysis. For Merleau-Ponty, there is no problem about how our presentations have objective purport, for our presentations are primarily of objects. Only subsequent to experience is it possible to abstract our subjective, perspectival apprehensions of objects from the experience of the object itself. These subjective apprehensions are not that out of which experience must be built; they are the result of reflection on experience.

According to Merleau-Ponty, our experience is primarily of the world (of things) because our perception is guided by our body schema, i.e., the passive coordination of the body's general possibilities for perception and action in virtue of which particular situations are taken up. Our uptake of the world is always mediated through this body-schema. For example, Merleau-Ponty considers the case of a patient whose occulomotor nerves have been paralyzed (2012, p. 48). When this patient has the intention of moving his eyes left, he sees the landscape in front of him move left. One might think that perception reasons that since the eye is (assumed to be) moving left, and the retinal image of the landscape has been left unchanged, the landscape itself must have moved left with the (assumed) movement of the eye. And yet there is no problem here of

\footnotetext{
${ }^{96}$ It is reasonable to have qualms about my application of the term "object” to Merleau-Ponty's description of perception, given that Merleau-Ponty calls experience "pre-objective," e.g., (2012, p. 81). The structures of objectivity, properly speaking, pertain to the subjects of empirical judgments, i.e., that of which predications are made. These are not the same structures as those of the pre-objective things disclosed in perception. I continue to use the term "object” when discussing Merleau-Ponty's philosophy for the sake of facilitating a discussion between Merleau-Ponty and Kant. Nevertheless, "object” ought to be understood in a qualified sense in this context.
} 
building the perception of motion out of our perspectival apprehension of the object (the retinal image). For the patient has no presentation of the retinal image. Instead, he immediately sees the landscape move left - this is the only presentation available to him. This is because he is from the beginning installed in the world by his body schema, in this case, the passive awareness of his eye movement which in this case has malfunctioned. The case of this patient makes clear what we ordinarily do not notice: that perception is always already (immediately) mediated by the body schema, such that we are immediately at the object and not our perspectival apprehension of it. There is no problem in perception of getting from perspectival presentations of an object to a presentation of the object itself. Instead, we begin with the presentation of the object, and afterwards can analyze out perspectival apprehensions. It is, in a sense, a surprise to me that of the table I am now seeing I in fact perceive only the thin veneer of a particular surface. To think this thought I must decompose my primary engagement with the table into the mere sensory contour of the table that I receive with my eye. The difficulty of learning to draw is not only the difficulty of learning to use one's hand with skill, but also of learning to see from a determinate perspective. A circular object, for example, a plate, must be drawn as an oval, which is to say as a condensation of the perspectival apprehension of depth into two dimensions. This phenomenon, that in perception we are immediately at the object, is what Merleau-Ponty calls perceptual faith: the fundamental conviction that in perception we have to do with the phenomenon itself and not mere appearance. But, according to Merleau-Ponty, because this conviction is only a faith, i.e., because it is unjustified, it is inherently open to skepticism. It is part of the very movement of perceptual faith that it gives way to the standards of judgment.

It would be a mistake to think that these phenomena disagree with Kant's insights. For Kant, I have argued, is not trying to show how the presentation of an object can be built out of perspectival presentations of an object, which Merleau-Ponty has shown is not a problem in prereflective experience. Instead, Kant is trying to show how the experience of an object can be justified, or rather, how there can be empirical judgment of objects at all. Doing this requires one 
to demonstrate, per impossibile, that one's presentations could not justifiedly be thought as more than subjective if they did not admit of being organized according to certain rules. But, this whole question is not the same as the question as to how there is pre-reflective experience of objects, which experience is normed not by justification but by motivation. However, reflection always runs the risk of forgetting the fact that by approaching experience with the standard of justification it transforms pre-reflective experience into empirical judgment. If it forgets this and claims to provide the basis of pre-reflective experience then it will misconstrue the lived character of perception; by holding perception to the standards of the intellect, it will make the parts prior to the whole, the moment prior to the sequence, the perspective prior to the thing. It is against this risk that Merleau-Ponty suggests a method of hyper-reflection, according to which reflection would reflect upon itself and its own conditions, i.e., would become genetic (1968, p. 38). Merleau-Ponty always distinguishes human perception from the sort of uptake of the world of which animals are capable. Whereas animals project a milieu around themselves, human perception engages a world. In other words, perception gives the world and things as transcendent, as beyond any immanent apprehension. As Merleau-Ponty puts it,

A thing is not actually given in perception, it is inwardly taken up by us, reconstituted and lived by us insofar as it is linked to a world whose fundamental structures we carry within ourselves and of which this thing is just one of several possible concretions. Although lived by us, the thing is no less transcendent to our life, because the human body, along with its habits that outline a human environment around itself, is crossed by a movement toward the world itself. Animal behavior aims at an animal milieu (Umwelt) and at centers of resistance (Widerstand).... Human behavior opens onto a world (Welt) and to an object (Gegenstand) beyond the tools that it constructs, it can even treat one's own body as an object. Human life is defined by this power that it has of denying itself in objective thought, and it draws this power from its primordial attachment to the world itself. Human life 'understands' not only some definite milieu, but rather an infinity of possible milieus, and it understands itself because it is thrown into a natural world (2012, p. 341). 
What is distinctive of human perception is that it opens onto a transcendent world: there are things for us and not only centers of attractions and resistance. ${ }^{97}$ Merleau-Ponty often invokes the example that for most primates, a box has either the significance of being a chair for sitting or a step for reaching, but never both. ${ }^{98}$ If the primate sees the box used for standing, even if it has used it for sitting in the past, it will no longer view it as a tool for sitting. Thus, the box has only a functional significance, and is not for the animal anything beneath this meaning that could coordinate multiple functional meanings, as it does for human perception, which "understands" the box. Note that Merleau-Ponty's claim is not that human perception is unique by the fact that it is taken up by the intellect (as McDowell, it seems to me, claims), but that human perception is intrinsically unique, insofar as it opens onto a world, which is why it does open onto the intellect. ${ }^{99}$ For it is the fact that human perception is geared toward the world that gives rise to the intellect, as that which, beyond perception, can contact the world in its depth. It is this orientation toward determinacy that Merleau-Ponty calls perception’s “silent thesis”:

Science and philosophy have for centuries been carried along by the originary faith of perception. Perception opens onto things. This means that perception is oriented - as if toward its own end - toward a truth in itself in which the reason for all appearances is found. Perception's silent thesis is that experience, at each moment, can be coordinated with the experience of the preceding moment and with that of the following one, that my perspective can be coordinated with the perspectives of other consciousnesses - that all contradictions can be removed, that monadic and intersubjective experience is a single continuous text - and that what is indeterminate for me at this moment could become determinate for a more complete knowledge, which is seemingly realized in advance in the thing, or rather, which is the thing itself (2012, p. 54).

\footnotetext{
${ }^{97}$ As Heidegger puts it, animal behavior is absorbed by its environment. It is "given over to" things in its environment, but does not apprehend those things as such: "The captivation of the animal therefore signifies, in the first place, essentially having every apprehending of something as something withheld from it” (Heidegger, 1995, p. 247).

${ }^{98}$ See, e.g., Merleau-Ponty 1973 (p. 104).

${ }^{99}$ For McDowell, human perception is unique in virtue of the fact that it employs conceptual capacities (of the sort that can be used in judgments). When McDowell, following Gadamer, distinguishes between a world and an environment, he does so in terms of the animal's inability to "weigh reasons and decide what to do” and think (McDowell, 1996, p. 115). McDowell's discussion of rationality and animality is fascinating and perspicacious, but on my principles, it misunderstands what is unique about human perception by understanding this uniqueness in terms of reason rather than in terms of perception itself.
} 
It is definitive of human perception that it has the intellect, and the whole critical infrastructure that involves, on its horizon. In a sense, it is true that if perception did not have the categories and the synthetic principles as a possibility that it opens onto, it would be no more than a dream, because then it would not be itself, i.e., geared toward the world. What this means is not that the intellect is a condition for perception, but that it must be able to accompany perception. As Merleau-Ponty writes,

We must say not that [the condition of possibility of experience] precedes experience (even in the transcendental sense) but that it must be able to accompany it, that is, that it translates or expresses its essential character but does not indicate a prior possibility whence it would have issued (Merleau-Ponty, 1968, p. 45).

\section{Reflective Method}

In this final section, I will argue that Kant depends on the motivating power of perception in a manner that he does not realize, and that this fact challenges the a priori status of the categories and the synthetic principles, at least on a certain understanding of what it means to be $a$ priori. The considerations that lead me to this conclusion have to do with an understanding of Kant's method, i.e., with the general form of transcendental argumentation. I will argue that this form requires that any a priori knowledge derived by transcendental argumentation be ultimately grounded in the motivating power of perception.

To make this argument, I first need to be clear about my understanding of the general form of Kant's transcendental argumentation. Karl Ameriks distinguished between two ways of interpreting Kant's transcendental deductions, one as progressive and the other as regressive (1978). Both interpretations agree that the basic step distinguishing a transcendental argument is

the conditional connection between a proposed body of knowledge and a transcendental condition for this body of knowledge. But on a progressive interpretation (proposed by, e.g., Strawson) Kant's purpose in drawing this conditional connection is to refute skeptical objections to the proposed body of knowledge, i.e., secure the proposed body of knowledge. In contrast, on a regressive interpretation (defended by Ameriks), Kant assumes the proposed body of knowledge 
as given, and on these grounds concludes that the transcendental condition for this knowledge is objectively valid. In the context of the Second Analogy, a progressive interpretation would hold that Kant is attempting to secure our knowledge of objective time order from skeptical worries. In contrast, a regressive interpretation would hold that Kant is assuming that we do have knowledge of objective time order, and is demonstrating the validity of causality as a condition for the possibility of that knowledge. ${ }^{100}$

I take it that Kant's transcendental argumentation is regressive. This is because the purpose of Kant's transcendental arguments is to establish the objectivity validity of transcendental conditions, and to do so he must presuppose the experience the conditions of which he is deducing. If instead he were attempting to secure our experience from the skeptic, his argument would not demonstrate the objective validity of transcendental conditions but presuppose it.

Consequently, I understand the general form of Kant's transcendental argumentation as follows: Kant deduces the objective validity of a priori knowledge as knowledge of structures which are condition for the possibility of experience. This form of argumentation can be explicated as follows:

a) If experience takes the form $\mathrm{X}$, then the objects of experience must be characterized by the general form Y.

b) Experience takes the form $\mathrm{X}$.

c) Therefore, the objects of experience must be characterized by the general form Y. Here $\mathrm{X}$ names a generally agreed to feature of our experience, and $\mathrm{Y}$ names a piece of $a$ priori knowledge. The minor premise describes our experience, while the major premise is the transcendental move; the turn from experience to the conditions for its possibility. For example, Kant's argument in the Second Analogy boils down to the claims that we do experience an

${ }^{100}$ See also Watkins 2004 (pp. 206-7). 
objective time order, and that only if the objects of experience are governed by causal necessity is it possible that we experience an objective time order. To reach the conclusion that the objects of experience are governed by causal necessity, then, Kant must hold that we do in fact experience an objective time order. So, the transcendental condition is justified in the conclusion only insofar as the minor premise holds. But the minor premise cannot be justified in this same fashion, precisely because it is the condition upon which the conclusion is justified. Instead, it must be presupposed. ${ }^{101}$

This poses a problem for Kant's account. For if the minor premise is presupposed, it cannot be justified a priori. Synthetic a priori judgments are justified as conditions for the possibility of experience. But the synthetic judgments that figure in the minor premise of a transcendental argument (such as "Experience takes the form X," for example, "Experience is disclosive of an objective time order”) are not conditions for the possibility of experience: they are descriptions of experience. ${ }^{102}$ Therefore, they do not count as synthetic a priori knowledge. And if these do not count as synthetic a priori knowledge, then the conclusions derived from these will not be justified purely a priori, but only a priori given certain features of experience. What can be known a priori by transcendental argument is only that the categories and the synthetic principles are objectively valid; as conditions for the possibility of experience, any object given in experience would have to have the look prescribed to it by the categories. But this does not settle whether any objects can in fact be given to a being whose experience is governed

\footnotetext{
${ }^{101}$ One might object to this line of thinking by claiming that Kant only presupposes the unity of apperception, which is justified analytically. The analytic unity of apperception requires an a priori synthesis of all presentations, i.e., the synthetic unity of apperception. This, in turn, requires laws of synthesis. So, these laws are justified analytically and not on the basis of any presuppositions about the character of experience. The problem with this response is that there is no way of getting from the synthetic unity of apperception to the laws of experience without knowing something about the character of experience. For example, the synthetic unity of apperception does not by itself entail causal order - it does so only if additionally one presupposes that experience has objective time order. Consequently, this response does not avoid the problem.

102 The minor premise of a transcendental argument is a judgment, because it predicates of experience a certain characteristic, e.g., objective time order. But they are not analytic, for nothing of the concept of experience as such entails time order (a being possessing intellectual intuition would have experience not characterized by time order).
} 
by the categories, a matter which can only be settled by experience itself. To move from objective validity to cognition of objects, then, one must supply an additional premise that can only be provided by experience. Perhaps Kant, ultimately, is only interested in demonstrating the objective validity of synthetic a priori judgments (i.e., that if there are objects, then they would have to have the form ... ). If this were so, then it would not conflict with the thesis I have been defending, namely, that there is no a priori justification that is not founded on experience. But it seems that the intent of the first critique moves in another direction, namely, determining what exactly is it that can be known a priori.

Might we think that the features of experience are known a priori but not in a manner that is justified by a transcendental argument? It seems to me that this would cut against the core principles of the first critique, for it would amount to a sort dogmatism, i.e., "The pretension that we can make progress by means of no more than a pure cognition from concepts ... without inquiring into the manner and the right by which reason has arrived at them” (p. B xxxv). In other words, such a response would not be fully critical.

To be clear, I am not making a skeptical objection. I assume we do know the features of experience that Kant presupposes in his transcendental arguments. My point is only that these features are not justified by Kant's own principles, and that if this is so, then the whole transcendental infrastructure will ultimately rely on something other than justification. The wrong conclusion would be to think that therefore Kant's conclusions are merely to be explained by facts about our subjectivity, i.e., the skeptical conclusion. Instead, the features of experience that Kant presupposes are motivated. They are known a priori, but in the sense of a priori knowledge I described in chapter 3, i.e., not known independently of experience, but founded on experience because motivated in the course of experience. ${ }^{103}$

103 This would include a kind of a priori not found in Kant: what Husserl calls the material a priori. See Gallagher (1972) for an explanation of the difference between Kant and Husserl here. 
Reflective thinking relies on the experience that it explains. The priority at the transcendental level of the condition to the conditioned is reversed phenomenologically and epistemologically: here the conditioned, experience, is itself the condition, the epistemic starting point. This does not contradict Kant's project; it only reframes this project by placing it within a genetic context that occurs beneath the level of description with which Kant is primarily concerned. As Merleau-Ponty puts it, "The whole reflective analysis is not false, but naïve, as long as it dissimulates from itself its own mainspring” (1968, p. 34). ${ }^{104}$ In contrast, it is into this main-spring - into its own ground - of reflective method that Merleau-Ponty's phenomenology inquires, and it is here that an account of motivation is required.

104 This line of thinking both partially converges with that of Fink (2005) - insofar as both are concerned with the origin or the world-form - but also moves in another direction. My critique has been epistemological, whereas Fink's is transcendental, holding that critical philosophy is mundane to the extent with the connection between worldly beings and the world-form, whereas phenomenology is concerned with the origin of the world. 

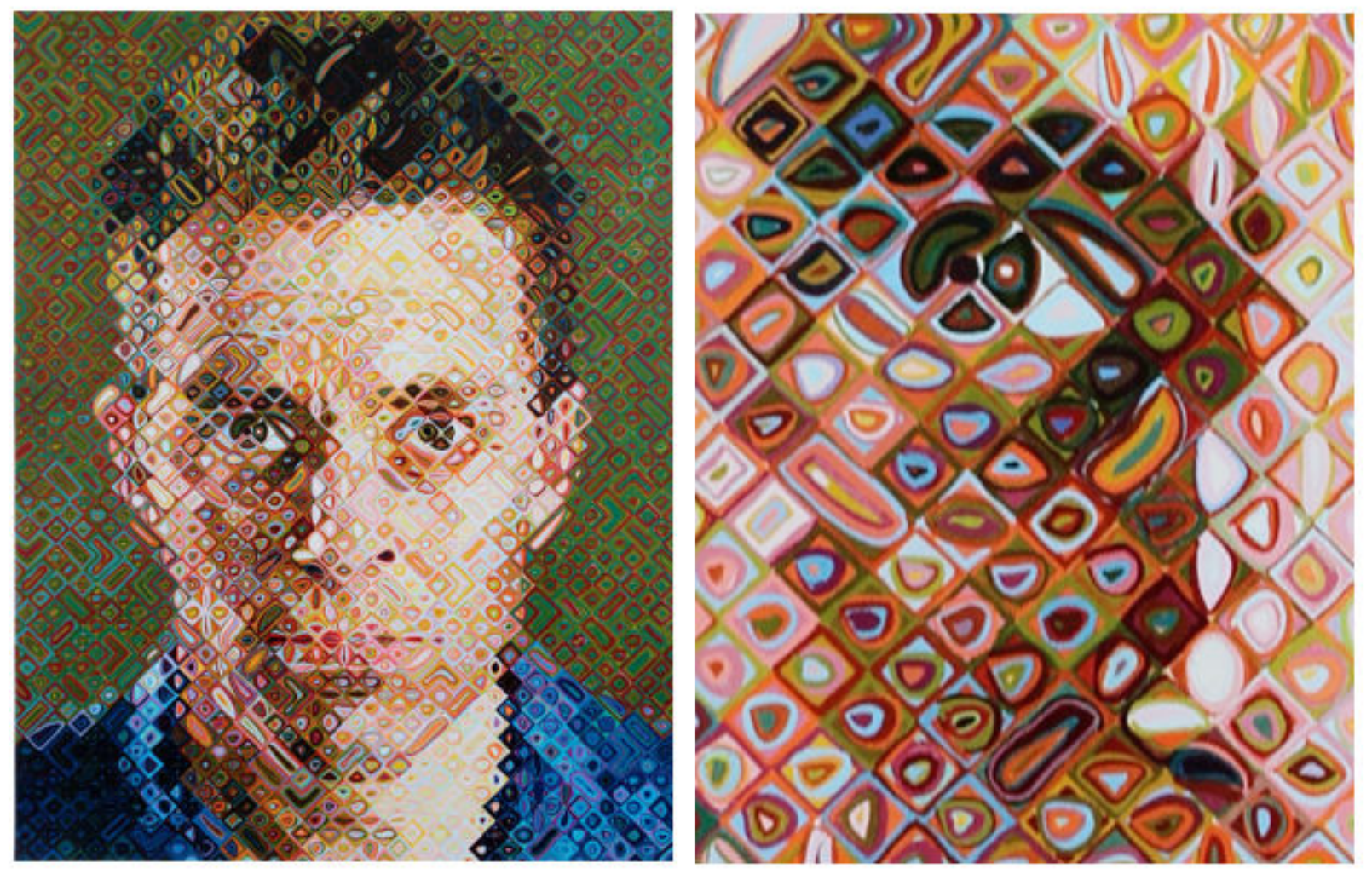

Figure 4.1. “James” with Close-up. Reprinted from artyfactory.com, 2004, Retrieved August 9, 2017 from https://www.artyfactory.com/art_appreciation/portraits/chuck_close.html. Reprinted with permission. 


\section{CHAPTER 5. SELF-CONSCIOUSNESS}

Kant, in the Critique of Pure Reason, provides a critique of metaphysics. By metaphysics, Kant means cognition wholly independent of experience: "Metaphysics is a speculative cognition by reason that is wholly isolated and rises entirely above being instructed by experience. It is cognition through mere concepts ... so that here reason is to be its own pupil" (p. B xiv). As I explained in chapter 4, Kant develops a kind of a priori justification in the first critique: transcendental justification, i.e., justification of synthetic a priori knowledge as a condition for the possibility of experience. Metaphysics, in contrast, aims to provide a priori justification through mere reason, and whereas the concepts produced by the understanding are constitutive of the objects of experience, the concepts produced by reason are not. Because metaphysics aims at cognition through mere reason, the sorts of judgments made by metaphysics cannot be described as conditions for the possibility of experience. Consequently, according to Kant, such judgments cannot be adequately justified, and so are purely speculative. In the "Transcendental Dialectic," Kant explores the dialectical (that is, sophistical or illusory) conclusions reached by reason independently of experience, demonstrating that these conclusions rest on a common error, namely, that "the subjective necessity of a certain connection of our concepts for the benefit of understanding is regarded as an objective necessity of the determination of things in themselves" (p. B 353).

In chapter 4, I showed that Kant's critical project is compatible with Merleau-Ponty's phenomenological one, insofar as these two conduct their investigations on different levels: the first on the level of empirical judgment with the standard of justification and the second on the level of perception with the standard of motivation. In the present chapter, I will consider the consequences of this line of thinking for Kant's critique of metaphysics. While I think Kant is right that the conclusions reached by dialectical reason are not justified by experience, these conclusions may yet be motivated by it. Motivation, in other words, opens the door to something like metaphysical thinking. This kind of metaphysical thinking - grounded on the motivating 
power of experience - could never suffice as a response to the skeptic. The skeptic approaches our beliefs with the standard of justification, and motivated thinking does not meet this standard. And yet, as I have argued, motivated thinking is the source of our epistemically fundamental beliefs. All reasoning comes back to motivated belief; all justification is at some point grounded on motivation. The skeptic merely turns the consequent against the ground, and not without reason, for this is in a sense the philosophical project: the deliverance of belief onto the firm ground of reason. The skeptic's project is legitimate, and so a response must be made to the skeptic. This is what Kant does in attempting to justify certain types of knowledge a priori. However, it would be wrong to think that all beliefs that are not justified are therefore unconstrained by experience; I have argued that motivated beliefs are unjustified but are solicited by experience. It would be improper, then, to call this kind of metaphysical thinking "illusory" it is normed by experience. In other words, there is a kind of thinking that, through describing experience, attempts to clarify the motivational lines running between experience and belief, and in this manner to make clear and distinct the evidence of experience. This kind of thinking is phenomenological. On this description, Merleau-Ponty’s phenomenology and critical philosophy do not conflict, they merely operate at different levels: phenomenology approaches belief with the standard of motivation and critical philosophy approaches it with the standard of justification. Yet neither are they properly independent of each other. The experience which phenomenology describes tends of itself to pursue a more thorough grounding, i.e., justification. Conversely, critical philosophy relies on the experience which phenomenology describes.

Bearing out this line of thinking to completion would require a dissertation of its own. My aim in the present chapter is to demonstrate how such a project would look by considering how it can be applied to a particular metaphysical question: that explored by Kant in the Third Paralogism, namely, the identity of the self. In this chapter, I will argue that experience motivates our belief in the identity of the self. But, as Kant points out, experience does not justify this belief, and so a different line of thinking is required at the level of justification. I will describe 
how Merleau-Ponty's phenomenological approach to self-identity is compatible with Kant's critical approach, given that the two evaluate this belief with different standards. However, I will also argue that Kant's approach tacitly draws on the phenomenological description of selfperception. I take this to be not a shortfall of Kant's project, just a demonstration that his project implies the phenomenological project.

\section{The Paralogisms}

Kant's claim in the Paralogisms is that rational psychology - the attempt to establish knowledge about the self through reason alone - makes each of its major inferences on the basis of a common error, namely, by conflating different manners in which we speak of a subject. The general form these inferences take is as follows:

i. What must be thought as $X$ is $X$

ii. A thinking being as such must be thought as $X$

iii. Therefore, a thinking being as such is $X$

According to Kant, the major premise refers to a being that can be thought in general, i.e., both thought and intuited, but the minor premise refers to a being that can be thought but not intuited. In other words, the major premise refers to being as it is in itself, as it would be known by an intellectual intuition. But, our intuition is not intellectual but sensible (i.e., it has space and time as forms), and so does not deliver beings as they are in themselves but only as they are for us. Consequently, we can have no knowledge of such a being. In the context of the Paralogisms, this means that we can have no knowledge of the self such as it is in itself. Any experience of myself necessarily occurs under the condition of time, the form of inner sense, and hence the "I" is experienced not as it is in itself, but as it appears in time. In the Transcendental Aesthetic, Kant writes,

Whatever is presented through a sense is ... always appearance. Hence either we must not grant that there is an inner sense at all, or we must grant that the subject who is the object of this sense can be presented through it only as appearance, and not as he would judge himself if his intuition were self-activity only ... (p. B $68)$. 
In contrast, the minor premise refers to the self, a thinking being, insofar as we are transcendentally constrained to think it. However, no intuition can be given that fulfills this thinking. In other words, the major premise refers to the self as it is in itself, whereas the minor premise refers to the self of transcendental apperception to which no content can be given by empirical apperception. For this reason, no conclusion can be drawn from these two premises.

At the core of each Paralogism, then, is the distinction between transcendental and empirical apperception. To understand the Paralogisms, we'll have to understand this distinction.

Empirical apperception names our experience of ourselves, the self we are given or of which we have intuition. The sort of intuition we have of ourselves is basically an awareness of the flux of consciousness, i.e., that I am thinking now X, now Y, now Z, etc.. These thoughts are an intuition of self because they are determinations of my mind, i.e., each thought is predicated of me: “I am thinking X”. Thus, Kant equates empirical apperception with “inner perception,” i.e., “consciousness of oneself in terms of the determinations of one’s state” (p. A 107). Such determinations include any manner of presentations, both subjective (such as feelings or sensations) and objective (such as experiences and cognitions). ${ }^{105} \mathrm{I}$ can attend to all such presentations as determinations of my state in virtue of my ability to perceive my own state. If I perceive that a storm is beginning, I can attend not only to the storm, but to the thrill it causes just under my skin, or to the perception itself of the storm, as a determination of my consciousness: that at such a moment I am having such a presentation and not some other one.

According to Kant, such empirical apperception is incapable of delivering anything constant. Our inner perception delivers instead a constant flux of determinations: a stream of presentations in which nothing holds. But this means that empirical apperception is incapable of demonstrating the subject's identity. For, following Hume, if this flux of presentations were to

\footnotetext{
105 "All presentations, whether or not they have outer things as their objects, do yet in themselves, as determinations of the mind, belong to our inner state” (p. B 50).
} 
justify us in thinking that the subject is identical throughout this flux, then there would have to be some constant presentation. Just as I cognize the identity of an external object by noting the identity of some presentation in it throughout a given time frame, so to cognize the identity of the self I would have to be given some identical presentation throughout the entire time frame that I attribute to myself. No such presentation is to be found. Consequently, Kant writes that empirical apperception "can give us no constant or enduring self in this flow of inner appearances” (p. A 107) and again that it is "intrinsically sporadic and without any reference to the subject's identity" (p. B 133).

In contrast, transcendental apperception presents the I not as it is given, but as we are transcendentally constrained to think of ourselves. We are, according to Kant, transcendentally constrained to think of the I as a unity for two distinct reasons. The first reason is that transcendental apperception is a condition for the possibility of experience. As we saw in chapter 4, I can only be justified in thinking that there is something like an object of experience in general if my presentations are bound by a necessary synthesis. And since we do experience objects, the manifold presentations given by the intuition must be bound by a necessary synthesis. Our sortal concepts (e.g., “triangle”) and the categories more generally provide particular rules for synthesis. But these rules can only be justifiedly applied to the manifold if we have some ground for thinking that all our presentations belong together. The transcendental unity of apperception - the thought of the necessary unity of all my presentations - is this ground. As a condition for the experience of objects (necessary unities), an experience which we do in fact have, this necessary unity of apperception is transcendentally justified. ${ }^{106}$

\footnotetext{
${ }^{106}$ This argument, while ultimately common to both deductions, is made slightly differently in each. In the A Deduction, Kant argues that concepts define a necessary synthesis of a manifold, and since any necessity must have a transcendental basis, there must be some transcendental basis for this necessary synthesis. This basis is transcendental apperception (pp. A 106-7). Similarly, Kant opens the B-Deduction by arguing that experience depends on combination or synthesis of the manifold of intuition, that combination is the presentation of synthetic unity of the manifold - such that the presentation of unity is not produced through combination but is that which allows combination - and hence that the presentation of synthetic unity is a
} 
Kant also adduces a second, distinct sort of justification for the transcendental unity of apperception. While in the first place this unity is justified as a condition for the possibility of experience, in the second it is justified analytically, by analyzing the very concept of "my presentation.” ${ }^{107}$ In $\S 16$ of the B-deduction, Kant argues that the I think must be capable of accompanying all my presentations (on threat of contradiction), and since my presentations are manifold, everything manifold in a presentation must have reference to the same subject (the same "I think"). The unity of apperception is thus derived analytically.

Transcendental apperception, while constraining our thinking, does not give an I, that is, it offers no intuition of the self. Kant writes of transcendental apperception that "this presentation is a thought, not an intuition" (p. B 157). As we saw above, it is this lack of intuitive fulfillment that makes the Paralogisms possible. Transcendentally, the I must be thought as substance (insofar as the "I" does not attach to thought as a predicate), as simple (a complex thought cannot be distributed through multiple subjects, and hence the subject of a complex thought must be simple), as identical through time (because variation occurs in time, and time is the form of inner sense, and hence is referred to the identical subject), and as distinct from things outside it. But in the Paralogisms this necessary form of thinking the subject - what Kant calls the "logical” subject - is confused with a "real” subject, i.e., a subject that is or could be really given (p. A 350). The rational psychologist mistakenly takes this necessary presentation of the self for a genuine cognition of an object.

\section{A. Apperception and Identity}

According to Kant, empirical apperception is insufficient to ground cognition of the I's identity. As we saw, he claims that empirical consciousness is "intrinsically sporadic" or

condition for experience (p. B 131). Transcendental apperception provides this presentation of unity, and hence is a condition for experience.

${ }^{107}$ Note: It is unclear exactly what concept is analyzed to derive the unity of apperception. Allison thinks it is the concept of discursive thinking (2004, p. 166). I follow Longuenesse, who claims it is the concept of "my presentation" (1998, pp. 67, note 13). But what is important, for my purposes, is not so much what concept is here analyzed, but that the unity of apperception is arrived at analytically. 
dispersed [zerstreuet] and "without reference to the subject’s identity” (p. B 133) and that inner perception "can give us no constant or enduring self” in the flow of inner appearance (p. A 107), i.e., in the shifting determinations of our state. Since Kant's meaning behind these claims is not immediately obvious, let me be clear about how I interpret them.

Kant equates empirical apperception with inner perception, i.e., "consciousness of oneself in terms of the determinations of one's state” (p. A 107). But the determinations of one's state are mutable. As Kant puts it in the third Paralogism, "We do not encounter in the soul any permanent appearance ...” (p. A 364). ${ }^{108}$ Kant, I take it, is referring to the arguments made by Hume in his Treatise of Human Nature. ${ }^{109}$ There, Hume argued that no impression gives rise to the idea of personal identity, and so personal identity is a fictitious idea. According to Hume, if any impression were to give rise to the idea of self, it would have to "continue invariably the same through the whole course of our lives," but we have no such "constant and invariable” impression (Hume, 2009, p. 526). What we are in reality, according to Hume, is a bundle of distinct perceptions. Hume's final argument runs as follows. The idea of identity is established in one of three ways: 1) Our perceptions are not actually distinct and can be "run into one," 2) We observe some real connection between our distinct perceptions, or 3) We associate these perceptions in the imagination and falsely attribute identity to them (Hume, 2009, p. 529). Hume argues that the first option won't work, because each perception is a distinct existence, separable from each other perception. Further, the second option won’t work because we never observe real connections among objects. Therefore, we associate perceptions on the basis of the relations of resemblance and causality, which leads us falsely to attribute identity to these perceptions. Kant, of course, argues that there is instead a transcendental basis for the unity of our perceptions, but agrees with

\footnotetext{
108 Kant excepts the mere presentation $I$, as an appearance that is permanent. But this appearance is not given by inner sense (by intuition), and is only a thought.

${ }^{109}$ For an argument for Kant's familiarity with Hume's critique of personal identity, see Kitcher 1990 (1990, pp. 97-100).
} 
Hume that empirical inner perception is insufficient to ground this identity, since empirical inner perception contains no constant or enduring perception.

While I am not, therefore, empirically licensed to think of the self as identical, I am transcendentally required to do so. This is because, at the transcendental level, time is in the "I," as the form of the I's inner sense, and so for whatever time I am conscious, this time belongs within the identical self. But for another subject, Kant considers, I am something within time, far from time being within me (p. A 362). In other words, at the empirical level, I am something within time, i.e., I intuit myself (through inner sense) and others intuit me (through their outer sense) under the form of time, and since there is no permanent element in this intuition, no permanent self is given. While I am transcendentally constrained to think of the self as identical, then, this does not give me any cognition of myself as an identical subject, because no intuition can be given for this thought. Consequently, the inference of rational psychology with regard to personal identity is paralogistic, i.e., it conflates the transcendental with a cognition of the in itself.

\section{The Tacit Cogito}

Merleau-Ponty might seem to be opposed to Kant’s thinking about apperception. Certainly, Merleau-Ponty indicates as much (2012, p. 449). But, again, these two projects are not opposed but compatible. Kant's account of the transcendental unity of apperception seems to me undeniable as a condition for the possibility of empirical judgment, but not as a condition for the possibility of perception. For, as we saw in chapter 4, if experience is approached with the standard of justification, then something like an object of experience is only possible if some rule prescribes a necessary synthesis to one's presentations: for any empirical judgment to have objective purport, it must aim at some necessary synthesis. And, as Kant puts it in the Adeduction, “Any necessity is always based on a transcendental condition” (p. A 106). The ultimate transcendental condition for any necessary synthesis of a manifold is that all the manifold of intuition be necessarily united in a single consciousness, i.e., the transcendental unity 
of apperception. Or as Kant puts it in the B-deduction, the condition for any judgment (because judgments, unlike associations, have objective purport) is a necessary unity of the manifold judged. As we saw in chapter 4, this does not mean that in any empirical (and hence contingent) judgment the "presentations belong necessarily to one another in empirical intuition" but rather that they "belong to one another by virtue of the necessary unity of apperception in the synthesis of intuitions” (p. B 142). If we approach experience with the standard of justification, the standard appropriate to empirical judgment, then the necessary unity of apperception is a transcendental condition for experience.

But justification is not the standard appropriate to perception, or so I have argued. Instead, motivation provides the kind of normativity characteristic of perception. A crucial consequence of this thought is that perception has objective purport without being governed by the necessity of laws (though as I argued at the end of chapter 4, the necessity of laws must be able to accompany perception). With respect to apperception, this means that a necessary synthesis of the manifold will not be a transcendental condition for perception, and so neither will a necessary unity of consciousness. Instead, because the perceptual synthesis of an object must only be actual and motivated, it has as its condition only that consciousness have an actual and motivated unity. Merleau-Ponty describes just such a unity of consciousness with his account of the cohesion of a pre-personal life, or what he also calls the tacit cogito. In this section, I will explain what kind of unity this is and how it is motivated in the course of experience. To do this, I begin by explaining a series of distinctions drawn by Merleau-Ponty: the personal and the prepersonal, the tacit and the spoken cogito, and cohesion and identity.

\section{A. Personal and Pre-personal Existence}

By “personal existence,” Merleau-Ponty means the I that is in the phenomenological sense active - the self that decides upon ends, deliberates, is directly conscious of objects, and 
articulates to itself its mode of existence (this is also the I that has a personal history). ${ }^{110}$ Beneath this personal self is a pre-personal self that both enables and challenges the personal self.

Whereas the personal self is active, conscious, and deliberate, the pre-personal self is spontaneous, implicit, and semi-autonomous in relation to personal decision. A couple examples will help to bear out this idea.

1) Merleau-Ponty introduces this distinction in his analysis of phantom limb, for in this disorder we can see the two levels of existence in conflict. At the personal level, a subject experiencing phantom limb knows themselves no longer to possess the lost limb. Yet they may continue not only to experience sensations in this limb, but to experience it as part of their body schema. They may feel the limb’s presence, may launch themselves into walking despite lacking a leg, may continue to reach out for objects with an arm that is no longer part of them. Beneath the actual body and the subject's personal experience of it, then, is a habitual body which sustains their interactions with the world without advertence. Merleau-Ponty writes,

My life is made up of rhythms that do not have their reason in what I have chosen to be, but rather have their condition in the banal milieu that surrounds me. A margin of almost impersonal existence thus appears around our personal existence, which ... is taken for granted, and to which I entrust the care of keeping me alive (Merleau-Ponty, 2012, p. 86).

We must distinguish then between our intentional interactions with the world and the habitual mode of being in the world which sustains it. This underlying existence is not fully personal, but neither is it impersonal: it is pre-personal. Of course, personal and pre-personal existence can be more or less well aligned - a novice violinist experiences the clumsiness of her body, while the virtuousa's body lends itself to and merges with her action.

2) This distinction between something like deliberate and habitual existence shows up again in Merleau-Ponty's analysis of freedom. There, Merleau-Ponty considers that a person who

\footnotetext{
${ }^{110}$ Husserl would draw a distinction here between pure ego and personal ego. See Ideas II §57 or (Husserl, 1999, p. 67). Merleau-Ponty wouldn't challenge this distinction, I think, but it involves a level of specificity that is not necessary at this point in Merleau-Ponty's analysis.
} 
has built their life upon an inferiority complex is not likely to change (2012, pp. 466-7). In a certain light, this "likely” makes no sense, he says: either one is free to change or one is not, either one makes the decision to change or one does not. Yet the freedom and the decision which belong to the level of personal existence - can gear into our lives more or less well. If the decision fails to take, as in the case of Sartre's gambler (Sartre, 1984, pp. 69-71), then tomorrow the motives for the decision will have disappeared, they will fail to have any weight for me when again I pass the gambling table. In contrast, if the decision “takes," it gradually becomes a generalized mode of existence: day by day the decision becomes less a decision and more habit. Merleau-Ponty writes, "Even our initiatives, and even the situations that we have chosen once they have been taken up, carry us along as if by a state of grace” (2012, p. 480). Along with personal existence, which deliberates and reaches the decision, is pre-personal existence, i.e., the generalized existence which either supports personal existence (“carries us along as if by a state of grace”) or erodes it, e.g., making it unlikely that the inferiority complex will be overcome.

3) This distinction bears also on our personal histories. Merleau-Ponty writes, When I am overcome with grief and wholly absorbed in my sorrow, my gaze already wanders out before me, it quietly takes interest in some bright object, it resumes its autonomous existence. After this moment, in which we attempted to lock up our entire life, time (or at least pre-personal time) again begins to flow, and it carries with it ... [our] heartfelt emotions ... . Personal existence is intermittent ... (2012, p. 86).

Here personal existence, which is locked up in grief, is distracted by pre-personal existence, which is open to the solicitation of stimuli in its environment. The autonomy of the gaze is the important thing. It is not consciously directed (I may not even be aware that I am moving my eyes), because consciousness is focused the experience of loss. Consciousness is closed to the environment around it, but the gaze remains open. And so even when, as in grief, the personal significance of a moment is immersive, the banal rhythms of the body - response to stimulation, hunger, tiredness - intervene and renew the passage of time. 
4) In chapter 1, we saw Merleau-Ponty's analysis of the Gestalt theory result that the following collection of dots

is always perceived as "six groups of dots, two millimeters apart.” This perception is not arrived at by a conscious synthesis that groups the near dots rather than the distant ones. It is not a personal decision. Instead, it is simply the manner in which I find things. As discussed in chapters 1 and 2, this perceptual structure is a "spontaneous valuation:" neither actively constituted nor a passive (causal) impression, neither personal nor material, but rather pre-personal. In perception, personal and pre-personal existence for the most part function in unison, though in the case of the illusion (recognized as such) they conflict.

In each of these cases, we see an active "personal” existence negotiated with an autonomous “pre-personal” existence. But how does this distinction play into Merleau-Ponty’s account of self-consciousness?

\section{B. Tacit Cogito and Spoken Cogito}

Merleau-Ponty uses his distinction between personal and pre-personal existence to draw a second distinction, between two kinds of self-awareness, namely, what he calls the "tacit cogito" and the "spoken cogito." I'll briefly explain this distinction, and then clarify its relation to the personal/pre-personal distinction. ${ }^{111}$

\footnotetext{
${ }^{111}$ Merleau-Ponty develops his notion of a "tacit cogito" in the Phenomenology of Perception and, as is well known, later draws it into question in The Visible and the Invisible, writing for example that the tacit cogito is "impossible" (1968, p. 171). One might wonder, in this case, both whether it is legitimate to attribute this concept to Merleau-Ponty and whether the concept itself is sound. But there is a question about how strongly to take Merleau-Ponty's rejection of the tacit cogito. Some, like Robert Vallier, take it strongly, suggesting it amounts to a "serious criticism" of Merleau-Ponty's earlier work (Vallier, 2005, p. 285). Others, like Marratto, argue that Merleau-Ponty is not so much "overcoming” as "refining” his earlier notion of the self (Marratto, 2012, p. 172). It seems to me that we should not take Merleau-Ponty's claim that the tacit cogito is "impossible" too strongly. For he goes onto explain that this is because something like a "cogito," a thinking or reflecting consciousness, is only possible in virtue of speech, and so the idea of a tacit cogito is an oxymoron. Yet, later in the same passage, he explains that there are nevertheless nonlanguage (i.e., tacit) significations, which are not "positive," and exemplifies this as follows: "There is for example no absolute flux of singular Erlebnisse; there are fields and a field of fields, with a style and a typicality" (Ibid.). But this, as we will see in the next section, is exactly how he describes the cohesion of the tacit cogito. Indeed, in a later note, Merleau-Ponty returns to using the term "tacit cogito" approvingly
} 
What Merleau-Ponty wishes to establish with this distinction is that I would not be able to express the cogito meaningfully (and with evidence) if it were not instantiated in my experience prior to expression. The spoken cogito - what we encounter, for example, when we read Descartes' Meditations - is a third-person cogito: when I read someone else’s "I think," the "I" specified is not my "I." ${ }^{112}$ If this proposition is going to have for me a) a sense and b) an authentic sense (evidence) - if I am to be able to affirm Descartes’ proposition of myself - then the spoken cogito must express and be founded upon a tacit cogito.

Merleau-Ponty is not so much interested in the capacity to verbalize self-consciousness as in the capacity to think it articulately. According to Merleau-Ponty, one cannot think a meaning that one cannot express, and so the capacity to express or articulate the cogito names the capacity explicitly to think the cogito. ${ }^{113}$ Thus the distinction between the spoken and the tacit cogito is a distinction between an explicit and an implicit self-consciousness, or rather, between judgment and experience. Put this way, Merleau-Ponty's claim is that we can only explicitly reflect on ourselves (in any meaningful way), because we have a kind of implicit self-awareness prior to reflection. This is revealed, for example, in the way that we are always concerned with ourselves (something like what Heidegger calls "Care") without constantly explicitly reflecting upon ourselves. Merleau-Ponty writes,

Beyond the spoken cogito, the one that is converted into utterances and into essential truth, there is clearly a tacit cogito, an experience of myself by myself. ... The tacit cogito, presence of self to self, being existence itself, is prior to every philosophy, but it only knows itself in limit situations in which it is threatened, such as in the fear of death or in the anxiety caused by another person's gaze upon me (2012, p. 426).

(Merleau-Ponty, 1968, pp. 178-9). Admittedly, there may be problems with the idea of the tacit cogito as formulated in the Phenomenology of Perception. But the idea that the self is in contact with itself prior to the explicit cogito is undeniable, and that it is so in virtue of "the cohesion of a field," soon to be discussed, is attested to by both the Phenomenology and The Visible and the Invisible.

${ }^{112}$ Descartes, of course, intends that readers take up the "I think" for themselves, not as a second-hand ego. The question here, however, is how it is possible for the readers to do this, to find themselves in the written "I".

${ }^{113}$ For the idea that one cannot think a meaning that one cannot express, see Phenomenology of Perception, Part I, chapter 6. 
Such limit situations reveal that I have a sort of presence to myself, in virtue of which I am always ready explicitly to recognize that a situation concerns myself (as in fear or embarrassment I recognize a situation as concerning myself).

But what exactly is the content of this tacit cogito? In other words, what is this experience of myself that licenses my explicit judgments about apperception? It is, I claim, what Merleau-Ponty calls the "cohesion of a life," i.e., the experience of our lives as cohesive.

\section{The Cohesion of a Life}

Merleau-Ponty characterizes the kind of unity that subjectivity possesses as follows:

I am not a series of psychical acts, nor for that matter a central I who gathers them together in a synthetic unity, but rather a single experience that is inseparable from itself, a single 'cohesion of life,' a single temporality that unfolds itself [s'explicite] from its birth and confirms this birth in each present (2012, p. 430).

The "I" should be understood neither as a "bundle" or "heap" of distinct sensations or acts nor as standing outside of these sensations or acts; it is their cohesion. The important thing is to understand the kind of unity that “cohesion” implies. One way to get at this unity is by contrasting it with Hume's claim that the sensations which we entertain are distinct and separable. For Merleau-Ponty, the kind of unity we possess means that our distinct experiences are in an important sense not separable.

Merleau-Ponty writes,

My first perception, along with the horizons that surrounded it, is an ever-present event, an unforgettable tradition; even as a thinking subject I am still this first perception, I am the continuation of the same life that it inaugurated. In a sense, there are no more distinct acts of consciousness or of Erlebnisse in a life than there are isolated things in the world (2012, pp. 429-430).

The point is not, of course, that there is no difference between our experiences. The content of inner perception does not all simply run together into a single sensation. ${ }^{114}$ The point is that while

\footnotetext{
${ }^{114}$ This is precisely the point on which Merleau-Ponty disagrees with Bergson's analysis of time (which Merleau-Ponty thinks does run moments together): "Instant C an instant D ... are never indiscernible, for then there would be no time at all” (Merleau-Ponty, 2012, p. 444).
} 
our experiences are different, they are not separable. One's feeling of grief, for example, is different from one's consciousness of a loss. Yet, they are not separate. Of course, it is possible to be conscious of a loss without grieving, and so there is an abstract sense in which the two are separable. Yet the meaning that this loss has for me and the meaning of my grief are two moments of a whole. The grief and the consciousness of the loss bear an internal relation to one another in the sense defined in chapter 1: the meaning of each founds the meaning of the other. Put otherwise, the two belong to a common field, where "field" is understood (roughly) to mean a generality each member of which is internally related (actually or potentially) to the generality. For example, lighting is a field, because the color of each member is perceived in terms of the color of the lighting. A melody is a field, because each note acquires its meaning in virtue of the melody, and in turn contributes to the meaning of the melody. The musical tone is, of course, separable from the melody. But the note has the meaning it does in virtue of the field of notes to which it belongs, the meaning of which it conversely influences: it would not have this meaning without the field, and so the meaning is not separable from the field. When Merleau-Ponty writes that there are no distinct Erlebnisse, he means that experience is a field in this sense: "I am a field. I am an experience" (Merleau-Ponty, 2012, p. 429). In other words, every experience is internally related to the whole of experience.

One way to illustrate the idea that experience is a field is to note every perception is passively interpreted in terms of typicalities. If I walk into a room for the first time, I will comport myself in terms of familiar features of the environment: I am familiar with floors, with tables, chairs, people, even if not with this particular floor, table, chair, or person. Or as MerleauPonty puts, things are always experienced in terms of style. ${ }^{115}$

Each thing appears to us through a medium that it colors with its fundamental quality. This piece of wood is neither an assemblage of colors and tactile givens, not even their total Gestalt; rather, something like a woody essence emanates from it, these 'sensible givens' modulate a certain theme or illustrate a certain

\footnotetext{
${ }^{115}$ For more on the concept of style in Merleau-Ponty, see Singer (1981).
} 
style that wood is, and that establishes an horizon of sense around this piece of wood and around the perception I have of it (Merleau-Ponty, 2012, p. 476). ${ }^{116}$

Even an object of a novel type is experienced according to generalities, e.g., whether it manifests agency. In fact, the difficult work is often not to see a particular as a case of a generality, but to see the sense of the particular in its uniqueness, as this unique modulation of a generality. ${ }^{117}$ Take a phenomenon that might seem to challenge this principle: Suppose I am writing at my desk, when suddenly a sound breaks into the silence of my apartment. The sound catches my attention; I am startled and distracted by it. Is the sound not, then, separable from the writing that came before it, is it not a fully distinct consciousness? But even if the sound were not mediated through past generalities, it would still count as a field member, because as soon as it breaks into my consciousness it is fully ready to join with a sequel: if a second note, a third, and so on sound, I will discover that it was the first note of a melody. Already as the first note it belonged to a temporal field, internally related to what was to come in virtue of this readiness. This kind of analysis - which shows how individual meanings are internally related to a field - could be repeated in any domain of human existence. ${ }^{118}$

Crucially, fields are not an accomplishment of active consciousness. I can advert to a field, as when I shift attention from the colored object to the lighting, from the particular notes to the melody. But I need not do so in order for the field to shape its members. For example, I do not

\footnotetext{
${ }^{116}$ In The Visible and the Invisible, Merleau-Ponty remarks that any particular perceived red is what it is only in virtue of the field "red," consisting of other reds presently perceived and a past history of perceived reds: "The color is yet a variant in another dimension of variation, that of its relations with the surroundings: this red is what it is only by connecting up from its place with other reds about it, with which it forms a constellation, or with other colors it dominates or that dominate it, that it attracts or that attract it ... . In short, it is a certain node in the woof of the simultaneous and the successive. ... [It is] a punctuation in the field of red things ...” (1968, p. 132).

${ }^{117}$ Cf. the distinction between originary and second-order perception at Merleau-Ponty 2012 (2012, pp. 45$6)$.

${ }^{118}$ In chapter 3, for example, I argued that intellectual evidence always belongs to a system of evidence this is another way of saying that intellectual evidence bears an internal relation to a field. Or in practical terms, each of us bears a style into their actions and interactions. Moreover, these distinct fields interact, as in the example of an emotion (grief) forming a whole with a cognition (the consciousness of loss). The "Instutition" lectures are concerned to show how domains as diverse as biological and psychological development, love, cultural developments, and domains of knowledge operate on the basis of the passive functioning of fields.
} 
need to advert to previously experienced instances of red for them to bear on this current experience of red. Moreover, these previous experiences may be forgotten beyond the possibility of recall to explicit consciousness and yet continue to bear on contemporary perceptions. The normal function of the field is to be the background against which a particular figure acquires its meaning. Further, the relation between particulars and a field is spontaneous: I do not normally synthesize the note with the melody, it is simply given as such. In this sense, fields are prepersonal, and more generally, the field of experience (as a whole) is pre-personal: it shapes particular experiences implicitly and passively, without itself being adverted to. ${ }^{119}$

Thus, while it is true that there is no constant impression within the flow of experience, this does not mean that experience constitutes a "bundle" or "heap" of distinct experiences. Our experiences bear an internal relation to each other, ultimately within the field of sense or experience that defines each individual. While this might not be apparent at the level of personal existence, in which the stream of experience appears as a sequence of distinct Erlebnisse, prepersonal existence is unified by the cohesion of a field.

\section{Motivation and Self-Consciousness}

I have drawn three parallel distinctions, between a) personal and pre-personal existence, b) the spoken and the tacit cogito, and c) identity and cohesion. If we now put these distinctions together, we are in a position to understand Merleau-Ponty's overall view of self-consciousness. Merleau-Ponty distinguishes two levels of self-consciousness: first, pre-personal cohesion that is tacitly aware of itself, and second, personal identity that is explicitly aware of itself. Pre-personal

\footnotetext{
${ }^{119}$ One way Merleau-Ponty makes this point is by describing the cohesion of the field of experience in terms of institution rather than constitution. He writes of this distinction that "To constitute in this sense is nearly the opposite of to institute: the instituted makes sense without me, the constituted makes sense only for me and for the 'me' of this instant" (Merleau-Ponty, 2010, p. 8). In other words, constitution is active; in it consciousness posits the being it apprehends. Institution, in contrast, is passive and does not depend on consciousness. Birth - in the sense of the inauguration of a new existence - is exemplary of institution: it is not an act and does not require consciousness. Yet with birth a new field of experience begins. Institution thus allows us to understand how we think of ourselves to be the same beings today that we were at age 2, an age to which we can attach no consciousness through memory. We can do this because our identity is not actively constituted, but passively instituted.
} 
existence is concerned with itself and internally related to each of its moments. Personal existence is explicitly aware of itself and of its identity across its moments. How should we conceive the relationship between these two moments of self-consciousness? I argue that Merleau-Ponty conceives the relation in terms of motivation.

On the one hand, personal existence is founded upon pre-personal existence. The unity of apperception is guaranteed by pre-personal cohesion. The pre-personal field of experience, as a generality, remains the same as itself throughout its many members. For example, a spatial field is the same field at two different points that belong to it. In this manner, pre-personal existence remains the same as itself - is in cohesion with itself - throughout the many contents of the stream of experience. Two steps move from pre-personal cohesion to the identity of apperception.

First, apperception, as self-consciousness, belongs to personal existence, i.e., conscious or intentional existence. In pre-personal cohesion, the I is merely tacit, a background feature of experience:

Just like the unity of the world, the unity of the I is invoked rather than experienced each time I perform an act of perception ..., and the universal $\mathrm{I}$ is the background against which these brilliant figures stand out ... (Merleau-Ponty, 2012, p. 429).

On the other hand, it is possible through reflection to advert to this background and make it a foreground. Much as Kant puts it, conscious experience can be raised to self-consciousness: I can attribute that consciousness to myself, can add the "I think ... " to it.

Second, I identify the "I" that I currently apperceive with past apperceptions, in order to arrive at personal identity. Pre-personal cohesion enables this move. As we have already seen, pre-personal existence is a field, and so it coheres with itself throughout the stream of experiences. Apperception adverts to this field. My apperception at the present moment can be 
identified with my apperception at a previous moment because both are a way of expressing the field of experience at a particular experience, and this field has cohesion with itself. ${ }^{120}$

There is thus a pre-reflective contact of myself with myself (a tacit cogito) that allows me to reflectively identify myself over time. But while the spoken cogito is thus founded on the tacit cogito, the tacit cogito conversely stands in need of the spoken cogito. In other words, MerleauPonty thinks the relation between these two forms of self-awareness in terms of expression, a form of relation with which we are now familiar as a case of motivation. The spoken cogito determines and clarifies what is only vague and indeterminate in the tacit cogito:

The consciousness that conditions language is merely a comprehensive and inarticulate grasp of the world, like that of the child's upon his first breath, or of the man who is about to drown and who frantically struggles back toward life. And if it is true that every particular piece of knowledge is established upon this first perspective, then it is also true that this first perspective waits to be reconquered, fixed, and made explicit through perceptual exploration and through speech. ... The tacit Cogito is only a Cogito when it has expressed itself (Merleau-Ponty, 2012, p. 426).

As a two-way relationship (foundation in one direction and determination in the other), the relationship between pre-personal cohesion and personal identity is well described in terms of motivation. Thus, there is actually a sort of personal identity motivated within the course of experience. This kind of personal identity does not suffice to meet the standard of justification because it provides no necessity, but it is nevertheless grounded in experience.

First, notice that the tacit cogito is not quite empirical apperception or transcendental apperception. It is not empirical apperception because it is not itself an element within the stream of consciousness (inner sense), which according to Hume and Kant, is what empirical apperception would have to be if it were to provide any impression of an identical self. But

\footnotetext{
${ }^{120}$ I might also express the foundational relation here in the following terms. As Husserl puts it, "Anything built by activity necessarily presupposes, at the lowest level, a passivity that gives something beforehand ... “ (Husserl, 1999, p. 78). What is the passive given upon which activity operates to identify personal existence? Suppose that the simplest form of the active operation of identification is this: I reflectively take I at time 1 and reflectively take I at time 2, then recognizing these as the same I; I identify them. The passive given that enables this operation is that I at time 1 and I at time 2 are given as cohering with each other. In identification I grasp this given cohesion explicitly, in terms of identity.
} 
neither is it transcendental apperception, because it is not a necessary unity of the stream of consciousness. Instead, it is something like the cohesion of this stream.

Second, Merleau-Ponty’s account of personal identity does not secure any necessity for the unity of apperception. This personal identity is not grounded as some permanent element in the stream of consciousness. Hume is right that there is no such impression. Instead, like transcendental apperception, personal identity has to do with the form taken by the varying elements within the stream of consciousness, namely, the cohesion of this stream; it is not an impression within the stream, but the fact that our different "impressions" are never fully distinct. Or more precisely, while our experiences are distinct, they are not separable: each bears an internal relation to the rest in virtue of belonging to a common field. This cohesion is normative and actual. It is actually the case that our impressions are never fully separable. Of course, it is possible to imagine our impressions as distinct from each other, by abstracting them from the horizon of sense which informs them, just as one can abstract notes from the melody to which they belong and arrange them in a different order. But if one intended this rearrangement to be actual, one would sense it to be wrong. For each impression is given with a horizon of sense which constrains us to arrange experience in a particular way. Only when we approach experience with the standard of justification, i.e., when we seek a necessary connection between our impressions, does this sort of cohesion turn out to be inadequate. Thus, pre-personal cohesion, and the personal identity that it motivates, are sufficient to provide for the sort of unity we find in perception. However, only a transcendental unity of apperception, such as that described by Kant, suffices to provide for the unity we find in empirical judgments.

\section{The Unity of Transcendental and Empirical Apperception}

So far, we have seen that the projects of Merleau-Ponty and of Kant are complementary. Whereas Merleau-Ponty describes the structures of pre-reflective experience or perception, Kant describes the essential structures of reflective experience or empirical judgment; whereas Merleau-Ponty describes the pre-reflective experience of the self, Kant describes the manner in 
which reflection is constrained to think of the self. I tried to show towards the end of chapter 4 that Merleau-Ponty's project needs Kant's, because Kant aims to provide an account of that to which pre-reflective experience tends (justification), and conversely that Kant’s project needs Merleau-Ponty's, because Merleau-Ponty provides an account of the ground of the structures of experience on which transcendental argumentation depends. In this section, I will make a similar claim about the reflective and pre-reflective experiences of the self. Specifically, I will argue that Kant's reflective account of the self draws on the pre-reflective experience of the self in a way which Kant does not recognize, namely, to hold that transcendental and empirical apperception pertain to the same subject. In other words, I do not see how Kant, on the terms of reflective judgment alone, can account for the fact that these two kinds of apperception refer to the same subject.

\section{A. The Problem}

The problem I wish to pose is that on the terms of Kant's account of transcendental and empirical apperception alone, Kant can refer to the I of transcendental apperception and the I of empirical apperception as the same I only homonymously. But transcendental and empirical apperception are supposed to refer to different ways of cognizing the same subject. The former names how I am a priori constrained to think the subject, while the latter names the subject as it can be intuited. But the I of transcendental apperception, even though it is supposed to refer to the same I as that of empirical apperception, does not allow us to cognize anything about that I, because the predicates pertaining to the I of transcendental apperception do not determine the contents of the intuition provided in empirical apperception; I am constrained to think of the subject as identical throughout its experience, existing, and spontaneous (as well as under the categories discussed in the Paralogisms), but these ways in which I must think the subject cannot be encountered in experience. This is a striking dissimilarity between apperception and the categories - a category like causality differs in content from empirical judgments of causal interactions only in its universality and necessity. In contrast, the intuition delivered in empirical 
apperception provides no content to the I of transcendental apperception. This is why transcendental apperception does not result in any cognition, but only a thought or a consciousness.

The issue is not that empirical and transcendental apperception share no intuitive or predicative content - this is a plausible consequence of Kant's transcendental idealism - but that this makes it incomprehensible how we know to refer transcendental and empirical apperception to the same subject at all. There is no reason to suppose that the I of transcendental apperception is the I of empirical apperception, since there is no overlap - intuitive or judicative - between the two. There is no clear answer, on Kant's account, of how we can identify the I in which there is time with the I which is in time.

In fact, Kant himself asks a similar question. In $\S 24$ of the B-Deduction, Kant asks, But how ... can the $I$ who thinks be distinct from the $I$ that intuits itself, and yet be the same as it by being the same subject? And hence how can I say: I, as intelligence and thinking subject, cognize myself as an object that is thought, viz., I so cognize myself insofar as in addition I am also given to myself in intuition except that I cognize myself, as I do other phenomena, not as I am to the understanding, but as I appear to myself? This question involves neither more nor less difficulty than does the question as to how I can be an object to myself at all, viz., an object of intuition and of inner perceptions. Yet so it must actually be ... (pp. B 155-6).

To understand Kant's question, it will help to take a step back and consider the larger context of §24. Kant's question takes place in something of an aside. After accomplishing the major task of $\S 24$ - to begin applying the transcendental deduction to specifically sensible intuition by introducing the figurative synthesis of the imagination - Kant claims that the time has come to clarify the paradoxical situation that inner sense presents us not as we are in ourselves, but only as we appear to ourselves. Specifically, what is paradoxical in this situation is that we intuit ourselves only as we are "inwardly affected," i.e., in inner sense we are passively related to ourselves. Just as I passively receive a manifold of intuition in perceiving external objects, in inner sense I passively receive a temporal manifold of the determinations of my state. This is paradoxical because I am an active being (the understanding is spontaneous), yet I receive myself 
only passively. Kant notes that some are tempted to resolve this paradox by assimilating apperception to inner sense (our activity to our passivity), but that this will not do: we know that the two are different because apperception determines inner sense. Inner sense, by itself, delivers an indeterminate manifold of intuition, which can only be organized into determinate perceptions in virtue of the understanding's activity of combination (e.g., it is the understanding's activity which determines a manifold of inner sense as some one perception, some one sensation, some one emotion, etc.). As we saw, Kant argued in $\S 15$ and 16 of the B-Deduction that such combination is only possible through the synthetic unity of apperception. Thus, it is only through the synthetic unity of apperception that inner sense is determined. Apperception and its synthetic unity affect or act upon inner sense. Consequently, inner sense and apperception cannot be the same thing.

But this sharp distinction between passive inner sense and active apperception has to be reconciled with the fact that the I presented in both is not different. Kant's answer is that we intuit ourselves not as we are, but only as we appear:

We intuit ourselves through [inner sense] only as we are inwardly affected by ourselves; i.e., we must concede that, as far as inner intuition is concerned, our own [self as] subject is cognized by us only as appearance, but not in terms of what it is in itself (p. B 156).

The I of apperception and the I given in inner perception are evidently distinct, and yet they are the same subject. This is only possible, according to Kant, through transcendental idealism about time. Inner sense gives the I according to the form of inner sense (namely, time), but things in time are appearances and not things in themselves, and so inner sense gives the I not as it is in itself but as it appears under the form of time. In other words, Kant diffuses the problem by distributing the I across the in-itself/for-us boundary: determining apperception is the I as it is in itself and determined apperception is the I as it is for us.

The distinctions at play here are expressed with greater clarity in §25. Kant begins that section by distinguishing transcendental apperception from both inner sense and myself as I am in 
myself: "... In the synthetic original unity of apperception, I am not conscious of myself as I

appear to myself, nor as I am in myself, but am conscious only that I am. This presentation is a thought, not an intuition." There are thus, in fact, not two but three ways of thinking the I under consideration: a) the I of transcendental apperception, b) the I of inner sense (myself as I appear to myself), and c) I as I am in myself (that self which is not phenomenal but noumenal). The I of transcendental apperception is not the I of inner sense, because the former determines the latter. But the I of transcendental apperception is also distinct from "I as I am in myself." The reason for this is that I could only cognize myself as I am in myself if I had some intuition of myself, but apperception gives no intuition, only a thought (recall that mistaking the one for the other, the "logical" for the "real" subject, is the source of the Paralogisms). ${ }^{121}$ Further, the I of inner sense is also not I as I am in myself, due to Kant's transcendental idealism about time.

We are now in a position to discuss the role of activity and passivity in the self. An important footnote to $\S 25$ does this work:

The I think expresses the act of determining my existence. Hence the existence [of myself] is already given through this I think; but there is not yet given through it the way in which I am to determine that existence, i.e., posit the manifold belonging to it. In order for that manifold to be given, self-intuition is required; and at the basis of this self-intuition lies a form given a priori, viz., time, which is sensible and belongs to the ability to receive the determinable. Now unless I have in addition a different self-intuition that gives, prior to the act of determination, the determinative in me (only of its spontaneity am I in fact conscious) just as time so gives the determinable, then I cannot determine my existence as that of a self-active being; instead I present only the spontaneity of my thought, i.e., of the [act of] determination, and my existence remains determinable always only sensibly, i.e., as the existence of an appearance. But it is on account of this spontaneity that I call myself an intelligence (pp. B 157-8).

\footnotetext{
${ }^{121}$ In fact, Kant draws this distinction even more starkly in the Paralogisms. There he clarifies that the transcendental unity of apperception does not give the subject as an object at all, but only as "the form of thought" or "the subject of consciousness" (pp. B 411-2). In contrast, when I refer to myself, as a thinking being, as I am in myself, I refer to myself as an object. It is confusing these two senses of "myself" that leads to the Paralogisms: in the major premise I take myself as an object (that could be given to an intellectual intuition) and in the minor premise I take myself merely as the formal subject of thought. This formal subject of thought names the way in which I am analytically constrained to think of myself (e.g., as identical, as subject, as active, as existing), but the self as it is in itself names an object that might be given to some form of intuition. Both are ways in which the understanding thinks the subject, but in the one case as the subject of thought and in the other as the object of thought. Inner sense, as an intuition of the self, gives the self as an object, but not as this object would be given to the understanding (i.e., in an intellectual intuition of the self as it is in itself).
} 
As we have already seen, apperception actively determines the manifold given in intuition, and conversely this manifold is passive with respect to the understanding's determining it. Kant thus calls apperception the "determinative" and the manifold of intuition the "determinable." The central conjecture is that I have intuition of myself only as determinable, never as determinative. I know that there is a "determinative" in me, because I am conscious of its spontaneity (i.e., I am conscious that I determine the manifold of inner sense). But inner sense does not deliver this determinative self. If it did - just as time gives the determinable - I would have an intuition of myself as active, i.e., I could "determine my existence as that of a self-active being." Lacking this intuition, I have the mere thought of my spontaneity, i.e., the "I think" of apperception. But I do not have myself as I am in myself, i.e., as a self-active being, because I lack any intuitive content to give to the mere consciousness of my spontaneity. My sole intuitive content is given under the form of time (as passively received), and this gives me not as determinative but only as determinable. In other words, when I cognize myself, I cognize myself only as a passive object (for this is how I necessarily appear under the form of inner sense), never as the active subject that I am in myself.

Thus, Kant divides the determinative I (the active I of transcendental apperception, or the noumenal self of which I have a bare consciousness of its existence and spontaneity in transcendental apperception) from the determinable I (which I empirically intuit) across the boundary between thing-in-itself and appearance. It is this boundary that allows Kant to maintain that the two are evidently different and yet are the identical subject.

This solution explains how it is possible that the empirical and transcendental apperception can be the same, but it gives us no reason to think that they are. What is totally mysterious on Kant's account is why we think of these as the same at all. Why do we not think them as two totally distinct ontological levels: objectivated being and objectivating subject? Kant's genius is to think this ontological difference radically. But what is unexplored, on Kant's 
account, is how these two belong together. In other words, Kant's account lacks the resources to explain how we could ever identify these as the same subject. Such an explanation may simply not be a part of Kant's project: he draws on this identity as pre-given. But then his project presupposes this identity, and for his project to make sense for us, we will have to understand how this identity is possible.

To see how the two can be identified, we would need to provide an account of a sort of apperception in which the determinative and determined coincide. Such an apperception would have to underlie the distinction between empirical and transcendental apperception, as the resource upon which one would rely in order to refer these to the same subject. It is precisely this sort of apperception that phenomenology aims to provide with its account of the pre-reflective experience of oneself.

\section{B. Reversibility}

At the reflective level, we must think of two exclusive kinds of apperception. Through empirical apperception, the self can never be cognized as active (as subject) and through transcendental apperception, the self can never be cognized as passively received (as object). But at the pre-reflective level, the self as subject and the self as object coincide. Every apperception at this level is reversible, i.e., can be cognized either as passive or active, can be experienced as a subject or received as an object of thought. The pre-reflective self - that of the tacit cogito - is both that which passively synthesizes the flow of consciousness and can itself be synthesized within the flow of consciousness.

The best way to see this difficult point is by turning to the phenomenological analysis of the passive synthesis of time. ${ }^{122}$ Recall that at the reflective level, apperception must be divided

\footnotetext{
${ }^{122}$ It may not be immediately clear that Kant and the phenomenology are on the same terrain here. But, first, both do draw a distinction between the self as active and the self as passive. As we will see, Husserl distinguishes between consciousness as objectivating and as objectivated. The former names the absolute flow of consciousness, and the second refers to the flow as attended to and treated as a temporal unity. Similarly, Kant distinguishes between the determinative and the determinable: the I as spontaneously synthesizing temporal unities and the I as a temporal manifold to be synthesized. In each case, the
} 
into, on the one hand, the temporal flow of consciousness (inner sense), and on the other, that which synthesizes this flow and so is not itself a part of the flow. ${ }^{123}$ In contrast, at the prereflective level, synthesizing consciousness is itself temporal and can be attended to as such, i.e., can itself be synthesized within the flow of consciousness. In other words, the passive synthesis of time is not atemporal, but is itself temporally extended. ${ }^{124}$

To bear out these points, I will make a brief excursus into Husserl's Phenomenology of Internal Time Consciousness. The passages I will consider are among the more challenging and

distinction is between the self as active - as subject - and the self as passively acted upon by consciousness - as object.

Further, as will be important in what follows, for both, the active and passive selves have different relations to temporality. For Kant, the I as determinable is a manifold of intuition given under the form of time: it is a temporal object. The active I is not a temporal object. Anything given in terms of time is passively acted upon by the synthesizing intellect, and so the I qua active cannot be given in terms of time. Similarly, Husserl calls the absolute flow of consciousness "timeless" (Husserl, 1991, p. 117). Absolute consciousness is timeless because, as that which constitutes temporal objects, it is not itself an object constituted within time. In both cases, as soon as the I is taken as an object, it is taken as a temporal object, as occupying a temporal position.

${ }^{123}$ I see no problem in assimilating inner sense and the flow of consciousness to each other. Kant's "inner sense" is a faculty for intuiting the ever-shifting determinations of one's state, i.e., the flow of presentations through consciousness. What is disclosed in empirical apperception, then, are the contents of what Husserl calls the flow of consciousness. The flow of consciousness itself would be intuited through something like pure inner sense, i.e., a pure intuition of time: pure in the sense that it is not itself an unfolding process, but an intuition insofar as what is intended is an individual, not merely a form. "Inner sense" and the "flow of consciousness" thus map onto each other, where inner sense is a faculty for intuiting the contents of the flow of consciousness.

Further, both Kant and Husserl agree that there is no constant and enduring content of this flow. Recall, this is originally Hume's point: Hume argued that if there was an impression of the identity of the self, it would have to be an impression constant and enduring throughout all of our experience, and since there is no such constant impression, neither is there an impression of identity. Kant similarly affirms that we have no intuition of a constant and enduring self. In the A deduction he writes that the consciousness of oneself given in inner sense is "merely empirical and always mutable; it can give us no constant or enduring self in this flow of inner appearances" (p. A 107). Similarly, Husserl writes that "it pertains to the essence of the flow that no persistence can exist in it" (1991, p. 118). Again, "As a matter of principle ... no concrete part of the flow can make its appearance as nonflow. The flow is not a contingent flow, as an objective flow is. The change of its phases can never cease and turn into a continuance of phases always remaining the same" (Ibid.). All that remains constant, in terms of the flow, is its form: the continuous modification of contents in terms of retention

${ }^{124}$ This is, of course, also the direction in which Heidegger wished to push Kant. Heidegger's argument in $\S 34$ of Kant and the Problem of Metaphysics is that Kant's own principles - what Kant is really striving after - commit him to a claim that he himself refuses to make, namely, that "The pure, finite self has, in itself, temporal character" (Heidegger, 1997, p. 134). Or as Heidegger puts it more contentiously, the pure self is time: "Time and the 'I think' no longer stand incompatibly and incomparably at odds; they are the same" (Ibid.). Whereas Heidegger criticizes Kant for not going far enough toward this account of the self, I take it that such an account of the self is not an intrinsic feature of Kant's project. My claim is not that the reflective account of the self is incorrect in its domain, only that it tacitly draws upon the pre-reflective experience of the self. 
contested passages of Husserl's corpus, and so to keep this material manageable, I will steer clear - as much as possible - from its complexities (I will not even consider, for example, his later thinking, e.g., in the C-Manuscripts). ${ }^{125}$ What results is a simplified version of Husserl's account, but is I think the version Merleau-Ponty has in mind when he writes about the relation between the self and temporality, and will convey the thoughts essential to my project.

In the third section of his 1905 "Lectures on the Consciousness of Internal Time", Husserl distinguishes three levels of the constitution of temporal objects: a) empirical objects in objective time (e.g., a tone sounding or a ball rolling), b) the "multiplicities of appearance" which serve to constitute these temporal objects (e.g., the temporal adumbrations of a tone, or the adumbrations of the ball rolling), and c) the "absolute time-constituting flow of consciousness" (cf. §34). ${ }^{126}$ In perception, we are given objects which persist through time. For example, I hear a siren wail. This sound persists for a period of time, say from T1 to T2 to T3, and I recognize it as a single sound throughout the time of its sounding. At no particular time is the entire duration of the sound immediately given. At T2, for example, the sound at T1 and the sound at T3 are not perceptually given. Yet I experience the siren not as a single instant, but as an enduring sound. This is possible, according to Husserl, because at T2 I have a retention of the sound I perceived at T1 and a protention of the sound as continuing (of the sound at T3). To perceive the enduring wail of the siren, then, I must maintain a series of temporal adumbrations (T1, T2, T3) of the sound, which I apprehend as a unity. We can thus distinguish the temporal object itself from the series of adumbrations which constitutes the temporal object as a unity.

\footnotetext{
${ }^{125}$ Note that there is a question about how much of the structure that I will describe (the self-constitution of the absolute flow of consciousness) is maintained in Husserl's later thinking about temporality, particularly in the C-Manuscripts. Kortooms has argued that the role of the ego in this late thinking displaces much of the structure I describe (2002). I find the responses forwarded by Brough (2016) and Mensch (2010) compelling, but in any case I am interested here in the portion of Husserl's thinking on which MerleauPonty draws.

${ }^{126}$ There is some controversy about how exactly Husserl means to carve up these three levels, namely whether the second and third level can be distinguished as intentional object and intentional act in prereflective experience. See Zahavi (2011) for an overview of this debate. My position is meant to remain neutral with respect to this debate.
} 
The temporal adumbrations of empirical objects belong to the flow of consciousness. If we reflect on our consciousness, we find an ever-changing set of temporal processes. My perception of the siren unfolds and gives way to a perception of the table before me, which gives way to a thought of my work, which gives way to feelings about this work, etc. Or more exactly, a number of temporal processes may be unfolding at the same time: while the siren sounds outside, the table remains constantly before me, and so too the cup that stands on it, which steam continuously rises out of, curls, and dissipates. All these processes unfold simultaneously for me, even though I do not advert to them all.

In each phase of this flow, then, there are adumbrations of temporal objects which stand in continuity with those in other phases of the flow. But as Hume and Kant had recognized, there is no constant and enduring content of this flow. As Husserl puts it,

No phase of this flow can be expanded into a continuous succession; and therefore the flow cannot be conceived as so transformed that this phase would be extended in identity with itself. Quite to the contrary, we necessarily find a flow of continuous 'change' ... (1991, p. 78).

Consciousness thus consists of an ever changing flow of particular temporal processes, e.g., empirical objects and our perceptions of them.

This flow must be distinguished from the temporal processes that take place within it. Husserl's argument for this distinction runs as follows: It is a property of any persisting object that it can change at differing rates. Say a tone is modulated to change gradually from high-C to low-C. This change could occur rapidly (perhaps over the course of a second) or more slowly (over the course of a minute) or at the limit, the tone could remain at rest. The flow of consciousness, however, has an in principle constant rate of change. Because the flow of consciousness is not itself the unfolding of any enduring content, it cannot change more or less rapidly, but only at a constant rate.

The interesting part of Husserl's account, for my purpose, is his claim that in the case of the flow of consciousness, constituting and constituted coincide. Husserl arrives at this claim 
initially to avoid the threat of regress. The problem can be put, in a relatively simple form, as follows: The temporal flow of consciousness - which is the constitutive condition of any temporal object - can itself be made into a temporal object. Husserl writes,

To be sure, in a way [each phase of the flow] is also an objectivity. I can direct my regard towards a phase that stands out in the flow or toward an extended section of the flow, and I can identify it in repeated re-presentation, return to the same section again and again, and say: this section of the flow (1991, p. 118).

This is true both of particular phases of the flow, and of the flow as a whole. But if the flow of consciousness can be turned into a temporal object, it seems that some further consciousness will be required in order to constitute this object. Since this further consciousness would itself admit of being treated as a temporal object, and so require a further consciousness, this line of thinking leads to a regress. ${ }^{127}$

Husserl's solution is to claim that in the case of the temporal flow, the constitutive and the constituted coincide. Specifically, Husserl claims that the flow of consciousness contains a double intentionality: a "transversal" intentionality, which intends temporal objects, and a "horizontal intentionality" through which the flow coincides with itself (Husserl, 1991, pp. 86-7). The former serves to constitute empirical objects, the latter serves to constitute the flow as a unity. Husserl writes,

The flow of the consciousness that constitutes immanent time not only exists but is so remarkably and yet intelligibly fashioned that a self-appearance of the flow necessarily exists in it, and therefore the flow itself must necessarily be apprehensible in the flowing. The self-appearance of the flow does not require a second flow; on the contrary, it constitutes itself as a phenomenon in itself. The constituting and the constituted coincide ... (Husserl, 1991, p. 88).

Yet Husserl immediately clarifies that constituting and the constituted do not coincide "in every respect." Husserl argues that the constituted and the constituting phases of the flow are not identical, because the constituted phases are past phases presently being constituted

${ }^{127}$ See Husserl 1991 (pp. 294-5) for another articulation of the problem. 
retentionally. ${ }^{128}$ Constituting and constituted phases are thus temporally distinct, even while the latter are retained within the former.

Elsewhere, Husserl distinguishes the two as follows:

If we speak of the perception of the sound, then here as everywhere else we must distinguish between this perception as absolute consciousness and the objectivated perception - more precisely, the perception as object of the perception reflecting on it (1991, p. 296).

In other words, we can distinguish between a perception as constituting (as the flow of absolute consciousness) or as constituted (the perception as object). Husserl goes on to say that it belongs to the essence of absolute consciousness, i.e., the flow of adumbrations, that it can be treated as a temporal unity in reflection, which is to say, it can be taken as an object. Thus, constituting and constituted are the same here, i.e., both as the flow of consciousness, but differently considered. Husserl spells out this distinction in the following passage:

The absolute consciousness lies, so to speak, before all positing of unity, that is, before all objectivation. Unity is unity of objectivation, and objectivation is precisely objectivating but not objectivated. All nonobjectivated objectivation belongs in the sphere of the absolute consciousness (1991, p. 297). ${ }^{129}$

"Constitution" and "objectivation" are here essentially equivalent, for Husserl is saying that the absolute flow of consciousness lies prior to constitution (objectivation), as that which is constituting (objectivating) and therefore not constituted (objectivated). Constituting and constituted phases are here distinguished as absolute consciousness and objectivated consciousness.

\footnotetext{
128 "The phases of the flow of consciousness in which phases of the same flow of consciousness become constituted phenomenally cannot be identical with these constituted phases, nor are they. What is brought to appearance in the actual momentary phase of the flow of consciousness - specifically, in its series of retentional moments - are the past phases of the flow of consciousness" (Husserl, 1991, p. 88).

${ }^{129}$ Note that Brough has claimed that this passage (dating from 1907) provides an inadequate account of the relation between absolute consciousness and the experiencing of immanent objects, a relation which is more fully worked out in later passages which we have been considering (1972, p. 309). But I do not think Husserl gives up the distinction between objectivating and objectivated in later passages, insofar as he maintains that the coincidence between the two does not amount to an identity.
} 
It is this thought - that constituted and constituting coincide in the passive synthesis of time - that Merleau-Ponty sees as the distinctive feature of pre-reflective apperception. ${ }^{130}$

Merleau-Ponty sums up his thinking as follows:

We will never understand how a thinking or constituting subject can posit or catch sight of itself within time. If the I is Kant's transcendental I, then we will never understand how it could ever merge with its own wake in inner sense, nor how the empirical self remains a self at all. But if the subject is temporality, then self-positing ceases to be contradictory because it expresses precisely the essence of living time ... The originary flow, says Husserl, does not merely exist, for it must necessarily give itself a 'manifestation of itself', otherwise we would need to install behind it another flow in order to become conscious of it. Time 'constitutes itself as a phenomenon in itself'; it is essential to time to be not only actual time or time that flows, but also time that knows itself ... (2012, pp. 449450).

Merleau-Ponty's conclusion is stronger than mine (for he claims that Kant is in error), but it gets to the point I am trying to make: the pre-reflective experience of self necessarily underlies the reflective experience of self given expression in Kant. ${ }^{131}$ This, as I will now argue, is because the reversibility of the pre-reflective experience of the self allows transcendental and empirical apperception to refer to the same subject: pre-reflective experience, as ambiguous, is capable of motivating two exclusive sorts of apperception (transcendental and empirical).

\footnotetext{
${ }^{130}$ Merleau-Ponty expressed the reversible nature of the flow of consciousness in the following passage: "If even our purest reflections in fact retrospectively appear to us as in time, and if our reflections upon the flow are inserted into the flow, this is because the most precise consciousness of which we are capable is always found to be affected by itself or given to itself, and because the word consciousness has no sense outside of this duality" (2012, p. 45).

${ }^{131}$ Merleau-Ponty's picture on the whole agrees with Husserl's: Whereas at the level of reflective judgment, Kant describes the determinative as that within which there is time, at the level of pre-reflective experience, Merleau-Ponty describes the determinative as the flow of time itself. The pre-reflective subject is "determinative" with respect to the flow of time, because it is responsible for the passive synthesis which makes distinct temporal moments into a temporal flow. As determinative, the pre-reflective subject is not itself properly something in time. It is not temporal, then, in the sense of having a place within a chronology, but in the sense of being that which undertakes time. Merleau-Ponty writes, "Ultimate subjectivity is not temporal in the empirical sense of the word; if the consciousness of time was built from successive states of consciousness, then a new consciousness would be necessary for the awareness of this succession, and so on. ... We can say that ultimate consciousness is 'timeless', in the sense that it is not intra-temporal. ... Subjectivity is not in time because it takes up or lives time and merges with the cohesion of a life" (2012, p. 446). In other words, the move to the pre-reflective level does not make the determinative and the determined indistinguishable. However, the relation of this distinction to time is redescribed, such that the determinative at this level is not that within which there is time, but is the movement of time.
} 
Whereas the self as subject and the self as object are opposed in Kant, for Husserl and Merleau-Ponty they coincide. According to Husserl, it is the flow of consciousness which constitutes the flow of consciousness as an object, a) in terms of the unity of specific phases of the flow, and b) in terms of the unity of the flow as a whole. Any phase of the flow (or indeed the flow as a whole) which is currently functioning as absolute subject in constituting temporal objects can in turn be objectivated. We can still distinguish between subject and object here, in terms of which temporal phase is objectivating (present) and which is objectivated (past), but there is a coincidence between the two, in the sense that it is the same thing which is both subject and object.

In contrast, there is no coincidence between passive and active self in Kant. Transcendental apperception does not count as a cognition of the self, for Kant, because no intuitive content corresponds to it: judgments about apperception cannot be brought to fulfillment. The intuitive content we do possess for cognition of the self does not give intuitive content to transcendental apperception, but only to empirical apperception, i.e., awareness of the determinations of our state. This intuitive content gives me to myself not as I am, but only as I appear. And in this sense, passive and active self cannot coincide: no temporal position can be attributed to the I of transcendental apperception, or in other words transcendental apperception is not objectivating, i.e., it cannot give the subject as an object of awareness.

In other words, the phenomenological description of the pre-reflective subject allows for the reversibility of constituted and constituting: the constituting can itself be placed within the temporal order as constituted. ${ }^{132}$ And this, in turn, allows us to understand how the constituting

\footnotetext{
${ }^{132}$ Reversibility is one of the central concepts of The Visible and the Invisible. Merleau-Ponty likely borrows this term from Gestalt psychology, in which reversible images are those which admit of two contradictory interpretations. For example, our perception of the Rubin vase is multi-stable or reversible, because the same image can be seen as either a vase or two opposed faces - depending on what is perceived as figure and what as ground - but not as both at the same time (see Figure 5.1). The curious thing about such cases is that the same image can motivate two different meanings. Similarly, according to Merleau-Ponty, reversibility is a basic characteristic of the body, insofar as it can be apprehended either as
} 
and constituted can refer to the same subject. Phenomenology avoids the problem about the identity of the constituting and constituted self by returning to the pre-reflective experience of self, in which the flow of consciousness constitutes itself as an object. The I of transcendental apperception, in contrast, cannot constitute itself as an object. This is because the I can only be intuited within time, and thus not as it is in itself, but only as it appears. If any intuitive content is given for the I, it is immediately within time, and therefore does not pertain to the I in itself, but only as it appears. In contrast, at the level of pre-reflective experience, the flow constituted as a unity is not the flow as it appears rather than the flow as it is in itself. Instead, the constituted flow "coincides" with the constituting flow. How is this possible? Only because at this level the constituting flow is not atemporal, but rather is temporality itself. At the reflective level, I am conscious of the I of transcendental apperception as spontaneous. But I am not conscious of it as spontaneous now (or at any time): this would violate its transcendence by making it intratemporal. In contrast, there is nothing in principle mistaken at the pre-reflective level in being conscious of the I's activity "now.” Because the constituting I is temporality (is the flow or thrust of time), it is not violated by being constituted as temporal. As Merleau-Ponty puts it,

The ultimate consciousness is not an eternal subject that catches sight of itself in an absolute transparency, for such a subject would definitively be incapable of descending into time and would thus have nothing in common with our experience; rather, ultimate consciousness is consciousness of the present. In the present and in perception, my being and my consciousness are one ... (2012, p. 448).

The problem at the reflective level arises because reflection distributes the constituting and constituted self into the category of the atemporal, on the one hand, and the intra-temporal, on the other. But a phenomenology of the self leaves no ultimate barrier between the self which constitutes the flow of time - what at the reflective level will be called transcendental - and the self which is constituted within the flow - what at the reflective level will be called empirical.

subject or object but never as both at the same time, e.g., if my right hand is touching the floor, and I touch my right hand with my left, I will never touch the right hand as touching, but only as touched. 
Instead, it describes subjectivity as the ambiguous situation in which the constituting and constituted coincide without being indistinguishable. Since reflective thinking lacks the resources to explain how these apperceptions can be referred to the same subject, it must rely on the prereflective experience of self to do so. This line of thinking does not entail that Kant's account of apperception is mistaken, only that is relies on a pre-judicative apperception. The ambiguity of this pre-judicative apperception, when raised to the reflective level, motivates two opposed sorts of apperception: of the self as a purely active subject (what is given in transcendental apperception) and the self as a purely passive object (what is given in empirical apperception). Each of these has motivational roots in the ambiguity of pre-reflective experience. In virtue of this shared root, the two can refer to the same subject. Taken by themselves, there is nothing that holds these two sorts of apperception together. But taken as two modes of describing the prereflective experience of the self, the two refer to the same subject.

\section{Conclusion}

My point, in the previous section, has not been that the distinction between transcendental and empirical apperception must be abolished, only that it is not stable. In fact, this distinction must be maintained, for Kant is right that empirical apperception does not suffice to justify the thought of self-identity, but transcendental apperception does. But if this distinction is to have its proper sense, i.e., if it is to name two ways of referring to the same subject, then it must rely on the ambiguity of pre-reflective apperception. For only if these two modes of apperception are motivated by the ambiguity of this pre-reflective experience can we see how they refer to the same subject. Without this ambiguity, empirical and transcendental apperception refer simply to different selves: one the universal form of all experience and the other this particular experiencing subject. What is remarkable, in Kant, is that these two must somehow be the same, that the I of transcendental apperception is not simply a universal form, but names myself as I would intuit myself if my intuition were intellectual. The question is how these two 
apperceptions belong together, and it can be answered, I have argued, only by returning to the ambiguity of pre-reflective experience.

The return to motivation, then, does not open the door to metaphysics, to "dialectical illusion,” as Kant would have it. It does however put transcendental and empirical apperception into dialectic, i.e., it shows both types of apperception to be insufficient in themselves and to be parts of a larger whole. I do not mean to affirm that rational psychology is in the right after all. I am only showing that the propositions of critical philosophy remain one sided and it must be shown how these sides belong together. In other words, something like speculative thinking, in Hegel's sense, is required. ${ }^{133}$ Merleau-Ponty's phenomenology, it seems to me, is speculative in this sense, for Merleau-Ponty's phenomenological effort is devoted to discovering the ambiguity of human nature underlying the antithetical judgments by which the understanding confronts experience. Merleau-Ponty writes that the sort of being referred to by dialectic "abounds in the sensible world [i.e., the world of perception], but on condition that the sensible world has been divested of all that the ontologies have added to it" (Merleau-Ponty, 1968, p. 92). The task of the dialectic, then, is "to shake off the false evidences." The method of the Phenomenology of Perception might well be described as dialectical in this sense, insofar as it, in each domain of perception, begins with the immediate evidence of the realist or empiricist standpoint, and then by exploring the inner insufficiency or negation of this standpoint moves to the intellectualist of idealist standpoint. From the inadequacy of this standpoint, in turn, it moves to uncover the ambiguity of the phenomena themselves.

It might seem odd to call Merleau-Ponty's thinking speculative or dialectical given how often Merleau-Ponty cautions against what he calls the "bad dialectic." But Merleau-Ponty's worry is not about dialectic per se, but that the dialectic readily turns from ambiguity to

\footnotetext{
${ }^{133}$ Hegel says of speculative thinking that, "It consists solely in grasping the opposed moments in their unity. Inasmuch as each moment shows, as a matter of fact, that it has its opposite in it, and that in this opposite it rejoins itself, the affirmative truth is this internally self-moving unity, the grasping together of both thoughts, their infinity - the reference to oneself which is not immediate but infinite" (2010, p. 122).
} 
ambivalence. Following Melanie Klein, Merleau-Ponty defines ambivalence as "having two alternative images of the same object, the same person, without making any effort to connect them or to notice that in reality they relate to the same object and the same person" (1964, p. 103). Such an attitude, for adult dealings, is often pathological, in contrast to which the ability to attend to ambiguity is mature: ambiguity "consists in admitting that the same being who is good and generous can also be annoying and imperfect. Ambiguity is ambivalence that one dares to look in the face" (Ibid.). Ambivalence, in other words, is ambiguity that is ruled by contradiction. In contrast, ambiguity consists in grasping the contradictory terms in their unity. As MerleauPonty puts it,

The dialectic is unstable ... it is even essentially and by definition unstable, so that it has never been able to formulate itself into theses without denaturing itself, and because if one wishes to maintain its spirit it is perhaps necessary to not even name it. The sort of being to which it refers, and which we have been trying to indicate, is in fact not susceptible of being designated positively. ... One of the tasks of the dialectic ... is to shake off the false evidences, to denounce the signification cut off from the experience of being, emptied - and to criticize itself in the measure that it itself becomes one of them. But this is what it is in danger of becoming as soon as it is stated in theses, in univocal significations, as soon as it is detached from its ante-predicative context (1968, p. 92).

Pre-predicative being, in its essential ambiguity, does not admit of univocal predicative significations; such significations are one-sided, and so lose sight of experience. ${ }^{134}$ Consequently, Merleau-Ponty thinks that the dialectic will not obtain a new position which unites opposites in a new predication (it will not obtain "the In-itself-for-itself which is the height of ambivalence") but will instead "rediscover the being that lies before the cleavage operated by reflection" (Merleau-

\footnotetext{
${ }^{134}$ We could think here about Hegel's claim that the form of judgment is essentially inadequate to speculative truth, for judgments are always one-sided: every judgment is a only moment of the self-moving unity of speculative thinking but risks taking on the appearance of fixity in abstraction from the movement of which it is a moment. As Hegel puts it, "Judgment joins subject and object in a connection of identity; abstraction is therefore made from the fact that the subject has yet more determinacies than the predicate has, just as that the predicate is wider than the subject. Now, if the content is speculative, the non-identity of subject and predicate is also an essential moment; but this is not expressed in judgment. ... For the purpose of expressing the speculative truth, the defect is first remedied by adding the contrary proposition ... . But another defect then crops up, for these propositions are disconnected and therefore present their content only in an antinomy, whereas the content refers to one and the same thing, and the determinations expressed in the two propositions should be united absolutely - in a union which can then only be said to be an unrest of simultaneous incompatibles, a movement" (2010, p. 67).
} 
Ponty, 1968, p. 95). The task of phenomenology, then, is not to unite opposites, but to discover the dialectical ferment that precedes, underlies, and brings the opposition into being; to trace the lines of motivation from divergent judgments to their common perceptual ground.

In this final chapter, I demonstrated how such a project would look by considering how this phenomenological dialectic can be applied to a particular metaphysical question: that explored by Kant in the Third Paralogism, namely, the identity of the self. With respect to selfidentity our experience can motivate two quite different interpretations. On one interpretation, the self has a necessary identity with itself throughout its presentations. On another, there is no selfidentity, but only a flux of presentations. The genius of Kant was to grasp these two interpretations together, as two kinds of apperception, the former transcendental and the latter empirical. But, as Merleau-Ponty points out and I argued in this chapter, Kant accomplishes this at the price of no longer being able to explain how these two kinds of apperception can both refer to the self at all. In other words, Kant's treatment of the paralogisms ends up in a situation of ambivalence. To comprehend the unity of the self, we must return to the ambiguous phenomenon that motivates both these interpretations, namely, what Merleau-Ponty calls the "cohesion of a life." 


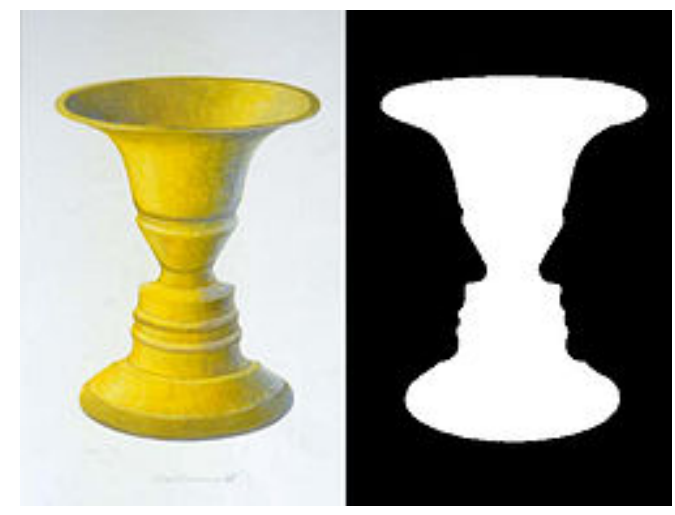

Figure 5.1. An example of Rubin’s Vase. Reprinted from Rubin Vase, in Wikipedia. Retrieved August 9, 2017, from https://en.wikipedia.org/wiki/Rubin_vase. 2007 by John Smithson. Reprinted with permission. 


\section{CONCLUSION}

In this dissertation, I have defended two theses. The first is that the dichotomy between two kinds of epistemic grounds, reason and causality, is a false one, because while reason and causality are grounds with respective domains, they are not exhaustive of the forms of grounding. There are not only two logical spaces, one in which beliefs are justified by reasons and another in which they are explained by causal interactions. There is a third form of grounding: motivation.

In my first chapter, I defended this claim. I argued that motivation can be considered as an epistemic ground, one which is irreducible to either reason or causality. Whereas reason grounds in virtue of explicit meanings and causality does not ground in virtue of meanings at all, motivation grounds in virtue of implicit meanings; whereas reasoning is active and causality passive, motivation is spontaneous. Further, I argued that motivation is the form of grounding characteristic of perception, for perception is spontaneous and shaped by implicit meanings.

The second thesis is that introducing motivation as an epistemic ground provides a new solution to debates between rationalism and empiricism. In brief, this solution holds that experience is the ground of all our knowledge while at the same time our knowledge transcends our experience: our knowledge is not contained in or definable in terms of experience. There is a contingent of beliefs - indeed, the most fundamental, what Merleau-Ponty called "perceptual faith" - which sustain all our epistemic interactions and provide the context within which any belief can be called into question or justified. These beliefs are not themselves justified, but neither are they caused. Instead, they are solicited by our interactions with the world.

In chapter 2, I began working toward this conclusion by considering the type of grounding with which experience provides empirical judgments. McDowell has argued that experience can count as a reason for empirical judgments. In contrast, Davidson has argued that because experiences are non-propositional and judgments are propositional, experiences can at most cause judgments. It seems to me that this debate is rooted in an inadequate phenomenology 
of the grounding relation between experience and empirical judgments. This relation is neither active nor passive, but spontaneous, and so is not well described in terms of either reason or causality. I argue that motivation is the type of grounding with which experience provides empirical judgments: experience grounds empirical judgments while at the same time empirical judgments (being propositional) transcend experience. I tried to illuminate this conclusion by considering cases of original or authentic expression, in which existing modes of expression do not suffice to give propositional form to our experiences.

In chapter 3, I confronted the debate between rationalism and empiricism directly by considering the type of grounding with which experience provides universal, and ultimately $a$ priori, judgments. Whereas the empiricist holds that all the content of our knowledge is provided by experience, the rationalist holds that experience (delivering contingent particulars) does not suffice to ground knowledge. I divided this debate into two parts, one concerning meanings and the other concerning evidence. With respect to both classical and contemporary debates, I showed that motivation provides a way of thinking about the relation between experience and knowledge that avoids both rationalism and empiricism. Once we introduce motivation as a form of grounding, we can see how experience can ground knowledge without containing it, a position which accommodates both rationalist and empiricist insights.

In chapter 4, I confronted what I consider to be the best alternative to my resolution of the debate between rationalism and empiricism: Kant's transcendental philosophy. Kant develops a method of a priori justification which avoids both empiricism and rationalism, by grounding synthetic a priori knowledge on experience with respect not to its actuality but its possibility: any knowledge which is a condition for the possibility of experience is justified a priori. I argued that, contrary to appearances, the projects of Merleau-Ponty and Kant are not so much opposed as compatible. This is because, while the two both describe experience, they consider experience in different ways. Kant thinks of experience in terms of empirical judgment and so approaches experience with the standard of justification. In contrast, Merleau-Ponty thinks of experience as 
perception and so approaches experience with the standard of motivation. Nevertheless, it seems to me that Kant's method of transcendental justification relies on motivation. Transcendental method justifies a piece of knowledge on the grounds that that knowledge is a condition for the possibility of a determinate feature of experience. It thereby presupposes that we have knowledge of the determinate features of experience. This type of knowledge, as the ground for transcendental justification, cannot itself be justified transcendentally. Instead, I argue, our knowledge of the structures of experience amounts to a type of a priori knowledge that must be motivated in the course of experience.

Finally, in chapter 5, I consider where this conclusion leaves us with respect to metaphysics. I argue that motivation opens the door to metaphysical thinking, but does not meet the standard of justification. It seems to me that Kant's critique of metaphysics is correct, if we take justification as our standard. I take self-identity, the question Kant addresses in the Third Paralogism, as an example, and argue that experience motivates judgments of self-identity without justifying these judgments. Kant's treatment of self-identity seems plausible to me, but here too I argue that it depends on the type of perceptual experience described by Merleau-Ponty.

In these final pages, I would like to consider where these conclusions leave us. The central thesis I have drawn from introducing motivation as an epistemic ground is that all our knowledge is founded on experience, i.e., the thesis that Merleau-Ponty called the primacy of perception. Perhaps it is obvious by now that, in a certain sense, this way of stating the conclusion is incomplete and an oversimplification: it treats what is a name for a problem as a solution to a problem. Describing the relation between experience and knowledge in terms of motivation does allow us to see how knowledge is grounded in experience, and yet it does not dispel the problem at the heart of this relation. It is, finally, not much more than a willingness to acknowledge this problem as a problem. Whereas empiricism explains knowledge in terms of experience and rationalism divorces knowledge from experience, thinking in terms of motivation leaves us with the puzzling conclusion that the contingent is capable of normatively grounding the necessary, 
i.e., that experience is capable of calling for knowledge. Motivation, as I claimed at the end of chapter 3 , is a structure of transcendence, which means that it is "a movement by which existence takes up for itself and transforms a de facto situation” into the rational and the necessary (Merleau-Ponty, 2012, p. 174). As participating in transcendence, motivation is ambiguous, or in other words it requires us to acknowledge a problem: that on the one hand, the necessary is right against the contingent, for it alone is properly true, and on the other the contingent is right against the necessary, for it alone sustains the necessary in its being for us, in short, that the contingent grounds the necessary.

If, as I have argued, our epistemological situation is ambiguous, then it might be best to conclude this study with a consideration of how one ought to conduct oneself with respect to ambiguity. For, according to Merleau-Ponty, there is a certain authenticity or virtue proper to authenticity (and it may, after all, be true that every virtue is proper to authenticity, i.e., is a way of taking up the discrete domains of our ambiguity authentically, as courage for example is a way of taking up our mortality, the ambiguous situation of being a finite reason). Just as Simone de Beauvoir distinguished between a natural and an ethical freedom (de Beauvoir, 1948, p. 24), so we might distinguish between a natural ambiguity - the ambiguity that is our element, i.e., the medium of our existence, or is the condition into which we arise - and a moral ambiguity ambiguity that is taken up and lived as ambiguous as opposed to ambiguity that is refused and lived in ambivalence.

\section{A. Love}

According to Merleau-Ponty, the same structure that we have located in epistemology pertains to intersubjectivity: the contingent founds the necessary, or in this case, the child's apprehension of the other founds the adult's apprehension of the other. The child's apprehension of the other is essentially confused. The child does not, according to Merleau-Ponty, distinguish itself from the other as two "psyches," conceived as two only internally accessible successions of states of consciousness. Instead, the child is oriented toward the other as a mode of conduct, a 
"postural schema," or a relation to the world (Merleau-Ponty, 1964, p. 117). Such a postural schema is relatively transferable between oneself and the other, and so what the child is fundamentally aware of is not herself and the other as two distinct beings, but only that there is behavior, conduct toward the world. The child's relations with others are defined by an "indistinction" between self and other (Merleau-Ponty, 1964, p. 120). Of course, such an apprehension of subjectivity is confused, and the adult relation, which does distinguish between self and other must, after all, be regarded as correct against the childhood relation. The whole process of maturation with regard to the other is a process of gradually distinguishing between oneself and the other, between oneself and one's mirror image, between one's own location and behaviors and the other's locations and behaviors. The childhood relation with the other must be regarded as a contingent starting point from which the necessary (the objective and correct) relation with the other is gradually developed. And yet, Merleau-Ponty argues, there are a number of ways in which adult intersubjectivity depends on childhood intersubjectivity.

First, adult intersubjectivity is unable to account for itself. Merleau-Ponty argues that if we accept the adult's understanding of the self as private subjectivity, then we will be forced into an irresolvable antinomy between the for-itself and the in-itself (Merleau-Ponty, 2012, p. 365). If I must constitute the other on the basis of my private sensations, then the other is for me not properly speaking a subject, but an object. But if I am to perceive the other as a genuine other - as my peer - I must perceive her as another constituting subject. Even if I do succeed in thinking the other as constituting (as constituting me on the basis of her private sensations), I am still constituting her as constituting, in which case I am the ultimate constituting consciousness. Conversely, if I conceive the other as ultimate subject, then I become an object for her. But I am forbidden from so doing by my awareness of myself as more than object (Merleau-Ponty, 2012, p. 368). The adult intersubjectivity is thus forced into an antinomy - or an ambivalent situation in 
which self and other trade positions - which ultimately makes the experience of the other as an other impossible. ${ }^{135}$

Adult intersubjectivity is thus unable to account for itself, for when it attempts to do so, it reaches an antinomy. We cannot understand how there is an other for me if we begin from the distinction of self and other. But if instead we understand the adult's perception of the other as the result of a process of clarification or differentiation of an originally indifferent self-other situation, then it makes sense that the other is an equal for me, i.e., that we are both selves. If I and the other are pieces of a common situation, then I cannot constitute without the other also constituting and the other cannot be constituted without myself being constituted. The antinomy of adult intersubjectivity can only be resolved by being placed back within the ambiguity of the child's intersubjectivity.

Second, Merleau-Ponty argues that the child's intersubjectivity is never suspended. Adult intersubjectivity is fragile; the adult can always regress to the child's mode of intersubjecitivity. Of course, what counts as normal sociability for a child is pathological in the case of the adult. The child's confusion of self and other reemerges when hallucinating patients identify their own speech as someone else's (Merleau-Ponty, 1964, p. 134). Further, according to Merleau-Ponty, jealousy implies a certain confusion of self and other, and so amounts to a regression to the child's state of indistinction (Merleau-Ponty, 1964, p. 143). The fact that Alzheimers patients

\footnotetext{
${ }^{135}$ Merleau-Ponty develops another line of argumentation for this principle. Because adult intersubjectivity thinks of the other as a private subjectivity, it faces a problem about how the other is identified as other. The best means of explaining how one private subjectivity can perceive another, i.e., that one pairs one's introceptive image with the extroceptive image of the other, contradicts facts we know about the perception of others. For example, we know that an adult's smile brings about a smile in even very young infants (Meltzoff \& Moore (1994) \& (1999)). If child and adult were each private subjectivities, the child would have to pair the self-awareness of her psyche with her introceptive self-image, and then pair this introceptive self-image with her extroceptive image of the other, and on this basis infer conclusions about the other's psyche. But the young child seems to respond to others before she can even pair her introceptive self-image with her extroceptive image in a mirror, and so this hypothesis is implausible. Instead, the very young child exists in a state of "indistinction" between herself and the other. She perceives the other as a mode of conduct or a relation toward the world, such that in the other's gesture, the other's smile, she perceives not that "He is happy," but that "There is happiness." This happiness is like a cloud that rolls through the child, and when she perceives it, it animates her face with a smile
} 
regress to pre-scientific beliefs about the world is generally taken as evidence that such beliefs are continuous throughout our lifespans, but are suppressed by capacities damaged by Alzheimers (Shtulman \& Lombrozo, 2016, pp. 59-60). Similarly, for the regressions we have been considering to be possible, the child's intersubjectivity must never have been eliminated, but only masked by adult intersubjectivity.

Third, the child's intersubjectivity reemerges in ways that are not only pathological, but also normal and important to adult life. For example, Merleau-Ponty claims that love requires a reappropriation of the child's intersubjectivity. This is because love depends on a degree of indistinction between oneself and the beloved. First of all, in love there is a mutual encroachment upon the freedom of the other, in the sense that if the love is real one cannot help but exert an influence on the other, to impose certain responsibilities on the other, and to some degree to choose for the other (and conversely, to be chosen for). As Merleau-Ponty puts it, "If one loves, one finds one's freedom precisely in the act of loving, and not in a vain autonomy" (MerleauPonty, 1964, p. 154). Further, love, according to Merleau-Ponty, is alienating: one becomes through love other that what one was. One's own situation overlaps with the other's, both in sympathy and in taking up the milieu of the other; a person in love enters into a shared situation, a mixed life. It is for this reason that love is also painful; having become more than one was, one is now vulnerable to the other. Consequently, love is always menaced by insecurity, that is, by the possibility of doubting the other. To the extent that in love one becomes confused with the other, one finds oneself dependent upon the other. At the same time, one cannot stand guarantee for the other's action. Thus, in love one entrusts oneself to the other and so finds oneself "dispossessed" and incapable of removing doubt about the other's fidelity. Love, so important to adult existence, is a reemergence of the child's relation to others. Yet the "normal," adult reaction to this dispossession is different from the child's. The child's love, writes Merleau-Ponty, is "ensnaring": the child can never have enough proofs of love, because these of course are always finite in number. In contrast, the non-pathological adult reaction is to have "confidence above and beyond 
what can be proved" (Merleau-Ponty, 1964, p. 155). ${ }^{136}$ The adult's love is a transformation of the child's, and consists in allowing the other a degree of independence. It is because the adult's love is a transformation of the child's that it is always menaced by the possibility of regression into jealousy and yet is not defined by jealousy. ${ }^{137}$

Merleau-Ponty’s defense of childhood intersubjectivity as an integral feature of adult intersubjectivity is no nostalgia for childhood. The child's relations with others are unstable or ambiguous, and this is why they give way to adult intersubjectivity. Further, the child's love does not amount to a recognition of the other as other: it is jealous or ensnaring. The development into adult intersubjectivity must be regarded as a progression. Yet if the independence which the adult attains were taken rigorously, if the individsion of the child's relations with other did not reemerge, we could not understand how there is an other, and we could not account for genuine love. The point I wish to make is that there is an authenticity that can only be understood as a reappropriation - and not a rejection - of genesis, namely, genuine love. If one refused to admit any confusion of self and other, love would wither; if one refused to admit any difference between self and other, one would return to the ensnaring love of the child. In love, we negotiate the limits of self and other, and in love we negotiate the paradox of genesis: that we transcend precisely what we do not leave behind. Love is, then, an authenticity proper to ambiguity.

\section{B. Heroism}

We can, second, consider the figure of the hero, with which Merleau-Ponty concludes the Phenomenology of Perception, writing that only the hero "fully lives his relation with men and

\footnotetext{
136 The difference between child and adult love is much like the distinction between passion and love that DeBeauvoir draws in Ethics of Ambiguity, when she writes that the passionate person is tormented by her distance from the desired and seeks to eliminate it, while to love the other genuinely is "to love him in his otherness and in that freedom by which he escapes. Love is then the renunciation of all possession, of all confusion. One renounces being in order that there may be that being which one is not" (de Beauvoir, 1948, p. 72). What is not made clear here, however, is that love depends on and would wither without the element of confusion that it must tame if it is not to devolve into passion.

${ }^{137}$ In this vein, the narrator of Swann's Way likens his anguish for his absent mother to Swann's anguish in the absence of his beloved (Proust, 2002, pp. 30-31).
} 
with the world.” Merleau-Ponty borrows an example from Antoine Saint-Exupery’s Night Flight, of a parent saving a child trapped in a fire, quoted somewhat liberally as follows:

You would trade your shoulder, if there were an obstacle, to knock it down. You reside in your very act. You are your very act ... You give yourself in exchange ... Your signification shines forth, dazzlingly. It is your duty, your hatred, your love, your loyalty, your creativity ... Man is a knot of relations, and relations alone count for man (Merleau-Ponty, 2012, p. 483).

On Merleau-Ponty’s definition, heroism comprises an authentic appropriation of the ambiguity of our relation with the world. This relation is ambiguous because it requires us to negotiate between a) our personal existence, which is deliberate and free, and b) our pre-personal existence, which is characterized by a received general style of existence and a set of relations with particular individuals and a particular time into which we are thrown. ${ }^{138}$ As we saw in chapter 5 , MerleauPonty thinks there are situations in which personal and pre-personal merge:

It can even happen that, when I am in danger, my human situation erases my biological one and that my body merges with action. But these moments can be no more than moments, and most of the time personal existence represses the organism without being able to transcend it or to renounce it, and without being able to reduce the organism to itself or itself to the organism (Merleau-Ponty, 2012, p. 86).

Personal and pre-personal therefore stand in a relation of ambiguity, which can be taken up authentically or inauthentically. We must understand this authenticity properly. One might be tempted, given that Merleau-Ponty describes the hero as one willing to sacrifice their body ("you would trade your shoulder") for their intention, to think that this authenticity consists in the subsumption of the body to the spirit. But this would overlook the fact that in heroism the body is not taken as a disposable, intrinsically inert, tool. Such a conclusion would contradict the core of

\footnotetext{
138 Ta-Nehisi Coates illuminates this sort of authenticity in his Between the World and Me. Coates describes growing up black in Baltimore as an experience of alienation from one's body (in terms of the constant vulnerability of one's body and in terms of the white public's apprehension of this body) and from the world (in terms of the gulf between Coates' lived experience and the white world he knew of through the "dispatches" of television). I point towards this articulation of authenticity because it puts the body front and center. Perhaps the centerpiece of this work is a description of Coates own attempt to reclaim his body from these various kinds of alienation. For example, he writes that he has been directed toward "the total possession of [his] body" (Coates, 2015, p. 48). The kind of authenticity described by Coates, then, consists in a proper relation between personal existence and the body and its relations to the world.
} 
Merleau-Ponty's thinking, which understands the body not as a collection of parts at the disposal of the mind's intention, but as an organism or a synergy of parts which itself "sketches out the movement of existence." In other words, the body is understood as the pre-personal cohesion which anchors us in a set of relations. This is why even an insect, which is not governed in its comportment to its milieu by a mind, can treat its limbs as replaceable: it is not a mere collection of parts, but a synergy geared toward a milieu. ${ }^{139}$ In a certain sense, the hero does no more than renew this animal orientiation toward a milieu, except that an animal milieu is not yet a world (see chapter 4), and so the hero renews this orientation on an entirely new level: whereas the animal is, in Heidegger's terms "captivated” with its milieu, the hero fully lives her being-in-theworld. Thus, heroism is not the "erasure" of the pre-personal, but the gearing of the pre-personal into the personal.

Moreover, without the pre-personal, there would be no heroism but only adventuring. For heroism requires something like history, i.e., the taking up of a situation in its given-ness and not an arbitrary determination of that situation. As Merleau-Ponty writes,

[If] nothing ever solicited freedom, then history would have no structure, we would not see an events take shape there, and anything might results from anything. ... History would never be going anywhere, and, even if a short period of time were examined, it could never be said that events are conspiring toward a certain outcome. The Statesman would forever be an adventurer, that is, he would commandeer events to his own advantage by giving them a sense that they did not have (2012, pp. 474-5).

In contrast, it is characteristic of the hero to take up the sense offered by the situation - to heed its solicitation - and transform it in a manner that is original or authentic, just as the good author takes up the sense of a story and transforms it through a speech that is not merely spoken but is speaking (chapter 2). As Aristotle said, it is in facing not any kind of death but the right kind of

${ }^{139}$ Cf. Merleau-Ponty 2012 (p. 80) 
death that courage is found. Heroism is thus a virtue proper to ambiguity, the virtue in which the personal and pre-personal are negotiated with integrity. ${ }^{140}$

\section{Conclusion}

So, there are virtues - for example, love and heroism - that are proper to ambiguity. These virtues are achieved when ambiguity is not diffused, but authentically appropriated. In a certain sense, love (in which the contingent foundation of intersubjectivity is reappropriated) is the model for handling our epistemic situation, for in love the contingent and the necessary are successfully negotiated. What is required first is that we not dispel the ambiguity of our epistemic situation through a dogmatism that lays claim to an absolute evidence or to a skepticism that denies the legitimacy of all evidence (Merleau-Ponty, 2012, p. 418). There are beliefs which are both contingent and at the core of normal adult life, for example, what Merleau-Ponty would call perceptual faith, i.e., the belief that being appears, that there is evidence, if never absolute. Such faith is contingent because it is not justified and because it is spontaneous - we could never be dissuaded from it, except in certain pathological cases. But it is also at the core of human life, for as Fichte showed, there is no such thing as a vocation if there is not a world in which it is exercised (Fichte, 1987, p. 71), or as Susan Wolf has argued, love binds us to the world, for love intends not merely a representation of the other, but the other itself (Wolf, 2015). If we interrogate these fundamental beliefs, which are motivated and not justified, we will not be able to reject them, for they are the framework within which all acceptance and rejection must be

\footnotetext{
140 This is the sense in which de Beauvoir distinguished the adventurer from the hero, insofar as the adventurer "finds joy in spreading through the world a freedom which remains indifferent to its content" (de Beauvoir, 1948, p. 62). Or as Heidegger also puts it, adventuring misunderstands the "uncanny" as that which is merely "unhomely," whereas the hero from within the unhomely seeks after the homely: "The adventurer is merely not-homely: the deinotatos [the most terrible one, i.e., humanity, or in this case Antigone], by contrast, is the most uncanny being in the specific manner of being homely, namely that which, within its own essence, finds no entry to this essence, remains excluded from it and without any way out that could allow it to enter the center of its own essence. The one who is properly unhomely relates back precisely to the homely, and to this alone, yet does so in the manner of not attaining it. The adventurer, by contrast, finds the homely precisely in what is constantly and merely not-homely, in the foreign taken in itself. To put it more precisely: For the heart that seeks adventure, this distinction between the homely and the unhomely is altogether lost. The wilderness becomes the absolute itself ..." (Heidegger, 1996, pp. 74-5).
} 
made. Neither will we, in them, finally reach a ground on which we could rest. But I have argued that this does not mean that our beliefs trade on nothing, for within the contingent we grasp the necessary. This insight lies at the bottom of Husserl's claim that "We have the truth ... not as falsely absolutized, but rather, in each case, as within its horizons” (Husserl, 1969, p. 279). The thesis of the primacy of perception, in founding knowledge upon experience, does not set us on a firm ground. It does not deliver an apodictic principle, such as the Cartesian cogito, nor a set of axioms from which a mathesis universalis would commence. But neither does it leave us groundless. As Merleau-Ponty wrote,

The progress of the inquiry toward the center is not the movement from the conditioned to the condition, from the founded unto the Grund: the so-called Grund is Abgrund. But the abyss one thus discovers is not such by lack of ground, it is [the] upsurge of a Hoheit which supports from above (MerleauPonty, 1968, p. 250). 


\section{APPENDIX. HISTORICAL BACKGROUND: MOTIVATION IN HUSSERL AND STEIN}

Despite the important role it plays at crucial junctures of Phenomenology of Perception, Merleau-Ponty does little to offer a formalized account of motivation or to flesh out what he does offer. Much of what I have done is to draw out implicit or superficially discussed features of Merleau-Ponty’s account. Perhaps part of the reason Merleau-Ponty is comfortable using this concept without developing it is that motivation is a central theme in the phenomenological tradition prior to Merleau-Ponty. At any rate, this tradition is certainly part of the context in which Merleau-Ponty thinks about and uses the concept of motivation, and thus a full account of Merleau-Ponty's use of the term requires a brief explanation of the role of the term in this tradition. ${ }^{141}$ The purpose of this section is primarily to outline this historical context. But the fact that Merleau-Ponty draws on phenomenological tradition is here not only of historical interest: it also allows us to open further avenues for filling out Merleau-Ponty’s account of motivation, both by articulating types of motivation characteristic of experience and exploring practical motivation.

In what follows, I will offer a brief account of the role motivation plays in the thinking of Husserl and Edith Stein, the two phenomenologists who do most to investigate this concept.

\section{Husserl}

Husserl does little more than Merleau-Ponty to offer a formal definition of motivation, but does much to flesh out Merleau-Ponty’s account. While I will offer a general presentation of Husserl's thought about motivation, I think that what this presentation offers my project is a rich set of phenomenological data about different kinds of motivation, i.e., it will help to articulate the concept of motivation into a differentiated set of species of the genus "motivation.” I will begin by defining what Husserl means by motivation generally, will then move to Husserl's contrast

\footnotetext{
${ }^{141}$ For example, Merleau-Ponty explicitly cites Stein on the concept of motivation (Merleau-Ponty, 2012,
} p. 503). 
between motivation and natural causality, and finally will highlight some of the major species of motivation discussed by Husserl.

\section{A. What Is Motivation?}

At no point does Husserl provide a sufficiently broad and descriptive definition of motivation. Thus, it is necessary to reconstruct one on the basis of what Husserl has said. To my knowledge, no adequate definition has yet been provided. Many define the term by contrasting it with natural causality. ${ }^{142}$ This is fine as far as it goes, but offers little positive content to our account of motivation. In my opinion, others are too vague, ${ }^{143}$ commit errors, or are too narrow. ${ }^{144}$ The key to Husserl's concept of motivation, I suggest, is that it describes the kind of explanatory grounding characteristic of the relation between lived experiences. If one is asked why one thinks or has done something, one will respond in terms of one's motives: the motives are the ground of the thought or action. Some mental occurrence give rise to or motivate others, and the former give (at least in part) the "because so" of the latter. In other words, motivation is the relationship of grounding between two mental occurrences, such that if mental occurrence $X$ motivates mental occurrence $Y$, one can say " $Y$ because $X$ ”. Because motivations operate according to general regularities that can be explicated, Husserl can write in Ideas II, that motivation is "the lawfulness of the life of spirit" (Husserl, 1989, p. 231).

For example, if I see smoke, I may be motivated to think that somewhere there is fire. Here, my belief in the presence of smoke motivates the further belief in the presence of fire, and

\footnotetext{
${ }^{142}$ See for example (Moran \& Cohen, 2012, pp. 213-4). Barry Smith similarly defines motivation in parallel with natural causality, but as "mental" rather than "material" (Smith, 1995, p. 412).

${ }^{143}$ For example, Ricouer's "Motivation designates the law according to which consciousness unfolds, is connected temporally, reacts to the world, and understands the conduct of others in a surrounding world of persons and things" (2007, pp. 73-4).

${ }^{144}$ Yoshimi, for example, has provided a precise definition of motivation, but only with respect to the motivation of perceptual expectations (Yoshimi, 2016). Or, Walsh has defined motivation for Husserl as "the experiential character of something feeling plausible, but not 'evident'” (2013, p. 71), but this does not describe all cases of motivation that Husserl might consider, e.g., a scene's motivating a flight of fancy does not involve "plausibility."
} 
if I were asked why I believe there is fire, I would respond in terms of my belief in the smoke. As

Husserl writes in the Logical Investigations,

Certain objects or states of affairs of whose reality someone has actual

knowledge indicate to him the reality of certain other objects or states of affairs, in the sense that his belief in the reality of the one is experienced (though not at all evidently) as motivating a belief or surmise in the reality of the other (2001, p. 184).

Notice that, for Husserl, the motivational relationship is not strictly speaking an evidential relationship. Strictly speaking, for Husserl, evidence [Evidenz] of an object names the intuitive givenness of that object, i.e., that an empty meaning-intention is fulfilled. As long as I am merely seeing smoke, but the fire is obscured from view, I have no evidence (in Husserl's sense) that there is fire. Rather, as Walsh points out, for Husserl the smoke "attests to" [Zeugnis ablegt] the fire, or gives evidence in quite another sense (secondary and indirect evidence, testimony) (Walsh, 2013, pp. 74-6). Motivation thus carries consciousness beyond what is strictly given (what is evident), opening intentional horizons of possibility. In this sense, Husserl writes, "Every motivation is apperception. The emergence of a lived-experience A motivates the livedexperience of a $B$ in the unity of a consciousness; the consciousness of $A$ is equipped with an intention that points beyond, 'indicating' a coexistence” (Husserl, 2001, p. 625).

\section{B. Motives and Causes}

When Husserl calls motivation the "lawfulness of the life of spirit," he means to distinguish motivation from natural causality - the "lawfulness of nature.” As Husserl puts it, the "because so" of motivation is different in kind than that of natural causality. When we ask why a natural event occurred, we would be content with an explanation - a "because so" - in terms of natural causality. But when we ask why a person acted as they did, a "because so" of natural causality would be unsatisfying. What this question seeks, what would satisfy it, is an understanding of a person’s motives. Husserl writes, “No causal research, not matter how farreaching, can improve the understanding which is ours when we have understood the motivation of a person” (1989, p. 241). The natural-causal order of explanation is insufficient for 
understanding a person, because it is not the sort of grounding or lawfulness proper to the "life of spirit.”

For Husserl, what differentiates these two realms is intentionality. Whereas the natural realm is characterized in terms of real relations, including between a real object and a real subject, the "spiritual" realm is characterized in terms of the intentional relation between the Ego and noemata, the object as given; whereas a noise on the street outside my window does really affect me, i.e., it is a natural-causal process which strikes my body and produces a sensation, it can only serve as a motive (e.g., to close the window) insofar as it enters into intentional life. Motivation, in short, is a grounding relation not between two real things or events, but between “lived experiences” or mental occurrences.

While Husserl, like Merleau-Ponty, draws a clear distinction between motivation and natural causality, he does not draw a distinction between motivation and reason. Instead, he distinguishes between passive and active motivations. These two kinds of motivation differ in terms of their content: whereas active motivation is a relation between two "position-takings" (consciousness involving an explicit intention), passive motivation occurs between non-positional lived experiences. But Husserl also suggests they differ in terms of the quality of motivation: whereas passive motivations are not necessarily responsible to reason, active motivations are. Husserl's point is not that all active motivations are rational (indeed, they often fail to be), but rather that they occur within "the sphere that stands under the norms of reason” (Husserl, 1989, p. 232). In contrast, the basic norm of passive motivation is not reason but habit or association. Further, for Husserl, these two regions are partially, but not totally closed to each other. Some kinds of passive motivation can be reapprehended at the level of active motivation, e.g., passive association can be converted into a rational principle (if whenever I see an X it is accompanied by a Y, when I next see an X I can expect to see a Y), though not all can (Husserl claims that sensation, which belongs to the passive realm is "a-rational” (Husserl, 1989, p. 234)). Conversely, habit can be informed by reason: an act of reason can be "sedimented" into a passive tendency. 
Certainly, not all habits are informed by reason, nor necessarily can all habits and associations be. Unlike Merleau-Ponty, Husserl does not, then, distinguish between motives and reasons. For Husserl, reasons are a kind of motive. But Husserl does at least share with Merleau-Ponty the claim that not all motives are reasons. We might say, then, for Husserl the space of reason is part, but not all, of the space of motivation.

\section{Kinds of Motivation}

One of the accomplishments of Husserl's discussion of motivation in Ideas II is to begin analyzing the genus, motivation, into various species. In so doing, Husserl furnishes us with a great deal of phenomenological data about motivation, thus providing an important supplement to Merleau-Ponty's work on motivation.

In what follows, I will offer a brief account of Husserl's description of a few major species of motivation.

\section{1) Judgments motivated by perception.}

According to Husserl, at least some judgments, namely perceptual judgments, are motivated by perceptions: perception serves as a motive for judging about that perception. If I see a person in a shop window, I might judge “That is a person.” Here, the judgment is motivated by the perception, insofar as the judgment is verified or draws its evidence from perception.

Perception motivates not just straightforward assertoric judgments, but can motivate the various modalizations and derivatives of judgment (say, as I move closer, I perceive that what I thought was a person is in fact a mannequin, or I hesitate between these two options): negation, hesitation, doubt, question, and possibility. ${ }^{145}$

2) Judgments motivated by affects and vice versa

\footnotetext{
${ }^{145}$ See Experience and Judgment, Part II, Chapter 3, “The Origin of the Modalities of Judgment.”
} 
Husserl does not elaborate on this sort of motivation, but there are several ways in which this sort of motivation might work. First, judgments about one’s affects (e.g., “I feel happy”) seem clearly motivated by one’s affects. Second, judgments about objects or states of affairs could be partially motivated by one’s affects, e.g., “The wine is bad.” Conversely, if one whose taste I trust judges “The wine is bad,” I may be more inclined to feel displeased by the wine.

\section{3) Valuations motivated by valuations}

While some things are valued, according to Husserl, as “absolute motivations,” i.e., they are not motivated by some further things outside themselves (they are "final” goods), others are valued because of other values (Husserl, 1989, p. 232). I might value wealth, for example, because of the security and freedom it brings, which I value for their own sake.

4) Attention motivated by an obtrusive stimulus

Active attention toward an object can be motivated by the object's obtruding on consciousness (i.e., standing out from a perceptual background). An object obtrudes, for example, when it contrasts with or has a considerable qualitative discontinuity with its background. This obtrusion motivates one to "turn toward" the object or awakens an intentional tendency toward it. ${ }^{146}$

\section{5) Expectations motivated by perceptions}

Present perceptions often motivate expectations of perceptions to come. This occurs, for example, by association (when I have perceived A in the past accompanied by B, in now perceiving A' I am motivated to expect B') or similarity (in perceiving the present fact of the object, I am motivated to expect the rest of it to be similar).

6) Apperception of real unities (apprehension of real objects)

${ }^{146}$ See Experience and Judgment §17, “Affection and the turning-toward of the ego.” 
According to Husserl, the motivation of expectations plays an integral in the constitution of objects: every real object is apprehended through a "web of motivations” (Husserl, 1989, p. 236). In the perception of a real object, I am only ever given a particular adumbration, a particular face or side of an object, and yet what I apprehend is not just this particular face, but a whole object, one containing faces now hidden from me, of which I yet feel assured. How can I apperceive a whole object through this single face? Husserl's answer is motivation. The perception of three sides of a cube motivates an anticipation of or tendency toward the other three sides. The perception of this side of a couch as brown motivates an expectation that the other side will also be brown. In general, the perception of a part of a thing motivates a vague anticipation of the other parts, it defines for them a particular range of possibilities that would allow a harmonious whole. If I see three sides of a white die, marked with one, two, and three dots, these parts suffice to motivate vague anticipations of the other sides: they will be white, will be sides of a cube, and will correspond to particular numbers. One’s motivations, then, correspond to the possible harmoniousness of the object: one anticipates the unseen sides will support and be in harmony with the seen side, and vice versa. There would be perceptual disharmony if, as I rotated the die before me, it ceased to show itself as a cube and was revealed instead to be a sphere. The limit case of such disharmony is the contradictory or the impossible, but within the realm of possibility, we are certainly familiar with perceptual disharmony: wherever a whole seems to lack sufficient integrity, where its parts don't quite cohere and support each other in a unitary whole. ${ }^{147}$ The perception of a particular part thus casts beyond itself a range of harmonious possibilities;

\footnotetext{
${ }^{147}$ Say if, instead of discovering the cube as a sphere, the three other sides were revealed as red, orange, and blue, again with one, two, and three dots, respectively. This possibility is not called for by the three sides I had previously perceived, at least not so much as is the possibility that the further three sides are white and marked by four, five, and six dots, respectively. On this possibility, the object is out of harmony, or has less harmony.
} 
the part points beyond itself, motivating an interpretation of the whole, and determinations of the other parts. While these anticipations may certainly be disappointed, they draw perception beyond any particular adumbration of a thing to the apprehension of a unitary whole. Thus, Husserl claims that “All thingly apperception and all apperception of unities of the nexus of several things and thingly processes would have their source in associative motivations” (Husserl, 1989, p. 237). Such unities are motivated not just in the perception of outer objects, but also in memory and imagination, according to Husserl.

\section{7) Unity of the stream of consciousness}

Obviously not every event present to consciousness can be said to occur "in consequence of" a prior event: when a sudden, loud noise attracts my attention, my consciousness of the noise is certainly not motivated by my prior consciousness of, say, reading a book. And yet, according to Husserl, at a deeper level, every conscious event stands in some motivational relation with every other, insofar as they are all bound by the unity of the temporality of the stream of consciousness. According to Husserl, the temporal forms, “past,” "present,” and "future” are ceaselessly motivating each other: that I experience a present at all motivates a retention of a past and an expectation of a future. Thus, the very unity of the stream of consciousness is made possible by motivation. As Husserl puts it, "even the pervasive unity of the stream of consciousness is a unity of motivation” (Husserl, 1989, p. 239). This idea is central to Merleau-Ponty's description of the “cohesion of a life.”

\section{8) Ideals motivated by consciousness of progress}

In Passive and Active Syntheses, Husserl claims that ideals (i.e., limit-ideas) are given through motivation. Such ideals are motivated when one is conscious of a gradation of possible givennesses. For example, if as I gradually approach something it is given in increasing clarity, I am given to anticipate a maximum of clarity, an ideal or pure clarity. 
Or, if I am given a gradation of possible reds, I may be motivated to anticipate a "pure red.” The ideal here is never something itself given, but only an anticipation motivated by the experience of progress through gradations. As Husserl says, "the idea in question is self-given as an evidently motivated anticipation, as a degree that is never self-given, and yet is self-given in evidence as an anticipatorily motivated limes, self-given precisely as ‘idea'” (2001, p. 254).

\section{Edith Stein}

Edith Stein’s Beiträge zur philosophischen Begründung der Psychologie under der Geisteswissenschaften is certainly a locus classicus for phenomenological analysis of motivation. Like Husserl in Ideas II, Stein is largely concerned in this work to distinguish motivation, as a "basic lawfulness of mental living,” from the kind of lawfulness of physical causality. But unlike Husserl, whose analysis is largely concerned with theoretical motivation, and unlike Pfänder, whose analysis in “Motive and Motivation” focuses on practical motivation, Stein’s analysis moves fluently between both the theoretical and the practical aspect of motivation, offering a general analysis of motivation - much like Merleau-Ponty's.

In what follows, I would like to do three things. First, I will provide a summary of Stein’s analysis of motivation. Next, I will examine in more depth two interesting claims made by Stein in the course of her analysis: a) motives do not constrain (i.e., compel or force) [zwingt] one to do or think a certain way, b) motivation can be mistaken.

Stein defines motivation as an internal connection of grounding between experiences. ${ }^{148}$ She writes,

\footnotetext{
${ }^{148}$ Commentators have attempted to articulate Stein's definition of motivation in a variety of ways, often not greatly satisfying. Bello has articulated motivation as "the type of link that exists between acts," but not a connection of "co-penetration" or association, but of "issuing" (Bello, 2010, p. 141). MacIntyre writes that motivation names "the relationship between earlier and later" (MacIntyre, 2006, p. 113). Sawicki perhaps puts it best in writing that motivation is "the valence or inclination of the current experience to flow forward from one active experience into the next” (Sawicki, 1998). While none of these articulations are incorrect, they seem to me to lack sufficient precision to give a well-defined articulation of Stein's thinking about motivation.
} 
Motivation, in our general sense, is the connection that acts get into with one another: not a mere blending like that of simultaneously or sequentially ebbing phases of experiences, or the associative tying together of experiences, but an emerging of the one out of the other, a self fulfilling or being fulfilled of the one on the basis of the other for the sake of the other (2000, p. 41).

Whereas some connections between experiences are external (i.e., seeing a person I have not met before, I associate them with someone I have, on the basis of a certain likeness), according to Stein, connections of motivation are internal: the motivatum emerges from the motive. For example, my wanting to purchase a plane ticket emerges from my wanting to visit the northwest. Here, my wanting the ticket is not "tied together" with my wanting the visit - while there is no necessary connection between wanting a plane ticket and wanting to visit the northwest (I might want the plane ticket because I am obligated to visit the northwest for work, not because I want to), in my case neither is the bond between the two accidental. ${ }^{149}$ And whereas some connections are not connections of grounding (for example, seeing two trees with similarly shaped leaves, I connect them in my thought - here neither is the ground of the other), connections of motivation are: if experience $X$ motivates experience $Y$, one could say that $Y$ occurs because of $X$. Further, motivation is not an internal, grounding connection between any kind of two given things, but only between intentional acts, or experiences.

I'd like briefly to point to a few other minor points of Stein's analysis before moving on to her claim that motives do not constrain. First, Stein argues that it is never the act (of hearing, seeing, thinking, etc.) that motivates, but the sense content [Sinnesgehalt] of the act: "Lightning turns into my motive for the expectation of thunder, not the perception of lightning” (Stein, 2000, p. 43). ${ }^{150}$ Second, while some motives motivate a particular motivatum (e.g., in relations of logical entailment), others can motivate a range of possible motivata, this range serving as the

${ }^{149}$ As with Merleau-Ponty, it is an open question how exactly one must specify the term "internal relation." Stein seems to suggests simply that any relation in which one of the relata is the generative ground of the other is internal. I think the most tenable specification of the term is the same I offered with reference to Merleau-Ponty in chapter 1.

${ }^{150}$ Of course, it's only qua correlate of an act that a sense content can serve as a motive (Stein, 2000, p. 43). 
limit of reasonable motivations. For example, if someone greets me on the street, no particular response is motivated on my part, but rather a range of possible reasonable responses comes into view. Recall that, in terms of Merleau-Ponty, I described this phenomenon as the indeterminacy of motivation or solicitation. ${ }^{151}$ Third, not all motives require their motivata (as do relations of logical entailment): some merely permit them. In this case, according to Stein, the connection is not one of rational grounding, but merely of an understandable connection of meaning. If in listening to a piece of music another is called to mind, this "calling to mind" is certainly understandable (I can say why this piece has been called to mind), but is neither reasonable nor unreasonable (Stein, 2000, p. 44). Fourth, a sense content serves as a motive within a particular “meaning ensemble,” or context of meaning. Thus, a sense content will function differently as a motive within different meaning contexts (a piece of music playing in the context of a concert might motivate my attention, but in the in the context of playing on my radio while I am trying to make a phone call might motivate me to turn off the radio), and with respect to different individuals (people with different tastes will be differently motivated by the same item). ${ }^{152}$

\section{A. Motives Do Not Constrain}

One of the more controversial claims made by Stein is that motives do not constrain us to think or act in a given way. While Stein thinks that no thought or action is unmotivated, i.e., motivation is a necessary condition for thought or action - she writes, e.g., that "free acts presuppose a motive” (Stein, 2000, p. 55) - she does not think that motives always suffice for thought or action. Stein argues this position by offering two kinds of counterexample to the claim

\footnotetext{
${ }^{151}$ Stein claims that some motives do entail a particular motivatum, because she includes logical reasoning within the space of motivation (following Husserl, but unlike Merleau-Ponty). The proper disagreement, then, isn’t about whether some of what Merleau-Ponty terms "motives” are not at all indeterminate, but what the scope of "motivation" is.

152 While, as a matter of fact, different individuals will be differently motivated by the same sense content, it does not follow that they are right to be so motivated - sometimes one individual will be motivated in a manner concordant with reason, while the other is motivated in a manner discordant with reason.
} 
that motives constrain us: one in terms of thoughts, the other in terms of willing. I will now look at these two kinds of counterexample more closely.

According to Stein, information (any kind of information - anything from sensory uptake to a written report) motivates belief [Stellungnahme - position-taking or opinion]. If I see a coat hanging at the other side of the room, I am motivated to believe that there is a coat there, that it exists, and exists as I see it. Of my beliefs, Stein thinks, I do not have control: they "befall” or "seize" me. At no point in the process of my forming a belief in the existence of the coat across the room am I consulted about this belief - the belief is not presented as a choice. As often happens in the case of optical illusions, even if I am told that that is no coat, but somehow an illusion, I may be unable to succeed in shaking my belief, in seeing it as other than a coat really over there. Thus, at the level of belief, the motivation provided by information does suffice for belief, and I will succeed in changing my belief only if presented with adequate countermotives.

However, while the motivation provided by information suffices for belief, neither the motivation of information nor of the belief suffices for adoption (or denial) of this belief. While I do not decide what I believe, I do decide whether or not to adopt my beliefs as true. Perceptual illusions are a good example of this principle. In the case of the Müller-Lyre illusion, though I may be unable to shake my perceptual belief that the lines are unequal, I can refuse to adopt this belief. Notice that refusing to adopt the belief isn’t the same as removing or changing the belief: I would need some information to serve as a countermotive, and not just a decision on my part, in order to do that. Here the motivation which suffices for the belief does not suffice for adoption of the belief. Thus, we seem to have a counterexample to the claim that motivation suffices for thought. One could object that from the phenomenal fact that the kind of motivation that suffices for belief does not suffice for adoption of belief, it does not follow that no motivation has sufficed for the refusal of adoption: in the example above, perhaps one measured the two lines, and this information has sufficed to motivate the refusal. In this case, I decide not to adopt the belief because the motives against it outweigh the motives for it. But Stein disagrees with this model of 
decision making. She thinks that decisions are not made simply by the weight of motives, automatically, like the tipping of a scale. The greater weight, by itself, does not suffice for my adoption: I must actively affirm this weightiness, and decide upon the adoption. For example, in the case of Cartesian doubt, the motives in favor of trusting one's senses generally outweigh those for doubt - and yet belief is not adopted, because the standard for adoption here is logical necessity.

The point is clearer if we move to the closely parallel case of the motivation of willing. With regard to willing, the place of belief is taken by inclinations [Strebungen]. Inclinations are a motive for willing, but are not themselves something that we choose or bring about: much like beliefs, they happen to us (they are spontaneous, in the language I used in chapters 1 and 2). But, according to Stein, though inclinations are motives for willing, they do not constrain us to willing. Stein argues that even if an inclination is uncontested by countermotives, it does not necessarily lead to willing (Stein, 2000, pp. 70-4). For example, one of us suggests going for a hike, and we are both inclined to do so. But, despite neither of us being disinclined to hike nor having compelling reasons not to do so, we never fully will to go on the hike, such that we do not go on it.

Thus, there seem to be some cases in which, even without countermotives, the motivation to think or will in a given manner is not sufficient for thinking or willing. According Stein, we are not determined by motives: the ego has the power to stand back and view motives critically before affirming or rejecting beliefs and inclinations. This does not mean that the ego is unmotivated, only that it is not constrained by its motives to think or will in a particular manner. The ego always has the power to suspend decision, and so motives do not suffice for decision.

\section{B. Motivation Can Be Mistaken}

The second claim made by Stein that I wish to consider is that it is possible to make mistakes with respect to motives. Stein distinguishes between motives and reasons [Grunde]. Whereas whatever actually gives rise to a thought is a motive, only what should give rise to a 
thought counts as a reason. A reason thus holds "objectively”: it should serve for anyone as a motive (Stein, 2000, p. 51). While one’s motive often coincide with reasons, they can also diverge from reasons or lack reason, in which case one may be mistaken. If I receive news from an objectively trustworthy source that someone for whom I cared deeply has died, I may refuse to believe the report, I may retain hope that they live and search for means of validating my faith. Here the trustworthiness of the source is a reason for belief in the report, but my attachment to the dead one is a motive against belief. Here reason and motive diverge, such that my disbelief in the report is unreasonable and mistaken.

But why, according to Stein, are reasons and motives separable? Stein gives two answers. First, lack of clarity. Most of the time, if one makes one's motives explicit and examines them carefully, they will lose their motive power, or will be reformed in conformity with rational grounds. Here there is not so much ill intent as ignorance: as soon as the mistake is clarified, revealed as a mistake, it loses its motive force. Second, humans are not solely rational beings, but also governed by feelings, which can subvert the rule of reason. Reason is neither a sufficient motive for action, nor does it necessarily even function as a motive. ${ }^{153}$

\footnotetext{
${ }^{153}$ Stein thus seems to be a sort of externalist about motives. She claims, for example, that even if someone grasps as valuable something that is truly valuable, they will not necessarily feel its value with the force commensurate to that value, as a matter of "available lifepower," i.e., the underlying energy or power that allows motives to have force (Stein, 2000, p. 86). MacIntyre certainly reads Stein as an externalist, writing of "some motivating factor over and above the ground" (MacIntyre, 2006, p. 114), or that for Stein motives and grounds do not suffice for action without inclination (MacIntyre, 2006, p. 116), something that itself depends on lifepower. But there is also an implicit internalism in Stein's thought that if one acquires clarity about one's motive by being explicit about them, these motives will tend to be replaced by objective grounds, i.e., reasons. This thought implies that properly executed judgments will serve to reform one's motives.
} 


\section{REFERENCES}

Allison. (2004). Kant's Transcendental Idealism: An Interpretation and Defense. New Haven, CT: Yale University Press.

Alweiss, L. (2000). On Perceptual Experience. Journal of the British Society for Phenomenology, 31(3), 264-76.

Ameriks, K. (1978). Kant's Transcendental Deduction as a Regressive Argument. Kant-Studien, 69(3), 273-287.

Baillargeon, R., Spelke, E. S., \& Wasserman, S. (1985). Object Permanence in 5-month-old infants. Cognition, 20, 191-208.

Barbaras, R. (2004). The Being of the Phenomenon: Merleau-Ponty's Ontology. (T. Toadvine, \& L. Lawlor, Trans.) Indianapolis, IN: Indiana University Press.

Bello, A. A. (2010). Causality and Motivation in Edith Stein. In R. Poli (Ed.), Causality and Motivation (pp. 135-150). Ontos Verlad.

Benacerraf, P. (1983). Mathematical Truth. In P. Benacerraf, \& H. Putnam, Philosophy of Mathematics: Selected Readings (2nd ed., pp. 403-420). Cambridge University Press.

Berendzen, J. C. (2009). Coping with Nonconceptualism? On Merleau-Ponty and McDowell. Philosophy Today, 53(2), 162-73.

Berendzen, J. C. (2010). Coping without Foundations: On Dreyfus' use of Merleau-Ponty. International Journal of Philosophical Studies, 18(5), 629-49.

Besmer, K. M. (2007). Merleau-Ponty's Phenomenology. New York, NY: Continuum International Publishing Group.

Boghossian, P. (2001). Inference and Insight. Philosophy and Phenomenologcal Research, 633640.

Bonjour, L. (1998). In Defense of Pure Reason. NY: Cambridge University Press.

Bonjour, L. (1998). In Defense of Pure Reason. NY: Cambridge University Press.

Brough, J. (1972). The Emergece of an Absolute Consciousness in Husserl's Early Writings on Time-Consciousness. Man and World, 5(3), 298-326.

Brough, J. (2016, Fall). Some Reflections on Time and the Ego in Husserl's Late Texts on TimeConsciousness. Quaestiones Disputatae, 7(1), 89-108.

Carey, S. (2009). The Origin of Concepts. NY: Oxford University Press.

Carey, S. (2010). The making of an abstract concept: Natural number. In D. Mareschal, P. Quinn, \& S. Lea, The Making of Human Concepts (pp. 265-294). NY: Oxford University Press.

Carman, T. (2007). Dennett on Seeming. Phenomenology and the Cognitive Sciences, 6, 99-106.

Carman, T. (2013). Retrieving Realism. In J. K. Schear (Ed.), Mind, Reason, and Being-in-theWorld: The McDowell-Dreyfus Debate. New York, NY: Routledge. 
Close, C. (2012, 1 20). Agnosia. (C. Rose, Interviewer)

Coates, T.-N. (2015). Between the World and Me. New York, NY: Spiegel \& Grau.

Davidson, D. (1986). A Coherence Theory of Truth and Interpretation. In E. Lepore (Ed.), Truth and Interpretation: Perspectives on the Philosophy of Donald Davidson (pp. 307-319). New York, NY: Blackwell.

de Beauvoir, S. (1948). The Ethics of Ambiguity. (B. Frechtman, Trans.) New York, NY: The Philosophical Library.

Dehaene, S. (1997). The Number Sense. NY: Oxford University Press.

Dennett, D. C. (1991). Consciousness Explained. Boston, MA: Little, Brown, and Company.

Devitt, M. (2005). There is no a priori. In S. Matthias, \& E. Sosa, Contemporary Debates in Epistemology (pp. 105-114). Malden, MA: Blackwell Publishing.

Dillon, M. C. (1987). Apriority in Kant and Merleau-Ponty. Kant-Studien, 78(4), 402-423.

Dillon, M. C. (1988). Merleau-Ponty's Ontology. Indianapolis, IN: Indiana University Press.

Dreyfus, H. L. (2007). The Return of the Myth of the Mental. Inquiry, 50(4), 352-65.

Dreyfus, H. L. (2013). The Myth of the Pervasiveness of the Mental. In J. K. Schear (Ed.), Mind, Reason, and Being-in-the-World. New York, NY: Routledge.

Ferrante, E. (2015, May). The Torment and The Engine. Harper's Magazine.

Fichte, J. (1987). The Vocation of Man. (P. Preuss, Trans.) Indianapolis, IN: Hackett Publishing Company.

Fichte, J. G. (2000). Foundations of Natural right. (F. Neuhouser, Trans.) New York, NY: Cambridge University Press.

Fink, E. (2005). The Phenomenological Philosophy of Edmund Husserl and Contemporary Criticism. In R. Bernet, D. Welton, \& G. Zavota (Eds.), Edmund Husserl: Critical Assessments of Leading Philosophers (Vol. 1, pp. 177-241). New York, NY: Routledge.

Fodor, J. (1975). The Language of Thought. Cambridge, MA: Harvard University Press.

Franzen, J. (2001). The Corrections. NY: Picador.

Gallagher, K. T. (1972). Kant and Husserl on the Synthetic A Priori. Kant-Studien, 63, 341-352.

Gardner, S. (2015). Merleau-Ponty's Transcendental Theory of Perception. In S. Gardner, \& M. Grist (Eds.), The Transcendental Turn. New York, NY: Oxford University Press.

Ginsborg, H. (2006). Reasons for Belief. Philosophy and Phenomenological Research, 72(2), 286-315.

Guyer, P. (1987). Kant and the Claims of Knowledge. New York, NY: Cambridge University Press.

Hall, H. (1979). The A Priori and the Empiricial in Merleau-Ponty's Phenomenology of Perception. Philosophy Today, 23(4), 304-309. 
Hass, M., \& Hass, L. (2000). Merleau-Ponty and the Origin of Geometry. In F. Evans, \& L. Lawlor (Eds.), Chiasms: Merleau-Ponty's Notion of Flesh (pp. 177-188). Albany, NY: State University of New York Press.

Heck, R. (2000). Nonconceptual Content and the 'Space of Reasons'. Philosophical Review, 109(4), 483-523.

Hegel, G. (2010). The Science of Logic. (G. di Giovanni, Trans.) New York, NY: Cambridge University Press.

Heidegger, M. (1995). The Fundamental Concepts of Metaphysics. (W. McNeill, \& N. Walker, Trans.) Indianapolis, IN: Indiana University Press.

Heidegger, M. (1996). Holderlin's Hymn 'Der Ister'. (W. McNeill, \& J. Davis, Trans.) Indianapolis, IN: Indiana University Press.

Heidegger, M. (1997). Kant and the Problem of Metaphysics. (R. Taft, Trans.) Indianapolis, IN: Indiana University Press.

Heidegger, M. (2010). Being and Time. (D. Schmidt, Ed., \& J. Stambaugh, Trans.) Albany, NY: State University of New York Press.

Hume, D. (2009). Treatise on Human Nature. In R. Ariew, \& E. Watkins (Eds.), Modern Philosophy (pp. 517-532). Indianapolis, IN: Hackett Publishing Company.

Husserl, E. (1969). Formal and Transcendental Logic. (D. Cairns, Trans.) The Hague, Netherlands: Martinus Nijhoff.

Husserl, E. (1973). Experience and Judgment. (J. A. Churchill, \& K. Ameriks, Trans.) Evanston, IL: Northwestern University Press.

Husserl, E. (1989). Ideas Pertaining to a Pure Phenomenology and to a Phenomenological Philosophy. Second Book: Studies in the Phenomenology of Constitution. (R. Rojcewicz, \& S. Andre, Trans.) Norwell, MA: Kluwer Academic Publishers.

Husserl, E. (1991). On the Phenomenology of the Consciousness of Internal Time. (J. B. Brough, Trans.) Springer Science + Bussiness Media.

Husserl, E. (1999). Cartesian Meditations. Norwell, MA: Kluwer Academic Press.

Husserl, E. (2001). Analyses Concerning Passive and Active Synthesis. (A. J. Steinbock, Trans.) Boston, MA: Kluwer Academic Publishers.

Husserl, E. (2001). Logical Investigations (Vol. 1). (J. N. Findlay, Trans.) New York, NY: Routledge.

Husserl, E. (2001). Logical Investigations, vol. 2 (Vol. 2). (D. Moran, Ed., \& J. N. Findlay, Trans.) New York, NY: Routledge.

Husserl, E. (2001). Logical Investigations, vol. 2 (Vol. 2). (D. Moran, Ed., \& J. N. Findlay, Trans.) New York, NY: Routledge.

Kant, I. (1996). Critique of Pure Reason. (W. S. Pluhar, Trans.) Indianapolis, IN: Hackett Publishing Company. 
Kelly, S. D. (2001). Demonstrative Concepts and Experience. Philosophical Review, 110(3), 397420.

Kitcher, P. (1990). Kant's Transcendental Psychology. New York, NY: Oxford University Press.

Knausgaard, K. (2013). My Struggle: Book 1. (D. Bartlett, Trans.) New York, NY: Farrar, Straus and Giroux.

Knausgaard, K. (2015, June 3). Karl Ove Knausgaard. (C. Rose, Interviewer)

Kortooms, T. (2002). Phenomenology of Time, Edmund Husserl's Analysis of TimeConsciousness. Dordrecht: Kluwer Academic Publishers.

Landes, D. A. (2013). The Merleau-Ponty Dictionary. New York, NY: Bloomsbury Academic.

Leibniz. (2000). New Essays on Human Understanding. NY: Cambridge University Press.

Lerman, H. (2010). Non-conceptual Experiential Content and Reason-giving. Philosophy and Phenomenological Research, 81(1), 1-23.

Locke, J. (2009). An Essay Concerning Human Understanding. In R. Ariew, \& E. Watkins, Modern Philosophy (pp. 316-421). Indianapolis, IN: Hackett Publishing Company.

Longuenesse, B. (1998). Kant and the Capacity to Judge. (C. T. Wolfe, Trans.) Princeton, NJ: Princeton University Press.

Low, D. (2013, Fall). Merleau-Ponty and Transcendental Philosophy. Philosophy Today, 279294.

MacIntyre, A. C. (2006). Edith Stein: A Philosophical Prologue, 1913-1922. Lanham, MD: Rowman \& Littlefield Publishers.

Marratto, S. L. (2012). The Intercorporeal Self: Merleau-Ponty on Subjectivity. Albany, NY: State University of New York Press.

Matherne, S. (2016). Kantian Themes in Merleau-Ponty's Theory of Perception. Archiv für Geschichte der Philosophie, 98(2), 193-230.

Matthews, E. (2006). Merleau-Ponty: A Guide for the Perplexed. New York, NY: Continuum International Publishing Group.

McDowell, J. (1996). Mind and World. Cambridge, MA: Harvard University Press.

McDowell, J. (2008). Avoiding the Myth of the Given. In J. Lindgaard (Ed.), John McDowell: Experience, Norm, and Nature. Malden, MA: Blackwell.

McDowell, J. (2013). The Myth of the Mind as Detached. In J. K. Schear (Ed.), Mind, Reason, and Being-in-the-World. New York NY: Routledge.

Melnick, A. (2013). Two Charges of Intellectualism against Kant. Kantian Review, 18(2), 197219.

Meltzoff, A. N., \& Moore, M. K. (1994). Imitation, Memory, and the Representation of Persons. Infant Behavior and Development, 17, 83-100. 
Meltzoff, A. N., \& Moore, M. K. (1999). Resolving the Debate about Early Imitation. In A. Slater, \& D. Muir (Eds.), The Blackwell Reader in Developmental Psychology (pp. 151155). Malden, MA: Blackwell.

Mensch, J. R. (2010). Husserl's Account of Our Consciousness of Time. Milwaukee, WI: Marquette University Press.

Merleau-Ponty, M. (1963). The Structure of Behavior. Boston, MA: Beacon Press.

Merleau-Ponty, M. (1964). The Primacy of Perception. (J. M. Edie, Ed.) Evanston, IL: Northwestern University Press.

Merleau-Ponty, M. (1968). The Visible and the Invisible. (A. Lingis, Trans.) Evanston, IL: Northwestern University Press.

Merleau-Ponty, M. (1973). The Prose of the World. (C. Lefort, Ed., \& J. O'Neill, Trans.) Evanston, IL: Northwestern University Press.

Merleau-Ponty, M. (1992). Sense and Non-sense. (P. A. Dreyfus, Trans.) Evanston, IL: Northwestern University Press.

Merleau-Ponty, M. (2010). Institution and Passivity. (L. Lawlor, \& H. Massey, Trans.) Evanston, IL: Northwestern University Press.

Merleau-Ponty, M. (2012). Phenomenology of Perception. (D. A. Landes, Trans.) NY: Routledge.

Moran, D., \& Cohen, J. D. (2012). The Husserl Dictionary. London: Continuum.

Morriston, W. (1979). Experience and Causality in the Philosophy of Merleau-Ponty. Philosophy and Phenomenological Research, 39(4).

O'Conaill, D. (2012). On Being Motivated. Phenomenology and the Cognitive Sciences, 12(4), 579-95.

O'Conaill, D. (2014). The Space of Motivations. International Journal of Philosophical Studies, 22(3), 440-55.

Osborne, G. (2006). Two Major Recent Approaches to Kant's Second Analogy. Kant-Studien, 97, 409-429.

Pietersma, H. (2006). Phenomenological Epistemology. New York, NY: Oxford University Press.

Proust, M. (2002). Swann's Way. (L. David, Trans.) New York, NY: Penguin Classics.

Putnam, H. (1968). Is Logic Empirical? Boston Studies in the Philosophy of Science, 5, 216-241.

Ricouer, P. (2007). Husserl: An Analysis of His Phenomenology. Evanston, IL: Northwestern University Press.

Rockmore, T. (2010). On Fichte and Phenomenology. In V. L. Waibel, D. Breazeale, \& T. Rockmore (Eds.), Fichte and the Phenomenological Tradition (pp. 11-24). New York, NY: De Gruyter.

Rockmore, T. (2011). Kant and Phenomenology. Chicago, IL: The University of Chicago Press. 
Rouse, J. (2013). What is Conceptually Articulated Understanding. In J. K. Schear (Ed.), Mind, Reason, and Being-in-the-World: The McDowell-Dreyfus Debate. New York, NY: Routledge.

Sartre, J.-P. (1984). Being and Nothingness. (H. E. Barnes, Trans.) NY: Washington Square Press.

Sartre, J.-P. (2007). Nausea. (L. Alexander, Trans.) New York, NY: New Directions.

Sawicki, M. (1998). Personal Connections: The Pre-Baptismal Philosophy of Edith Stein. Retrieved from Baltimorecarmel.org: http://www.baltimorecarmel.org/saints/Stein/sawicki\%20prebaptismal\%20philosphy\%20of\%20edit\%20stein.htm

Schmid, H. (2001). Apodictic Evidence. Husserl Studies, 17, 217-237.

Sellars, W. (1997). Empiricism and the Philosophy of Mind. Cambridge, MA: Harvard University Press.

Shtulman, A., \& Lombrozo, T. (2016). Bundles of Contradiction: A Coexistence View of Conceptual Change. In D. Barner, \& A. Baron (Eds.), Core Knowledge and Conceptual Change (pp. 53-72). New York, NY: Oxford University Press.

Singer, L. (1981). Merleau-Ponty on the Concept of Style. Man and World, 14(2), 153-163.

Smith, B. (1995). Common Sense. In B. Smith, \& D. W. Smith (Eds.), The Cambridge Companion to Husserl (pp. 394-437). New York, NY: Cambridge University Press.

Stampe, D. (1987). The Authority of Desire. The Philosophical Review, 96, 335-381.

Stein, E. (2000). Philosophy of Psychology and the Humanities. (M. Sawicki, Trans.) Washington, D. C.: ICS Publications.

Vallier, R. (2005). Institution: the Significance of Merleau-Ponty's 1954 Course at the College de France. Chiasmi International, 7, 281-302.

Varela, F., Thompson, E., \& Rosch, E. (1991). The Embodied Mind. Cambridge, MA: The MIT Press.

Walsh, P. J. (2013). Husserl's Concept of Motivation. Logical Analysis and History of Philosophy, 16, 70-83.

Watkins, E. (2004). Kant and the Metaphysics of Causality. Cambridge University Press.

Wertheimer, M. (1945). Productive Thinking. NY: Harper \& Brothers Publishers.

Wiser, M., \& Smith, C. (2016). How is Conceptual Change Possible? Insights from Science Education. In D. Barner, \& A. S. Baron, Core Knowledge and Conceptual Change (pp. 29-52). NY: Oxford University Press.

Wiser, M., Smith, C., \& Doubler, S. (2012). Learning progressions as tools for curriculum development: Lessons from the Inquiry Project. In A. Alonzo, \& A. Gotwals, Learning progressions in science: Current challenges and future directions (pp. 359-404). Rotterdam: Sense Publishers. 
Wittgenstein, L. (1972). On Certainty. (D. Paul, \& G. Ascombe, Trans.) NY: Harper Torchbooks.

Wolf, S. (2015). The Importance of Love. In The Variety of Values: Essays of Morality, Meaning, and Love. New York, NY: Oxford University Press.

Wrathall, M. A. (2005). Motives, Reasons, and Causes. In T. Carman (Ed.), The Cambridge Companion to Merleau-Ponty (pp. 111-28). New York, NY: Cambridge University Press.

Xu, F., \& Carey, S. (1996). Infant's Metaphysics: The Case of Numerical Identity. Cognitive Psychology, 30, 111-153.

Yoshimi, J. (2016). Husserlian Phenomenology: A Unifying Interpretation. SpringerBriefs in Philosophy.

Zahavi, D. (2007). Killing the Straw Man: Dennett and Phenomenology. Phenomenology and the Cognitive Sciences, 6, 21-43.

Zahavi, D. (2011). Objects and Levels: Reflections on the Relation between Time-Consciousness and Self-Consciousness. Husserl Studies, 27, 13-25. 
VITA

Peter Antich will receive a Ph.D. in Philosophy from the University of Kentucky in December 2017, where he also received a M.A. in Philosophy in December 2015. He earned a B.A. from the University of Dallas in May 2012. He is currently an instructor in the Department of Philosophy at the University of Kentucky. 